\title{
Observed Climate Variability and Change
}

\section{Co-ordinating Lead Authors}

C.K. Folland, T.R. Karl

\section{Lead Authors}

J.R. Christy, R.A. Clarke, G.V. Gruza, J. Jouzel, M.E. Mann, J. Oerlemans, M.J. Salinger, S.-W. Wang

\section{Contributing Authors}

J. Bates, M. Crowe, P. Frich, P. Groisman, J. Hurrell, P. Jones, D. Parker, T. Peterson, D. Robinson, J. Walsh, M. Abbott, L. Alexander, H. Alexandersson, R. Allan, R. Alley, P. Ambenje, P. Arkin, L. Bajuk, R. Balling, M.Y. Bardin, R. Bradley, R. Brázdil, K.R. Briffa, H. Brooks, R.D. Brown, S. Brown, M. Brunet-India, M. Cane, D. Changnon, S. Changnon, J. Cole, D. Collins, E. Cook, A. Dai, A. Douglas, B. Douglas, J.C. Duplessy, D. Easterling, P. Englehart, R.E. Eskridge, D. Etheridge, D. Fisher, D. Gaffen, K. Gallo, E. Genikhovich, D. Gong, G. Gutman, W. Haeberli, J. Haigh, J. Hansen, D. Hardy, S. Harrison, R. Heino, K. Hennessy, W. Hogg, S. Huang, K. Hughen, M.K. Hughes, M. Hulme, H. Iskenderian, O.M. Johannessen, D. Kaiser, D. Karoly, D. Kley, R. Knight, K.R. Kumar, K. Kunkel, M. Lal, C. Landsea, J. Lawrimore, J. Lean, C. Leovy, H. Lins, R. Livezey, K.M. Lugina, I. Macadam, J.A. Majorowicz, B. Manighetti, J. Marengo, E. Mekis, M.W. Miles, A. Moberg, I. Mokhov, V. Morgan, L. Mysak, M. New, J. Norris, L. Ogallo, J. Overpeck, T. Owen, D. Paillard, T. Palmer, C. Parkinson, C.R. Pfister, N. Plummer, H. Pollack, C. Prentice, R. Quayle, E.Y. Rankova, N. Rayner, V.N. Razuvaev, G. Ren, J. Renwick, R. Reynolds, D. Rind, A. Robock, R. Rosen, S. Rösner, R. Ross, D. Rothrock, J.M. Russell, M. Serreze, W.R. Skinner, J. Slack, D.M. Smith, D. Stahle, M. Stendel, A. Sterin, T. Stocker, B. Sun, V. Swail, V. Thapliyal,

L. Thompson, W.J. Thompson, A. Timmermann, R. Toumi, K. Trenberth, H. Tuomenvirta, T. van Ommen, D. Vaughan, K.Y. Vinnikov, U. von Grafenstein, H. von Storch, M. Vuille, P. Wadhams, J.M. Wallace, S. Warren, W. White, P. Xie, P. Zhai

\section{Review Editors}

R. Hallgren, B. Nyenzi 


\section{Contents}

Executive Summary

101

2.1 Introduction

105

2.2 How Much is the World Warming?

2.2.1 Background

2.2.2 Temperature in the Instrumental Record for Land and Oceans

2.2.2.1 Land-surface air temperature $\quad 105$

2.2.2.2 Sea surface temperature and ocean air temperature

110

2.2.2.3 Land and sea combined

112

2.2.2.4 Are the land and ocean surface temperature changes mutually consistent?

2.2.2.5 Sub-surface ocean temperatures and salinities

2.2.3 Temperature of the Upper Air

2.2.4 How do Surface and Upper Air Temperature Variations Compare?

2.2.5 Changes in the Cryosphere

2.2.5.1 Snow cover, including snowfall

2.2.5.2 Sea-ice extent and thickness

2.2.5.3 Permafrost

2.2.5.4 Mountain glaciers

2.2.5.5 Lake and river ice

2.2.6 Are the Retreat of Glaciers, Sea Ice, and Snow Cover Consistent with the Surface Temperature Trends?

2.2.7 Summary

2.3 Is the Recent Warming Unusual?

2.3.1 Background

2.3.2 Temperature of the Past 1,000 Years 2.3.2.1 Palaeoclimate proxy indicators 2.3.2.2 Multi-proxy synthesis of recent temperature change

2.3.3 Was there a "Little Ice Age" and a "Medieval Warm Period"?

2.3.4 Volcanic and Solar Effects in the Recent Record

2.3.5 Summary

136

2.4 How Rapidly did Climate Change in the Distant Past?

2.4 .1

2.4.3 How Fast did Climate Change during the Glacial Period?

2.4.4 How Stable was the Previous Inter-glacial? 141

2.4.5 Summary
2.5 How have Precipitation and Atmospheric Moisture Changed?

142

2.5.1 Background

142

2.5.2 Changes in Precipitation and Related Variables

142

2.5.2.1 Land

142

2.5.2.2 Palaeo-drought 143

2.5.2.3 Ocean 145

2.5.3 Water Vapour 146

2.5.3.1 Surface water vapour $\quad 146$

2.5.3.2 Lower-tropospheric water vapour 147

2.5.3.3 Upper-tropospheric and lowerstratospheric water vapour $\quad 147$

2.5.4 Evaporation

148

2.5.4.1 Land 148

2.5.5 Clouds 148

2.5.5.1 Land 149

2.5.5.2 Ocean 149

2.5.5.3 Global 149

$\begin{array}{lll}2.5 .6 & \text { Summary } & 149\end{array}$

2.6 Are the Atmospheric/Oceanic Circulations

Changing? 150

2.6.1 Background 150

2.6.2 El Niño-Southern Oscillation and Tropical/ Extra-tropical Interaction 150

2.6.3 Decadal to Inter-decadal Pacific Oscillation, and the North Pacific Oscillation 151

2.6.4 Monsoons 152

2.6.5 The Northern Hemisphere, excluding the North Pacific Ocean

2.6.6 The Southern Hemisphere 153

2.6.7 Summary 154

2.7 Has Climate Variability, or have Climate

Extremes, Changed? 155

2.7.1 Background 155

2.7.2 Is There Evidence for Changes in Variability or Extremes? 155

2.7.2.1 Temperature 156

2.7.2.2 Precipitation 157

2.7.3 Is There Evidence for Changes in Extreme Weather or Climate Events? 160

2.7.3.1 Tropical cyclones 160

2.7.3.2 Extra-tropical cyclones $\quad 160$

2.7.3.3 Droughts and wet spells 162

2.7.3.4 Tornadoes, hail and other severe local weather $\quad 163$

2.7.4 Summary

163
163

2.8 Are the Observed Trends Internally Consistent? 163 


\section{Executive Summary}

\section{Overview}

The best estimate of global surface temperature change is a $0.6^{\circ} \mathrm{C}$ increase since the late 19 th century with a $95 \%$ confidence interval of 0.4 to $0.8^{\circ} \mathrm{C}$. The increase in temperature of $0.15^{\circ} \mathrm{C}$ compared to that assessed in the IPCC WGI Second Assessment Report (IPCC, 1996) (hereafter SAR) is partly due to the additional data for the last five years, together with improved methods of analysis and the fact that the SAR decided not to update the value in the First Assessment Report, despite slight additional warming. It is likely that there have been real differences between the rate of warming in the troposphere and the surface over the last twenty years, which are not fully understood. New palaeoclimate analyses for the last 1,000 years over the Northern Hemisphere indicate that the magnitude of 20th century warming is likely to have been the largest of any century during this period. In addition, the 1990s are likely to have been the warmest decade of the millennium. New analyses indicate that the global ocean has warmed significantly since the late 1940s: more than half of the increase in heat content has occurred in the upper $300 \mathrm{~m}$, mainly since the late 1950s. The warming is superimposed on strong global decadal variability. Night minimum temperatures are continuing to increase, lengthening the freeze-free season in many mid- and high latitude regions. There has been a reduction in the frequency of extreme low temperatures, without an equivalent increase in the frequency of extreme high temperatures. Over the last twenty-five years, it is likely that atmospheric water vapour has increased over the Northern Hemisphere in many regions. There has been quite a widespread reduction in daily and other sub-monthly time-scales of temperature variability during the 20th century. New evidence shows a decline in Arctic sea-ice extent, particularly in spring and summer. Consistent with this finding are analyses showing a near $40 \%$ decrease in the average thickness of summer Arctic sea ice over approximately the last thirty years, though uncertainties are difficult to estimate and the influence of multi-decadal variability cannot yet be assessed. Widespread increases are likely to have occurred in the proportion of total precipitation derived from heavy and extreme precipitation events over land in the mid- and high latitudes of the Northern Hemisphere.

\section{Changes in Temperature and Related Variables}

\section{Changes in near-surface temperature from the instrumental record}

- Average global surface temperature has increased by approximately $0.6^{\circ} \mathrm{C}$ since the late 19 th century, with $95 \%$ confidence limits of close to 0.4 and $0.8^{\circ} \mathrm{C}$. Most of this increase has occurred in two periods, from about 1910 to 1945 and since 1976, and the largest recent warming is in the winter extratropical Northern Hemisphere. The warming rate since 1976, $0.17^{\circ} \mathrm{C} /$ decade, has been slightly larger than the rate of warming during the 1910 to 1945 period $\left(0.14^{\circ} \mathrm{C} /\right.$ decade $)$, although the total increase in temperature is larger for the 1910 to 1945 period. The most recent warming period also has a faster rate of warming over land compared with the oceans. The high global temperature associated with the 1997/98 El Niño event stands out in both surface and tropospheric temperatures as an extreme event, even after consideration of the recent rate of warming.

- Confidence in the magnitude of global warming since the late 19th century has increased since the SAR due to new analyses, including model simulations of land-surface temperature changes and new studies of the effect of urbanisation on global land temperature trends. There is a high level of consistency between changes in sea surface temperatures (SSTs) and nearsurface land air temperatures across the land-ocean boundary over the 20th century, despite independent observing systems and independent bias correction factors for SSTs before 1942. The assessed warming is considerably larger than the total contributions of the plausible sources of error.

- Twentieth century temperature trends show a broad pattern of tropical warming, while extra-tropical trends have been more variable. Warming from 1910 to 1945 was initially concentrated in the North Atlantic and nearby regions. The Northern Hemisphere shows cooling during the period 1946 to 1975 while the Southern Hemisphere shows warming. The recent 1976 to 2000 warming was largely globally synchronous, but emphasised in the Northern Hemisphere continents during winter and spring, with year-round cooling in parts of the Southern Hemisphere oceans and Antarctica. North Atlantic cooling between about 1960 and 1985 has recently reversed. Overall, warming over the Southern Hemisphere has been more uniform during the instrumental record than that over the Northern Hemisphere.

- The patterns of global temperature change since the 1970s are related in part to the positive westerly phase of the North Atlantic/Arctic Oscillation and possibly to decadal to multidecadal variability in the Pacific.

- A multi-decadal fluctuation of SST in the North Atlantic has been in a rising phase since about the mid-1980s. Warming in many regions of this ocean has accelerated over the last five years and is likely to have contributed to quite rapid parallel increases of near-surface air temperature in much of Europe.

- New analysis shows that the global ocean heat content has increased since the late 1950s. This increase is superimposed on substantial global decadal variability. More than half the heating is contained in the uppermost $300 \mathrm{~m}$ where it is equivalent to an average temperature increase of $0.037^{\circ} \mathrm{C} /$ decade.

- Analyses of mean daily maximum and minimum land surface air temperatures continue to support a reduction in the diurnal temperature range in many parts of the world, with, globally, minimum temperatures increasing at nearly twice the rate of maximum temperatures between about 1950 and 1993. The rate of temperature increase during this time has been $0.1^{\circ} \mathrm{C}$ and $0.2^{\circ} \mathrm{C}$ for the maximum and minimum, respectively. This is about half of the rate of temperature increase over the oceans during this time. 
Changes in temperature-related variables

- Alpine and continental glaciers have extensively retreated in response to 20th century warming. Glaciers in a few maritime regions are advancing, mainly due to increases in precipitation related to atmospheric circulation changes, e.g., Norway, New Zealand.

- The duration of Northern Hemisphere lake-ice and river-ice cover over the past century, or more, shows widespread decreases averaging to about two fewer weeks of ice cover.

- There is a highly significant interannual (+0.6) and multi-decadal correlation between increases in the Northern Hemisphere spring land temperature and a reduction in the Northern Hemisphere spring snow cover since data have been available (1966). Snow cover extent has decreased by about $10 \%$ since 1966 .

- A 10 to $15 \%$ reduction in sea-ice extent in the Arctic spring and summer since the 1950s is consistent with an increase in spring, and to a lesser extent, summer temperatures in the high latitudes. There is little indication of reduced Arctic sea-ice extent during winter when temperatures have increased in the surrounding region.

- New data from submarines indicate that there has been about a 40\% decline in Arctic sea-ice thickness in summer or early autumn between the period 1958 to 1976 and the mid-1990s, an average of near $4 \mathrm{~cm}$ per year. Other independent observations show a much slower decrease in winter sea-ice thickness of about $1 \mathrm{~cm}$ per year. The influence of substantial interannual and inter-decadal variability on these changes cannot be assessed because of restricted sampling.

- By contrast, there is no readily apparent relationship between decadal changes in Antarctic temperatures and sea-ice extent since 1973. Satellite data indicate that after a possible initial decrease in the mid-1970s, Antarctic sea-ice extent has stayed almost stable or even increased since 1978.

Changes in temperature above the surface layer

- Analysis of global temperature trends since 1958 in the low to mid-troposphere from balloons shows a warming of about $+0.1{ }^{\circ} \mathrm{C} /$ decade, which is similar to the average rate of warming at the surface. Since the early 1960 s no significant trends have been detected for the global mean temperature in the uppermost troposphere.

- Satellites have only been available since 1979. Between 1979 and 2000, based on satellites and balloons, the lower-tropospheric trend has been $+0.04 \pm 0.11^{\circ} \mathrm{C} /$ decade and $0.03 \pm$ $0.10^{\circ} \mathrm{C} /$ decade, respectively. By contrast, surface temperature trends for 1979 to 2000 were greater, at $0.16 \pm 0.06^{\circ} \mathrm{C} / \mathrm{dec}$ ade The trend in the difference of the surface and lower-tropospheric series of $0.13 \pm 0.06^{\circ} \mathrm{C} /$ decade is clearly statistically significant. This is in contrast to near zero surface temperature trends over 1958 to 1978 when the global lower-tropospheric temperature warmed by $0.03^{\circ} \mathrm{C} /$ decade relative to the surface.
- It is very likely that these significant differences in trends between the surface and lower troposphere are real and not solely an artefact of measurement bias, though differences in spatial and temporal sampling are likely to contribute. The differences are particularly apparent in many parts of the tropics and sub-tropics where the surface has warmed faster than the lower troposphere. In some other regions, e.g., North America, Europe and Australia, lower-tropospheric and surface trends are very similar.

- Throughout the stratosphere, negative temperature trends have been observed since 1979, ranging from a decrease of 0.5 or $0.6^{\circ} \mathrm{C} /$ decade in the lower stratosphere to $2.5^{\circ} \mathrm{C} /$ decade in the upper stratosphere.

\section{Changes in temperature during the pre-instrumental period}

The past millennium

- New analyses indicate that the magnitude of Northern Hemispher warming over the 20th century is likely to have been the largest of any century in the last 1,000 years.

- The 1990s are likely to have been the warmest decade of the millennium in the Northern Hemisphere and 1998 is likely to have been the warmest year. Because less data are available, less is known about annual averages prior to 1,000 years before the present and for conditions prevailing in most of the Southern Hemisphere prior to 1861.

- Evidence does not support the existence of globally synchronous periods of cooling or warming associated with the 'Little Ice Age' and 'Medieval Warm Period'. However, reconstructed Northern Hemisphere temperatures do show a cooling during the 15 th to 19 th centuries and a relatively warm period during the 11 th to 14 th centuries, though the latter period is still cooler than the late 20th century.

- Analyses of borehole temperatures indicate a non-linear increase in global average ground surface temperature over land of $1.0 \pm 0.3^{\circ} \mathrm{C}$ over the last 500 years, with most of the increase occurring since the late 19th century. There may be additional uncertainties due to the assumptions used in this technique, and decreasing resolution back in time limits confidence in the exact timing of the warming.

\section{Changes across the last 500,000 years}

- It is very likely that large and rapid decadal temperature changes occurred during the last glacial and its deglaciation (between about 100,000 and 10,000 years ago), particularly in higher latitudes of the Northern Hemisphere. During the last deglaciation, local increases in temperature are likely to have been as large as 5 to $10^{\circ} \mathrm{C}$ over a few decades. Over the same period there is evidence of less pronounced but nearly synchronous changes worldwide, except in high southern latitudes.

- Antarctic ice cores have provided new evidence of almost inphase changes of temperature, carbon dioxide and methane through the ice age cycles over the past 420,000 years. 
- There is emerging evidence for significant, rapid (timescales of several decades or more), regional temperature changes during the last 10,000 years. However, the evidence does not indicate that any such events were global in scale.

\section{Changes in Precipitation and Related Variables}

\section{Precipitation}

- Instrumental records of land-surface precipitation continue to show an increase of 0.5 to $1 \% /$ decade in much of the Northern Hemisphere mid- and high latitudes. A notable exception includes parts of eastern Russia. In contrast, over much of the sub-tropical land areas rainfall has decreased during the 20th century (by $-0.3 \% /$ decade), but this trend has weakened in recent decades. Other precipitation indicators suggest that large parts of the tropical oceans have had more precipitation in recent decades, and that precipitation has significantly increased over tropical land areas during the 20 th century (2.4\%/century). The increase in precipitation over the tropics is not evident during the past few decades.

- In the Southern Hemisphere, the pattern of island rainfall in parts of the South Pacific has changed since the mid-1970s, associated with the more frequent occurrence of the warm phase of the El Niño-Southern Oscillation (ENSO).

- Where data are available, changes in annual streamflow usually relate well to changes in total precipitation.

\section{Water vapour}

- Changes in water vapour mixing ratio have been analysed for selected regions using in situ surface observations as well as lower-tropospheric measurements based on satellites and weather balloons. A pattern of overall surface and lower-tropospheric water vapour mixing ratio increases over the past few decades is emerging, although there are likely to be some time-dependent biases in these data and regional variations in trends. The more reliable data sets show that it is likely that total atmospheric water vapour has increased several per cent per decade over many regions of the Northern Hemisphere since the early 1970s. Changes over the Southern Hemisphere cannot yet be assessed.

- Satellite observations of upper-tropospheric humidity from 1980 to 1997 show statistically significant positive trends of $0.1 \%$ /year for the zone $10^{\circ} \mathrm{N}$ to $10^{\circ} \mathrm{S}$. Other trends are not statistically significant, but include a $0.04 \% / y e a r$ positive trend for the zone $60^{\circ} \mathrm{N}$ to $60^{\circ} \mathrm{S}$ but a negative trend of $-0.1 \% /$ year over the region $30^{\circ} \mathrm{S}$ to $60^{\circ} \mathrm{S}$.

- Balloon observations of stratospheric water vapour above $18 \mathrm{~km}$ show an increase of about 1\%/year for the period from 1981 to 2000. Shorter satellite records show a similar positive trend, suggesting that the change is global in character, but they also indicate a slowing of the positive trend after 1996.
Clouds

- It is likely that there has been an increase in total cloud cover of about $2 \%$ over many mid- to high latitude land areas since the beginning of the 20th century. The increases in total cloud amount are positively correlated with decreases in the diurnal temperature range. Changes in total cloud amount are uncertain both over sub-tropical and tropical land areas as well as over the oceans.

\section{Changes in Atmospheric/Oceanic Circulation}

\section{El Niño-Southern Oscillation (ENSO)}

- The frequency and intensity of ENSO has been unusual since the mid-1970s compared with the previous 100 years. Warm phase ENSO episodes have been relatively more frequent, persistent, or intense than the opposite cold phase during this period.

- This recent behaviour of ENSO is related to variations in precipitation and temperature over much of the global tropics and subtropics and some mid-latitude areas. The overall effect is likely to have made a small contribution to the increase in global surface temperature during the last few decades.

\section{Other Oscillations}

- The Inter-decadal Pacific Oscillation is likely to be a Pacificwide manifestation of the Pacific Decadal Oscillation. Both are associated with decadal climate variability over the Pacific basin. It is likely that these related phenomena modulate ENSOrelated climate variability.

- The winter North Atlantic Oscillation (NAO) and the associated Arctic Oscillation (AO), which appear to be largely the same phenomenon, show decadal to multi-decadal variability. Since the 1970s these oscillations have been in a phase that gives stronger westerly winds over much of extra-tropical Eurasia in the winter half year. This is associated with cold season warming over extra-tropical Eurasia, but cooling in some regions further south.

- The High Latitude Mode (HLM) or Antarctic Oscillation (AAO) in the Southern Hemisphere has been in an enhanced positive phase in the last fifteen years, with stronger westerly winds over the Southern Ocean.

- It is likely that rapid (time-scales of several decades or more) changes of atmospheric and ocean circulation occurred during inter-glacial periods, affecting regional climate, without human interference.

\section{Changes in Extreme (within the upper or lower ten percentiles) Weather and Climate Events}

\section{Precipitation}

- New analyses show that in regions where total precipitation has increased it is very likely that there have been even more pronounced increases in heavy and extreme precipitation events. The converse is also true. 
- In some regions, heavy and extreme precipitation events have increased despite the fact that total precipitation has decreased or remained constant. This is attributed to a decrease in the frequency of precipitation events. Changes in the frequency of heavy precipitation events can arise from several causes, e.g., changes in atmospheric moisture or circulation.

- Over the latter half of the 20th century it is likely that there has been a 2 to $4 \%$ increase in the frequency of heavy precipitation events reported by the available observing stations in the midand high latitudes of the Northern Hemisphere.

- Trends for severe drought and wet area statistics for 1900 to 1995 are relatively small over global land areas. However, during the last two or three decades there have been some increases in the globally combined severe dry and wet areas.

\section{Temperature}

- In many regions inter-daily temperature variability has decreased. Increases in the daily minimum temperatures are lengthening the freeze-free season in most mid- and high latitude regions.

- A significant reduction in the frequency of extreme low monthly and seasonal average temperatures across much of the globe has occurred since the late 19th century. However, a relatively smaller increase in the frequency of extreme high monthly and seasonal average temperatures has been observed.

Storms

- Changes in tropical and extra-tropical storm intensity and frequency are dominated by inter-decadal to multi-decadal variations, with no significant trends over the 20th century evident. Conflicting analyses make it difficult to draw definitive conclusions about changes in storm activity, especially in the extra-tropics.

- No systematic changes in the frequency of tornadoes, thunder days, or hail events are evident in the limited areas analysed. 


\subsection{Introduction}

Observed climate change and variability (for definitions, see the IPCC Glossary, Appendix I) are considered in this chapter by addressing seven commonly asked questions related to the detection of climate change and sensitivity of the climate to anthropogenic activity. The questions are:

How much is the world warming?

Is the recent warming unusual?

How rapidly did climate change in the distant past?

Have precipitation and atmospheric moisture changed?

Are the atmospheric/oceanic circulations changing?

Has climate variability, or have climate extremes, changed?

Are the observed trends internally consistent?

This chapter emphasises change against a background of variability. The certainty of conclusions that can be drawn about climate from observations depends critically on the availability of accurate, complete and consistent series of observations. For many variables important in documenting, detecting, and attributing climate change, Karl et al. (1995a) demonstrate that the data are still not good enough for really firm conclusions to be reached, as noted in the IPCC WGI Second Assessment Report (IPCC, 1996) (hereafter SAR). This especially applies to global trends in variables that have large regional variations, such as precipitation, whereas conclusions about temperature changes are often considerably more firmly based. The recently designated Global Climate Observing System (GCOS) upper air network (Wallis, 1998) and a GCOS surface network (Peterson et al., 1997), maintained and reporting to higher standards, may have had a limited positive impact on the quality and availability of some of our results. New data sets e.g., on surface humidity, sea-ice thickness and sub-surface ocean temperature, have widened the range of conclusions than can be drawn since the SAR, albeit tentatively. However, a wider range of analytical techniques and tests of the data have increased our confidence in areas such as surface temperature changes.

Throughout the chapter we try to consistently indicate the degree of our confidence in trends and other results. Sometimes we provide quantitative estimates of uncertainty, as far as possible the value of twice the standard error, or we estimate statistical significance at the $0.05(5 \%)$ level. This is the appropriate terminology and implies that what we see is very unusual, given the null hypothesis. We use the word "trend" to designate a generally progressive change in the level of a variable. Where numerical values are given, they are equivalent linear trends, though more complex changes in the variable will often be clear from the description. We use the word "consistent" to imply similarity between results or data sets that are expected to be related on physical grounds. Where this is not possible, we use the following words to indicate judgmental estimates of confidence: virtually certain ( $>99 \%$ chance that a result is true); very likely ( $\geq 90 \%$ but $\leq 99 \%$ chance); likely ( $>66 \%$ but $<90 \%$ chance); medium likelihood ( $>33 \%$ but $\leq 66 \%$ chance), unlikely ( $>10 \%$ but $\leq 33 \%$ chance); very unlikely ( $\geq 1 \%$ but $\leq 10 \%$ chance) and exceptionally unlikely $(<1 \%$ chance).

\subsection{How Much is the World Warming?}

\subsubsection{Background}

The SAR concluded that, on a global average, land-surface air and sea surface temperature rose by between $0.3^{\circ} \mathrm{C}$ and $0.6^{\circ} \mathrm{C}$ between the late 19th century and 1994. In this section, the recent warming is re-examined, using updated data. We include recent analyses of the diurnal asymmetry of the warming and its geographical structure. Conventional temperature observations are supplemented by indirect evidence and by satellite-based data. For the first time, we make objective estimates of uncertainties in the surface temperature data, though these are preliminary. We also assess recent work in compiling hemispheric and global temperature records from palaeoclimatic data, especially for the most recent millennium.

\subsubsection{Temperature in the Instrumental Record for Land and Oceans}

Note that all data sets are adjusted to have zero anomaly when averaged over the period 1961 to 1990.

\subsubsection{Land-surface air temperature}

The SAR reviewed the three databases of land-surface air temperature due to Jones (1994), Hansen and Lebedeff (1988) and Vinnikov et al. (1990). The first and second databases have been updated by Jones et al. (2001) and Hansen et al. (1999), respectively, and a further analysis has become available (Peterson and Vose, 1997; Peterson et al., 1998a, 1999). The last paper also separates rural temperature stations in the Global Historical Climatology Network (GHCN) (Peterson and Vose, 1997) from the full set of stations which, in common with the other three analyses, have been screened for urbanisation effects. While there is little difference in the long-term (1880 to 1998) rural $\left(0.70^{\circ} \mathrm{C} /\right.$ century $)$ and full set of station temperature trends (actually less at $0.65^{\circ} \mathrm{C} /$ century), more recent data (1951 to 1989), as cited in Peterson et al. (1999), do suggest a slight divergence in the rural $\left(0.80^{\circ} \mathrm{C} /\right.$ century $)$ and full set of station trends $\left(0.92^{\circ} \mathrm{C} /\right.$ century $)$. However, neither pair of differences is statistically significant. In addition, while not reported in Peterson et al., the 1951 to 1989 trend for urban stations alone was $0.10^{\circ} \mathrm{C} /$ decade. We conclude that estimates of long-term (1880 to 1998) global land-surface air temperature variations and trends are relatively little affected by whether the station distribution typically used by the four global analyses is used, or whether a special effort is made to concentrate on rural stations using elaborate criteria to identify them. Part of the reason for this lack of sensitivity is that the average trends in available worldwide urban stations for 1951 to 1989 are not greatly more than those for all land stations $\left(0.09^{\circ} \mathrm{C} /\right.$ decade $)$. The differences in trend between rural and all stations are also virtually unaffected by elimination of areas of largest temperature change, like Siberia, because such areas are well represented in both sets of stations.

These results confirm the conclusions of Jones et al. (1990) and Easterling et al. (1997) that urban effects on 20th century globally and hemispherically averaged land air temperature time- 
Box 2.1: Urban Heat Island and the Observed Increases in Land Air Temperature.

There are two primary reasons why urban heat islands have been suspected as being partially responsible for the observed increases in land air temperatures over the last few decades. The first is related to the observed decrease in the diurnal temperature range and the second is related to a lower rate of warming observed over the past twenty years in the lower troposphere compared with the surface.

Since the 1950s both daily maximum and minimum temperatures are available over more than $50 \%$ of the global land area. These data indicate that on average the mean minimum temperature has increased at nearly twice the rate of the maximum temperature, reducing the daily temperature range by about $0.8^{\circ} \mathrm{C}$ over these areas. This has raised questions related to whether the growth of urban heat islands may be responsible for a substantial portion of the observed mean temperature increase, because it is well-known that compared to non-urban areas urban heat islands raise night-time temperatures more than daytime temperatures. Nonetheless, the relatively strong correlation between observed decreases in the daily temperature range with increases of both precipitation (leading to more moist surface conditions) and total cloud amount support the notion that the reduction in diurnal temperature range is in response to these physical changes.

Since 1979 satellite observations and weather balloons (which generally agree well) show substantially less warming of the global lower troposphere (around $2 \mathrm{~km}$ ) than surface temperatures $\left(0.03\right.$ and $0.04^{\circ} \mathrm{C} /$ decade, respectively, compared to $0.16^{\circ} \mathrm{C} / \mathrm{dec}$ de at the surface). However, over the Northern Hemisphere land areas where urban heat islands are most apparent, both the trends of lowertropospheric temperature and surface air temperature show no significant differences. In fact, the lower-tropospheric temperatures warm at a slightly greater rate over North America (about $0.28^{\circ} \mathrm{C} /$ decade using satellite data) than do the surface temperatures $\left(0.27^{\circ} \mathrm{C} /\right.$ decade $)$, although again the difference is not statistically significant. In the global average, the trend differences arise largely from the tropical and sub-tropical oceans. In many such regions, the near-surface marine air temperatures tend to be cool and dense compared with conditions aloft, allowing for the lapse rate with height, disconnecting near-surface (up to about $1 \mathrm{~km}$ ) conditions from higher layers in the atmosphere. Thus the surface marine layer and the troposphere above can have differing variations and trends.

Clearly, the urban heat island effect is a real climate change in urban areas, but is not representative of larger areas. Extensive tests have shown that the urban heat island effects are no more than about $0.05^{\circ} \mathrm{C}$ up to 1990 in the global temperature records used in this chapter to depict climate change. Thus we have assumed an uncertainty of zero in global land-surface air temperature in 1900 due to urbanisation, linearly increasing to $0.06^{\circ} \mathrm{C}$ (two standard deviations $0.12^{\circ} \mathrm{C}$ ) in 2000 .

series do not exceed about $0.05^{\circ} \mathrm{C}$ over the period 1900 to 1990 (assumed here to represent one standard error in the assessed non-urban trends). However, greater urbanisation influences in future cannot be discounted. Note that changes in borehole temperatures (Section 2.3.2), the recession of the glaciers (Section 2.2.5.4), and changes in marine temperature (Section 2.2.2.2), which are not subject to urbanisation, agree well with the instrumental estimates of surface warming over the last century. Reviews of the homogeneity and construction of current surface air temperature databases appear in Peterson et al. (1998b) and Jones et al. (1999a). The latter shows that global temperature anomalies can be converted into absolute temperature values with only a small extra uncertainty.

Figure 2.1a shows the Jones et al. (2001) CRU (Climatic Research Unit) annual averages, together with an approximately decadally smoothed curve, to highlight decadal and longer changes. This is compared with smoothed curves from the other three analyses in Figure 2.1b. We do not show standard errors for the CRU land data using the Jones et al. (1997b) method as tests suggest that these may not be reliable for land data on its own. Instead we use an optimum averaging method (Folland et al., 2001) where the calculated uncertainties are centred on the simple CRU average. We have added an estimate of the additional, independent, uncertainty (twice the standard error) due to urbanisation increasing from zero in 1900 to $0.12^{\circ} \mathrm{C}$ in 2000. (The Jones et al. (1990) estimates can be interpreted as one standard error equal to $10 \%$ of the global warming to that time of about $0.05^{\circ} \mathrm{C}$, see also Box 2.1 on urbanisation.) Note that the warming substantially exceeds the calculated uncertainties. (We have not included the possible refinement of assuming urbanisation uncertainties to apply to the cold side of the trend line only, which would reduce the total uncertainty range in Figure 2.1.)

Over global land, a further warming of surface air temperature has occurred since the SAR. The Peterson and Vose (1997) NCDC (National Climate Data Center) series gives distinctly more warming than does the CRU series since the mid-1980s. The former series is a straightforward average of local land areas, weighted according to their size, whereas the CRU series is a simple average of the two hemispheres which gives more weight to the relatively small area of the Southern Hemisphere land. Because the Northern Hemisphere land has warmed considerably faster than the Southern Hemisphere land since the mid-1980s (reflected in Table 2.1), the simple average results in less warming. The Hansen et al. (1999) GISS (Goddard Institute for Space Studies) series has recently been revised and shows a little less warming than the CRU series since the late 1980s. One reason for this behaviour lies in the way that the Hansen series is constructed. Among other differences, this series gives much more 
weight to oceanic islands and Antarctica. Because the oceans and Antarctica have warmed less than the rest of the global land in the last fifteen years (see below), the Hansen series can be expected to show less warming. Some of these considerations apply to the Vinnikov et al. (1990) SHI (State Hydrological Institute) series, though this excludes areas south of $60^{\circ} \mathrm{S}$.

A new record was set in all four series in 1998 (anomalies relative to 1961 to 1990 of $\mathrm{CRU}, 0.68^{\circ} \mathrm{C}$; $\mathrm{NCDC}, 0.87^{\circ} \mathrm{C}$; GISS, $0.58^{\circ} \mathrm{C}$; and $\left.\mathrm{SHI}, 0.58^{\circ} \mathrm{C}\right) .1998$ was influenced by the strong $1997 / 98$ El Niño; the warming influence of El Niño on global temperature is empirically well attested (e.g., Jones, 1994) and the physical causes are starting to be uncovered (Meehl et al., 1998). However, 1998 was considerably warmer than 1983, a year warmed by the comparable 1982/83 El Niño. In fact 1998 was between 0.34 and $0.54^{\circ} \mathrm{C}$ warmer than 1983 over land, depending on the temperature series used, though there was some offsetting cooling from volcanic aerosols from the $1982 \mathrm{El}$ Chichon eruption in 1983. 1999 was globally much cooler than 1998, with an anomaly of $0.40^{\circ} \mathrm{C}$ in the CRU series, as it was cooled by the strongest La Niña since 1988/89. Despite its relative coolness, 1999 was still the fifth warmest year in the CRU record. Depending on the record used, 1999 was between $0.11^{\circ} \mathrm{C}$ and $0.33^{\circ} \mathrm{C}$ warmer than the last comparable La Niña year, 1989. It is noteworthy, however, that north of $20^{\circ} \mathrm{N}, 1999$ was nearly as warm as 1998 . Mitigation of the warming trend in the early 1990s was short-lived and was mainly due to the cooling influence of the eruption of Mount Pinatubo in 1991 (Parker et al., 1996), highlighted in the SAR. The ten warmest years in all four records have occurred after 1980, six or seven of them in the 1990s in each series.

Based on the CRU series, equivalent linear trends in global, Northern and Southern Hemisphere land-surface air temperature are shown in Table 2.1. Because warming may not persist at the rates shown, all trends are shown in ${ }^{\circ} \mathrm{C} / \mathrm{decade}$. The two main periods of warming in all three series are between about 1910 to 1945 and between 1976 to 2000 (updated from Karl et al., 2000). Trends have been calculated using a restricted maximum likelihood method (Diggle et al., 1999) that allows for serial correlation in the data. It gives larger standard errors than ordinary least squares methods when data have a complex temporal structure, as is true here. Table 2.1 and Figure 2.1 show that the rate of global and hemispheric warming in land-surface air temperature from 1976 to 2000 was about twice as fast (but interannually more variable) than that for the period 1910 to 1945. However, trends over such short periods are very susceptible to end effects so the values in Table 2.1, and Table 2.2 below, should be viewed with caution for these periods. Both periods of warming are statistically significant, as is (easily) the warming since 1861 or 1901 . Uncertainties in the annual values due to data gaps, including an additional estimate of uncertainties due to urbanisation, are included for land-surface air temperature but equivalent uncertainties are not currently available for the marine data alone. Thus estimates in Table 2.1 for the marine data may be conservative, though the effect of adding the influence of annual uncertainties to the land-surface air temperature data trends was small. The period 1946 to 1975 had no significant change of temperature, though there was a small nonsignificant, but regionally more marked, cooling over the Northern Hemisphere, as discussed by Parker et al. (1994). (a) Globe

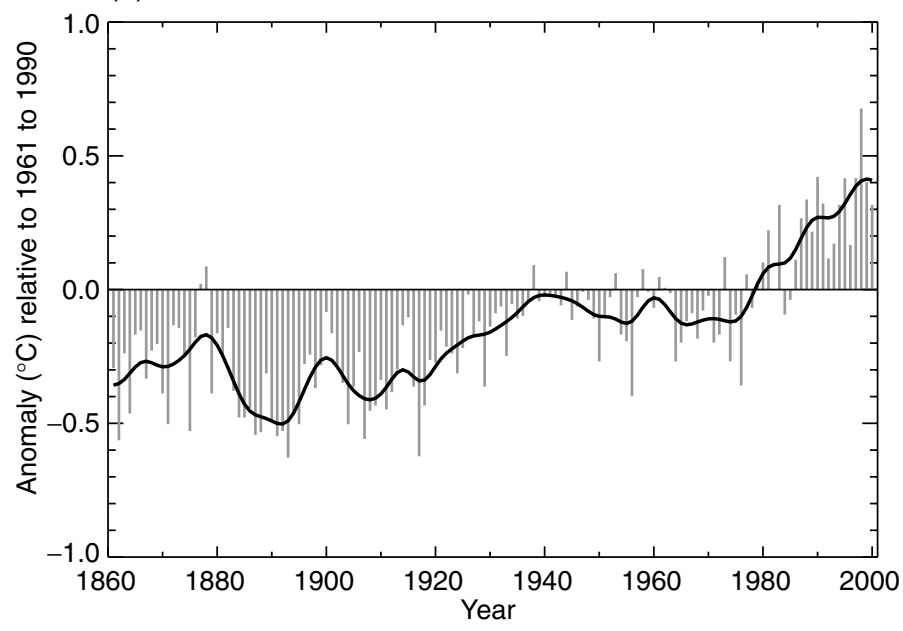

(b) Globe

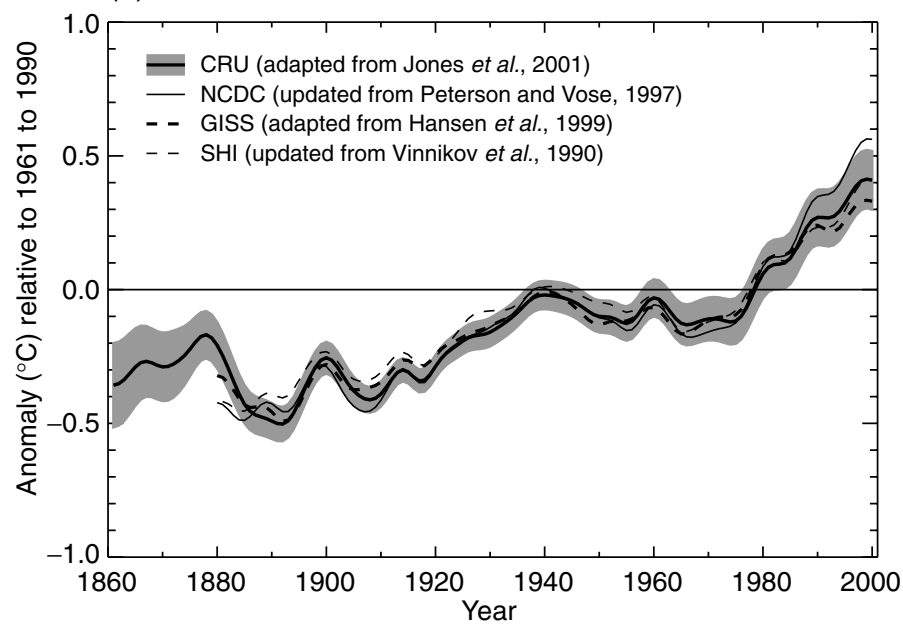

Figure 2.1: (a) Annual anomalies of global average land-surface air temperature $\left({ }^{\circ} \mathrm{C}\right), 1861$ to 2000 , relative to 1961 to 1990 values. Bars and solid curve are from CRU (Jones et al., 2001). Values are the simple average of the anomalies for the two hemispheres. The smoothed curve was created using a 21-point binomial filter giving near decadal averages. (b) As (a) but smoothed curves only from NCDC (updated from Peterson and Vose, 1997) - thin solid curve; GISS (adapted from Hansen et al., 1999) - thick dashed curve; SHI (updated from Vinnikov et al., 1990) - thin dashed curve to 1999 only; Peterson and Vose (1997) - thin solid curve. Thick solid curve - as in (a). Two standard error uncertainties are centred on the CRU curve and are estimated using an optimum averaging method (Folland et al., 2001) and include uncertainties due to urbanisation but not due to uncertainties in thermometer exposures. The NCDC curve is the weighted average of the two hemispheres according to the area sampled, which accounts for most of the differences from the CRU curve.

The equivalent linear changes in global average CRU landsurface air temperature over 1861 to 2000 and 1901 to 2000 that take into account annual sampling errors and uncertainties due to urbanisation are $0.63 \pm 0.24^{\circ} \mathrm{C}$ and $0.61 \pm 0.18^{\circ} \mathrm{C}$ respectively. Corresponding Northern and Southern Hemisphere changes for 1901 to 2000 are $0.71 \pm 0.31^{\circ} \mathrm{C}$ and $0.52 \pm 0.13^{\circ} \mathrm{C}$, respectively. Marine surface temperatures are discussed further in Section 2.2.2.2. 
Table 2.1: Restricted maximum likelihood linear trends in annual average land-surface air temperature (LSAT) anomalies from CRU and sea surface temperature (SST) and night marine air temperature (NMAT) anomalies from the UK Met Office (UKMO). Twice the standard errors of the trends are shown in brackets. Trends significant at the 5\% level or better, according to calculations made using an appropriate form of the t test, are shown in bold type. The significances of the trends are indicated beneath their twice standard errors. The method for calculating the trends, standard errors and significances allows for serial correlation and can result in a trend for the globe that is not exactly equal to the average of the trends for the hemispheres, consistent with uncertainties in the trends. The estimates of trends and errors for the land data account for uncertainties in the annual anomalies due to data gaps and urbanisation. Uncertainties in annual marine anomalies are not available. Trends are given in ${ }^{\circ} \mathrm{Cldecade.}$

\begin{tabular}{|c|c|c|c|c|c|}
\hline & 1861 to 2000 & 1901 to 2000 & 1910 to 1945 & 1946 to 1975 & 1976 to 2000 \\
\hline $\begin{array}{l}\text { Northern Hemisphere } \\
\text { CRU LSAT } \\
(\text { Jones } \text { et al., 2001) }\end{array}$ & $\begin{array}{c}0.06 \\
(0.02) \\
1 \% \\
\end{array}$ & $\begin{array}{c}\mathbf{0 . 0 7} \\
(\mathbf{0 . 0 3}) \\
\mathbf{1 \%} \\
\end{array}$ & $\begin{array}{c}0.14 \\
(0.05) \\
1 \% \\
\end{array}$ & $\begin{array}{c}-0.04 \\
(0.06)\end{array}$ & $\begin{array}{c}0.31 \\
(0.11) \\
1 \% \\
\end{array}$ \\
\hline $\begin{array}{l}\text { Southern Hemisphere } \\
\text { CRU LSAT } \\
(\text { Jones } \text { et al., 2001) }\end{array}$ & $\begin{array}{c}0.03 \\
(0.01) \\
1 \% \\
\end{array}$ & $\begin{array}{c}0.05 \\
(0.01) \\
1 \% \\
\end{array}$ & $\begin{array}{c}0.08 \\
(0.04) \\
1 \% \\
\end{array}$ & $\begin{array}{c}0.02 \\
(0.05)\end{array}$ & $\begin{array}{c}0.13 \\
(0.08) \\
1 \% \\
\end{array}$ \\
\hline $\begin{array}{l}\text { Global } \\
\text { CRU LSAT } \\
\text { (Jones et al., 2001) } \\
\end{array}$ & $\begin{array}{c}0.05 \\
(0.02) \\
1 \% \\
\end{array}$ & $\begin{array}{c}0.06 \\
(0.02) \\
1 \% \\
\end{array}$ & $\begin{array}{c}0.11 \\
(0.03) \\
1 \% \\
\end{array}$ & $\begin{array}{l}-0.01 \\
(0.05)\end{array}$ & $\begin{array}{c}0.22 \\
(0.08) \\
1 \% \\
\end{array}$ \\
\hline $\begin{array}{l}\text { Northern Hemisphere } \\
\text { UKMO SST } \\
(\text { Jones } \text { et al., 2001) }\end{array}$ & $\begin{array}{c}0.03 \\
(0.01) \\
1 \% \\
\end{array}$ & $\begin{array}{c}0.05 \\
(0.02) \\
1 \% \\
\end{array}$ & $\begin{array}{c}0.15 \\
(0.04) \\
1 \% \\
\end{array}$ & $\begin{array}{c}-0.05 \\
(0.10)\end{array}$ & $\begin{array}{c}0.18 \\
(0.05) \\
1 \% \\
\end{array}$ \\
\hline $\begin{array}{l}\text { Southern Hemisphere } \\
\text { UKMO SST } \\
(\text { Jones } \text { et al., 2001) }\end{array}$ & $\begin{array}{c}0.04 \\
(0.01) \\
1 \% \\
\end{array}$ & $\begin{array}{c}0.06 \\
(0.01) \\
1 \% \\
\end{array}$ & $\begin{array}{c}0.13 \\
(0.05) \\
1 \% \\
\end{array}$ & $\begin{array}{c}0.06 \\
(0.07)\end{array}$ & $\begin{array}{c}0.10 \\
(0.05) \\
1 \% \\
\end{array}$ \\
\hline $\begin{array}{l}\text { Global } \\
\text { UKMO SST } \\
\text { (Jones et al., 2001) } \\
\end{array}$ & $\begin{array}{c}0.04 \\
(0.01) \\
1 \% \\
\end{array}$ & $\begin{array}{c}0.06 \\
(0.01) \\
1 \% \\
\end{array}$ & $\begin{array}{c}0.15 \\
(0.04) \\
1 \% \\
\end{array}$ & $\begin{array}{c}0.01 \\
(0.06)\end{array}$ & $\begin{array}{c}0.14 \\
(0.04) \\
1 \% \\
\end{array}$ \\
\hline $\begin{array}{l}\text { Global } \\
\text { UKMO NMAT } \\
\text { (Parker } \text { et al., 1995) }\end{array}$ & & $\begin{array}{c}0.05 \\
(0.02) \\
1 \%\end{array}$ & $\begin{array}{c}0.14 \\
(0.04) \\
1 \%\end{array}$ & $\begin{array}{c}-0.01 \\
(0.06)\end{array}$ & $\begin{array}{c}0.11 \\
(0.05) \\
1 \%\end{array}$ \\
\hline
\end{tabular}

\section{Maximum and minimum temperature}

As reported in the SAR, and updated by Easterling et al. (1997), the increase in temperature in recent decades has involved a faster rise in daily minimum than daily maximum temperature in many continental regions. This gives a decrease in the diurnal temperature range (DTR) in many parts of the world. The analysis by Easterling et al. (1997) increased total global coverage from $37 \%$ to 54\% of global land area. Large parts of the world have still not been analysed due to a lack of observations or inaccessible data, particularly in the tropics. Updating all the data remains a problem, so the analysis ends in 1993.

The overall global trend for the maximum temperature during 1950 to 1993 is approximately $0.1^{\circ} \mathrm{C} /$ decade and the trend for the minimum temperature is about $0.2^{\circ} \mathrm{C} /$ decade. Consequently, the trend in the DTR is about $-0.1^{\circ} \mathrm{C} /$ decade. The rate of temperature increase for both maximum and minimum temperature over this period is greater than for the mean temperature over the entire 20th century, reflecting the strong warming in recent decades. Note that these trends for 1950 to 1993 will differ from the global trends due to the restricted data coverage so we only quote trends to $0.1^{\circ} \mathrm{C}$.

Since the DTR is the maximum temperature minus the minimum temperature, the DTR can decrease when the trend in the maximum or minimum temperature is downward, upward, or unchanging. This contributes to less spatial coherence on the DTR map than on maps of mean temperature trend. Maximum temperatures have increased over most areas with the notable exception of eastern Canada, the southern United States, portions of Eastern and southern Europe (Brunetti et al., 2000a), southern China, and parts of southern South America. Minimum temperatures, however, increased almost everywhere except in eastern Canada and small areas of Eastern Europe and the Middle East. The DTR decreased in most areas, except over middle Canada, and parts of southern Africa, south-west Asia, Europe, and the western tropical Pacific Islands. In some areas the pattern of temperature change has been different. In both New Zealand (Salinger, 1995) and central Europe (Weber et al., 1994; Brázdil et al., 1996) maximum and minimum temperatures have increased at similar rates. In India the DTR has increased due to a decrease in the minimum temperature (Kumar et al., 1994). Eastern Canada also shows a slight increase in DTR due to a stronger cooling in maximum temperatures relative to minimum temperatures (Easterling et al., 1997). However, recently annual mean maximum and minimum temperatures for Canada have been analysed using newly homogenised data (Vincent, 1998; Vincent and Gullet, 1999); these have increased by 0.3 and $0.4^{\circ} \mathrm{C}$, respectively, over the last fifty years (Zhang et al., 1999). Central England temperature also shows no decrease in DTR since 1878 (Parker and Horton, 1999). Similarly, a new temperature data set for north-east Spain (not available on Figure 2.2 below, Brunet-India et al., 1999a,b), shows an increase in maximum temperature over 1913 to 1998 to be about twice as fast as that of minimum temperature. Recent analyses by Quintana-Gomez (1999) reveal a large reduction in the DTR over Venezuela and Colombia, primarily due to increasing minimum temperatures (up to $0.5^{\circ} \mathrm{C} /$ decade). In northern China, the decrease in DTR is due to a stronger warming 


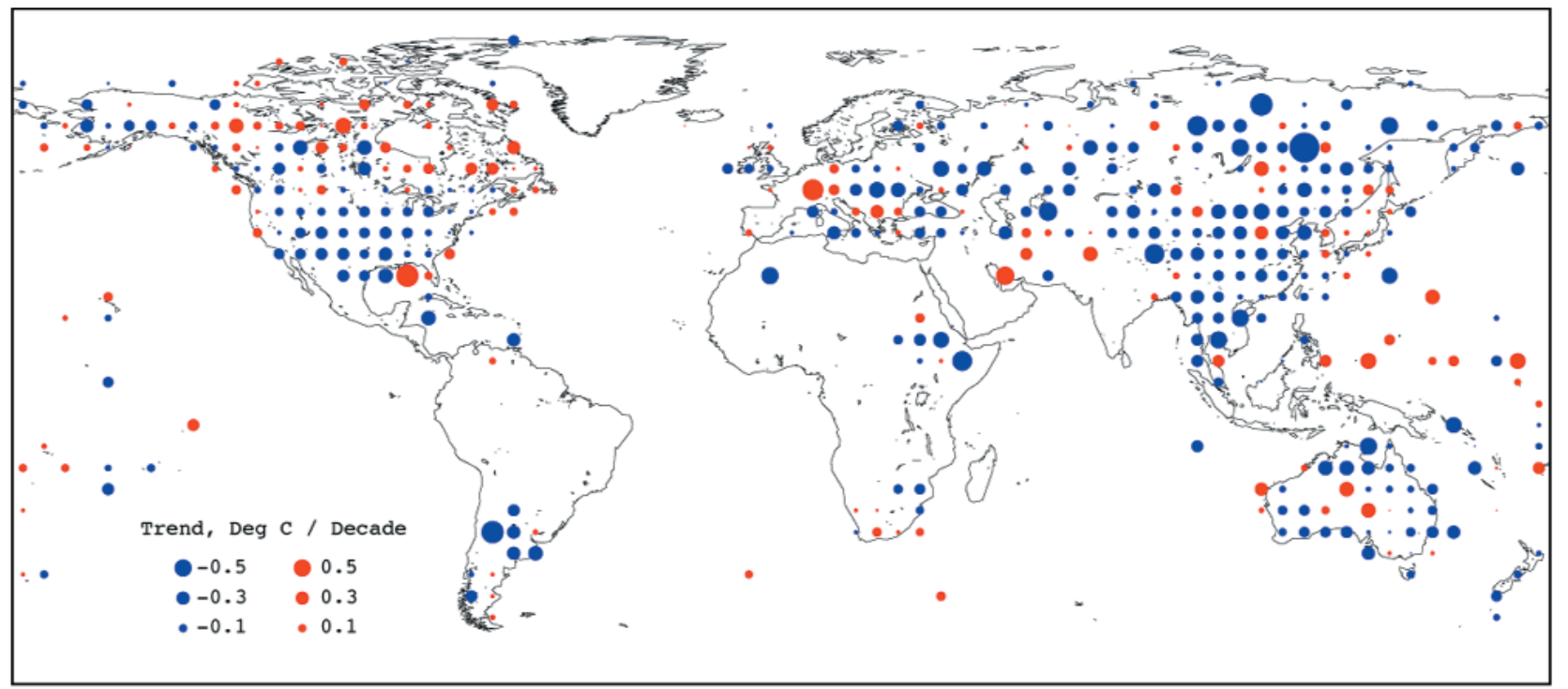

Figure. 2.2: Trends in annual diurnal temperature range (DTR, ${ }^{\circ} \mathrm{C} / \mathrm{dec}$ de), from 1950 to 1993 , for non-urban stations only, updated from Easterling et al. (1997). Decreases are in blue and increases in red. This data set of maximum and minimum temperature differs from and has more restricted coverage than those of mean temperature used elsewhere in Section 2.2.

in minimum temperature compared with maximum temperatures. However, in southern China the decreased DTR is due to a cooling in maximum with a slight warming in minimum temperature (Zhai and Ren, 1999).

The DTR is particularly susceptible to urban effects. Gallo et al. (1996) examined differences in DTR between stations based on predominant land use in the vicinity of the observing site. Results show statistically significant differences in DTR between stations associated with predominantly rural land use/land cover and those associated with more urban land use/land cover, with rural settings generally having larger DTR than urban settings. Although this shows that the distinction between urban and rural land use is important as one of the factors that can influence the trends observed in temperatures, Figure 2.2 shows annual mean trends in diurnal temperature range in worldwide non-urban stations over the period 1950 to 1993 (from Easterling et al., 1997). The trends for both the maximum and minimum temperatures are about $0.005^{\circ} \mathrm{C} /$ decade smaller than the trends for the full network including urban sites, which is consistent with earlier estimated urban effects on global temperature anomaly timeseries (Jones et al., 1990).

Minimum temperature for both hemispheres increased abruptly in the late 1970s, coincident with an apparent change in the character of the El Niño-Southern Oscillation (ENSO) phenomenon, giving persistently warmer sea temperatures in the tropical central and east Pacific (see Section 2.6.2). Seasonally, the strongest changes in the DTR were in the boreal winter $\left(-0.13^{\circ} \mathrm{C} /\right.$ decade for rural stations $)$ and the smallest changes were during boreal summer $\left(-0.065^{\circ} \mathrm{C} /\right.$ decade $)$, indicating some seasonality in the changes. Preliminary extensions of the Easterling et al. (1997) analysis to 1997 show that the declining trends in DTR have continued in much of North America and Asia.

Figure 2.3 shows the relationship between cloudiness and the DTR for a number of regions where long-term cloud cover data are available (Dai et al., 1997a). For each region there was an increase in cloud cover over the 20th century and generally a

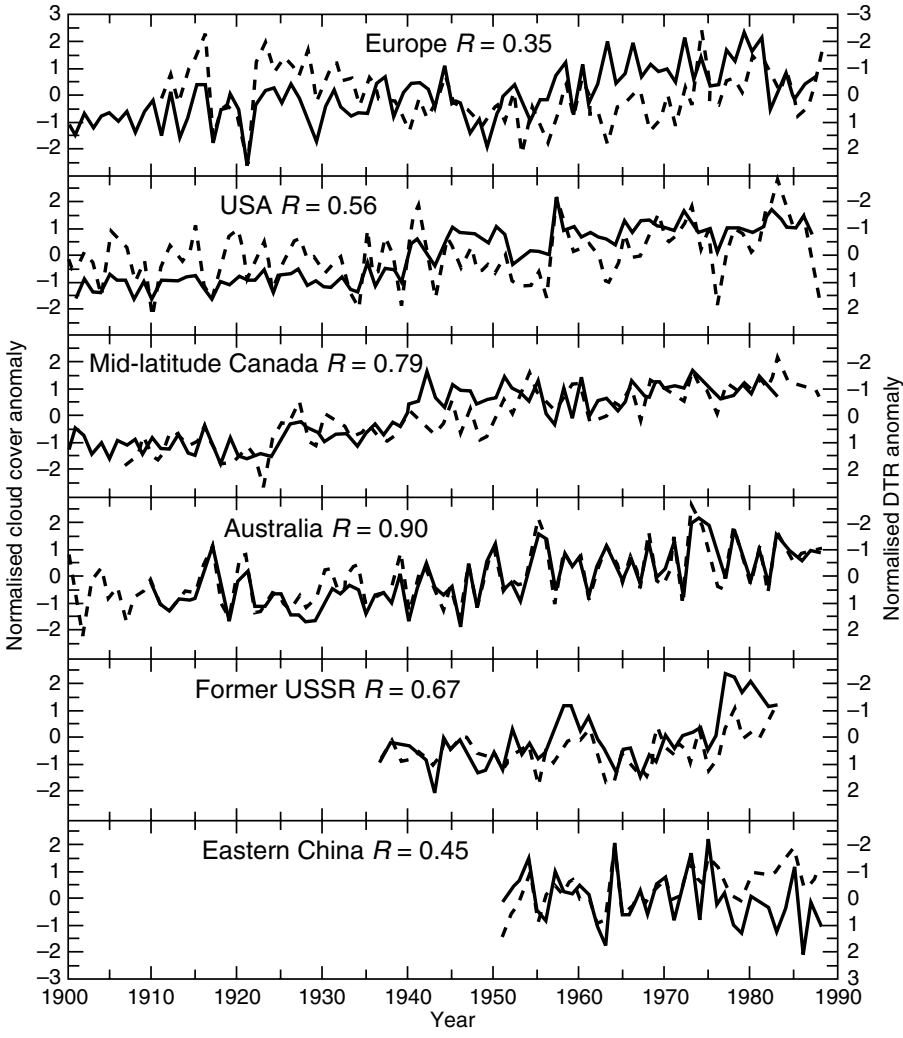

Figure 2.3: Cloud cover (solid line) and DTR $\left({ }^{\circ} \mathrm{C}\right.$, dashed line) for Europe, USA, Canada, Australia, the former Soviet Union, and eastern China (from Dai et al., 1997a). Note that the axis for DTR has been inverted. Therefore, a positive correlation of cloud cover with inverted DTR indicates a negative cloud cover/DTR correlation.

decrease in DTR. In some instances the correlation between annual cloud cover and annual DTR is remarkably strong, suggesting a distinct relationship between cloud cover and DTR. This would be expected since cloud dampens the diurnal cycle of radiation balance at the surface. Anthropogenically-caused 
increases in tropospheric aerosol loadings have been implicated in some of these cloud cover changes, while the aerosols themselves can cause small changes in DTR without cloud changes (Hansen et al., 1998 and Chapter 6).

\subsubsection{Sea surface temperature and ocean air temperature}

The analyses of SST described here all estimate the sub-surface bulk temperature, (i.e. the temperature in the first few metres of the ocean) not the skin temperature. Thus the Reynolds and Smith (1994) and Smith et al. (1996) data, which incorporate polar orbiting satellite temperatures, utilise skin temperatures that have been adjusted to estimate bulk SST values through a calibration procedure.

Many historical in situ marine data still remain to be digitised and incorporated into the database, to improve coverage and reduce the uncertainties in our estimates of marine climatic variations. A combined physical-empirical method (Folland and Parker, 1995) is used, as in the SAR, to estimate adjustments to ships' SST data obtained up to 1941 to compensate for heat losses from uninsulated (mainly canvas) or partly-insulated (mainly wooden) buckets (see Box 2.2). The corrections are independent of the land-surface air temperature data. Confirmation that these spatially and temporally complex adjustments are quite realistic globally is emerging from simulations of the Jones (1994) landsurface air temperature anomalies using the Hadley Centre atmospheric climate model HadAM3 forced with observed SST and sea-ice extents since 1871, updated from Rayner et al. (1996). Figure 2.4 (Folland et al., 2001) shows simulations of global land-surface air temperature anomalies in model runs forced with SST, with and without bias adjustments to the SST data before 1942. All runs with uncorrected SST (only the average is shown) give too cold a simulation of land-surface air temperature for much of the period before 1941 relative to the 1946 to 1965 base period, with a dramatic increase in 1942. All

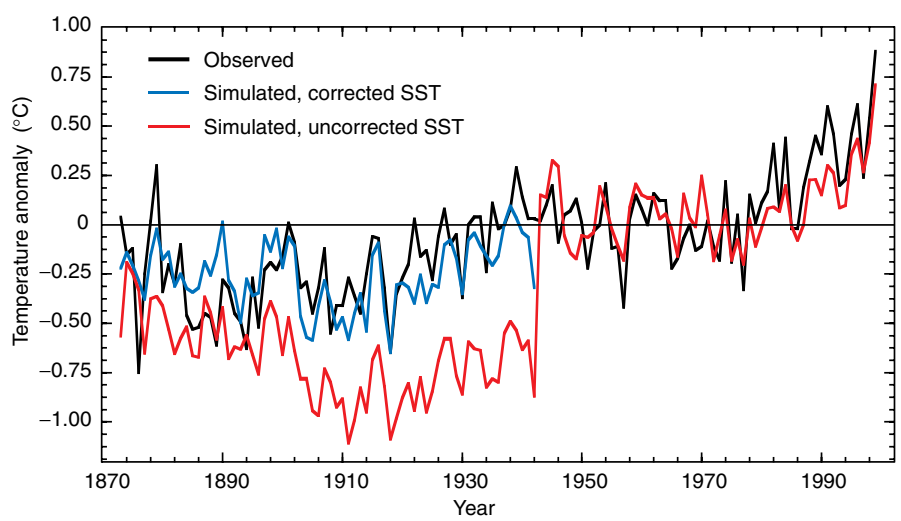

Figure 2.4: Tests of bias adjustments to sea surface temperature (SST) using a climate model (Folland et al., 2001). Black line - annual mean observed land surface air temperature (SAT) anomaly $\left({ }^{\circ} \mathrm{C}\right)$ from a 1946 to 1965 average (Jones, 1994), a period before major anthropogenic warming. Red line - annual averages of four simulations of SAT anomalies using uncorrected SST data, 1872 to 1941, and an average of six simulations for 1941 to 1998 . Blue line - average of six simulations of SAT, forced with SST data corrected up to 1941 (Folland and Parker, 1995). Simulated data are collocated with available observations. six individual runs with bias-adjusted SST (only the average is shown) give simulated land air temperatures close to those observed so that internal model variability is small on decadal time-scales compared to the signal being sought. These global results are mostly confirmed by ten similar large regional landsurface air temperature analyses (not shown). Hanawa et al. (2000) have provided independent confirmation of the SST bias corrections around Japan. Therefore, our confidence in the SST data sets has increased. Marine data issues are discussed further in Box 2.2, in Trenberth et al. (1992) and Folland et al. (1993).

Figure 2.5a shows annual values of global SST, using a recently improved UKMO analysis that does not fill regions of missing data (Jones et al., 2001), together with decadally smoothed values of SST from the same analysis. NMAT is also shown. These generally agree well after 1900, but NMAT data are warmer before that time with a slow cooling trend from 1860 not seen in the SSTs, though the minimum around 1910 is seen in both series. The SST analysis from the SAR is also shown. The changes in SST since the SAR are generally fairly small, though the peak warmth in the early 1940s is more evident in the more recent analysis, supported by the NMAT analysis. A contribution to decadally averaged global warmth at that time is likely to have arisen from closely spaced multiple El Niño events centred near 1939 to 1941 and perhaps 1942 to 1944 (Bigg and Inonue, 1992; and Figure 2.29). The NMAT data largely avoid daytime heating of ships' decks (Bottomley et al., 1990; Folland and Parker, 1995). Although NMAT data have been corrected for warm biases in World War II they may still be too warm in the Northern Hemisphere at that time (Figure 2.5c), though there is good agreement in the Southern Hemisphere (Figure 2.5d). The NMAT analysis is based on that in Parker et al. (1995) but differs from that used in the SAR in that it incorporates optimal interpolated data using orthogonal spatial patterns (eigenvectors). This is similar to the technique described by Kaplan et al. (1997, 1998) but with additional allowance for non-stationarity of the data (Parker et al, 1995). Great care is needed in making these reconstructions in a changing climate, as pointed out by Hurrell and Trenberth (1999). This NMAT analysis has been chosen because of the often very sparse data. NMAT confirms the SST trends in the 20th century until 1991 (see also Table 2.1). After 1991, NMAT warmed at a slower rate than SST in parts of the Southern Hemisphere, notably the South Indian and the tropical South Pacific Oceans. Overall, however, the SST data should be regarded as more reliable, though the relative changes in NMAT since 1991 may be partly real (Christy et al., 2001). The similar trends in SST and island air temperature found by Folland et al. (1997) for four regions of the tropical and extra-tropical South Pacific over much of the last century support the generally greater reliability of the SST data.

Figure $2.5 \mathrm{~b}$ shows three time-series of changes in global SST. The UKMO series (as in Figure 2.5a) does not include polar orbiting satellite data because of possible time-varying biases in them that remain difficult to correct fully (Reynolds, 1993) though the NCEP (National Centers for Environmental Prediction) data (adapted from Smith et al., 1996 and Reynolds and Smith, 1994), starting in 1950, do include satellite data after 1981. The NCDC series (updated from Quayle et al., 1999) starts in 1880 and 


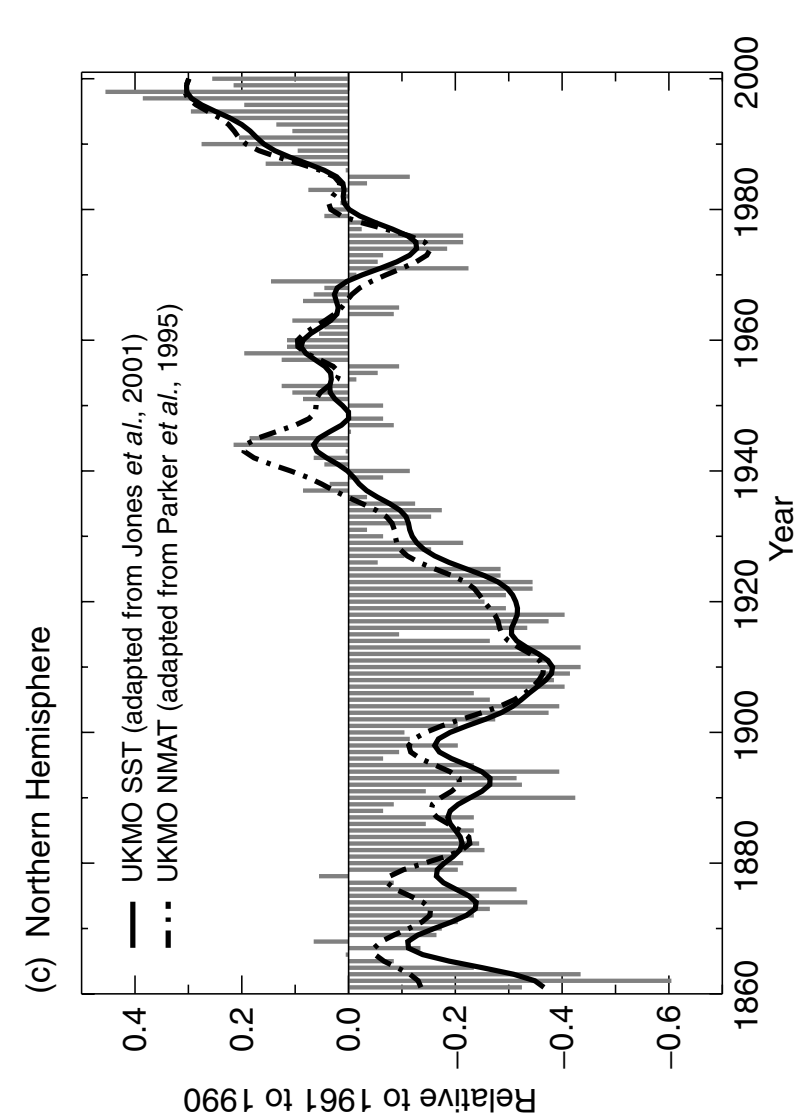

066 나 아 196 아 ㅅ!리바

(๖。) Кјешои

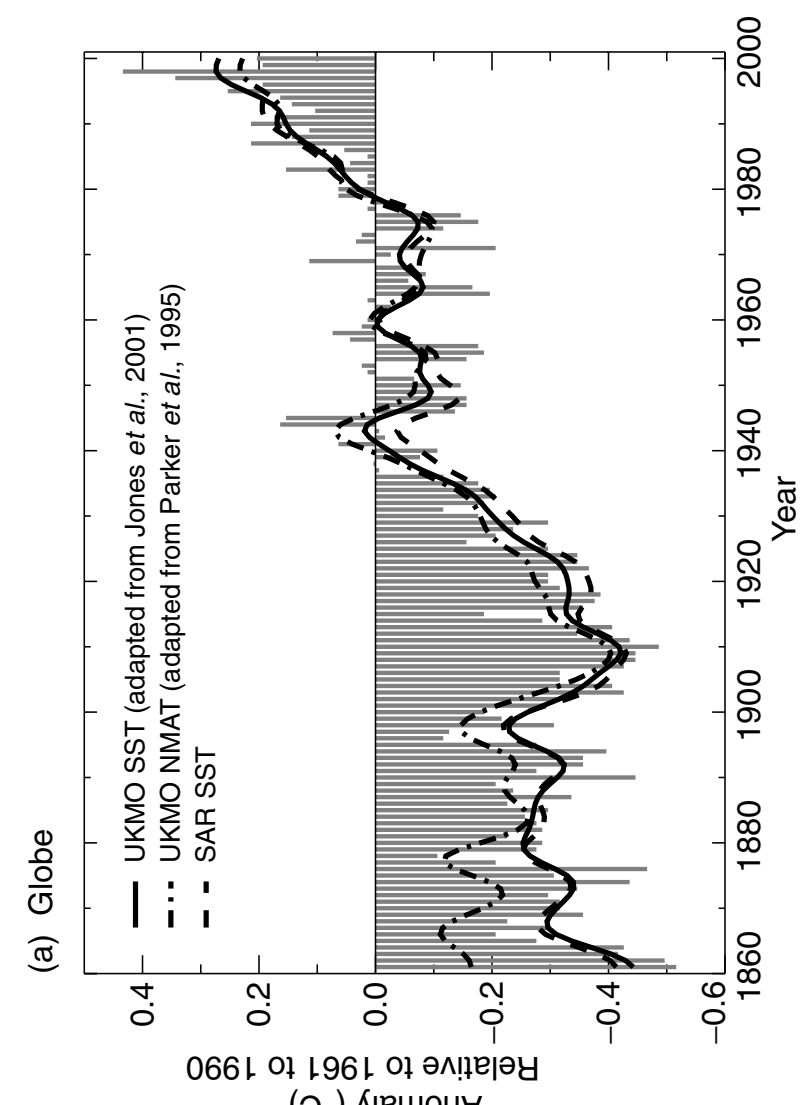

(৩。) Кןеmou $\forall$

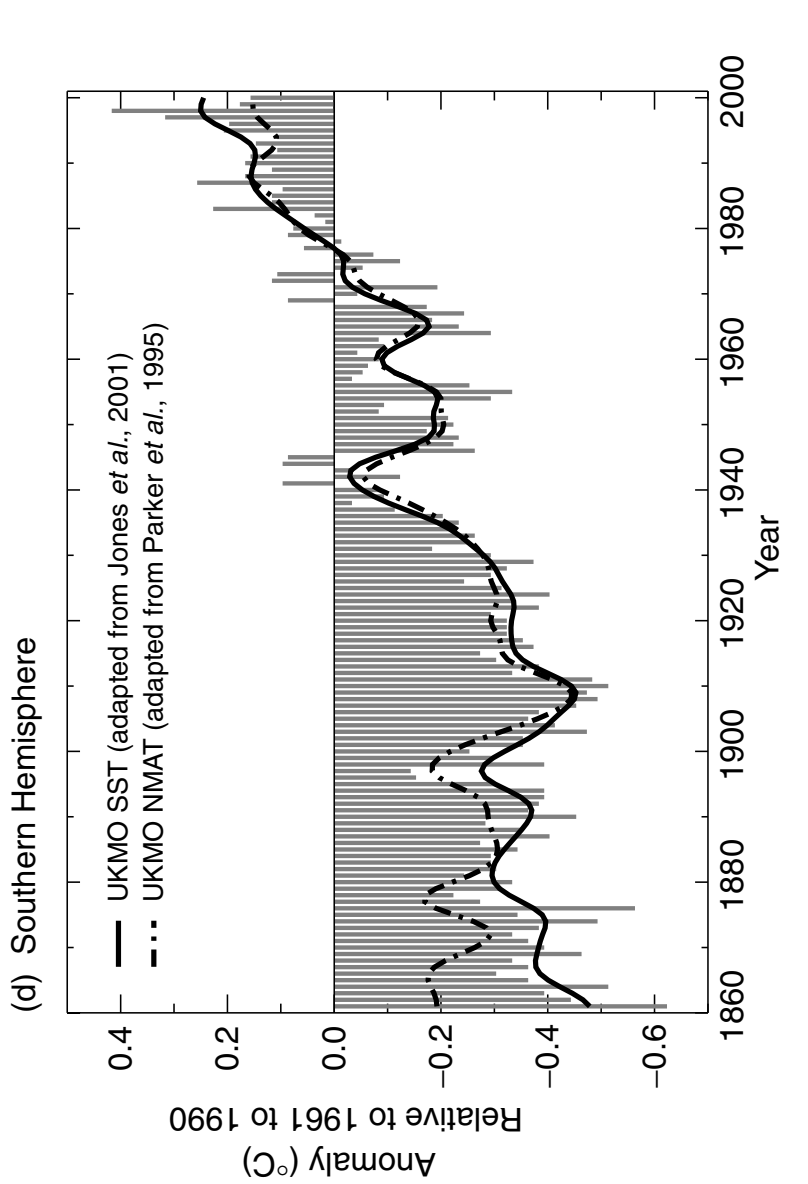

(О。) Кㄹmout

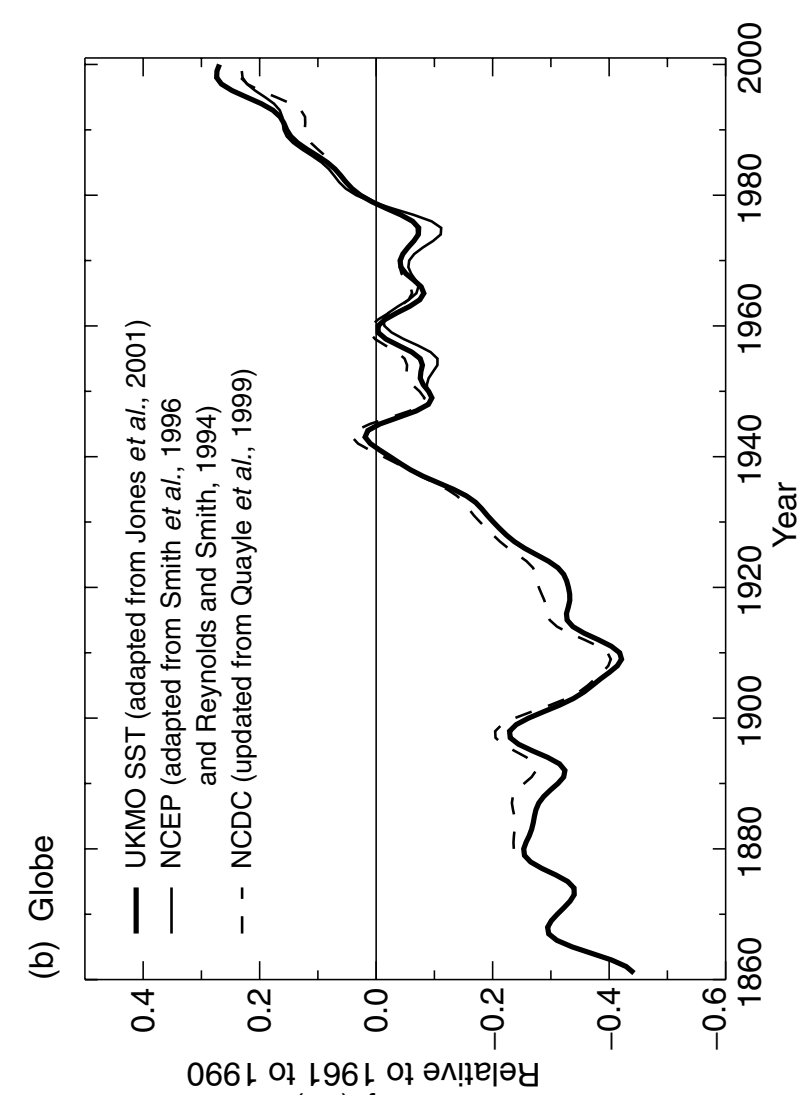

(つ) Крешои

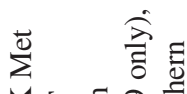

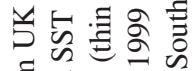

르워ำ

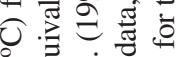

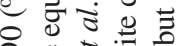

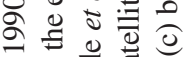

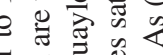

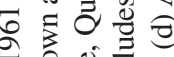

○ 的瓶

¿ U⿺辶寸

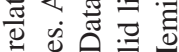

8

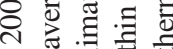

저

○

बิ

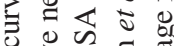

施氙

응 츤

-

¿

乙

후은

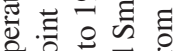

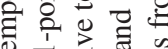

ये $\vec{d}$

需 $\frac{\pi}{0}$

๕

킁 ڤ

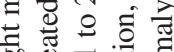

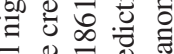

กี้

on 0 严

记昰艺

(1) -

记包

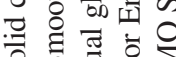

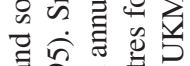

के छे च

ฮิ

印艺

赔合䒕

즐

요

훙

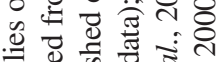

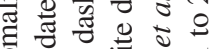

引 1 Ð

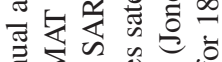

完之导导

సิ \& in

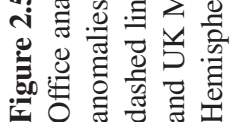


Box 2.2: Adjustments and Corrections to Marine Observations.

The SST data used here comprise over 80 million observations from the UK Main Marine Data Bank, the United States Comprehensive Ocean Atmosphere Data Set (COADS) and recent information telecommunicated from ships and buoys from the World Weather Watch. These observations have been carefully checked for homogeneity and carefully corrected for the use of uninsulated wooden and canvas buckets for collecting seawater prior to 1942. However, corrections prior to about 1900 are less well known because of uncertainties in the mix of wooden and canvas buckets. Nevertheless, Figure 2.4 provides good evidence that even in the 1870s, SST was little biased relative to land-surface air temperatures globally. Since 1941, observations mainly come from ship engine intake measurements, better insulated buckets and, latterly, from buoys. SST anomalies (from a 1961 to 1990 average) are first averaged into $1^{\circ}$ latitude by $1^{\circ}$ longitude boxes for five-day periods; the anomaly for a given observation is calculated from a $1^{\circ}$ box climatology that changes each day throughout the year. The five-day $1^{\circ}$ box anomalies are then aggregated into $5^{\circ}$ boxes for the whole month with outlying values rejected, and monthly average anomalies calculated. Further adjustments are made to monthly SST anomalies for the varying numbers of observations in each $5^{\circ}$ box because when observations are few, random errors tend to increase the variance of the monthly mean. NMAT data are treated similarly and have quite similar characteristics. However, a variance adjustment to NMAT data is not yet made. NMAT data are also corrected for the progressive increase in the height of thermometer screens on ships above the ocean surface, though no corrections have been made since 1930. Because there are only about half as many NMAT as SST data and NMAT have smaller temporal persistence, monthly NMAT anomalies may be less representative than SST anomalies even on quite large space scales. On longer time-scales, and over the majority of large ocean regions in the 20th century, there is good agreement between NMAT and SST. 19th century NMAT anomaly timeseries should be viewed cautiously because of the sparse character of the constituent observations, and regionally varying biases, only some of which have been corrected.

includes satellite data to provide nearly complete global coverage. Up to 1981, the Quayle et al series is based on the UKMO series, adjusted by linear regression to match the NCEP series after 1981. It has a truly global coverage based on the optimally interpolated Reynolds and Smith data. The Kaplan et al. (1998) global analysis is not shown because it makes no allowance for non-stationarity (here the existance of global warming) in its optimum interpolation procedures, as noted by Hurrell and Trenberth (1999). The warmest year globally in each SST record was 1998 (UKMO, $0.43^{\circ} \mathrm{C}, \mathrm{NCDC}, 0.39^{\circ} \mathrm{C}$, and NCEP, $0.34^{\circ} \mathrm{C}$, above the 1961 to 1990 average). The latter two analyses are in principle affected by artificially reduced trends in the satellite data (Hurrell and Trenberth, 1999), though the data we show include recent attempts to reduce this. The global SST show mostly similar trends to those of the land-surface air temperature until 1976, but the trend since 1976 is markedly less (Table 2.1). NMAT trends are not calculated from 1861, as they are too unreliable. The difference in trend between global SST and global land air temperature since 1976 does not appear to be significant, but the trend in NMAT (despite any residual data problems) does appear to be less than that in the land air temperature since 1976. Figures $2.5 \mathrm{c}$ and $\mathrm{d}$ show that NMAT and SST trends remain very similar in the Northern Hemisphere to the end of the record, but diverge rather suddenly in the Southern Hemisphere from about 1991, as mentioned above. The five warmest years in each of the UKMO, NCDC and NCEP SST analyses have occurred after 1986, four of them in the 1990s in the UKMO analysis.

Particularly strong warming has occurred in the extratropical North Atlantic since the mid-1980s (approximately $35^{\circ}$ to $65^{\circ} \mathrm{N}, 0^{\circ}$ to $35^{\circ} \mathrm{W}$ not shown). This warming appears to be related in part to the warming phase of a multi-decadal fluctuation (Folland et al., 1986, 1999a; Delworth and Mann, 2000; see Section 2.6), perhaps not confined to the North Atlantic (Minobe, 1997; Chao et al., 2000), though global warming is likely to be contributing too. In addition, the cooling in the north-western North Atlantic south of Greenland, reported in the SAR, has ceased. These features were noted by Hansen et al. (1999).

\subsubsection{Land and sea combined}

Figure 2.6 summarises the relative changes of UKMO SST, UKMO NMAT and CRU land-surface air temperature. The greater warming of the land in recent years is clear, but otherwise all three curves have a generally similar shape except that modest cooling of NMAT in the late 19th century is not seen in the SST data as noted for Figure 2.5. The relative coldness of the land around 1885 to 1895 comes from the Northern Hemisphere continental interiors, particularly in winter, as global coastal land air temperature and adjacent SST anomalies agree well at this time (Parker et al., 1995), confirmed by the Jones et al. (2001) data. Note that there are some systematic compensating differences between the land and SST in the late 19th century in both hemispheres (not shown). The CRU land data are generally about 0.1 to $0.2^{\circ} \mathrm{C}$ colder in the Northern Hemisphere except at the beginning of the record (early 1860s), when they agree, and rather colder than this in 1885 to 1890 . The opposite is seen in the Southern Hemisphere before 1885 when SST is generally 0.1 to $0.2^{\circ} \mathrm{C}$ colder and $0.3^{\circ} \mathrm{C}$ colder around 1875 . Overall the SST data are less variable in each hemisphere in these rather poorly observed periods. The Southern Hemisphere land temperature at this time can actually represent a very small observed area of the hemisphere while the SST data, though sparse, are generally considerably more widespread. The sharp cooling in SST around 1903/4 in Figures 2.5 and 2.6, seen in the land as well as the two ocean surface data sets, was discussed for the North Atlantic and Indian Oceans by Helland-Hansen and Nansen (1920) not long after the event. The reduced warming of the NMAT in the last decade reflects differences in the Southern Hemisphere discussed above. Slightly greater warming of the global ocean than the 


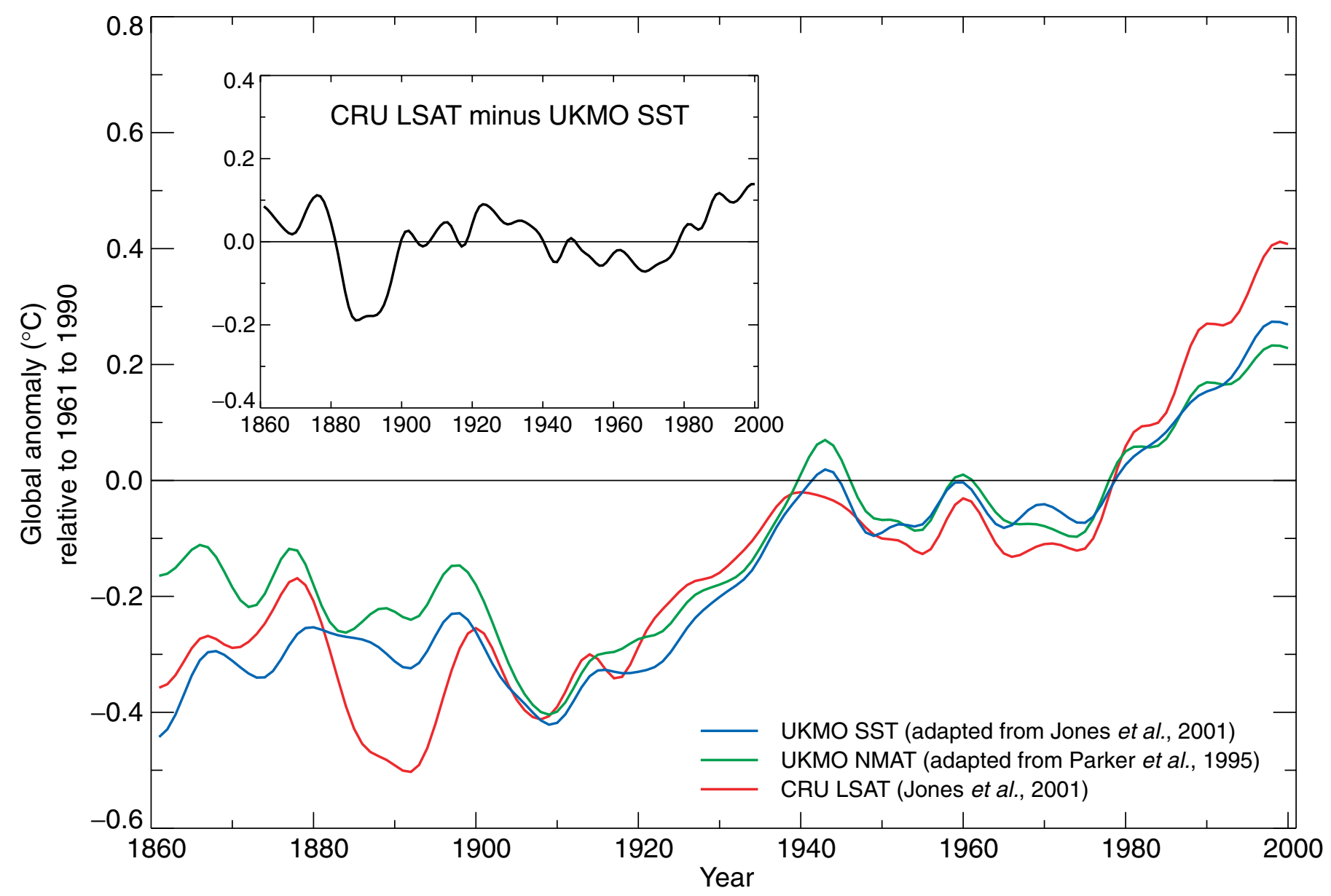

Figure 2.6: Smoothed annual anomalies of global average sea surface temperature $\left({ }^{\circ} \mathrm{C}\right) 1861$ to 2000 , relative to 1961 to 1990 (blue curve), night marine air temperature (green curve), and land-surface air temperature (red curve). The data are from UK Met Office and CRU analyses (adapted from Jones et al., 2001, and Parker et al., 1995). The smoothed curves were created using a 21-point binomial filter giving near-decadal averages. Also shown (inset) are the smoothed differences between the land-surface air and sea surface temperature anomalies.

global land in 1910 to 1945 (seen in Table 2.1) is within the uncertainties of either data set, as a slightly slower warming of the ocean might be expected on physical grounds.

Figures 2.7a to c show annual time-series of anomalies of combined land-surface air temperature and SST for the hemispheres and globe since 1861, based on the latest CRU land air temperature data and the UKMO SST data. Jones et al. (2001) temperature data have been averaged by both a standard weighting method, used in the SAR, as shown by the dashed smoothed curves, and by an optimum averaging method (Shen et al., 1998; Folland et al., 2001) as shown by the bars and solid smoothed curves. The latter method uses the variance-covariance matrix instead of correlation functions (Kagan, 1997). The calculated uncertainties (twice the standard error) in the annual values are also shown (including the independent urbanisation and SST bias correction uncertainties). Optimum averaging gives less weight to areas of high data uncertainty than do ordinary averaging methods, and it takes much better account of data gaps. It also gives more weight to Antarctica, the great bulk of which (away from the Antarctic Peninsula) has warmed little in the last two decades (Comiso, 2000). Optimum averages can affect individual years markedly when data are sparse. Thus extra warmth of the warm year 1878 (strongly affected by the $1877 / 78 \mathrm{El} \mathrm{Niño)} \mathrm{in} \mathrm{the}$ Northern relative to the Southern Hemisphere in the area weighted average (not shown) disappears when optimum averages are used. In the Northern Hemisphere, the optimum averages are little different from area weighted averages, but they are consistently warmer in the sparsely sampled Southern Hemisphere before 1940 , often by more than one tenth of a degree. The overall effect on global temperature is small, however (Figure 2.7c)

The five warmest global optimally averaged years since the beginning of the record in 1861 all occurred in the 1990s with 1998 having the warmest anomaly $\left(0.55^{\circ} \mathrm{C}\right)$. This year was significantly warmer than the second warmest year, $1995\left(0.38^{\circ} \mathrm{C}\right)$, while 1999 was fourth warmest year, despite the strong La Niña event. The remarkably consistent monthly global warmth of 1998 is discussed in Karl et al. (2000).

Table 2.2 shows linear trends of the annual optimum averages, and twice their standard errors, for the globe and hemispheres using the restricted maximum likelihood method as in Table 2.1 and allowing for the annual uncertainties due to data gaps, urbanisation over land, and bias corrections to SST. Since 
(a) Northern Hemisphere

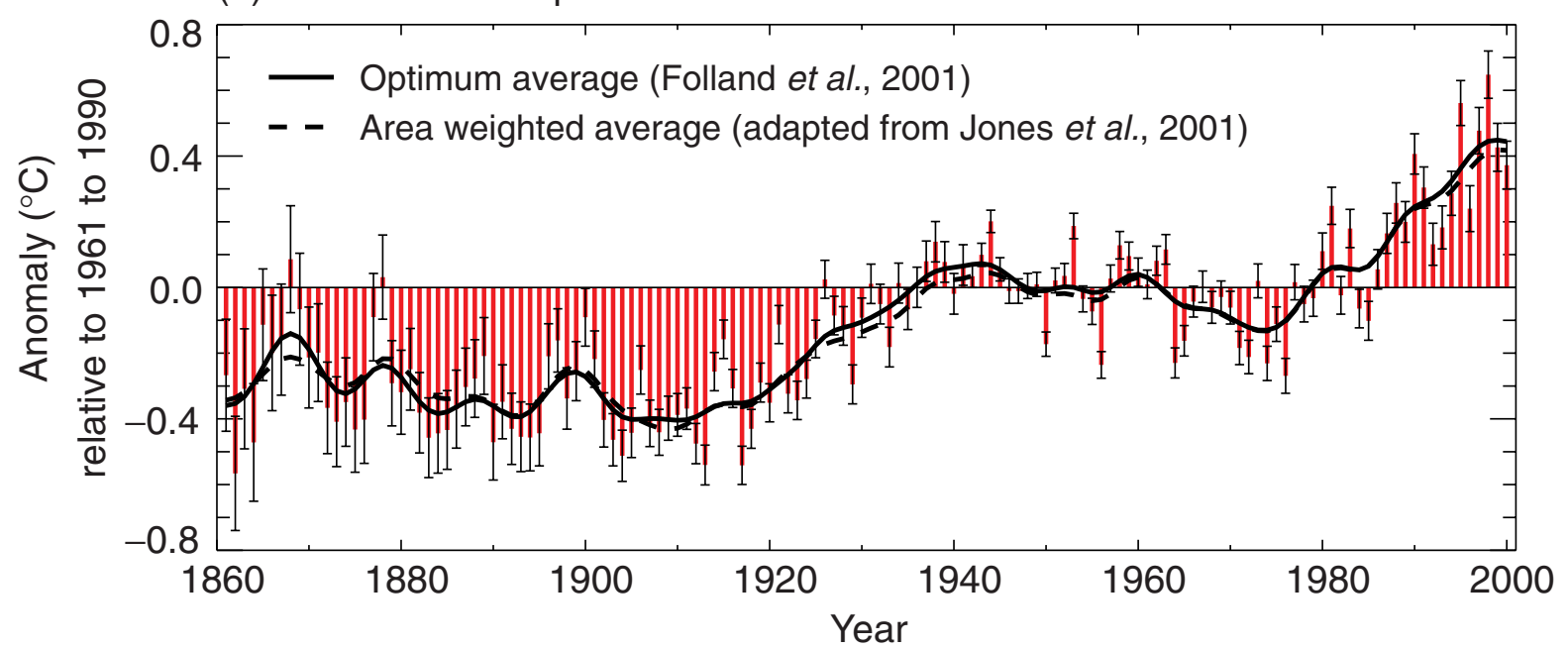

(b) Southern Hemisphere

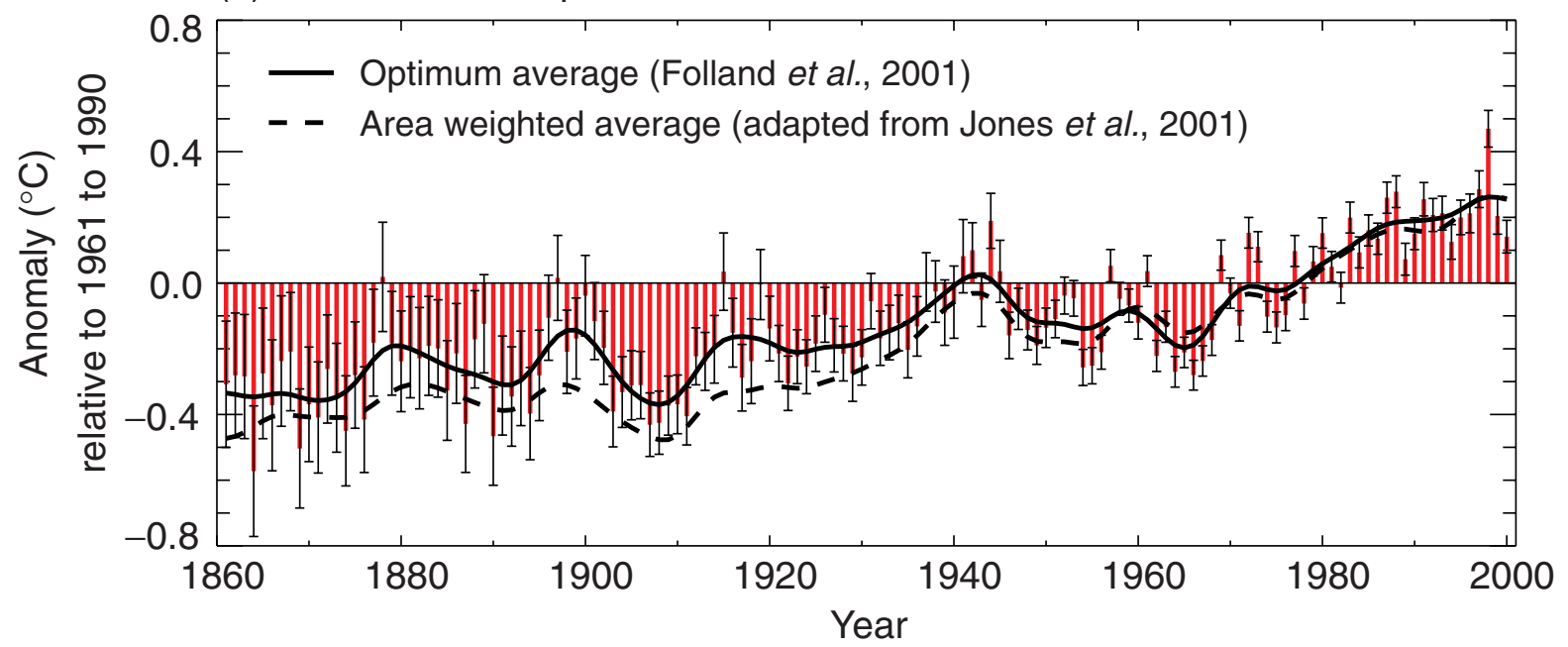

(c) Globe

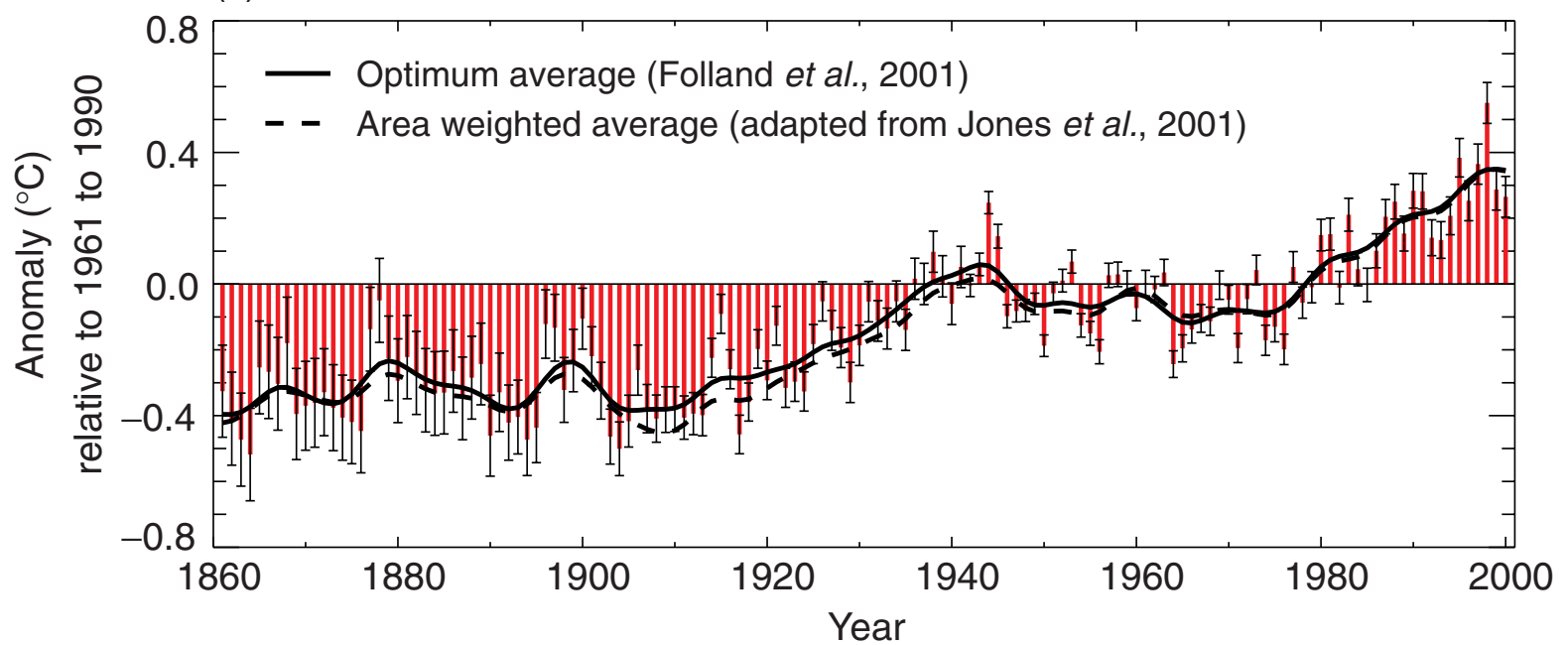

Figure 2.7: Smoothed annual anomalies of combined land-surface air and sea surface temperatures $\left({ }^{\circ} \mathrm{C}\right), 1861$ to 2000 , relative to 1961 to 1990 , for (a) Northern Hemisphere; (b) Southern Hemisphere; and (c) Globe. The smoothed curves were created using a 21-point binomial filter giving near-decadal averages. Optimally averaged anomalies (Folland et al., 2001) - solid curves; standard area weighted anomalies (adapted from Jones et al., 2001) - dashed curves. Also shown are the unsmoothed optimum averages - red bars, and twice their standard errors - width denoted by black "I". Note that optimum averages for the Southern Hemisphere are a little warmer before 1940, when the data are sparse, than the areaweighted averages. However, the two types of averaging give similar results in the Northern Hemisphere. 
Table 2.2: As Table 2.1 but for annual optimally averaged combined CRU land-surface air temperature anomalies and UKMO sea surface temperature anomalies (CRU LSAT + UKMO SST). All of the estimates of trends and errors in the table account for uncertainties in the annual anomalies due to data gaps, urbanisation over land, and bias corrections to SST.

\begin{tabular}{|l|c|c|c|c|c|}
\hline & 1861 to 2000 & 1901 to 2000 & 1910 to 1945 & 1946 to 1975 & 1976 to 2000 \\
\hline Northern Hemisphere & $\mathbf{0 . 0 5}$ & $\mathbf{0 . 0 6}$ & $\mathbf{0 . 1 7}$ & -0.05 & $\mathbf{0 . 2 4}$ \\
CRU LSAT + UKMO SST & $\mathbf{( 0 . 0 2}$ ) & $\mathbf{( 0 . 0 2}$ & $\mathbf{( 0 . 0 3 )}$ & $(0.05)$ & $\mathbf{( 0 . 0 7 )}$ \\
(Folland et al., 2001) & $\mathbf{1 \%}$ & $\mathbf{1 \%}$ & $\mathbf{1 \%}$ & & $\mathbf{1 \%}$ \\
\hline Southern Hemisphere & $\mathbf{0 . 0 4}$ & $\mathbf{0 . 0 5}$ & $\mathbf{0 . 0 9}$ & 0.03 & $\mathbf{0 . 1 1}$ \\
CRU LSAT + UKMO SST & $\mathbf{( 0 . 0 1})$ & $\mathbf{( 0 . 0 2}$ & $\mathbf{( 0 . 0 5})$ & $(0.07)$ & $\mathbf{( 0 . 0 5})$ \\
(Folland et al., 2001) & $\mathbf{1 \%}$ & $\mathbf{1 \%}$ & $\mathbf{1 \%}$ & & $\mathbf{1 \%}$ \\
\hline Global & $\mathbf{0 . 0 4}$ & $\mathbf{0 . 0 6}$ & $\mathbf{0 . 1 4}$ & -0.01 & $\mathbf{0 . 1 7}$ \\
CRU LSAT + UKMO SST & $\mathbf{( 0 . 0 1})$ & $\mathbf{( 0 . 0 2}$ & $\mathbf{( 0 . 0 4 )}$ & $(0.04)$ & $\mathbf{( 0 . 0 5})$ \\
(Folland et al., 2001) & $\mathbf{1 \%}$ & $\mathbf{1 \%}$ & $\mathbf{1 \%}$ & & $\mathbf{1 \%}$ \\
\hline
\end{tabular}

1861 the hemispheres have warmed by approximately the same amount. However both the earlier period of warming (1910 to 1945 ) and the more recent one (1976 to 1999) saw rates of warming about twice as great in the Northern Hemisphere. There was continued (non-significant) warming in the Southern Hemisphere, though at a reduced rate, in 1946 to 1975, which partially offset (non-significant) cooling in the Northern Hemisphere over the same period to give a (non-significant) $0.03^{\circ} \mathrm{C}$ cooling globally. The global trend from 1861 to 2000 can be cautiously interpreted as an equivalent linear warming of $0.61{ }^{\circ} \mathrm{C}$ over the 140 -year period, with a $95 \%$ confidence level uncertainty of $\pm 0.16^{\circ} \mathrm{C}$. From 1901 an equivalent warming of $0.57^{\circ} \mathrm{C}$ has occurred, with an uncertainty of $\pm 0.17^{\circ} \mathrm{C}$.

Figure 2.8 shows a smoothed optimally averaged annual global time-series with estimates of uncertainty at \pm twice the standard error of the smoothed (near decadal) estimate. Note that the optimum average uncertainties increase in earlier years mainly because of the much larger data gaps. Also shown are uncertainties estimated by Jones et al. (1997b) using a different method centred on the Jones et al. (2001) land and sea surface temperature series. This series uses the average of anomalies from all available grid boxes, weighted according to grid box area. Therefore, in contrast to the Jones et al. (2001) global landsurface air temperature data, the global land and sea surface temperature data are not a simple average of the hemispheres. The optimally averaged uncertainties vary from about 15 to $65 \%$ less than those given by Jones et al. (1997b). This is reasonable as optimum averages have minimum variance amongst the range of unbiased estimates of the average. Not surprisingly, there is relatively little difference in the decadal averages themselves. However unlike the Jones et al. estimates of uncertainty, the optimum average also includes uncertainties in bias corrections to SST up to 1941 (Folland and Parker, 1995) and the uncertainties (as included in Figure 2.1) in the land data component that are due to urbanisation. Cessation of the SST component of uncertainty after 1941 is the reason for a lack of increase in uncertainties in the fairly poorly observed period 1942 to 1945 . Uncertainties due to changes in thermometer screens are poorly known but could be $0.1{ }^{\circ} \mathrm{C}$ globally in the 19th and early 20th centuries (Parker, 1994); they are not included here, but a preliminary analysis appears in Folland et al. (2001). For further discussion of changes in land and ocean surface temperature, see Jones et al. (1999a).

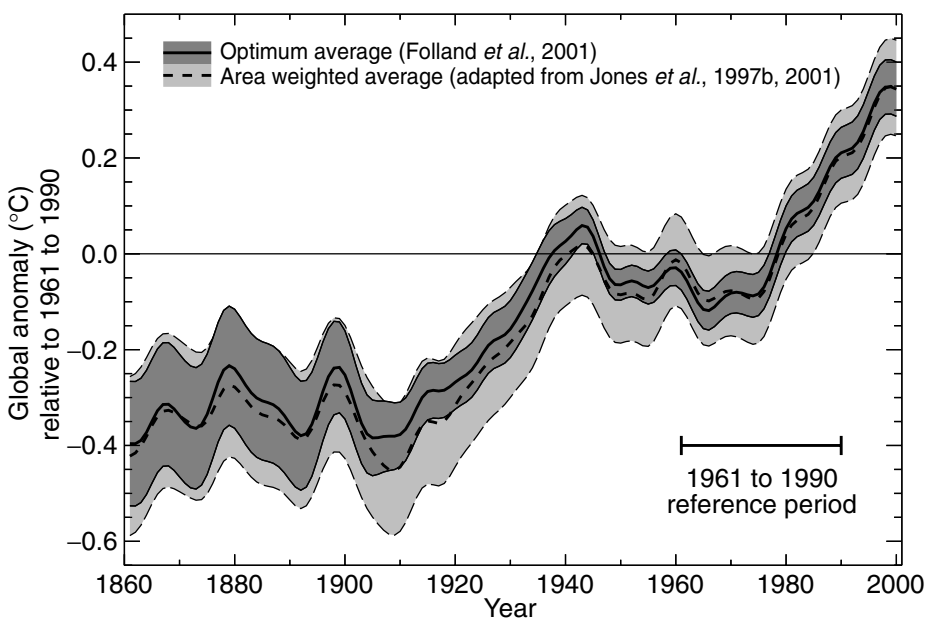

Figure 2.8: Smoothed annual anomalies of global combined landsurface air and sea surface temperatures $\left({ }^{\circ} \mathrm{C}\right), 1861$ to 2000 , relative to 1961 to 1990 , and twice their standard errors. The smoothed curves and shaded areas were created using a 21-point binomial filter giving near-decadal averages, with appropriate errors. Optimally averaged anomalies and uncertainties (Folland et al., 2001) - solid curve and dark shading; standard area weighted anomalies and uncertainties (adapted from Jones et al., 1997b, 2001) - dashed curve and light shading. Note that uncertainties decrease after 1941 due to the cessation of uncertainties due to bias corrections in sea surface temperature. On the other hand, uncertainties due to urbanisation of the land component, assessed as zero in 1900, continue to increase after 1941 to a maximum in 2000 .

Referring back to Table 2.2 and including the second decimal place, our best estimate of the equivalent linear rate of global land and ocean surface warming between 1861 to 2000 is $0.044^{\circ} \mathrm{C} /$ decade, or a warming of $0.61 \pm 0.16^{\circ} \mathrm{C}$. Over the period 1901 to 2000 , the equivalent values are $0.058^{\circ} \mathrm{C} / \mathrm{dec}$ ade or a warming of $0.57 \pm 0.17^{\circ} \mathrm{C}$. These values include the modifying effects of the annual uncertainties. So we calculate that since the late 19th or the beginning of the 20th century, up to 2000, global warming has been $0.6 \pm 0.2^{\circ} \mathrm{C}$. This is $0.15^{\circ} \mathrm{C}$ more warming than the 0.3 to $0.6^{\circ} \mathrm{C}$ estimated more subjectively up to 1994 by the SAR. This relatively large increase is explained by the increase in temperature since the SAR was completed, improved 
(a) Annual temperature trends, 1901 to 2000

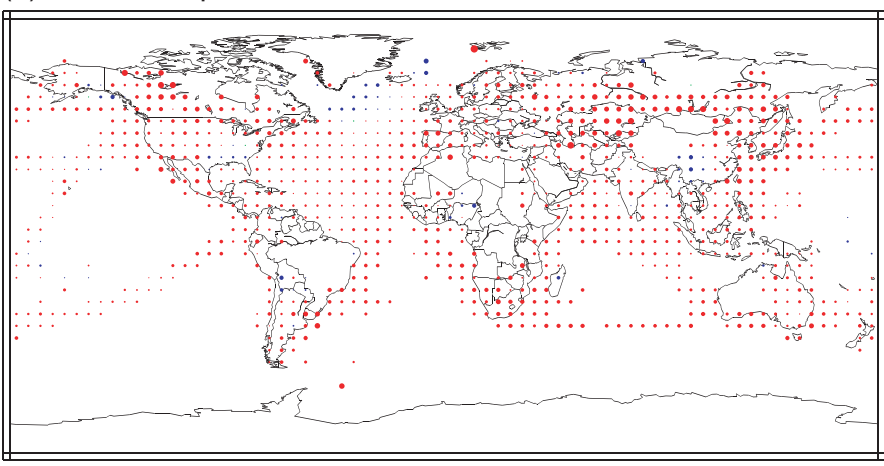

(c) Annual temperature trends, 1946 to 1975

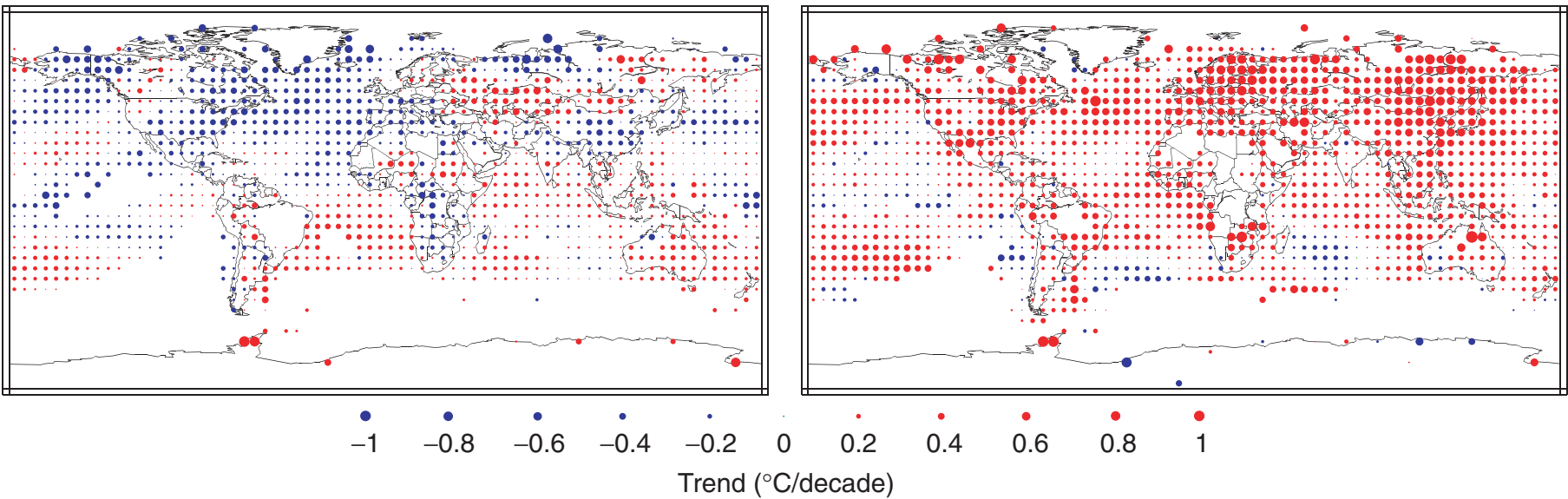

(b) Annual temperature trends, 1910 to 1945

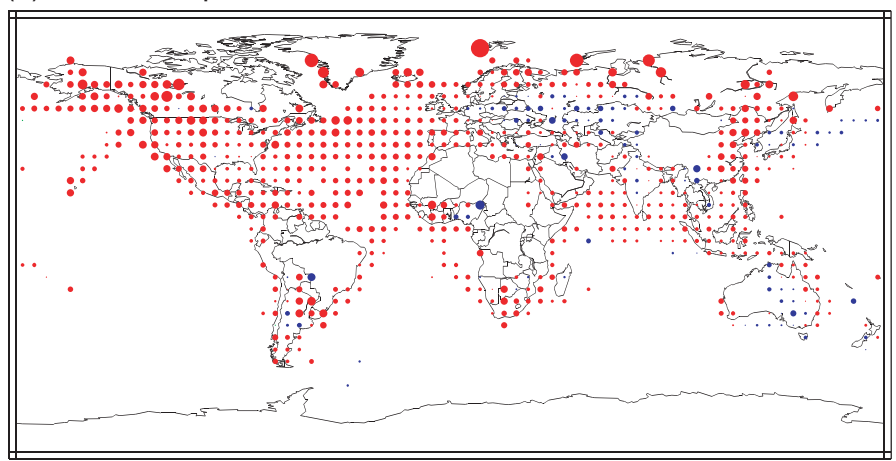

(d) Annual temperature trends, 1976 to 2000

Figure 2.9: (a) to (d) Annual surface temperature trends for the periods 1901 to 2000, 1910 to 1945,1946 to 1975 , and 1976 to 2000 , respectively $\left({ }^{\circ} \mathrm{C} /\right.$ decade), calculated from combined land-surface air and sea surface temperatures adapted from Jones et al. (2001). The red, blue and green circles indicate areas with positive trends, negative trends and little or no trend respectively. The size of each circle reflects the size of the trend that it represents. Trends were calculated from annually averaged gridded anomalies with the requirement that annual anomalies include a minimum of 10 months of data. For the period 1901 to 2000, trends were calculated only for those grid boxes containing annual anomalies in at least 66 of the 100 years. The minimum number of years required for the shorter time periods (1910 to 1945, 1946 to 1975 , and 1976 to 2000) was 24,20 , and 16 years, respectively.

methods of analysis and the fact that the SAR decided not update the value in the First Assessment Report, despite slight additional warming. The latter decision was likely to have been due to a cautious interpretation of overall uncertainties which had at that time to be subjectively assessed.

\subsubsection{Are the land and ocean surface temperature changes mutually consistent?}

Most of the warming in the 20th century occurred in two distinct periods separated by several decades of little overall globally averaged change, as objectively identified by Karl et al. (2000) and discussed in IPCC $(1990,1992,1996)$ and several references quoted therein. Figures 2.9 and 2.10 highlight the worldwide behaviour of temperature change in the three periods. These linear trends have been calculated from the Jones et al. (2001) gridded combination of UKMO SST and CRU land-surface air temperature, from which the trends in Table 2.2 were calculated. Optimum averaging has not been used for Figures 2.9 and 2.10, and only trends for grid boxes where reasonably complete time-series of data exist are shown. The periods chosen are 1910 to 1945 (first warming period), 1946 to 1975 (period of little global temperature change), 1976 to 2000 (second warming period, where all four seasons are shown in Figure 2.10) and the 20th century, 1901 to 2000. It can be seen that there is a high degree of local consistency between the SST and land air temperature across the land-ocean boundary, noting that the corrections to SST (Folland and Parker, 1995) are independent of the land data. The consistency with which this should be true locally is not known physically, but is consistent with the similarity of larger-scale coastal land and ocean surface temperature anomalies on decadal time-scales found by Parker et al. (1995). The warming observed in the period from 1910 to 1945 was greatest in the Northern Hemisphere high latitudes, as discussed in Parker et al. (1994). By contrast, the period from 1946 to 1975 shows widespread cooling in the Northern Hemisphere relative to much of the Southern, consistent with Tables 2.1 and 2.2 and Parker et al. (1994). Much of the cooling was seen in the Northern Hemisphere regions that showed most warming in 1910 to 1945 (Figure 2.9 and Parker et al., 1994). In accord with the results in the SAR, recent warming (1976 to 2000) has been greatest over the mid-latitude Northern 
(a) DJF temperature trends, 1976 to 2000

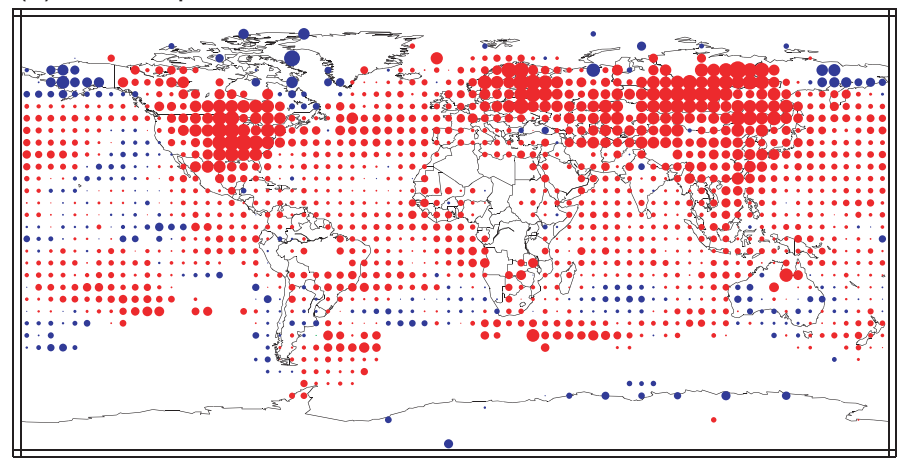

(c) JJA temperature trends, 1976 to 2000

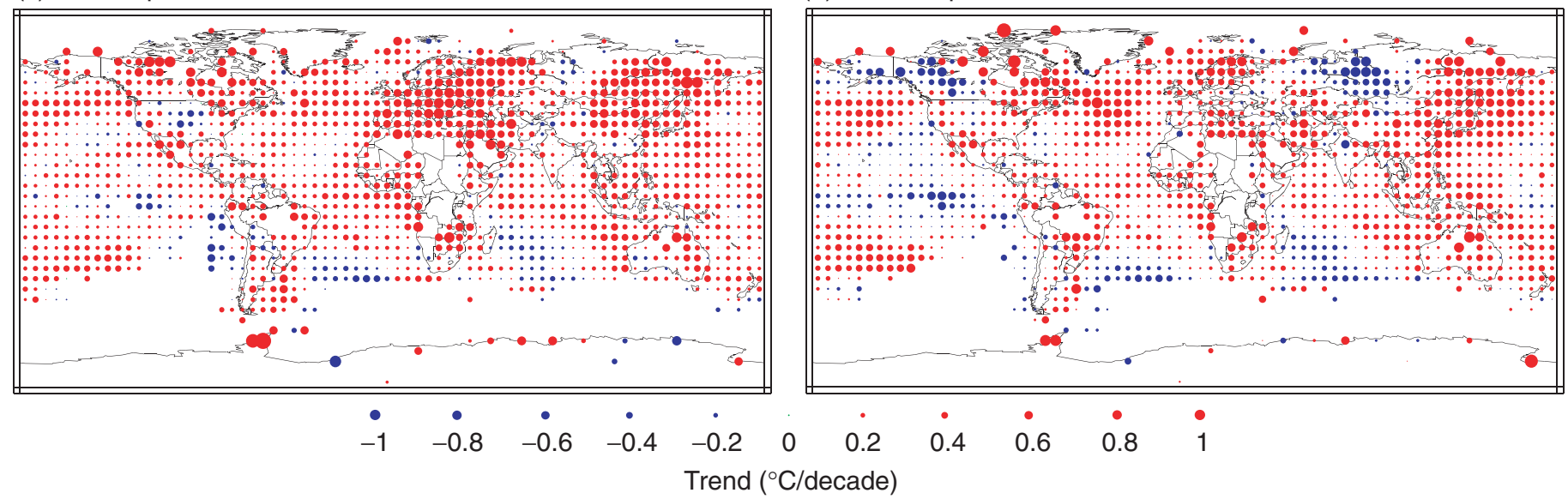

Figure 2.10: (a) to (d) Seasonal surface temperature trends for the period 1976 to $2000\left({ }^{\circ} \mathrm{C} / \mathrm{decade}\right)$, calculated from combined land-surface air and sea surface temperatures adapted from Jones et al. (2001). The red, blue and green circles indicate areas with positive trends, negative trends and little or no trend respectively. The size of each circle reflects the size of the trend that it represents. Trends were calculated from seasonally averaged gridded anomalies with the requirement that the calculation of seasonal anomalies should include all three months. Trends were calculated only for those grid boxes containing seasonal anomalies in at least 16 of the 24 years.

Hemisphere continents in winter. However, the updated data shows only very limited areas of year-round cooling in the north-west North Atlantic and mid-latitude North Pacific. Over 1901 to 2000 as a whole, noting the strong consistency across the land-ocean boundary, most warming is observed over mid- and high latitude Asia and parts of western Canada. The only large areas of observed cooling are just south and east of Greenland and in a few scattered continental regions in the tropics and sub-tropics.

Faster warming of the land-surface temperature than the ocean surface temperature in the last two decades, evident in Figure 2.6, could in part be a signal of anthropogenic warming (see Chapters 9 and 12). However, a component, at least in the Northern Hemisphere north of 40 to $45^{\circ} \mathrm{N}$, may result from the sharp increase in the positive phase of the winter half year North Atlantic Oscillation (NAO)/Arctic Oscillation (AO) since about 1970 (Section 2.6.5), though this itself might have an anthropogenic component (Chapter 7). There has also been a strong bias to the warm phase of El Niño since about 1976 (Section 2.6.2). In particular, Hurrell and van Loon (1997) and Thompson et al. (2000a) show that the positive phase of the NAO advects additional warm air over extra-tropical Eurasia north of about $45^{\circ} \mathrm{N}$. The positive phase of the NAO or $\mathrm{AO}$ is therefore likely to be a major cause of (b) MAM temperature trends, 1976 to 2000

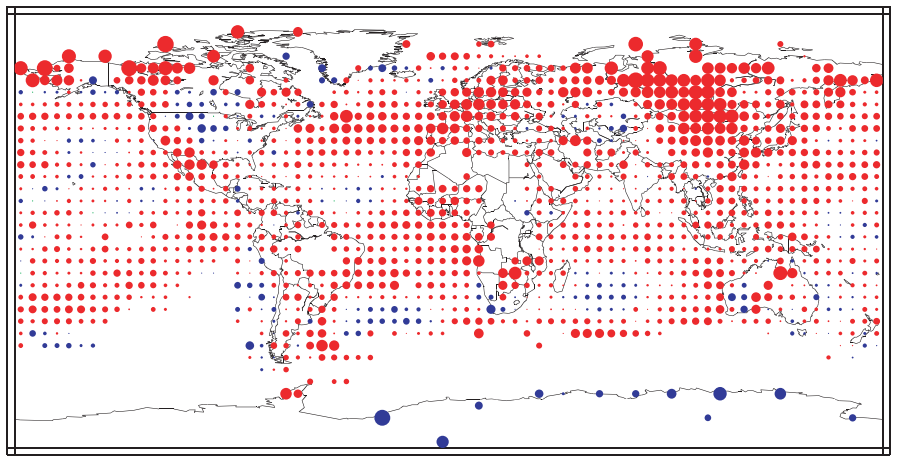

(d) SON temperature trends, 1976 to 2000 


\subsubsection{Sub-surface ocean temperatures and salinities}

While the upper ocean temperature and salinity are coupled to the atmosphere on diurnal and seasonal time-scales, the deep ocean responds on much longer time-scales. During the last decade, data set development, rescue, declassification and new global surveys have made temperature and salinity profile data more readily available (Levitus et al., 1994, 2000a).

\section{Global}

Levitus et al. (1997, 2000b) made annual estimates of the heat content of the upper $300 \mathrm{~m}$ of the world ocean from 1948 through to 1998 (Figure 2.11). The Atlantic and Indian Oceans each show a similar change from relatively cold to relatively warm conditions around 1976. The Pacific Ocean exhibits more of a bidecadal signal in heat storage. In 1998, the upper $300 \mathrm{~m}$ of the world ocean contained $(1.0 \pm 0.5) \times 10^{23}$ Joules more heat than it did in the mid-1950s, which represents a warming of $0.3 \pm$ $0.15^{\circ} \mathrm{C}$. A least squares linear regression to the annual temperature anomalies from 1958 to 1998 gives a warming of $0.037^{\circ} \mathrm{C} /$ decade. White et al. $(1997,1998 \mathrm{~b})$ computed changes in diabatic heat storage within the seasonal mixed layer from 1955 to 1996 between $20^{\circ} \mathrm{S}$ and $60^{\circ} \mathrm{N}$ and observed a warming of 0.15 $\pm 0.02^{\circ} \mathrm{C}$ or $0.036^{\circ} \mathrm{C} /$ decade.

Extension of the analysis to the upper $3,000 \mathrm{~m}$ shows that similar changes in heat content have occurred over intermediate and deep waters in all the basins, especially in the North and South Atlantic and the South Indian Oceans. The change in global ocean heat content from the 1950s to the 1990s is equivalent to a net downwards surface heat flux of $0.3 \mathrm{Wm}^{-2}$ over the whole period.

\section{Pacific}

The winter and spring mixed-layer depths over the sub-tropical gyre of the North Pacific deepened 30 to $80 \%$ over the period 1960 to 1988 (Polovina et al., 1995). Over the sub-polar gyre, mixed-layer depths reduced by 20 to $30 \%$ over the same period. The surface layer of the sub-polar gyre in the north-east Pacific has both warmed and freshened, resulting in a lower surface density (Freeland et al., 1997). Wong et al. (1999) compared trans-Pacific data from the early 1990s to historical data collected about twenty years earlier. The changes in temperature and salinity are consistent with surface warming and freshening at mid- and higher latitudes and the subsequent subduction (downward advection) of these changes into the thermocline. From 1968/69 and 1990/91, the South Pacific waters beneath the base of the thermocline have cooled and freshened (Johnson and Orsi, 1997); the greatest cooling and freshening of $-1.0^{\circ} \mathrm{C}$ and 0.25 , respectively, occurred near $48^{\circ} \mathrm{S}$ and were still observed at $20^{\circ} \mathrm{S}$. All the deep water masses show a cooling and freshening at these high southern latitudes.

\section{Arctic}

Recent surveys of the Arctic Ocean (Quadfasel et al., 1993; Carmack et al., 1995; Jones et al., 1996) have revealed a subsurface Atlantic-derived warm water layer that is up to $1^{\circ} \mathrm{C}$ warmer and whose temperature maximum is up to $100 \mathrm{dbar}$ shallower than observed from ice camps from the 1950s to the

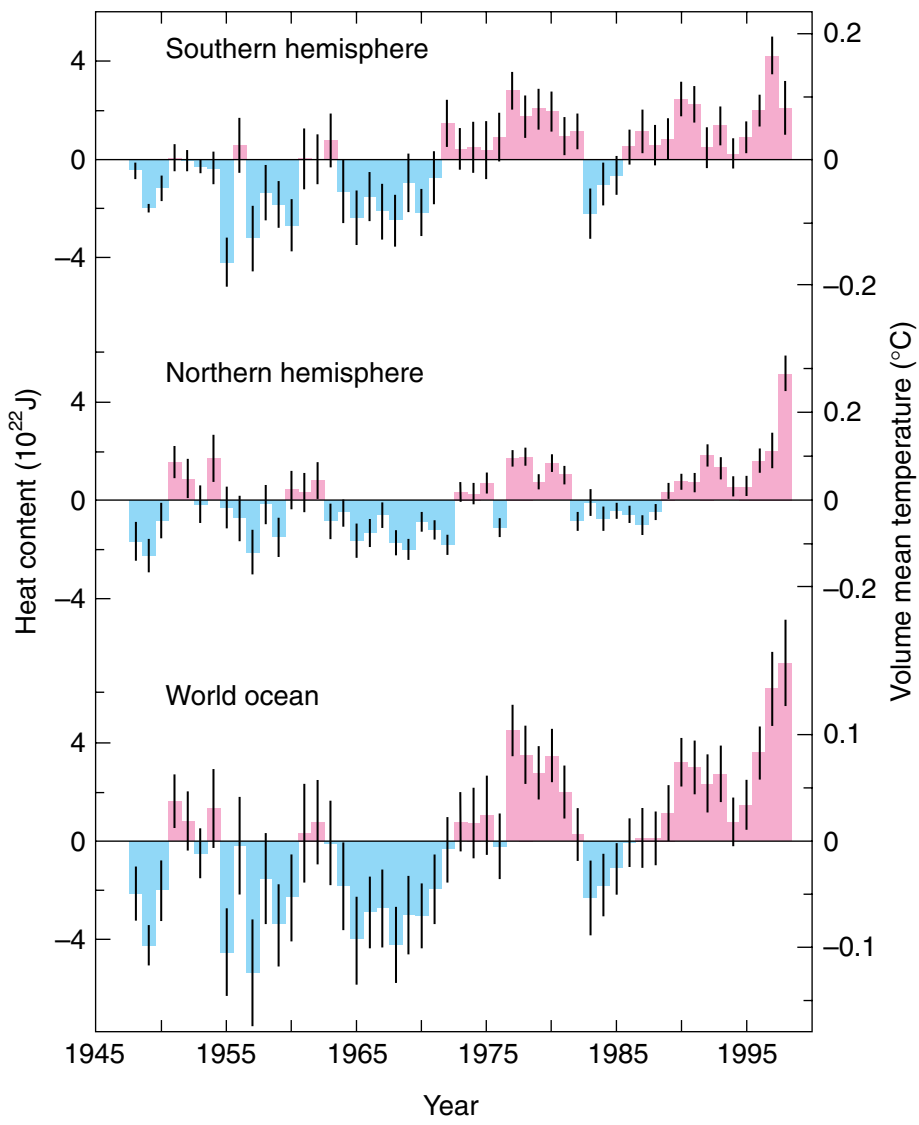

Figure 2.11: Time-series for 1948 to 1998 of ocean heat content anomalies in the upper $300 \mathrm{~m}$ for the two hemispheres and the global ocean. Note that $1.5 \times 10^{22} \mathrm{~J}$ equals 1 watt-year- $\mathrm{m}^{-2}$ averaged over the entire surface of the earth. Vertical lines through each yearly estimate are \pm one standard error (Levitus et al., 2000b).

1980s, as well as from ice-breaker data in the late 1980s and early 1990s. Warming is greatest in the Eurasian Basin. Annual surveys of the southern Canada Basin since 1979 (Melling, 1998), have shown a warming and deepening lower Atlantic layer, the lower halocline layer cooling by $0.12^{\circ} \mathrm{C}$ and the upper halocline layer warming by $0.15^{\circ} \mathrm{C}$. Steele and Boyd (1998) compared winter temperature and salinity profiles obtained over the central and eastern Arctic Basins from submarine transects in 1995 and 1993 with Soviet data collected over the period 1950 to 1989 (Environmental Working Group, 1997). They showed that the cold halocline waters cover significantly less area in the newer data. This is consistent with a decreased supply of cold, fresh halocline waters from the Pacific Shelf areas.

\section{Atlantic}

The sub-arctic North Atlantic exhibits decadal variability in both temperature and salinity (Belkin et al., 1998). Reverdin et al. (1997) found that the variability of salinity around the entire subarctic gyre for the period 1948 to 1990 was most prominent at periods of 10 years and longer, and extended from the surface to below the base of the winter mixed layer. This salinity signal was only coherent with elsewhere in the north-western Atlantic. A single spatial pattern explains $70 \%$ of the variance of the upper 
ocean salt content of the subarctic gyre, corresponding to a signal propagating from the west to the north-east. Reverdin et al. also found that fluctuations in the outflow of fresh water from the Arctic are associated with periods of greater or fewer than usual northerly winds east of Greenland or off the Canadian Archipelago.

North Atlantic deep waters begin as intermediate waters in the Nordic seas. These waters have freshened over the 1980s and 1990s (Bönisch et al., 1997). In addition, the absence of deep convection over the same period has caused Nordic Sea bottom waters to become warmer, saltier and less dense. The FaroesShetland Channel is the principal pathway between the north-east Atlantic and the Norwegian Sea and has been surveyed regularly since 1893 (Turrell et al., 1999). Unfortunately, the quality of the salinity measurements was poor from 1930 through to 1960 . Since the mid-1970s, the intermediate and bottom waters entering the North Atlantic through the channel have freshened at rates of $0.02 /$ decade and $0.01 /$ decade, respectively. The decreased salinities have resulted in decreased water densities and a decrease of between 1 and 7\%/decade in the transport of deep water into the North Atlantic.

In the Labrador Sea, winter oceanic deep convection was intense during the earlier 1990s, extending to deeper than 2,400 $\mathrm{m}$ in 1992 to 1994. This produced a Labrador Sea water mass colder, denser and fresher than has been observed over at least the last five decades (Lazier, 1995; Dickson et al., 1996).

Within the tropical and sub-tropical gyres of the North Atlantic, the deep and intermediate water masses are warming. Ocean station S (south-east of Bermuda, $32^{\circ} 17^{\prime} \mathrm{N}, 64^{\circ} 50 \mathrm{~W}$ ) has been sampled bi-weekly since 1954. Joyce and Robins (1996) extended the hydrographic record from ocean station $\mathrm{S}$ back from 1954 to 1922 using nearby observations. They find an almost constant rate of warming over the 1,500 to 2,500 dbar layer of $0.05^{\circ} \mathrm{C} /$ decade over the 73 -year period 1922 to 1995 . This corresponds to a net downward heat flux of $0.7 \mathrm{Wm}^{-2}$. Sections completed in 1958, 1985 and 1997 along $52^{\circ} \mathrm{W}$ and $66^{\circ} \mathrm{W}$ between $20^{\circ} \mathrm{N}$ to $35^{\circ} \mathrm{N}$ (Joyce et al., 1999) show a rate of warming of $0.06^{\circ} \mathrm{C} / \mathrm{dec}$ ade, similar to that seen at Bermuda but averaged over a larger $1,700 \mathrm{~m}$ depth interval. Trans-Atlantic sections along $24^{\circ} \mathrm{N}$ in 1957, 1981 and 1992 show a similar warming between 800 and 2,500 m (Parrilla et al., 1994; Bryden et al., 1996). The maximum warming at $1,100 \mathrm{~m}$ is occurring at a rate of $0.1^{\circ} \mathrm{C} /$ decade. At $8^{\circ} \mathrm{N}$ between 1957 and 1993, Arhan $e t$ al. (1998) showed warming from 1,150 and 2,800 $\mathrm{m}$ with the maximum warming of $0.15^{\circ} \mathrm{C}$ at $1,660 \mathrm{~m}$.

The Antarctic bottom water in the Argentine Basin of the South Atlantic experienced a marked cooling $\left(0.05^{\circ} \mathrm{C}\right)$ and freshening (0.008) during the 1980s (Coles et al., 1996). The bottom waters of the Vema Channel at the northern end of the Argentine basin did not change significantly during the 1980s but warmed steadily during a 700-day set of current meter deployments from 1992 to 1994 (Zenk and Hogg, 1996).

\section{The Indian Ocean}

Bindoff and Mcdougall (2000) have examined changes between historical data collected mostly in the period 1959 to 1966 with WOCE data collected in 1987 in the southern Indian Ocean at latitudes 30 to $35^{\circ} \mathrm{S}$. They found warming throughout the upper $900 \mathrm{~m}$ of the water column (maximum average warming over this section of $0.5^{\circ} \mathrm{C}$ at $220 \mathrm{dbar}$ ).

\subsubsection{Temperature of the Upper Air}

Uncertainties in discerning changes

Several measuring systems are available to estimate the temperature variations and trends of the air above the surface, though all contain significant time-varying biases as outlined below.

\section{Weather balloons}

The longest data sets of upper air temperature are derived from instruments carried aloft by balloons (radiosondes). Changes in balloon instrumentation and data processing over the years have been pervasive, however, resulting in discontinuities in these temperature records (Gaffen, 1994; Parker and Cox, 1995; Parker et al., 1997). Gaffen et al. (2000b) attempted to identify these biases by using statistical tests to determine "change-points" sudden temperature shifts not likely to be of natural origin (e.g., instrument changes). However, they found that alternative methods for identifying change points yield different trend estimates and that the analysis was hampered by the lack of complete documentation of instrument and data processing changes for many stations. This study, however, only analysed change points in the time-series of individual stations in isolation. Another technique, used successfully with surface data, relies on differences produced from comparisons among several stations in close proximity. In addition, Santer et al. (1999) noted that temperature trends estimated from radiosonde data sets are sensitive to how temperature shifts are dealt with, which stations are utilised, and the method used for areal averaging.

Worldwide temperatures from the Microwave Sounding Unit (MSU) data (Christy et al., 2000) have been available from the beginning of 1979 for intercomparison studies. Parker et al. (1997) used the lower-stratospheric and lower-tropospheric MSU products to adjust monthly radiosonde reports for stations in Australia and New Zealand at times when instrumental or dataprocessing changes were documented. Some individual stratospheric corrections were as much as $3^{\circ} \mathrm{C}$ due to radiosonde instrument changes. The main disadvantage of the Parker et al. technique is that the raw MSU record has time-varying biases which must first be estimated and eliminated (Christy et al., 2000).

Gaffen et al. (2000b) compared trends for 1959 to 1995, calculated using linear regression, for twenty-two stations with nearly complete data records at levels between 850 and $30 \mathrm{hPa}$. Each of these stations is included in two data sets created since the SAR: (a) monthly mean temperatures reported by the weather balloon station operators (Parker et al., 1997; CLIMAT TEMP data) and (b) monthly mean temperatures calculated from archived daily weather balloon releases (Eskridge et al., 1995; CARDS data). Decadal trends at individual sites differed randomly between the two data sets by typically $0.1^{\circ} \mathrm{C} /$ decade, with the largest differences at highest altitudes. In a few cases the differences were larger and statistically significant at the $1 \%$ level. The discrepancies were sometimes traceable to time-of-observation differences of the data used to calculate the averages. 
The analysis of trends requires long station data records with minimal missing data. The records for 180 stations in the combined Global Climate Observing System Upper Air Network (GUAN) and the Angell $(1988,2000)$ network do not generally meet this standard, as only 74 of the GUAN stations, for instance, have at least $85 \%$ of tropospheric monthly means available for 1958 to 1998. In the lower stratosphere (up to $30 \mathrm{hPa}$ ), only twenty-two stations meet this requirement (Gaffen et al., 2000b). These deficiencies present the dilemma of using either relatively small networks of stations with adequate data (the Southern Hemisphere, in particular, is poorly sampled) or larger networks with poorer quality data (adding uncertainty to the resulting trend estimates).

Characteristics, such as spatial coverage, of each data set derived from the weather balloon data are different. For example, Sterin (1999) used data from over 800 stations from the CARDS and telecommunicated data sets, with only gross spatial and temporal consistency checks. The data were objectively interpolated to all unobserved regions, introducing extra uncertainty. Parker et al. (1997) placed CLIMAT TEMP data into $5^{\circ}$ latitude $\times$ $10^{\circ}$ longitude grid boxes from about 400 sites, leaving unobserved boxes missing. Further data sets were created employing limited spatial interpolation and bias-adjustments, but uncertainties related to spatial under-sampling remain (Hurrell et al., 2000). Angell (1988) placed observations from 63 stations into seven broad latitudinal bands, calculated the simple average for each band and produced global, hemispheric and zonal mean anomalies.

\section{Satellites}

Radiosondes measure temperatures at discrete levels, but satellite instruments observe the intensity of radiation from deep atmospheric layers. The advantage of satellites is the essentially uniform, global, coverage. The three temperature products that are commonly available from MSU are: the low to mid-troposphere (MSU 2LT, surface to about $8 \mathrm{~km}$ ), mid-troposphere (MSU 2, surface to about $18 \mathrm{~km}$, hence including some stratospheric emissions) and the lower stratosphere (MSU 4, 15 to $23 \mathrm{~km}$, hence including some tropical tropospheric emissions) (Christy et al., 2000). No other data, such as from radiosondes, are used to construct these MSU data sets. It is important to note that the troposphere and stratosphere are two distinct layers of the atmosphere with substantially different temperature variations and trends. The altitude of the troposphere/stratosphere boundary varies with latitude, being about 16 to $17 \mathrm{~km}$ in the tropics but only 8 to $10 \mathrm{~km}$ at high latitudes.

Since the SAR, several issues have emerged regarding MSU temperatures. Mo (1995) reported that for one of the longest-lived satellites (NOAA-12, 1991 to 1998) the non-linear calibration coefficients were erroneous, affecting MSU 2 and MSU 2LT. Wentz and Schabel (1998) discovered that satellite orbit decay introduces gradual, spurious cooling in MSU 2LT. Christy et al. (1998, 2000) found that instrument responses often differ between the laboratory assessments and on-orbit performance, requiring further corrections. Additional adjustments were also made by recalculating and removing spurious temperature trends due to diurnal effects induced by the east-west drift of the spacecraft (Christy et al., 2000). The magnitude of the spurious trends (1979 to 1998) removed from version D compared to version $\mathrm{C}$ were: orbit decay, -0.11 ; instrument response, +0.04 and diurnal drift, $+0.03^{\circ} \mathrm{C} /$ decade.

Version D of the MSU data is used in Figure 2.12. The SAR presented version $\mathrm{B}$ that for the low to mid-troposphere indicated a global trend about $0.05^{\circ} \mathrm{C} /$ decade more negative than version D (for 1979 to 1995). Quite separately, Prabhakara et al. (1998) generated a version of MSU 2 without corrections for satellite drift or instrument body effects, in many ways similar to MSU 2 version A of Spencer and Christy (1992a, 1992b).

The Stratospheric Sounding Unit (SSU) detects the intensity of thermal emissions and measures deep layer temperatures at altitudes above $20 \mathrm{~km}$ (Nash and Forrester, 1986). As with the MSU products, adjustments are required for radiometer biases, diurnal sampling and orbital drift (Chanin and Ramaswamy, 1999).

\section{Rocketsondes and lidar}

Data sets generated from rocketsondes have been updated (Golitsyn et al., 1996; Lysenko et al., 1997), providing temperature information to as high as $75 \mathrm{~km}$. Important difficulties arise with these data due to different types of instrumentation, tidal cycles (amplitude $2^{\circ} \mathrm{C}$ ) and to assumed corrections for aerodynamic heating. The last set of adjustments has the most significant impact on trends. The approximately 11-year solar cycle forces a temperature perturbation of $>1{ }^{\circ} \mathrm{C}$ in the mid- to upper stratosphere (30 to $50 \mathrm{~km}$ ). Keckhut et al. (1999) and Dunkerton et al. (1998) created a quality-controlled data set of these measurements, which is used in Chanin and Ramaswamy (1999). The very limited number of launch sites leads to some uncertainty in deduced temperatures, and most launches were terminated in the mid-1990s.

Rayleigh lidar measurements began in 1979 at the Haute Provence Observatory in southern France and have spread to locations around the world. Lidar techniques generate the vertical profile of temperature from 30 to $90 \mathrm{~km}$, providing absolute temperatures within $2.5^{\circ} \mathrm{C}$ accuracy. Chanin and Ramaswamy (1999) have combined MSU 4, SSU, radiosonde, lidar and rocketsonde data to estimate 5-km thick layer temperature variations for altitudes of 15 to $50 \mathrm{~km}$, generally limited to the Northern Hemisphere mid-latitudes.

\section{Reanalyses}

The principle of reanalysis is to use observations in the data assimilation scheme of a fixed global weather forecasting model to create a dynamically consistent set of historical atmospheric analyses (Kalnay et al., 1996). Within the assimilation scheme, potentially errant data are amended or excluded using comparisons with neighbours and/or calculated conditions. However, small, time-dependent biases in the observations, of magnitudes important for climate change, are virtually impossible to detect in the model, even in areas of adequate in situ data. Furthermore, in areas with few in situ data the reanalyses are often affected by inadequate model physics or satellite data for which time-varying biases have not been removed.

Though interannual variability is reproduced well, known discontinuities in reanalysed data sets indicate that further research is required to reduce time-dependent errors to a level suitable for climate change studies (Basist and Chelliah, 1997; 
a) Lower troposphere and surface

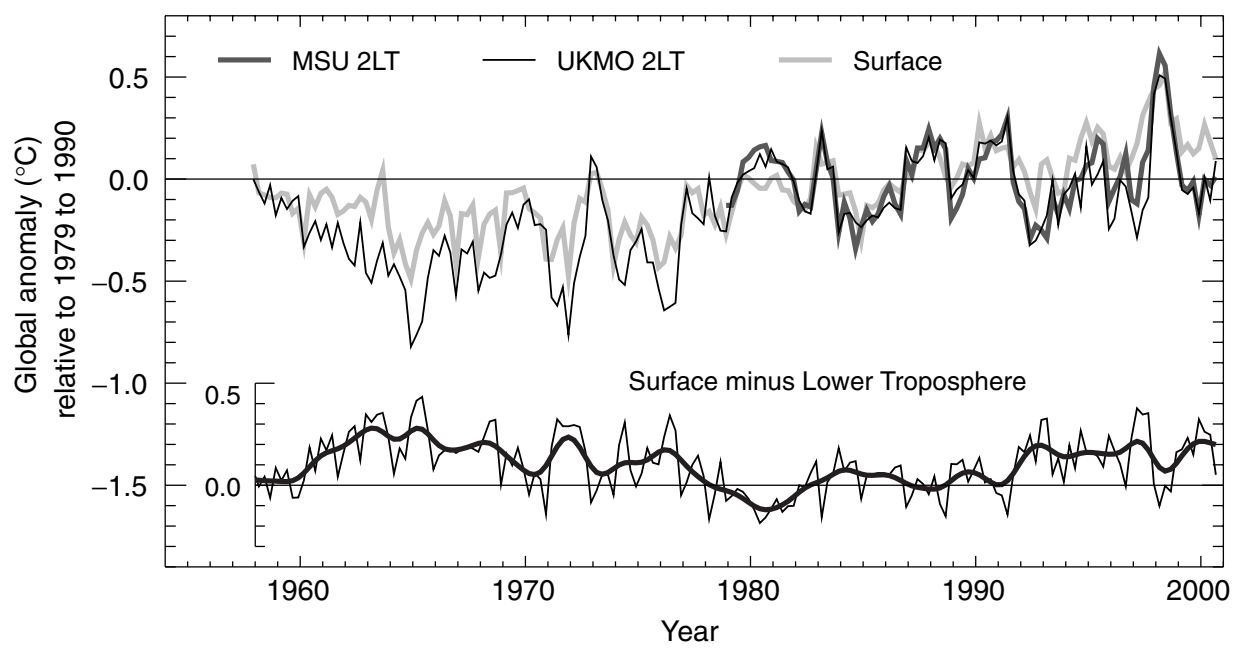

b) Lower stratosphere

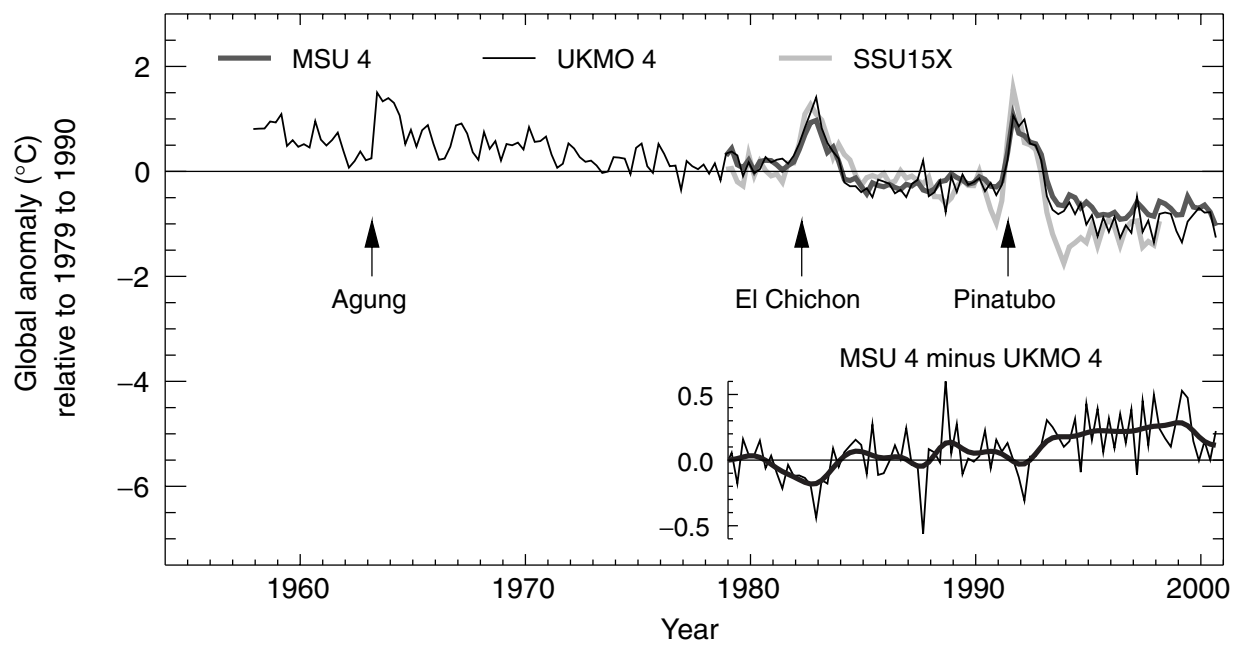

Figure 2.12: (a) Seasonal anomalies of global average temperature $\left({ }^{\circ} \mathrm{C}\right), 1958$ to 2000, relative to 1979 to 1990 for the lower troposphere, as observed from satellites (MSU 2LT) and balloons (UKMO 2LT), and for the surface (adapted from Jones et al., 2001). Also shown (bottom graph) are the differences between the surface temperature anomalies and the averages of the satellite and balloon-based observations of the lower-tropospheric temperature anomalies. (b) As (a) but for the temperature of the lower stratosphere, as observed from satellites (MSU 4 and SSU 15X) and balloons (UKMO 4). The times of the major explosive eruptions of the Agung, El Chichon and Mt. Pinatubo volcanoes are marked. Also shown (bottom graph) are the differences between the MSU 4 and UKMO 4 based temperature anomalies.

Hurrell and Trenberth, 1998; Santer et al., 1999, 2000; Stendel et al., 2000). It is anticipated that future assessments of climate change will utilise reanalysis products to which substantial improvements will have been made. Data from the NCEP reanalysis are included below for comparison purposes, but longer-term stratospheric trends from NCEP are especially suspect due to a large shift in temperature when satellite data were incorporated for the first time in 1978 (Santer et al., 1999).

\subsubsection{How do Surface and Upper Air Temperature Variations Compare?}

In Figure 2.12 we display the surface, tropospheric and stratospheric temperature variations using representative data sets from those described above. Trend values $\left({ }^{\circ} \mathrm{C} / \mathrm{decade}\right)$ are shown in
Table 2.3 with $95 \%$ confidence intervals, which in part represent uncertainties due to temporal sampling, not those due to measurement error (see below). The effect of explosive volcanic events (Agung, 1963; El Chichon, 1982; and Mt. Pinatubo, 1991) is evident in Figure 2.12, as is a relative shift to warmer temperatures in the lower troposphere compared to the surface in the late 1970s, followed by large variations in both due to ENSO (particularly in 1998). After the shift in the late 1970s, the overall tropospheric temperature trend is near zero but the surface has warmed (see Figure 2.12a and Table 2.3).

Global variations and trends in the lower stratosphere are temporally more coherent than in the troposphere (Figure 2.12b), though the warming effects due to the volcanic eruptions are clearly evident. For the period 1958 to 2000, all stratospheric data sets except NCEP 4, which contains erroneous trends, show signif- 
Table 2.3: As Table 2.1 but for annual average surface and upper air temperature anomalies from various data sets. The surface temperature trends are of combined land-surface air temperature (LSAT) and sea surface temperature (SST) or sea ice and sea surface temperature (ISST) anomalies. The upper air trends are of temperature anomalies corresponding to or approximately corresponding to temperature anomalies from MSU channels $2 L T$ and 4. The tropical region is defined as the latitude band $20^{\circ} \mathrm{S}$ to $20^{\circ} \mathrm{N}$ for all the data sets except for the GISS LSAT + UKMO ISST data set where the region is defined as the latitude band $23.6^{\circ} \mathrm{S}$ to $23.6^{\circ} \mathrm{N}$. The last line of the table shows trends in the differences between temperature anomalies for the surface, from the UKMO LSAT + UKMO SST data set, and for the lower troposphere, taken as the average of the UKMO $2 L T$ and MSU 2LT anomalies for 1979 to 2000 and as the UKMO 2LT anomalies alone before 1979. None of the estimates of trends and errors account for uncertainties in the annual anomalies as these are not available. All calculations use data to the end of 2000 except for those for the NOAA data sets, which include data up to August 2000 only.

\begin{tabular}{|c|c|c|c|c|c|c|}
\hline & \multicolumn{2}{|c|}{1958 to 2000} & \multicolumn{2}{|c|}{1958 to 1978} & \multicolumn{2}{|c|}{1979 to 2000} \\
\hline & Globe & Tropics & Globe & Tropics & Globe & Tropics \\
\hline \multicolumn{7}{|l|}{ Surface } \\
\hline $\begin{array}{l}\text { UKMO LSAT + UKMO SST } \\
\text { (Jones et al., 2001) }\end{array}$ & $\begin{array}{c}0.10 \\
(0.05) \\
\end{array}$ & $\begin{array}{c}0.08 \\
(0.06) \\
\end{array}$ & $\begin{array}{l}-0.05 \\
(0.07) \\
\end{array}$ & $\begin{array}{l}-0.09 \\
(0.12) \\
\end{array}$ & $\begin{array}{c}0.16 \\
(0.06)\end{array}$ & $\begin{array}{c}0.10 \\
(0.10) \\
\end{array}$ \\
\hline $\begin{array}{l}\text { GISS LSAT + UKMO ISST } \\
\text { (Hansen } \text { et al., 1999; Rayner } \text { et al., 2000) }\end{array}$ & $\begin{array}{c}0.09 \\
(0.04) \\
\end{array}$ & $\begin{array}{c}0.09 \\
(0.06) \\
\end{array}$ & $\begin{array}{l}-0.03 \\
(0.07) \\
\end{array}$ & $\begin{array}{l}-0.09 \\
(0.11) \\
\end{array}$ & $\begin{array}{c}0.13 \\
(0.07) \\
\end{array}$ & $\begin{array}{c}0.09 \\
(0.10) \\
\end{array}$ \\
\hline $\begin{array}{l}\text { NCDC LSAT + NCEP SST } \\
\text { (Quayle et al., 1999; Reynolds and Smith, 1994) }\end{array}$ & $\begin{array}{c}0.09 \\
(0.05)\end{array}$ & $\begin{array}{l}0.09 \\
(0.06)\end{array}$ & $\begin{array}{l}-0.05 \\
(0.06)\end{array}$ & $\begin{array}{l}-0.08 \\
(0.11) \\
\end{array}$ & $\begin{array}{c}0.14 \\
(0.06) \\
\end{array}$ & $\begin{array}{c}0.10 \\
(0.11) \\
\end{array}$ \\
\hline \multicolumn{7}{|l|}{ Lower troposphere } \\
\hline $\begin{array}{l}\text { UKMO 2LT } \\
\text { (Parker et al., 1997) }\end{array}$ & $\begin{array}{c}0.11 \\
(0.07) \\
\end{array}$ & $\begin{array}{c}0.13 \\
(0.08) \\
\end{array}$ & $\begin{array}{l}-0.03 \\
(0.12) \\
\end{array}$ & $\begin{array}{c}0.07 \\
(0.16) \\
\end{array}$ & $\begin{array}{c}0.03 \\
(0.10) \\
\end{array}$ & $\begin{array}{l}-0.08 \\
(0.12) \\
\end{array}$ \\
\hline $\begin{array}{l}\text { MSU 2LT } \\
\text { (Christy et al., 2000) }\end{array}$ & & & & & $\begin{array}{c}0.04 \\
(0.11) \\
\end{array}$ & $\begin{array}{l}-0.06 \\
(0.16) \\
\end{array}$ \\
\hline $\begin{array}{l}\text { NCEP 2LT } \\
\text { (Stendel } \text { et al., 2000) }\end{array}$ & $\begin{array}{r}0.13 \\
(0.07) \\
\end{array}$ & $\begin{array}{c}0.08 \\
(0.08) \\
\end{array}$ & $\begin{array}{r}0.02 \\
(0.18) \\
\end{array}$ & $\begin{array}{l}-0.05 \\
(0.17) \\
\end{array}$ & $\begin{array}{c}0.01 \\
(0.11) \\
\end{array}$ & $\begin{array}{l}-0.07 \\
(0.14) \\
\end{array}$ \\
\hline $\begin{array}{l}\text { NOAA } 850-300 \mathrm{hPa} \\
\text { (Angell, 2000) }\end{array}$ & $\begin{array}{c}0.07 \\
(0.08) \\
\end{array}$ & $\begin{array}{c}0.07 \\
(0.07) \\
\end{array}$ & $\begin{array}{l}-0.08 \\
(0.15) \\
\end{array}$ & $\begin{array}{c}0.04 \\
(0.20) \\
\end{array}$ & $\begin{array}{l}-0.03 \\
(0.15) \\
\end{array}$ & $\begin{array}{l}-0.11 \\
(0.19) \\
\end{array}$ \\
\hline $\begin{array}{l}\text { RIHMI 850-300hPa } \\
\text { (Sterin, 1999) }\end{array}$ & $\begin{array}{c}0.04 \\
(0.04) \\
\end{array}$ & $\begin{array}{c}0.07 \\
(0.05) \\
\end{array}$ & $\begin{array}{l}-0.03 \\
(0.06) \\
\end{array}$ & $\begin{array}{c}0.07 \\
(0.08) \\
\end{array}$ & $\begin{array}{c}0.00 \\
(0.07) \\
\end{array}$ & $\begin{array}{l}-0.06 \\
(0.09) \\
\end{array}$ \\
\hline \multicolumn{7}{|l|}{ Lower stratosphere } \\
\hline $\begin{array}{l}\text { UKMO } 4 \\
\text { (Parker et al., 1997) } \\
\end{array}$ & $\begin{array}{l}-0.39 \\
(0.15) \\
\end{array}$ & $\begin{array}{l}-0.31 \\
(0.19) \\
\end{array}$ & $\begin{array}{l}-0.37 \\
(\mathbf{0 . 2 1}) \\
\end{array}$ & $\begin{array}{l}-0.07 \\
(0.51) \\
\end{array}$ & $\begin{array}{l}-0.64 \\
(0.47) \\
\end{array}$ & $\begin{array}{l}-0.50 \\
(0.54) \\
\end{array}$ \\
\hline $\begin{array}{l}\text { MSU } 4 \\
\text { (Christy et al., 2000) }\end{array}$ & & & & & $\begin{array}{l}-0.52 \\
(0.48)\end{array}$ & $\begin{array}{l}-0.29 \\
(0.51)\end{array}$ \\
\hline $\begin{array}{l}\text { NCEP } 4 \\
\text { (Stendel } \text { et al., 2000) }\end{array}$ & $\begin{array}{l}-0.25 \\
(0.62) \\
\end{array}$ & $\begin{array}{l}-0.04 \\
(0.32) \\
\end{array}$ & $\begin{array}{r}-0.36 \\
(0.33) \\
\end{array}$ & $\begin{array}{l}-0.46 \\
(0.29) \\
\end{array}$ & $\begin{array}{l}-0.61 \\
(1.21) \\
\end{array}$ & $\begin{array}{l}-0.57 \\
(0.77) \\
\end{array}$ \\
\hline $\begin{array}{l}\text { NOAA 100-50hPa } \\
\text { (Angell, 2000) }\end{array}$ & $\begin{array}{l}-0.64 \\
(0.30) \\
\end{array}$ & $\begin{array}{l}-0.58 \\
(0.39) \\
\end{array}$ & $\begin{array}{l}-0.23 \\
(0.22) \\
\end{array}$ & $\begin{array}{c}0.20 \\
(0.43) \\
\end{array}$ & $\begin{aligned}-1.10 \\
(0.58) \\
\end{aligned}$ & $\begin{array}{l}-0.68 \\
(2.08) \\
\end{array}$ \\
\hline $\begin{array}{l}\text { RIHMI 100-50hPa } \\
\text { (Sterin, 1999) }\end{array}$ & $\begin{array}{r}-0.25 \\
(0.12) \\
\end{array}$ & $\begin{array}{r}-0.22 \\
(0.12)\end{array}$ & $\begin{array}{l}-0.20 \\
(0.27) \\
\end{array}$ & $\begin{array}{l}-0.08 \\
(0.10) \\
\end{array}$ & $\begin{array}{r}-0.43 \\
(0.24) \\
\end{array}$ & $\begin{array}{r}-0.45 \\
(0.28) \\
\end{array}$ \\
\hline \multicolumn{7}{|l|}{ Surface minus lower troposphere } \\
\hline & $\begin{array}{l}-0.01 \\
(0.05)\end{array}$ & $\begin{array}{l}-0.05 \\
(0.07)\end{array}$ & $\begin{array}{l}-0.03 \\
(0.08)\end{array}$ & $\begin{array}{l}-0.16 \\
(0.10)\end{array}$ & $\begin{array}{c}0.13 \\
(0.06) \\
\end{array}$ & $\begin{array}{c}0.17 \\
(0.06)\end{array}$ \\
\hline
\end{tabular}

icant negative trends (Table 2.3). Note that MSU 4, and simulations of MSU 4 (UKMO 4 and NCEP 4), include a portion of the upper troposphere below $100 \mathrm{hPa}$ and so are expected to show less negative trends than those measuring at higher altitudes (e.g., the 100 to $50 \mathrm{hPa}$ layers in Table 2.3 and the SSU in Figure 2.12b).

Blended information for $5 \mathrm{~km}$ thick levels in the stratosphere at $45^{\circ} \mathrm{N}$ compiled by Chanin and Ramaswamy (1999) show a negative trend in temperature increasing with height: $-0.5^{\circ} \mathrm{C} /$ decade at $15 \mathrm{~km},-0.8^{\circ} \mathrm{C} /$ decade at 20 to $35 \mathrm{~km}$, and $-2.5^{\circ} \mathrm{C} /$ decade at $50 \mathrm{~km}$. These large, negative trends are consistent with models of the combined effects of ozone depletion and increased concentrations of infrared radiating gases, mainly water vapour and carbon dioxide (Chapters 6 and 12).

The vertical profile of temperature trends based on surface data and radiosondes is consistent with the satellite temperatures. Global trends since 1979 are most positive at the surface, though less positive for night marine air temperatures in the Southern Hemisphere (see Section 2.2.2.2), near zero for levels between 850 to $300 \mathrm{hPa}(1.5$ to $8 \mathrm{~km})$ and negative at $200 \mathrm{hPa}(11 \mathrm{~km})$ and above. Thus during the past two decades, the surface, most of the troposphere, and the stratosphere have responded differently to climate forcings because different physical processes have 
dominated in each of these regions during that time (Trenberth $e t$ al., 1992; Christy and McNider, 1994; NRC, 2000 and Chapter 12). On a longer time-scale, the tropospheric temperature trend since 1958, estimated from a sparser radiosonde network, is closer to that of the surface, about $+0.10^{\circ} \mathrm{C} /$ decade (Figure 2.12a and Table 2.3) (Angell, 1999, 2000; Brown et al., 2000; Gaffen et al., 2000a). Gaffen et al. (2000a) and Brown et al. (2000) noted a decreasing lower-tropospheric lapse rate from 1958 to 1980, and an increasing lower-tropospheric lapse rate after 1980 (Figure 2.12a). However, Folland et al. (1998) showed that global upper-tropospheric temperature has changed little since the late 1960s because the observed stratospheric cooling extended into the uppermost regions of the troposphere.

Between 1979 and 2000, the magnitude of trends between the surface and MSU 2LT is generally most similar in many parts of the Northern Hemisphere extra-tropics $\left(20^{\circ} \mathrm{N}\right.$ to pole) where deep vertical mixing is often a characteristic of the troposphere. For example, the northern extra-tropical trends for the surface and MSU 2LT were 0.28 and $0.21^{\circ} \mathrm{C} /$ decade, respectively, and over the North American continent trends were $0.27 \pm 0.24$ and 0.28 $\pm 0.23^{\circ} \mathrm{C} /$ decade, respectively, with an annual correlation of 0.92 . Over Europe the rates were $0.38 \pm 0.36$ and $0.38 \pm 0.30^{\circ} \mathrm{C} /$ decade, respectively. Some additional warming of the surface relative to the lower troposphere would be expected in the winter half year over extra-tropical Asia (whole year warming rates of $0.35 \pm 0.20$ and $0.18 \pm 0.18^{\circ} \mathrm{C} /$ decade, respectively), consistent with the vertical temperature structure of the increased positive phase of the Arctic Oscillation (Thompson et al., 2000a, Figure 2.30). The vertical structure of the atmosphere in marine environments, however, generally reveals a relatively shallow inversion layer (surface up to 0.7 to $2 \mathrm{~km}$ ) which is somewhat decoupled from the deep troposphere above (Trenberth et al., 1992; Christy, 1995; Hurrell and Trenberth, 1996). Not only are local surface versus tropospheric correlations often near zero in these regions, but surface and tropospheric trends can be quite different (Chase et al., 2000). This is seen in the different trends for the period 1979 to 2000 in the tropical band, $0.10 \pm 0.10$ and $-0.06 \pm 0.16^{\circ} \mathrm{C} /$ decade, respectively (Table 2.3 ) and also in the southern extra-tropics where the trends are $0.08 \pm 0.06$ and -0.05 $\pm 0.08^{\circ} \mathrm{C} /$ decade, respectively. Trends calculated for the differences between the surface and the troposphere for 1979 to 2000 are statistically significant globally at $0.13 \pm 0.06^{\circ} \mathrm{C} /$ decade, and even more so in the tropics at $0.17 \pm 0.06^{\circ} \mathrm{C} /$ decade. Statistical significance arises because large interannual variations in the parent time-series are strongly correlated and so largely disappear in the difference time-series (Santer et al., 2000; Christy et al., 2001). However, as implied above, they are not significant over many extra-tropical regions of the Northern Hemisphere such as North America and Europe and they are also insignificant in some Southern Hemisphere areas. The sequence of volcanic eruption, ENSO events, and the trends in the Arctic Oscillation have all been linked to some of this difference in warming rates (Michaels and Knappenburg, 2000; Santer et al., 2000; Thompson et al., 2000a; Wigley, 2000) and do explain a part of the difference in the rates of warming (see Chapter 12).

The linear trend is a simple measure of the overall tendency of a time-series and has several types of uncertainty; temporal sampling uncertainty owing to short data sets, spatial sampling errors owing to incomplete spatial sampling, and various other forms of measurement error, such as instrument or calibration errors. Temporal sampling uncertainties are present even when the data are perfectly known because trends calculated for short periods are unrepresentative of other short periods, or of the longer term, due to large interannual to decadal variations. Thus confidence intervals for estimates of trend since 1979 due to temporal sampling uncertainty can be relatively large, as high as $\pm 0.2^{\circ} \mathrm{C} /$ decade below $300 \mathrm{hPa}$ (Table 2.3, Santer et al., 2000). Accordingly, the period from 1979 to 2000 provides limited information on long-term trends, or trends for other 22-year periods.

Uncertainties arising from measurement errors due to the factors discussed in Section 2.2.3, including incomplete spatial sampling, can be substantial. One estimate of this uncertainty can be made from comparisons between the various analyses in Table 2.3. For trends below $300 \mathrm{hPa}$, this uncertainty may be as large as $\pm 0.10^{\circ} \mathrm{C} /$ decade since 1979 , though Christy et al. (2000) estimate the $95 \%$ confidence interval as $\pm 0.06^{\circ} \mathrm{C}$ for the MSU 2LT layer average. For example, Santer et al. (2000) find that when the satellite observations from MSU 2LT are masked to match the less than complete global coverage of the surface observations during the past few decades, the differences in the trends between the surface and the troposphere are reduced by about one third.

Summarising, it is very likely that the surface has warmed in the global average relative to the troposphere, and the troposphere has warmed relative to the stratosphere since 1979 (Figure 2.12a,b; Pielke et al., 1998a,b; Angell, 1999, 2000; Brown et al., 2000; Christy et al., 2000; Gaffen et al., 2000a; Hurrell et al., 2000; NRC, 2000; Stendel et al., 2000). However, the relative warming is spatially very variable and most significant in the tropics and sub-tropics. There is evidence that the troposphere warmed relative to the surface in the pre-satellite era (1958 to 1979, see Brown et al., 2000; Gaffen et al., 2000a), though confidence in this finding is lower. Uncertainties due to limited temporal sampling prevent confident extrapolation of these trends to other or longer time periods (Christy et al., 2000; Hurrell et al., 2000; NRC, 2000; Santer et al., 2000). Some physical explanations for changes in the vertical profile of global temperature trends are discussed in Chapter 12 but a full explanation of the lower-tropospheric lapse rate changes since 1958 requires further research.

\subsubsection{Changes in the Cryosphere}

This chapter does not describe changes in the major ice sheets as this is dealt with in detail in Chapter 11.

\subsubsection{Snow cover, including snowfall}

Satellite records indicate that the Northern Hemisphere annual snow-cover extent (SCE) has decreased by about 10\% since 1966 largely due to decreases in spring and summer since the mid1980s over both the Eurasian and American continents (Figure 2.13a; Robinson, 1997, 1999). Winter and autumn SCE show no statistically significant change. Reduction in snow cover during the mid- to late 1980 s was strongly related to temperature 


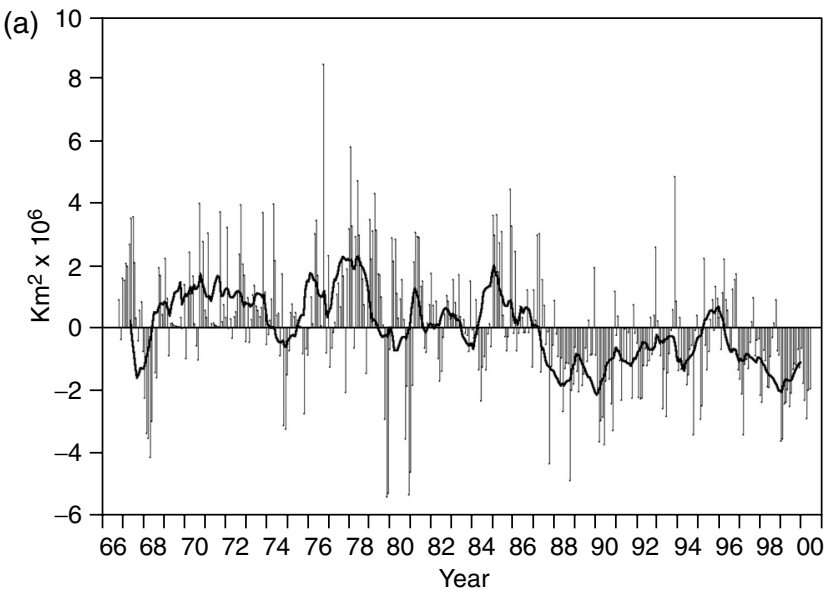

(b)

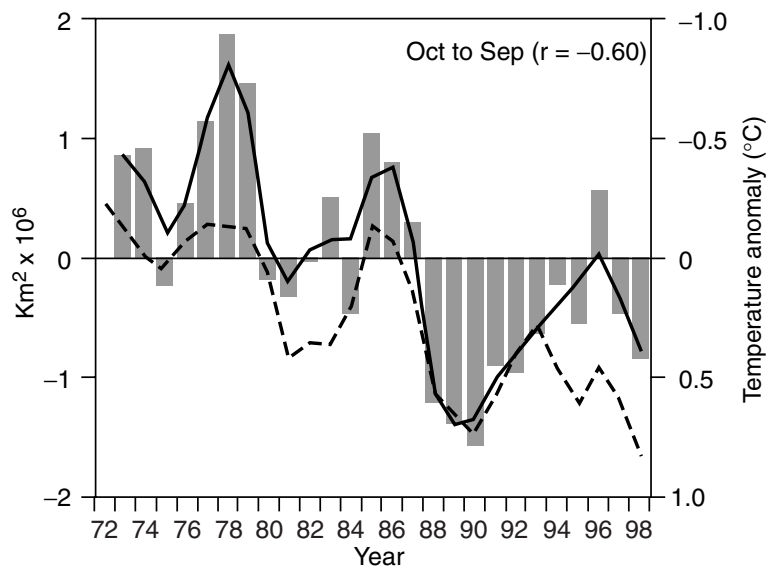

Figure 2.13: (a) Anomalies of monthly snow cover over the Northern Hemisphere lands (including Greenland) between November 1966 and May 2000. Also shown are twelve-month running anomalies of hemispheric snow extent, plotted on the seventh month of a given interval. Anomalies are calculated from NOAA/NESDIS snow maps. Mean hemispheric snow extent is 25.2 million $\mathrm{km}^{2}$ for the full period of record. the curve of running means is extrapolated by using period of record monthly means for 12 months in the late 1960s in order to create a continuous curve of running means. Missing months fell between May and October, and no winter months are missing. June 1999 to May 2000 values are based on preliminary analyses. (b) Seasonal snowcover anomalies (in million $\mathrm{km}^{2}$ ) versus temperature anomalies (in ${ }^{\circ} \mathrm{C}$ ). Both snow and temperature anomalies are area averages over the region for which climatological values of seasonal snow-cover frequency (based on the 1973 to 1998 period) are between 10 and $90 \%$. Season is indicated at the top of each panel. Axis for snow anomaly on the left-hand-side $y$ axis, axis for temperature anomaly is on the right-hand-side $y$ axis. Bar plot indicates time-series of snow cover anomalies. Continuous colour curve indicates nine-point weighted average of snow-cover anomaly. Dashed black curve indicates time-series of nine-point weighted average of area average temperature anomaly. Snow-cover calculations are based on the NOAA/NESDIS snow cover data for the period 1973 to 1998 (updated from Robinson et al., 1993). Temperature calculations are based on the Jones data set, hence anomalies are with respect to the time period 1961 to 1990. Snow anomalies are with respect to the time period 1973 to 1998. Correlation coefficient (r) between seasonal snow cover anomalies and temperature anomalies is indicated in parentheses. (Figure contributed by David A. Robinson and Anjuli Bamzai, Rutgers University.) increases in snow covered areas (Figure 2.13b). There is a highly significant interannual $(+0.6)$ and multi-decadal correlation between increases in the Northern Hemisphere spring land temperature and a reduction in the Northern Hemisphere spring snow cover since data have been available (1966). Snow cover extent has decreased about $10 \%$ since 1966 . The improvements in the quantity and quality of the visible satellite imagery used to produce the operational snow-cover product cannot account for the observed changes in snow cover.

Longer regional time-series based on station records and reconstructions suggest that Northern Hemisphere spring and summer SCEs in the past decade have been at their lowest values in the past 100 years. In the other seasons, it is likely that extents in the latter portion of the 20th century exceeded those of earlier years (Brown, 2000).

Reconstructions for North America suggest that while there has been a general decrease in spring SCE since 1915, it is likely that winter SCE has increased (Brown and Goodison, 1996; Frei et al., 1999; Hughes and Robinson, 1996; Hughes et al., 1996). Similar to the results in North America, in Eurasia April SCE has significantly decreased; but lack of data has prevented an analysis of winter trends (Brown, 2000). Over Canada, there has been a general decrease in snow depth since 1946, especially during spring, in agreement with decreases in SCE (Brown and Braaten, 1998). Winter depths have declined over European Russia since 1900 (Meshcherskaya et al., 1995), but have increased elsewhere over Russia in the past few decades (Fallot et al., 1997). The common thread between studies that have examined seasonality is an overall reduction in spring snow cover in the latter half of the 20th century.

There have been relatively few studies of snowfall trends across the globe. Statistically significant increases in seasonal snowfall have been observed over the central USA in the 20th century (Hughes and Robinson, 1996). In recent decades, snowfall has also been heavier to the lee of the North American Great Lakes than earlier in the century (Leathers and Ellis, 1996). These findings are in line with observations from Canada and the former Soviet Union, reflecting a trend towards increased precipitation over the mid-latitude lands in the Northern Hemisphere (Groisman and Easterling, 1994; Brown and Goodison, 1996; Ye et al., 1998).

\subsubsection{Sea-ice extent and thickness}

Sea-ice extent

Sea-ice extent is expected to become a sensitive indicator of a warming climate, although only recently have long records become available in the Arctic, and our knowledge of Antarctic sea-ice extent before the 1970s is very limited.

Sea-ice extent (the area within the ice-ocean margin) was observed from space from 1973 to 1976 using the ESMR (Electrically Scanning Microwave Radiometer) satellite-based instrument, and then continuously from 1978 using the SSMR (Scanning Multichannel Microwave Radiometer) (1978 to 1987) and SSM/I (Special Sensor Microwave/Imager) (1987 to present). By inter-calibrating data from different satellites, Bjørgo et al. (1997) and subsequently Cavalieri et al. (1997) obtained uniform monthly estimates of sea-ice extent for both hemispheres from 


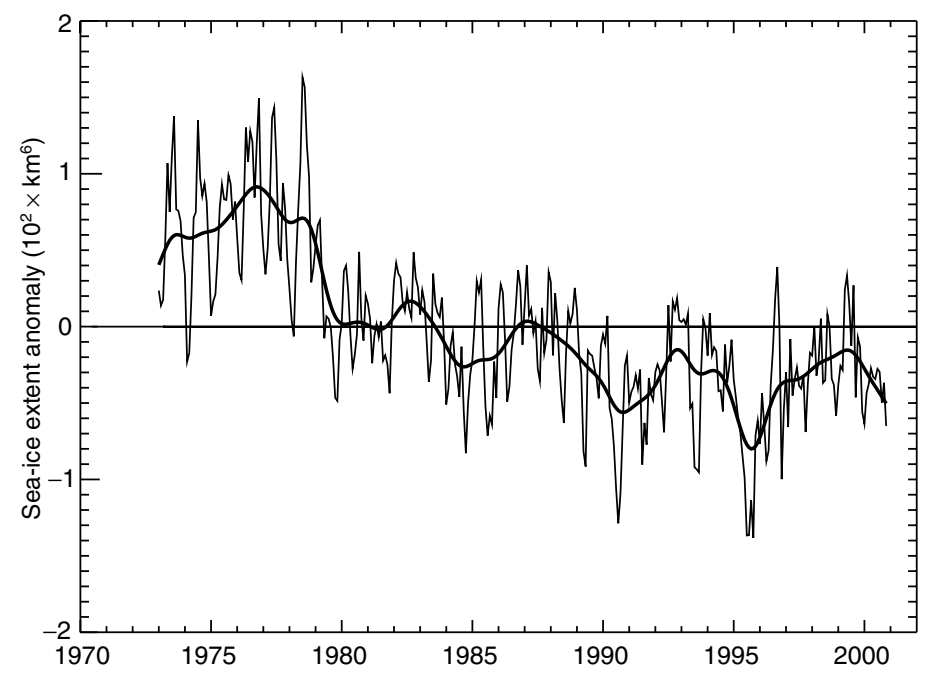

Figure 2.14: Monthly Arctic sea-ice extent anomalies, 1973 to 2000, relative to 1973 to 1996. The data are a blend of updated Walsh (Walsh, 1978), Goddard Space Flight Center satellite passive microwave (Scanning Multichannel Microwave Radiometer (SMMR) and Special Sensor Microwave/Imager (SSM/I)) derived data (Cavalieri et al., 1997) and National Centers for Environmental Prediction satellite passive microwave derived data (Grumbine, 1996). Updated digitised ice data for the Great Lakes are also included (Assel, 1983).

November 1978 through to December 1996. Over this period, the sea-ice extent over the Northern Hemisphere showed a decrease of $-2.8 \pm 0.3 \% /$ decade (Parkinson et al., 1999), consistent with Johannessen et al. (1995) (Figure 2.14). The Arctic decrease was strongest in the Eastern Hemisphere and most apparent in summer (Maslanik et al., 1996; Parkinson et al., 1999).

Hemispheric and regional data sets for the Arctic enable the satellite-derived trends in Figure 2.14 to be placed into a century scale context. Figure 2.15 shows annual time-series of the Northern Hemisphere ice extent by season from 1901 to 1999 using in situ data before the satellite era (Vinnikov et al., 1999a). It should be emphasised that the spatial coverage of earlier data is not complete, with the largest data voids in the autumn and winter. Because few data were available, the variability of the autumn and wintertime series in Figure 2.15 is smaller during the early decades of the century. Essentially no data for summer and autumn are available for the World War II period. The summer decrease that is largely responsible for the overall downward trend during the satellite era is present during the entire second half of the 20th century (Figure 2.15). This decrease represents about $15 \%$ of the average summer extent in the first half of the 20th century. Spring values show a somewhat weaker negative trend over the same period with a total reduction of near $8 \%$, but there is only a slight and uncertain downward trend in autumn and winter since about 1970.

The overall recent decrease of Arctic ice extent is, at first sight, consistent with the recent pattern of high latitude temperature change, which includes a warming over most of the sub-arctic land areas (Section 2.2.2.1). Some of this pattern of warming has been attributed to recent trends in the atmospheric circulation of the North Atlantic Oscillation and its Arctic-wide manifestation, the Arctic Oscillation (Section 2.6).

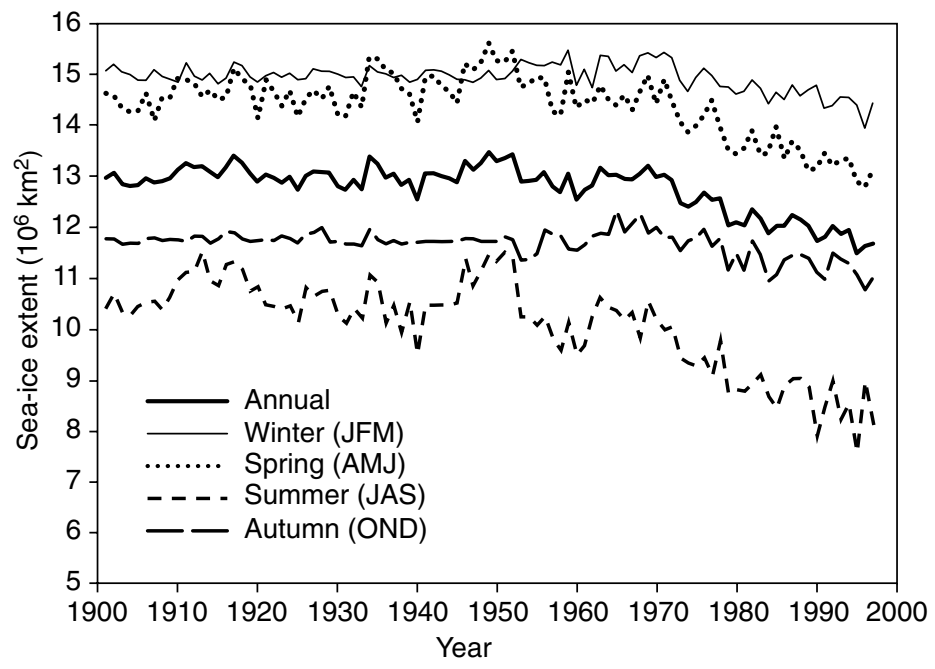

Fig 2.15: Time-series of annual and seasonal sea-ice extent in the Northern Hemisphere, 1901 to 1999, (Annual values from Vinnikov et al., 1999b; seasonal values updated from Chapman and Walsh, 1993.)

Related to the decline in sea-ice extent is a decrease in the length of the sea-ice season (Parkinson, 2000) and an increase in the length of the Arctic summer melting season between 1979 and 1998, also derived from satellite data. The shortest season was 1979 (57 days) and the longest was in 1998 (81 days) with an increasing trend of 5 days per decade (Smith, 1998, updated). The $7 \%$ per decade reduction in the multi-year ice area during 1978 to 1998 is relatively large compared with an approximately $2 \% /$ decade decrease in the total ice area in winter (Johannessen $e t$ al., 1999). This reflects greater summer melting, consistent with the results of Smith (1998).

Over the period 1979 to 1996, the Antarctic (Cavalieri et al., 1997; Parkinson et al., 1999) shows a weak increase of $1.3 \pm$ 0.2\%/decade. Figure 2.16 (for 1973 to 1998) shows a new integrated data set of Antarctic sea-ice extent that was put together for the new European Centre for Medium-range Weather Forecasts (ECMWF) 40-year reanalysis that extends the record back to 1973. While showing the same weak increase after 1979, it also suggests greater ice extents in the mid-1970s. Although century scale time-series cannot be constructed for the Antarctic, de la Mare (1997) has used whaling ship logs to infer significantly greater ice extent in the Southern Ocean during the 1930s and 1940s than during recent decades. The indirect nature of the earlier evidence, however, introduces substantial uncertainty into this conclusion.

\section{Antarctic Peninsula ice shelves}

Although warming over Antarctica as a whole appears to have been perhaps half of a degree in the last half century (Jacka and Budd, 1998), the Antarctic Peninsula has warmed more rapidly, by more than $2^{\circ} \mathrm{C}$ since the 1940s (King, 1994). This regional 


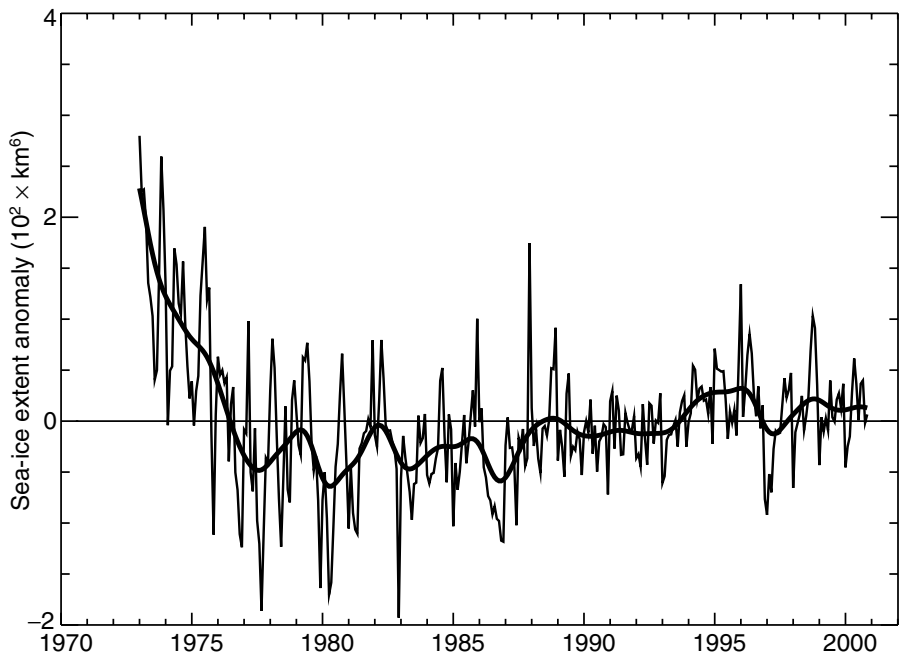

Figure 2.16: Monthly Antarctic sea-ice extent anomalies, 1973 to 2000, relative to 1973 to 1996 . The data are a blend of National Ice Center (NIC) chart-derived data (Knight, 1984), Goddard Space Flight Center satellite passive-microwave (Scanning Multichannel Microwave Radiometer (SMMR) and Special Sensor Microwave/Imager (SSM/I)) derived data (Cavalieri et al., 1997) and National Centers for Environmental Prediction satellite passivemicrowave derived data (Grumbine, 1996). It is uncertain as to whether the decrease in interannual variability of sea ice after about 1988 is real or an observing bias.

warming, whose cause has yet to be fully discovered (but see Section 2.6.6), has led to a southerly migration of the climatic limit of ice shelves so that five ice shelves have retreated over the last century (Vaughan and Doake, 1996). The progressive retreat of ice shelves eventually resulted in the spectacular final-stage collapse of the Prince Gustav and parts of the Larsen ice shelves in 1995. Each left only a small residual shelf. After the collapse, James Ross Island, situated off the northern end of the Antarctic Peninsula, is now circumnavigable by ship for the first time since it was discovered in the early 19th century (Vaughan and Lachlan-Cope, 1995).

\section{Sea-ice thickness}

Our knowledge of sea-ice thickness in the Arctic comes largely from upward sonar profiling by USA and British submarines since 1958 and 1971, respectively. Rothrock et al. (1999) compared late summer September to October data from 1993, 1996 and 1997 from an USA civilian submarine research programme with data from six summer cruises from the period 1958 to 1976. Thickness was adjusted to mid-September values to account for seasonal variability. The significant decline in mean ice thickness was observed for all regions, increasing from the Canada Basin towards Europe (Figure 2.17). Overall, there was a mean reduction in thickness of $42 \%$ from 3.1 to $1.8 \mathrm{~m}$ the earlier period to the present.

Wadhams and Davis (2000) have compared ice thickness changes between October 1976 and September 1996 between $81^{\circ} \mathrm{N}$ and $90^{\circ} \mathrm{N}$ near the $0^{\circ}$ meridian. The overall decline in mean sea-ice thickness between 1976 and 1996 was 43\%. Over every one degree of latitude, both a significant decline in ice thickness
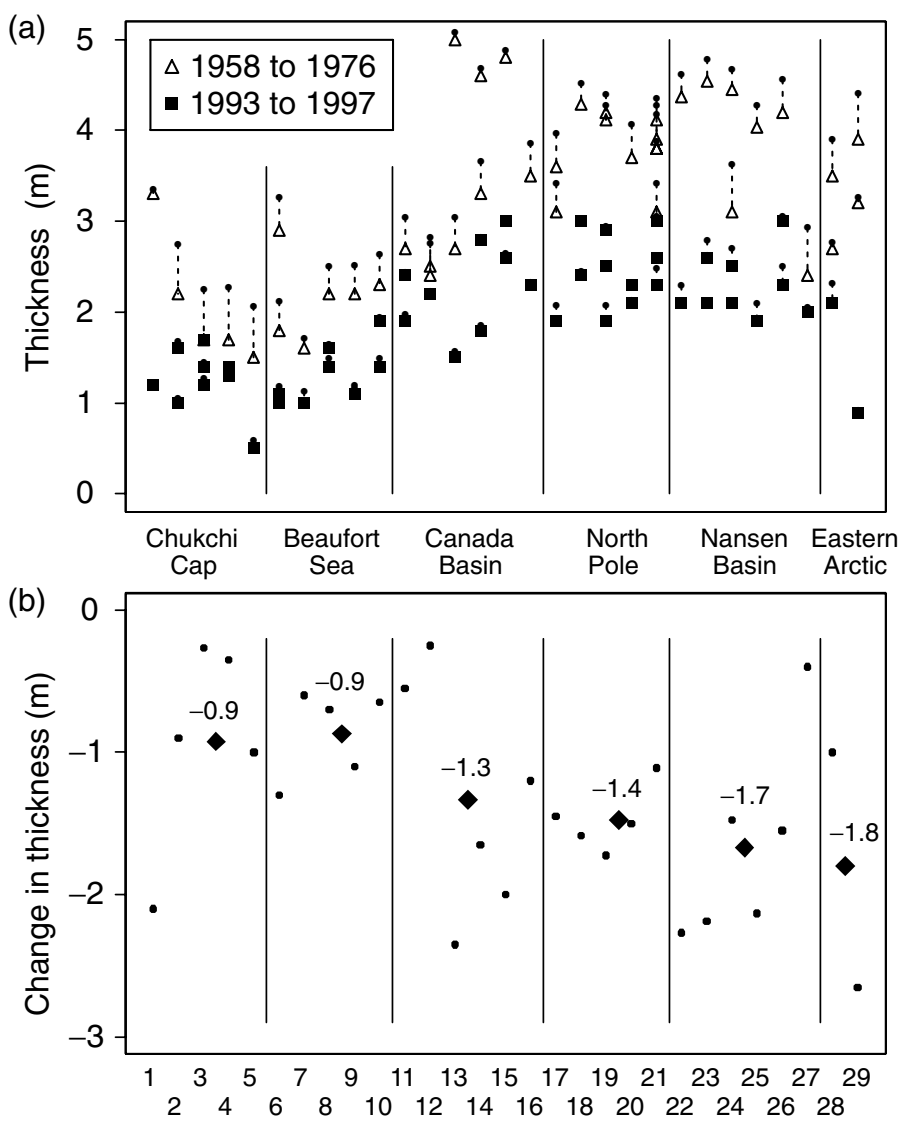

Figure 2.17: Mean ice thickness at places where early cruises were (nearly) collocated with cruises in the 1990s. Early data (1958 to 1976) are shown by open triangles, and those from the 1990s by solid squares, both seasonally adjusted to September 15 . The small dots show the original data before the seasonal adjustment. The crossings are grouped into six regions separated by the solid lines. From Rothrock et al. (1999).

and some completely open water were observed. Despite these dramatic results, it is not known whether these changes reflect long-term change or a major mode of multi-decadal variability. Vinje et al. (1998) measured the thickness of ice exiting the Arctic Ocean through Fram Strait from 1990 to 1996 using moored upward looking sonars and reported a rather different result. The mean annual ice thickness in Fram Strait varied from 2.64 to $3.41 \mathrm{~m}$. These observations were consistent with Arctic Ocean-wide ice thickness estimates made by drilling from Soviet Ice Stations from 1972 to 1981 and from submarine transects from 1960 to 1982, suggesting little change in ice thickness from the 1960s and 1970s to the 1990s.

Nagurnyi et al. $(1994,1999)$ used measurements of long surface gravity waves in the Arctic ice pack to estimate the mean ice thickness from wave attenuation. These measurements are available for the winters of 1978/79 to 1990/91. Johannessen et al. (1999) demonstrated a strong correlation between these ice thickness estimates and the area of multi-year (MY) ice in the Arctic Ocean as obtained from the SSMR and SSM/I. Both the area of MY ice and the ice thickness (winter) estimates show a decrease of 5 to $7 \% /$ decade, considerably less than the submarine 
estimates (late summer). Even though the satellite measurements have continued for more than twenty years, they are inadequate to distinguish between changes due to long-term trends or interannual/inter-decadal variability (Johannessen et al., 1999).

\subsubsection{Permafrost}

About 25\% of the land mass of the Northern Hemisphere is underlain by permafrost, including large regions of Canada, China, Russia and Alaska, with smaller permafrost areas in mountain chains of many other countries in both the Northern and Southern Hemisphere (Brown et al., 1997; Zhang et al., 1999). Permafrost in large part depends on climate. Over half of the world's permafrost is at temperatures a few degrees below $0^{\circ} \mathrm{C}$. Temperature variations in near-surface permafrost $(20$ to $200 \mathrm{~m}$ depth) can be used as a sensitive indicator of the inter-annual and decade-to-century climatic variability and long-term changes in the surface energy balance (Lachenbruch and Marshall, 1986; Lachenbruch et al., 1988; Clow et al., 1991; Beltrami and Taylor, 1994; Majorowicz and Judge, 1994). Very small changes in surface climate can produce important changes in permafrost temperatures. Lachenbruch and Marshall (1986) used climate reconstructions from deep ( $>125 \mathrm{~m}$ depth) temperature measurements in permafrost to show that there has been a general warming of the permafrost in the Alaskan Arctic of 2 to $4^{\circ} \mathrm{C}$ over the last century.

Evidence of change in the southern extent of the discontinuous permafrost zone in the last century has also been recorded. In North America, the southern boundary of the discontinuous permafrost zone has migrated northward in response to warming after the Little Ice Age, and continues to do so today (Thie, 1974; Vitt et al., 1994; Halsey et al., 1995; Laberge and Payette, 1995; French and Egorov, 1998). In China both an increase in the lower altitudinal limit of mountain permafrost and a decrease in areal extent have been observed (Wang et al., 2000).

Long-term monitoring of shallow permafrost began in earnest in the last few decades. Recent analyses indicate that permafrost in many regions of the earth is currently warming (Gravis et al., 1988; Haeberli et al., 1993; Osterkamp, 1994; Pavlov, 1994; Wang and French, 1994; Ding, 1998; Sharkhuu, 1998; Vonder Mühll et al., 1998; Weller and Anderson, 1998; Osterkamp and Romanovsky, 1999; Romanovsky and Osterkamp, 1999). However, the onset, magnitude (from a few tenths to a few degrees centigrade) and rate of warming varies regionally, and not all sites in a given region show the same trend (Osterkamp and Romanovsky, 1999). This variability, as well as short-term (decadal or less) trends superimposed on long-term (century) trends, is briefly discussed in Serreze et al. (2000). There has also been evidence of recent permafrost cooling into the mid-1990s in parts of north-eastern and north-western Canada (Allard et al., 1995; Burn, 1998). However, there are regional data gaps, such as in the central and high Arctic in North America. A new international permafrost thermal monitoring network (Burgess et al., 2000) is being developed to help address these gaps and document the spatial and temporal variability across the globe.

Properties of the surface and the active layer (that having seasonal freezing and thawing) affect surface heat exchanges in permafrost regions. Other conditions remaining constant, the thickness of the active layer could be expected to increase in response to warming of the climate. A circumpolar network to monitor active-layer thickness at representative locations was developed in the 1990s to track long-term trends in active layer thickness (Nelson and Brown, 1997). Active layer thickness timeseries are becoming available (Nelson et al., 1998; Nixon and Taylor, 1998), and evidence of increasing thaw depths is starting to be reported (Pavlov, 1998; Wolfe et al., 2000).

\subsubsection{Mountain glaciers}

The recession of mountain glaciers was used in IPCC (1990) to provide qualitative support to the rise in global temperatures since the late 19th century. Work on glacier recession has considerable potential to support or qualify the instrumental record of temperature change and to cast further light on regional or worldwide temperature changes before the instrumental era. Two types of data from glaciers contain climatic information: (i) mass balance observations and (ii) data on the geometry of glaciers, notably glacier length. More comprehensive information is now becoming available and worldwide glacier inventories have been updated (e.g., IAHS (ICSI)/UNEP/UNESCO, 1999). Note that changes in the Greenland and Antarctic ice sheets are discussed in Chapter 11.

We first discuss mass balance observations. The specific mass balance is defined as the net annual gain or loss of mass at the glacier surface, per unit area of the surface. The mass balance averaged over an entire glacier is denoted by $B_{m}$. Systematic investigations of glacier mass balance started after 1945, so these records are shorter than the instrumental climate records normally available in the vicinity. In contrast to frequently made statements, $B_{m}$ is not necessarily a more precise indicator of climate change than is glacier length. Time-series of $\mathrm{B}_{\mathrm{m}}$ do contain year-to-year variability reflecting short-term fluctuations in meteorological quantities but of concern on longer time-scales is the effect of changing glacier geometry. A steadily retreating glacier will get thinner and the mass balance will become more negative because of a slowly increasing surface air temperature due to a lowering surface that is not reflected in a large-scale temperature signal. Climatic interpretation of long-term trends in of mass balance data requires the use of coupled mass balance-ice flow models to separate the climatic and geometric parts of the signal. Such studies have only just begun. However, mass balance observations are needed for estimating the contribution of glacier melt to sea level rise, so are discussed further in Chapter 11.

A wealth of information exists on the geometry of valley glaciers. Glacier records are very useful for studies of Holocene climate variability (e.g., Haeberli et al., 1998; and Section 2.4). Written documents going back to the 16th century exist that describe catastrophic floods caused by the bursting of glacierdammed lakes or arable land and farms destroyed by advancing glaciers, e.g., in 18th century Norway (Østrem et al., 1977). A large amount of information is available from sketches, etchings, paintings and old photographs of glaciers, though many show the same glaciers (Holzhauser and Zumbühl, 1996). About fifty glaciers have two or more useful pictures from distinctly different times. In many cases geomorphologic evidence in the form of terminal moraines and trimlines can be used as reliable comple- 
mentary information to construct the history of a glacier over the last few centuries. Systematic mapping of glaciers started only 100 years ago and has been limited to a few glaciers. The most comprehensive data are of length variations. Glacier length records complement the instrumental meteorological record because (i) some extend further back in time; (ii) some records are from remote regions where few meteorological observations exist; (iii) on average, glaciers exist at a significantly higher altitude than meteorological stations.

The last point is of particular interest in the light of the discrepancy between recent tropical glacier length reduction and lack of warming in the lower troposphere since 1979 indicated by satellites and radiosondes in the tropics (Section 2.2.3). Longterm monitoring of glacier extent provides abundant evidence that tropical glaciers are receding at an increasing rate in all tropical mountain areas. This applies to the tropical Andes (Brecher and Thompson, 1993; Hastenrath and Ames, 1995; Ames, 1998), Mount Kenya and Kilimanjaro (Hastenrath and Kruss, 1992; Hastenrath and Greischar, 1997) and to the glaciers in Irian Jaya (Peterson and Peterson, 1994).

Relating mass balance fluctuations to meteorological conditions is more complicated for tropical glaciers than for midand high latitude glaciers, and it has not been demonstrated that temperature is the most important factor. Nevertheless, the fast glacier recession in the tropics seems at first sight to be consistent with an increase in tropical freezing heights of $100 \mathrm{~m}$ over the period 1970 to 1986 as reported by Diaz and Graham (1996), corresponding to an increase of $0.5^{\circ} \mathrm{C}$ at tropical high mountain levels, which they also link to increases in tropical SST since the mid-1970s (Figure 2.10). However, although Gaffen et al. (2000) found a similar increase over 1960 to 1997, they found a lowering of freezing level over 1979 to 1997 which, at least superficially, is not consistent with glacier recession.

Figure 2.18 shows a representative selection of glacier length records from different parts of the world and updates the diagram in IPCC (1990). It is clear from Figure 2.18 that glacier retreat on the century time-scale is worldwide. The available data suggest that this retreat generally started later at high latitudes but in low and mid-latitudes the retreat generally started in the mid-19th century.

On the global scale, air temperature is considered by most glaciologists to be the most important factor reflecting glacier retreat. This is based on calculations with mass balance models (Greuell and Oerlemans, 1987; Oerlemans, 1992; Fleming et al., 1997; Jóhannesson, 1997). For a typical mid-latitude glacier, a $30 \%$ decrease in cloudiness or a $25 \%$ decrease in precipitation would have the same effect as a $1{ }^{\circ} \mathrm{C}$ temperature rise. Such changes in cloudiness or precipitation can occur locally or even regionally on a decadal time-scale associated with changes in circulation, but global trends of this size on a century time-scale are very unlikely. As mentioned in the SAR, Oerlemans (1994) concluded that a warming rate of $0.66 \pm 0.20^{\circ} \mathrm{C}$ per century at the mean glacier altitude could explain the linear part of the observed retreat of 48 widely distributed glaciers.

Glaciers are generally not in equilibrium with the prevailing climatic conditions and a more refined analysis should deal with the different response times of glaciers which involves modelling (Oerlemans et al., 1998). It will take some time before a large
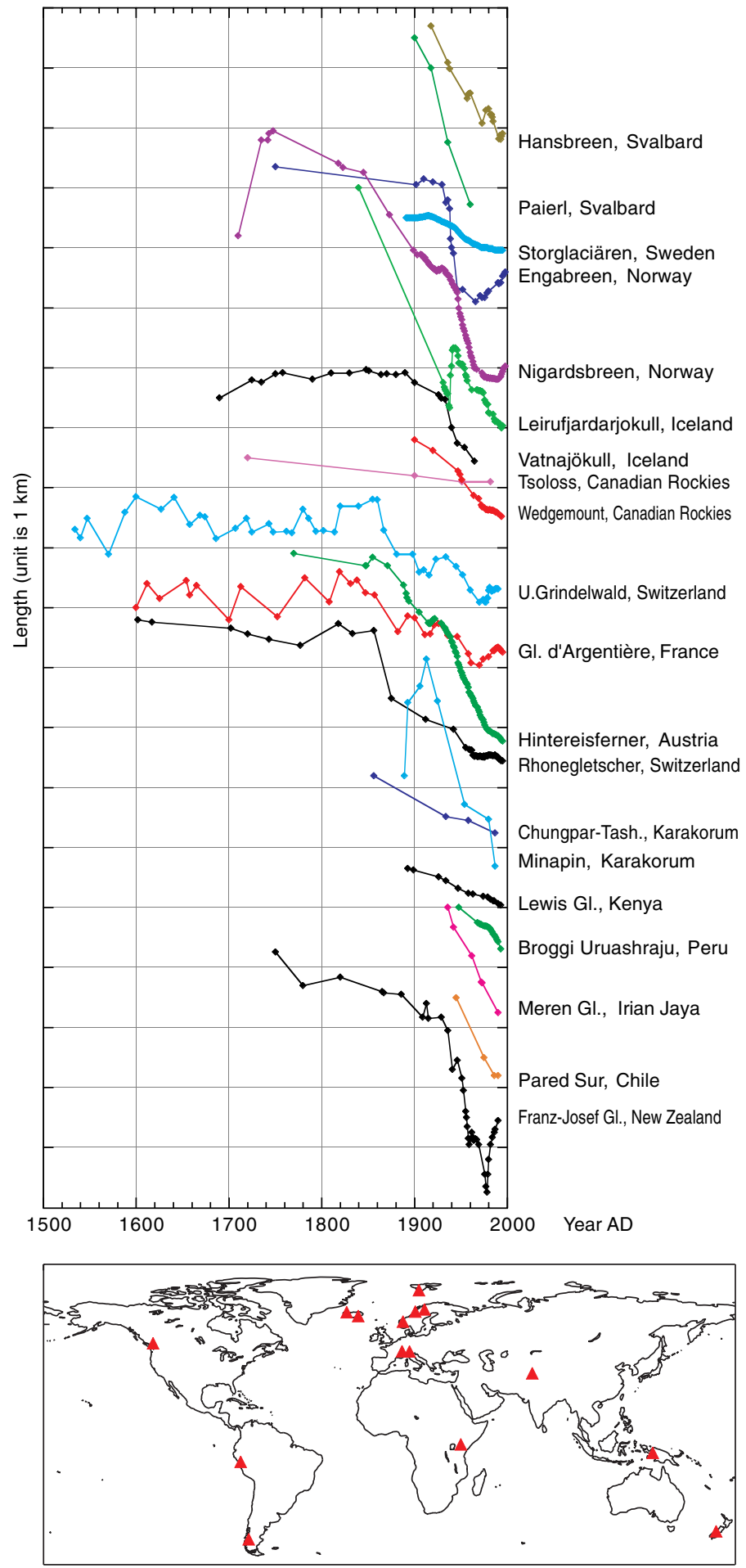

Figure 2.18: A collection of twenty glacier length records from different parts of the world. Curves have been translated along the vertical axis to make them fit in one frame. The geographical distribution of the data is also shown, though a single triangle may represent more than one glacier. Data are from the World Glacier Monitoring Service (http://www.geo.unizh.ch/wgms/) with some additions from various unpublished sources. 
number of glaciers are modelled. Nevertheless, work done so far indicates that the response times of glacier lengths shown in Figure 2.18 are in the 10 to 70 year range. Therefore the timing of the onset of glacier retreat implies that a significant global warming is likely to have started not later than the mid-19th century. This conflicts with the Jones et al. (2001) global land instrumental temperature data (Figure 2.1), and the combined hemispheric and global land and marine data (Figure 2.7), where clear warming is not seen until the beginning of the 20th century. This conclusion also conflicts with some (but not all) of the palaeo-temperature reconstructions in Figure 2.21, Section 2.3, where clear warming, e.g., in the Mann et al. (1999) Northern Hemisphere series, starts at about the same time as in the Jones et al. (2001) data. These discrepancies are currently unexplained.

For the last two to three decades, far more records have been available than are shown in Figure 2.18. Many are documented at the World Glacier Monitoring Service in Zürich, Switzerland (e.g., IAHS (ICSI)/UNEP/UNESCO, 1998) The general picture is one of widespread retreat, notably in Alaska, Franz-Josef Land, Asia, the Alps, Indonesia and Africa, and tropical and subtropical regions of South America. In a few regions a considerable number of glaciers are currently advancing (e.g., Western Norway, New Zealand). In Norway this is very likely to be due to increases in precipitation owing to the positive phase of the North Atlantic Oscillation (Section 2.6), and in the Southern Alps of New Zealandand due to wetter conditions with little warming since about 1980. Finally, indications in the European Alps that current glacier recession is reaching levels not seen for perhaps a few thousand years comes from the exposure of radiocarbondated ancient remains in high glacial saddles. Here there is no significant ice flow and melting is assumed to have taken place in situ for the first time in millennia (e.g., the finding of the 5,000year-old Oetzal "ice man").

\subsubsection{Lake and river ice}

Numerous studies suggest the importance of lake and river ice break-up as an index of climate variability and change, especially as related to temperature and snow cover (Palecki and Barry, 1986; Schindler et al., 1990; Robertson et al., 1992; Assel and Robertson, 1995; Anderson et al., 1996; Wynne et al., 1998; Magnuson et al., 2000). Records of lake and river ice can be used to independently evaluate changes of temperature and, to some extent, snow cover. Like other proxy measurements they have limitations, and are subject to their own time-dependent biases such as changes in observers and protocols related to the identification of "ice on" and "ice off" conditions. Larger lakes often have the best records, but are often located near human settlements which can affect the homogeneity of the record, e.g., associated cooling water discharges and urban heat islands, so care is needed to select suitable lakes.

A recent analysis has been made of trends in 39 extensive Northern Hemisphere lake and river ice records over the 150-year period from 1846 to 1995 . Ice break-up dates now occur on average about nine days earlier in the spring than at the beginning of the record, and autumn freeze-up occurs on average about ten days later (Magnuson et al., 2000). Only one of the 39 records, in Japan, showed changes that indicate a slight cooling.

\subsubsection{Are the Retreat of Glaciers, Sea Ice, and Snow Cover Consistent with the Surface Temperature Trends?}

A significant relationship has been found between interannual variations (correlation $=-0.60$ ) of the Northern Hemisphere snow-cover extent and land-surface air temperature in spring since the 1960s. However, the observed increase in temperature during the winter is not reflected in a reduced snow-cover extent. Reduced ice cover on the Northern Hemisphere lakes and rivers, primarily due to earlier onset in spring of ice-free conditions during the 20th century, is consistent with reduced snow cover extent in that season. Sea-ice retreat in the Arctic spring and summer is also consistent with an increase in spring, and to a lesser extent, summer temperatures in the high northern latitudes. Summer temperature increases have been less than in spring in nearby land areas, but Arctic sea-ice extent and especially thickness have markedly decreased. Nevertheless, there is only a small indication of reduced Arctic sea ice during winter when temperatures have also increased. Antarctic sea-ice extent has not decreased since the late 1970s, possibly related to recent indications of little change in Antarctic temperatures over much of the continent in that period. There is now ample evidence to support a major retreat of most mountain glaciers during the last 100 years in response to widespread increases in temperature. There has been especially fast glacial recession in the tropics in recent decades, although tropical temperatures in the free atmosphere near glacier levels have increased little since 1980 according to radiosonde and MSU data.

\subsubsection{Summary}

Global surface temperatures have increased between 0.4 and $0.8^{\circ} \mathrm{C}$ since the late 19th century, but most of this increase has occurred in two distinct periods, 1910 to 1945 and since 1976. The rate of temperature increase since 1976 has been over $0.15^{\circ} \mathrm{C} /$ decade. Our confidence in the rate of warming has increased since the SAR due to new analyses including: model simulations using observed SSTs with and without corrections for time-dependent biases, new studies of the effect of urbanisation on global land temperature trends, new evidence for mass ablation of glaciers, continued reductions in snow-cover extent, and a significant reduction in Arctic sea-ice extent in spring and summer, and in thickness. However, there is some disagreement between warming rates in the various land and ocean-based data sets in the 1990s, though all agree on appreciable warming.

New analyses of mean daily maximum and minimum temperatures continue to support a reduction in the diurnal temperature range with minimum temperatures increasing at about twice the rate of maximum temperatures over the second half of the 20th century. Seasonally, the greatest warming since 1976 over land has occurred during the Northern Hemisphere winter and spring, but significant warming has also occurred in the Northern Hemisphere summer. Southern Hemisphere warming has also been strongest during the winter over land, but little difference between the seasons is apparent when both land and oceans are considered. The largest rates of warming continue to be found in the mid- and high latitude continental regions of the Northern Hemisphere. 
Analyses of overall temperature trends in the low to midtroposphere and near the surface since 1958 are in good agreement, with a warming of about $0.1^{\circ} \mathrm{C}$ per decade. Since the beginning of the satellite record (1979), however, low to midtroposphere temperatures have warmed in both satellite and weather balloon records at a global rate of only 0.04 and $0.03^{\circ} \mathrm{C} /$ decade respectively. This is about $0.12^{\circ} \mathrm{C} /$ decade less than the rate of temperature increase near the surface since 1979. About half of this difference in warming rate is very likely to be due to the combination of differences in spatial coverage and the real physical affects of volcanoes and ENSO (Santer et al., 2000), see also Chapter 12. The remaining difference remains unexplained, but is likely to be real. In the stratosphere, both satellites and weather balloons continue to show substantial cooling. The faster rate of recession of tropical mountain glaciers in the last twenty years than might have been expected from the MSU and radiosonde records remains unexplained, though some glaciers may still be responding to the warming indicated by radiosondes that occurred around 1976 to 1981.

\subsection{Is the Recent Warming Unusual?}

\subsubsection{Background}

To determine whether 20th century warming is unusual, it is essential to place it in the context of longer-term climate variability. Owing to the sparseness of instrumental climate records prior to the 20th century (especially prior to the mid-19th century), estimates of global climate variability during past centuries must often rely upon indirect "proxy" indicators natural or human documentary archives that record past climate variations, but must be calibrated against instrumental data for a meaningful climate interpretation (Bradley, 1999, gives a review). Coarsely resolved climate trends over several centuries are evident in many regions e.g., from the recession of glaciers (Grove and Switsur, 1994; and Section 2.2.5.4) or the geothermal information provided by borehole measurements (Pollack et al., 1998). Large-scale estimates of decadal, annual or seasonal climate variations in past centuries, however, must rely upon sources that resolve annual or seasonal climatic variations. Such proxy information includes width and density measurements from tree rings (e.g., Cook, 1995; see Fritts, 1991, for a review), layer thickness from laminated sediment cores (e.g., Hughen $e t$ al., 1996; Lamoureux and Bradley, 1996), isotopes, chemistry, and accumulation from annually resolved ice cores (e.g., Claussen et al., 1995; Fisher et al., 1998), isotopes from corals (e.g., Tudhope et al., 1995; Dunbar and Cole, 1999), and the sparse historical documentary evidence available over the globe during the past few centuries (see e.g., Bradley and Jones, 1995; Pfister et al., 1998). Taken as a whole, such proxy climate data can provide global scale sampling of climate variations several centuries into the past, with the potential to resolve large-scale patterns of climate change prior to the instrumental period, albeit with important limitations and uncertainties.

The SAR examined evidence for climate change in the past, on time-scales of centuries to millennia. Based on information from a variety of proxy climate indicators, reconstructions of mountain glacier mass and extent, and geothermal sub-surface information from boreholes, it was concluded that summer temperatures in the Northern Hemisphere during recent decades are the warmest in at least six centuries. While data prior to AD 1400 were considered too sparse for reliable inferences regarding hemispheric or global mean temperatures, regional inferences were nonetheless made about climate changes further back in time.

Since the SAR, a number of studies based on considerably expanded databases of palaeoclimate information have allowed more decisive conclusions about the spatial and temporal patterns of climate change in past centuries. A number of important advances have been in key areas such as ice core palaeoclimatology (e.g., White et al., 1998a), dendroclimatology (e.g., Cook, 1995; Briffa et al., 1998b), and geothermal palaeo-temperature estimation (e.g., Pollack et al., 1998). Moreover, the latest studies based on global networks of "multi-proxy" data have proved particularly useful for describing global or hemispheric patterns of climate variability in past centuries (e.g., Bradley and Jones, 1993; Hughes and Diaz, 1994; Mann et al., 1995; Fisher, 1997; Overpeck et al., 1997; Mann et al., 1998, 1999). Such estimates allow the observed trends of the 20th century to be put in a longer-term perspective. These have also allowed better comparisons with possible physical influences on climate forcings (Lean et al., 1995; Crowley and Kim, 1996, 1999; Overpeck et al., 1997; Mann et al., 1998; Waple et al., 2001), and for new evaluations of the low-frequency climate variability exhibited by numerical climate models (Barnett et al., 1996; Jones et al., 1998; Crowley and Kim, 1999; Delworth and Mann, 2000).

\subsubsection{Temperature of the Past 1,000 Years}

The past 1,000 years are a particularly important time-frame for assessing the background natural variability of the climate for climate change detection. Astronomical boundary conditions have strayed relatively little from their modern-day values over this interval (but see Section 2.3.4 for a possible caveat) and, with the latest evidence, the spatial extent of large-scale climate change during the past millennium can now be meaningfully characterised (Briffa et al., 1998b; Jones et al., 1998; Mann et al., 1998; 1999; 2000a; 2000b). Moreover, estimates of volcanic and solar climate forcings are also possible over this period, allowing model-based estimates of their climate effects (Crowley and Kim, 1999; Free and Robock, 1999).

\subsubsection{Palaeoclimate proxy indicators}

A "proxy" climate indicator is a local record that is interpreted using physical or biophysical principles to represent some combination of climate-related variations back in time. Palaeoclimate proxy indicators have the potential to provide evidence for large-scale climatic changes prior to the existence of widespread instrumental or historical documentary records. Typically, the interpretation of a proxy climate record is complicated by the presence of "noise" in which climate information is immersed, and a variety of possible distortions of the underlying climate information (e.g., Bradley, 1999; Ren, 1999a,b). Careful calibration and cross-validation procedures are necessary to establish a reliable relationship between a proxy indicator and the 
climatic variable or variables it is assumed to represent, providing a "transfer" function through which past climatic conditions can be estimated. High-resolution proxy climate indicators, including tree rings, corals, ice cores, and laminated lake/ocean sediments, can be used to provide detailed information on annual or nearannual climate variations back in time. Certain coarser resolution proxy information (from e.g., boreholes, glacial moraines, and non-laminated ocean sediment records) can usefully supplement this high-resolution information. Important recent advances in the development and interpretation of proxy climate indicators are described below.

\section{Tree rings}

Tree-ring records of past climate are precisely dated, annually resolved, and can be well calibrated and verified (Fritts, 1976). They typically extend from the present to several centuries or more into the past, and so are useful for documenting climate change in terrestrial regions of the globe. Many recent studies have sought to reconstruct warm-season and annual temperatures several centuries or more ago from either the width or the density of annual growth rings (Briffa et al., 1995; D'Arrigo et al., 1996; Jacoby et al., 1996; D'Arrigo et al., 1998; Wiles et al., 1998; Hughes et al., 1999; Cook et al., 2000). Recently, there has been a concerted effort to develop spatial reconstructions of past temperature variations (e.g., Briffa et al., 1996) and estimates of hemispheric and global temperature change (e.g., Briffa et al., 1998b; Briffa, 2000). Tree-ring networks are also now being used to reconstruct important indices of climate variability over several centuries such as the Southern Oscillation Index (Stahle et al., 1998), the North Atlantic Oscillation (Cook et al., 1998; Cullen et al., 2001) and the Antarctic Oscillation Index (Villalba et al., 1997) (see also Section 2.6), as well as patterns of pre-instrumental precipitation and drought (Section 2.5.2.2).

Several important caveats must be borne in mind when using tree-ring data for palaeoclimate reconstructions. Not least is the intrinsic sampling bias. Tree-ring information is available only in terrestrial regions, so is not available over substantial regions of the globe, and the climate signals contained in tree-ring density or width data reflect a complex biological response to climate forcing. Non-climatic growth trends must be removed from the tree-ring chronology, making it difficult to resolve time-scales longer than the lengths of the constituent chronologies (Briffa, 2000). Furthermore, the biological response to climate forcing may change over time. There is evidence, for example, that high latitude tree-ring density variations have changed in their response to temperature in recent decades, associated with possible nonclimatic factors (Briffa et al., 1998a). By contrast, Vaganov et al. (1999) have presented evidence that such changes may actually be climatic and result from the effects of increasing winter precipitation on the starting date of the growing season (see Section 2.7.2.2). Carbon dioxide fertilization may also have an influence, particularly on high-elevation drought-sensitive tree species, although attempts have been made to correct for this effect where appropriate (Mann et al., 1999). Thus climate reconstructions based entirely on tree-ring data are susceptible to several sources of contamination or non-stationarity of response. For these reasons, investigators have increasingly found tree-ring data most useful when supplemented by other types of proxy information in "multi-proxy" estimates of past temperature change (Overpeck $e t$ al., 1997; Jones et al., 1998; Mann et al., 1998; 1999; 2000a; 2000b; Crowley and Lowery, 2000).

\section{Corals}

Palaeoclimate reconstructions from corals provide insights into the past variability of the tropical and sub-tropical oceans and atmosphere, prior to the instrumental period, at annual or seasonal resolutions, making them a key addition to terrestrial information. Because of their potential to sample climate variations in ENSOsensitive regions, a modest network of high-quality coral site records can resolve key large-scale patterns of climate variability (Evans et al., 1998). The corals used for palaeoclimate reconstruction grow throughout the tropics in relatively shallow waters, often living for several centuries. Accurate annual age estimates are possible for most sites using a combination of annual variations in skeletal density and geochemical parameters. Palaeoclimate reconstructions from corals generally rely on geochemical characteristics of the coral skeleton such as temporal variations in trace elements or stable isotopes or, less frequently, on density or variations in fluorescence. Dunbar and Cole (1999) review the use of coral records for palaeoclimatic reconstruction.

\section{Ice cores}

Ice cores from polar regions of northern Greenland, Canada and the islands of the North Atlantic and Arctic Oceans, Antarctica, and alpine, tropical and sub-tropical locations (e.g., Thompson, 1996) can provide several climate-related indicators. These indicators include stable isotopes (e.g., ${ }^{18} \mathrm{O}$ ), the fraction of melting ice, the rate of accumulation of precipitation, concentrations of various salts and acids, the implied atmospheric loading of dust pollen, and trace gases such as $\mathrm{CH}_{4}$ and $\mathrm{CO}_{2}$.

Recently, there has been increased activity in creating highresolution Antarctic ice core series e.g., for the past millennium (Peel et al., 1996; Mayewski and Goodwin, 1997; Morgan and van Ommen, 1997). In certain regions, isotope information from ice cores shows the late 20th century temperatures as the warmest few decades in the last 1,000 years (Thompson et al., 2000a). Key strengths of ice core information are their high resolution (annual or even seasonal where accumulations rates are particularly high - see van Ommen and Morgan, 1996, 1997), availability in polar and high-elevation regions where other types of proxy climate information like tree-ring data are not available, and their provision of multiple climate- and atmosphere-related variables from the same reasonably well dated physical location (e.g., the GISP2 core; White et al., 1998a). A weakness of ice core data is regional sampling bias (high elevation or high latitude) and melt water and precipitation accumulation data are not easy to date accurately.

The best dated series are based on sub-annual sampling of cores and the counting of seasonal ice layers. Such series may have absolute dating errors as small as a few years in a millennium (Fisher et al., 1996). Dating is sometimes performed using volcanic acid layers with assumed dates (e.g., Clausen et al., 1995) but uncertainties in the volcanic dates can result in dating uncertainties throughout the core (Fisher et al., 1998). 


\section{Lake and ocean sediments}

Annually laminated (varved) lake sediments offer considerable potential as high-resolution archives of palaeo-environmental conditions where other high-resolution proxy indicators are not available (e.g., arid terrestrial regions), and latitudes poleward of the treeline (Lamoureux and Bradley, 1996; Wohlfarth et al., 1998; Hughen et al., 2000). When annual deposition of the varves can be independently confirmed (e.g., through radiometric dating), they provide seasonal to interannual resolution over centuries to millennia. Varved sediments can be formed from biological processes or from the deposition of inorganic sediments, both of which are often influenced by climate variations. Three primary climate variables may influence lake varves: (a) summer temperature, serving as an index of the energy available to melt the seasonal snowpack, or snow and ice on glaciers; (b) winter snowfall, which governs the volume of discharge capable of mobilising sediments when melting; and (c) rainfall. Laminated lake sediments dominated by (a) can be used for inferences about past high latitude summer temperature changes (e.g., Overpeck et al., 1997), while sediments dominated by the latter two influences can be used to estimate past drought and precipitation patterns (Section 2.5.2.2)

Ocean sediments may also be useful for high-resolution climate reconstructions. In rare examples, annually laminated sediments can be found (e.g., Hughen et al., 1996; Black et al., 1999) and it is possible to incorporate isotope and other information in climate reconstructions, much as varved lake sediments are used. Otherwise, sedimentation rates may sometimes still be sufficiently high that century-scale variability is resolvable (e.g., the Bermuda rise ocean sediment oxygen isotope record of Keigwin, 1996). Dating in such cases, however, must rely on radiometric methods with relatively poor age control.

\section{Borehole measurements}

Borehole measurements attempt to relate profiles of temperature with depth to the history of temperature change at the ground surface. The present global database of more than 600 borehole temperature-depth profiles has the densest geographic coverage in North America and Europe, but sparser data are available in other regions (e.g., Australia, Asia, Africa and South America). The depths of the temperature profiles range from about 200 to greater than $1,000 \mathrm{~m}$, allowing palaeo-temperature reconstructions back several hundred to a thousand years. Although largescale temperature reconstructions have been made to more than a millennium ago (Huang et al., 1997), they show substantial sensitivity to assumptions that are needed to convert the temperature profiles to ground surface temperature changes. Borehole data are probably most useful for climate reconstructions over the last five centuries (Pollack et al., 1998).

Figure 2.19 shows a reconstructed global ground surface temperature history (Pollack et al., 1998; see also Huang et al., 2000) from an average of the 358 individual sites, most located in North America and Eurasia, but some located in Africa, South America and Australia (similar results are obtained by Huang et $a l ., 2000$, using an updated network of 616 sites). Superimposed is an instrumental estimate of global surface air temperature (Jones and Briffa, 1992). The ensemble of reconstructions shows

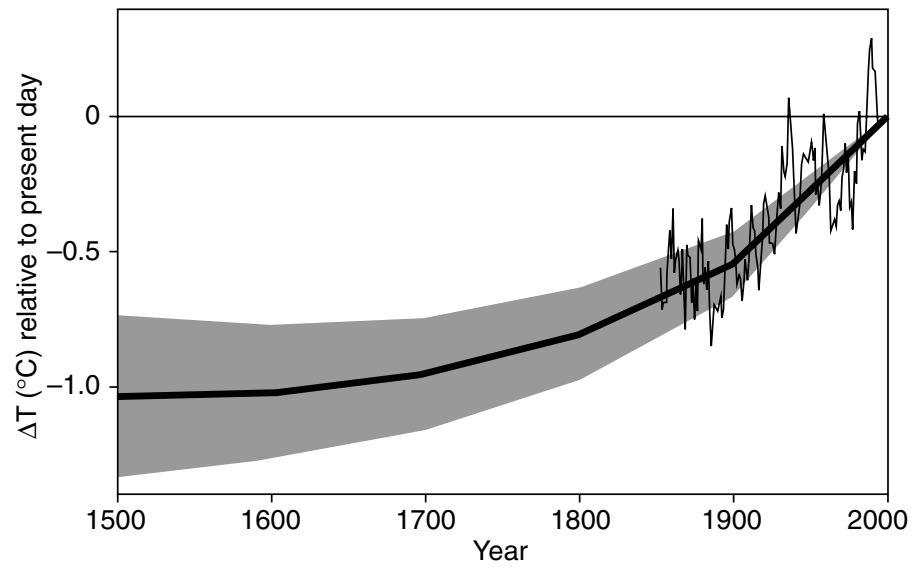

Figure 2.19: Reconstructed global ground temperature estimate from borehole data over the past five centuries, relative to present day. Shaded areas represent \pm two standard errors about the mean history (Pollack et al., 1998). Superimposed is a smoothed (five-year running average) of the global surface air temperature instrumental record since 1860 (Jones and Briffa, 1992).

that the average ground temperature of the Earth has increased by about $0.5^{\circ} \mathrm{C}$ during the 20th century, and that this was the warmest of the past five centuries. About $80 \%$ of the sites experienced a net warming over this period. The estimated mean cumulative ground surface temperature change since 1500 is close to $1.0 \pm 0.3^{\circ} \mathrm{C}$. Uncertainties due to spatial sampling (see Pollack et al., 1998 and Huang et al., 2000) are also shown. It should be noted that the temporal resolution of the borehole estimates decreases sharply back in time, making it perilous to compare the shape of the trend shown in Figure 2.19 with betterresolved trends determined from higher-resolution climate proxy data discussed below.

While borehole data provide a direct estimate of ground surface temperatures under certain simplifying assumptions about the geothermal properties of the earth near the borehole, a number of factors complicate their interpretation. Non-temperature-related factors such as land-use changes, natural land cover variations, long-term variations in winter snow cover and soil moisture change the sub-surface thermal properties and weaken the interpretation of the reconstructions as estimates of surface air temperature change. In central England, where seasonal snow cover is not significant, and major land-use changes occurred many centuries ago, borehole ground surface temperature trends do tend to be similar to those in long instrumental records (Jones, 1999). In contrast, Skinner and Majorowicz (1999) show that borehole estimates of ground surface temperature warming during the 20th century in north-western North America are 1 to $2{ }^{\circ} \mathrm{C}$ greater than in corresponding instrumental estimates of surface air temperature. They suggest that this discrepancy may be due to land-use changes that can enhance warming of the ground surface relative to that of the overlying atmospheric boundary layer (see also Lewis, 1998). Such factors need to be better understood before borehole temperature measurements can be confidently interpreted. 


\section{Documentary evidence}

Historical documentary data are valuable sources of information about past climate (e.g., Brown and Issar, 1998; Bradley, 1999). However, their use requires great care, as such documents may be biased towards describing only the more extreme events, and are, in certain cases, prone to the use of inconsistent language between different writers and different epochs, and to errors in dating. As for all proxy information, historical documents require careful calibration and verification against modern instrumental data. Two areas particularly strong in historical documents describing climate are Europe and China. In Europe, attempts have been made to extend long climate series back in time using a combination of documentary evidence and fragmentary instrumental records (e.g., Pfister, 1995; Pfister et al., 1998). Additional information about past climate change has also been obtained purely from documentary records in Europe (e.g., Martin-Vide and Barriendos, 1995; Brázdil, 1996; Pfister et al., 1996, 1998, 1999; Pfister and Brázdil, 1999; Rodrigo et al., 1999). In China, regional instrumental temperature series have been extended back over much of the past millennium using documentary data combined with inferences from ice cores and tree rings (Wang et al., 1998a, 1998b; Wang and Gong, 2000).

\section{Mountain glacier moraines}

The position of moraines or till left behind by receding glaciers can provide information on the advances (and, less accurately, the retreats) of mountain glaciers. Owing to the complex balance between local changes in melting and ice accumulation, and the effects of topography which influence mountain glaciers (see Section 2.2.5.4), it is difficult to reconstruct regional (as opposed to global) climate changes from the extent of mountain glaciers alone (Oerlemans, 1989). For example, both increased winter precipitation (through greater accumulation) and lower summer temperatures (through decreased melting or "ablation") can lead to more positive glacial mass balances. The inertia of large glaciers dictates that they respond to climate change relatively slowly, with delays of decades or occasionally centuries. For smaller, fast moving glaciers in regions where precipitation and accumulation are moderate, temperature changes are usually the dominant factor influencing mountain glacier masses and lengths. Here glacier moraine evidence in combination with other lines of evidence can provide reliable information on past regional temperature changes (Salinger, 1995; Holzhauser and Zumbühl, 1996; Raper et al., 1996; Salinger et al., 1996).

\subsubsection{Multi-proxy synthesis of recent temperature change}

Since the SAR there have been several attempts to combine various types of high-resolution proxy climate indicators to create large-scale palaeoclimate reconstructions that build on earlier work by e.g., Bradley and Jones (1993); Hughes and Diaz (1994) and Mann et al. (1995). Overpeck et al. (1997) and Fisher (1997) have sought to combine information from ice cores, varved lake sediment cores, and tree rings to reconstruct high latitude climate trends for past centuries. Jones et al. (1998) estimated extratropical Northern and Southern Hemisphere warm-season temperature changes during the past millennium using a sparse set of extra-tropical warm-season temperature proxy indicators (10 and
8 respectively). Mann et al. (1998) reconstructed global patterns of annual surface temperature several centuries back in time. They calibrated a combined terrestrial (tree ring, ice core and historical documentary indicator) and marine (coral) multi-proxy climate network against dominant patterns of 20th century global surface temperature. Averaging the reconstructed temperature patterns over the far more data-rich Northern Hemisphere half of the global domain, they estimated the Northern Hemisphere mean temperature back to $\mathrm{AD} 1400$, a reconstruction which had significant skill in independent cross-validation tests. Self-consistent estimates were also made of the uncertainties. This work has now been extended back to AD 1000 (Figure 2.20, based on Mann et al., 1999). The uncertainties (the shaded region in Figure 2.20) expand considerably in earlier centuries because of the sparse network of proxy data. Taking into account these substantial uncertainties, Mann et al. (1999) concluded that the 1990s were likely to have been the warmest decade, and 1998 the warmest year, of the past millennium for at least the Northern Hemisphere. Jones et al. (1998) came to a similar conclusion from largely independent data and an entirely independent methodology. Crowley and Lowery (2000) reached the similar conclusion that medieval temperatures were no warmer than mid-20th century temperatures. Borehole data (Pollack et al., 1998) independently support this conclusion for the past 500 years although, as discussed earlier (Section 2.3.2.1), detailed interpretations comparison with long-term trends from such of such data are perilous owing to loss of temporal resolution back in time.

The largely independent multi-proxy Northern Hemisphere temperature reconstructions of Jones et al. (1998) and Mann et al. (1999) are compared in Figure 2.21, together with an independent (extra-tropical, warm-season) Northern Hemisphere temperature estimate by Briffa (2000) based on tree-ring density data. The estimated uncertainties shown are those for the smoothed Mann et al. series. Significant differences between the three reconstructions are evident during the 17th and early 19th centuries where either the Briffa et al. or Jones et al. series lie outside the estimated uncertainties in the Mann et al. series. Much of these differences appear to result from the different latitudinal and seasonal emphases of the temperature estimates. This conclusion is supported by the observation that the Mann et al. hemispheric temperature average, when restricted to just the extra-tropical (30 to $70^{\circ} \mathrm{N}$ band) region of the Northern Hemisphere, shows greater similarity in its trend over the past few centuries to the Jones et al. reconstruction. The differences between these reconstructions emphasise the importance of regional and seasonal variations in climate change. These are discussed in the next section.

\subsubsection{Was there a "Little Ice Age" and a "Medieval Warm Period"?}

The terms "Little Ice Age" and "Medieval Warm Period" have been used to describe two past climate epochs in Europe and neighbouring regions during roughly the 17 th to 19 th and 11 th to 14th centuries, respectively. The timing, however, of these cold and warm periods has recently been demonstrated to vary geographically over the globe in a considerable way (Bradley and 


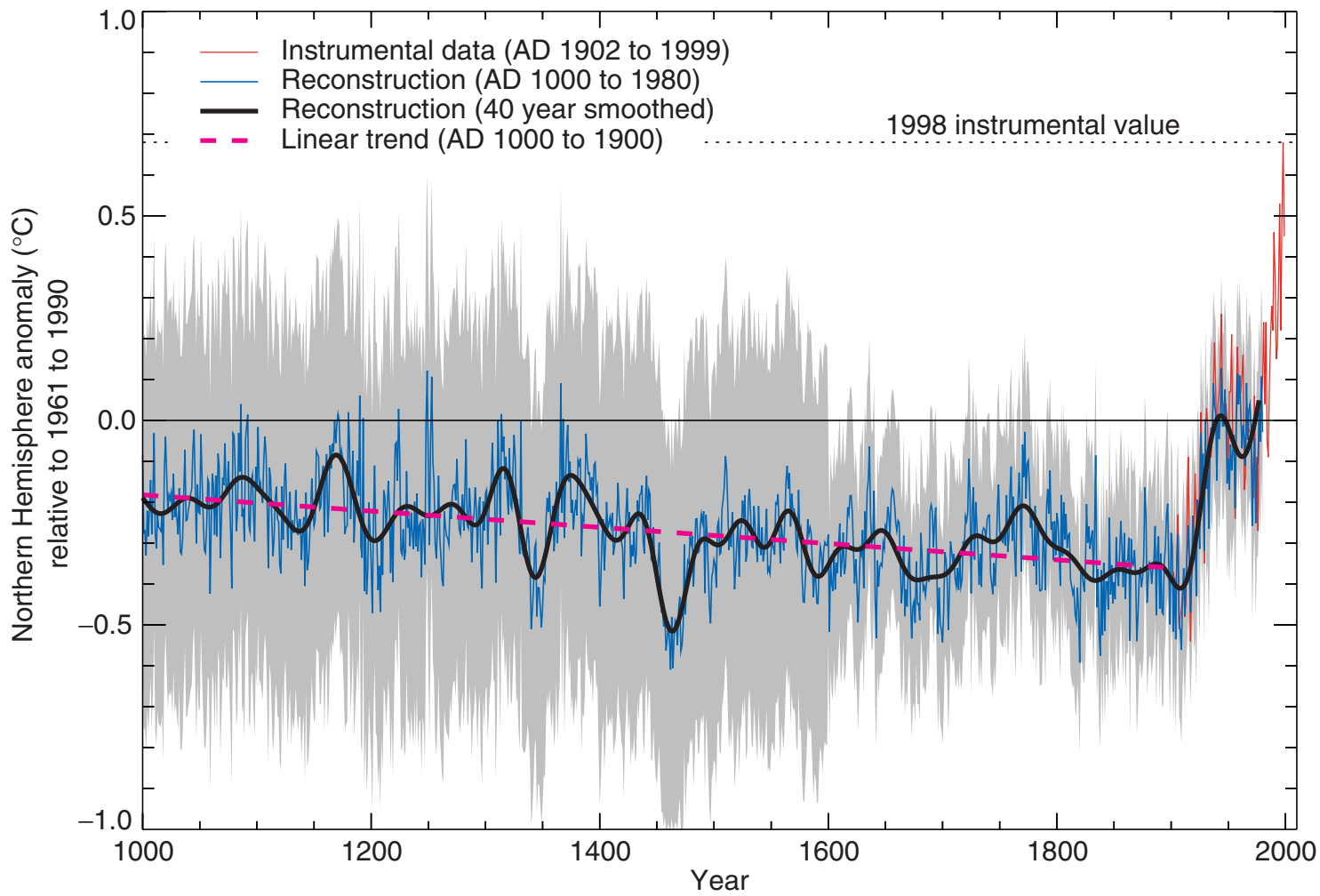

Figure 2.20: Millennial Northern Hemisphere (NH) temperature reconstruction (blue) and instrumental data (red) from AD 1000 to 1999 , adapted from Mann et al. (1999). Smoother version of NH series (black), linear trend from AD 1000 to 1850 (purple-dashed) and two standard error limits (grey shaded) are shown.

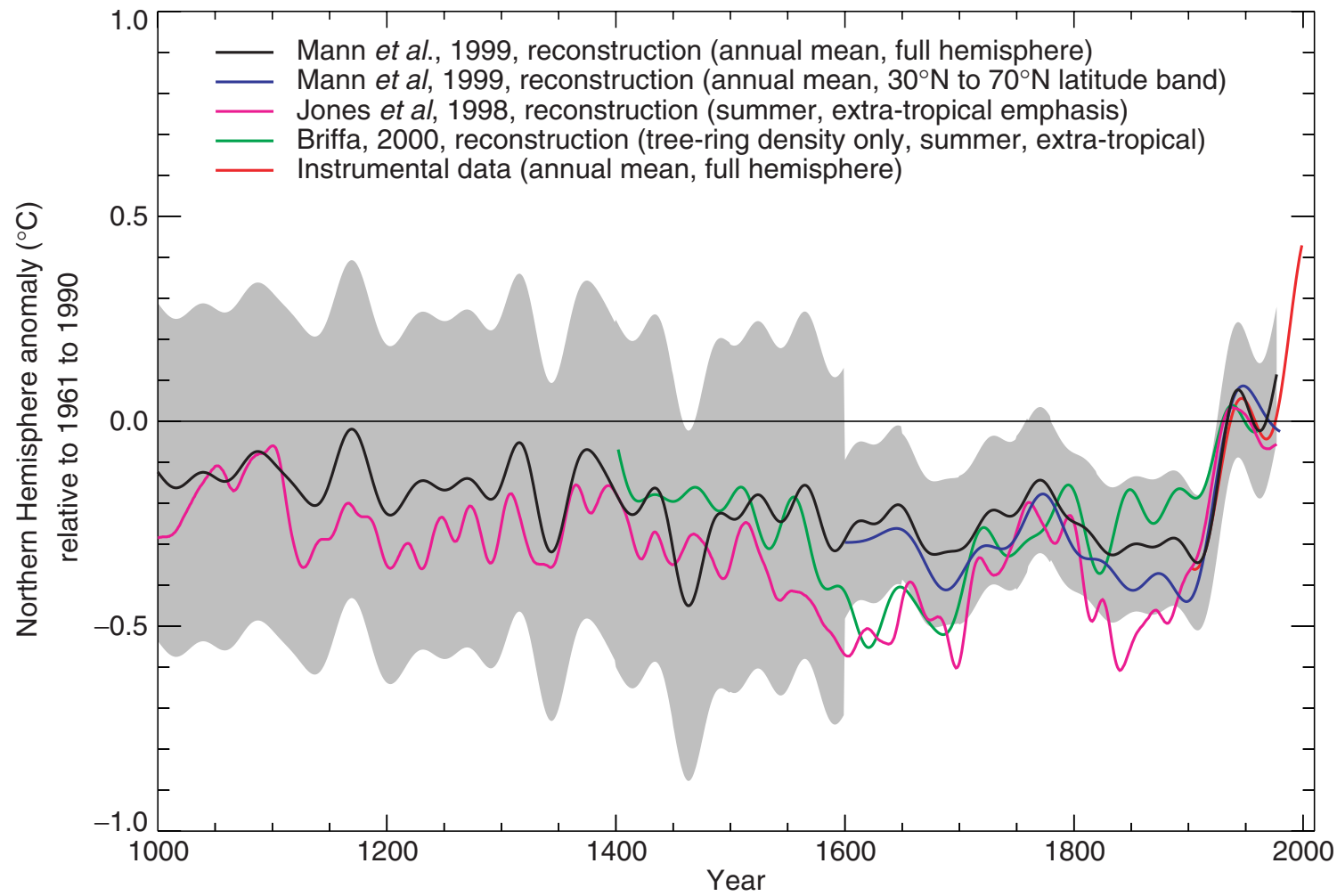

Figure 2.21: Comparison of warm-season (Jones et al., 1998) and annual mean (Mann et al., 1998, 1999) multi-proxy-based and warm season tree-ring-based (Briffa, 2000) millennial Northern Hemisphere temperature reconstructions. The recent instrumental annual mean Northern Hemisphere temperature record to 1999 is shown for comparison. Also shown is an extra-tropical sampling of the Mann et al. (1999) temperature pattern reconstructions more directly comparable in its latitudinal sampling to the Jones et al. series. The self-consistently estimated two standard error limits (shaded region) for the smoothed Mann et al. (1999) series are shown. The horizontal zero line denotes the 1961 to 1990 reference period mean temperature. All series were smoothed with a 40-year Hamming-weights lowpass filter, with boundary constraints imposed by padding the series with its mean values during the first and last 25 years. 
Jones, 1993; Hughes and Diaz, 1994; Crowley and Lowery, 2000). Evidence from mountain glaciers does suggest increased glaciation in a number of widely spread regions outside Europe prior to the 20th century, including Alaska, New Zealand and Patagonia (Grove and Switsur, 1994). However, the timing of maximum glacial advances in these regions differs considerably, suggesting that they may represent largely independent regional climate changes, not a globally-synchronous increased glaciation (see Bradley, 1999). Thus current evidence does not support globally synchronous periods of anomalous cold or warmth over this timeframe, and the conventional terms of "Little Ice Age" and "Medieval Warm Period" appear to have limited utility in describing trends in hemispheric or global mean temperature changes in past centuries. With the more widespread proxy data and multi-proxy reconstructions of temperature change now available, the spatial and temporal character of these putative climate epochs can be reassessed.

Mann et al. (1998) and Jones et al. (1998) support the idea that the 15th to 19th centuries were the coldest of the millennium over the Northern Hemisphere overall. However, viewed hemispherically, the "Little Ice Age" can only be considered as a modest cooling of the Northern Hemisphere during this period of less than $1^{\circ} \mathrm{C}$ relative to late 20th century levels (Bradley and Jones, 1993; Jones et al., 1998; Mann et al., 1998; 1999; Crowley and Lowery, 2000). Cold conditions appear, however, to have been considerably more pronounced in particular regions. Such regional variability can be understood in part as reflecting accompanying changes in atmospheric circulation. The "Little Ice Age" appears to have been most clearly expressed in the North Atlantic region as altered patterns of atmospheric circulation (O'Brien et al., 1995). Unusually cold, dry winters in central Europe (e.g., 1 to $2^{\circ} \mathrm{C}$ below normal during the late 17th century) were very likely to have been associated with more frequent flows of continental air from the north-east (Wanner et al., 1995; Pfister, 1999). Such conditions are consistent (Luterbacher et al., 1999) with the negative or enhanced easterly wind phase of the NAO (Sections 2.2.2.3 and 2.6.5), which implies both warm and cold anomalies over different regions in the North Atlantic sector. Such strong influences on European temperature demonstrate the difficulty in extrapolating the sparse early information about European climate change to the hemispheric, let alone global, scale. While past changes in the NAO have likely had an influence in eastern North America, changes in the El Niño phenomenon (see also Section 2.6), are likely to have had a particularly significant influence on regional temperature patterns over North America.

The hemispherically averaged coldness of the 17th century largely reflected cold conditions in Eurasia, while cold hemispheric conditions in the 19th century were more associated with cold conditions in North America (Jones et al., 1998; Mann et al., 2000b). So, while the coldest decades of the 19th century appear to have been approximately 0.6 to $0.7^{\circ} \mathrm{C}$ colder than the latter decades of the 20th century in the hemispheric mean (Mann et al., 1998), the coldest decades for the North American continent were closer to $1.5^{\circ} \mathrm{C}$ colder (Mann et al., 2000b). In addition, the timing of peak coldness was often specific to particular seasons. In Switzerland, for example, the first particularly cold winters appear to have been in the 1560 s, with cold springs beginning around 1568, and with 1573 the first unusually cold summer (Pfister, 1995).

The evidence for temperature changes in past centuries in the Southern Hemisphere is quite sparse. What evidence is available at the hemispheric scale for summer (Jones et al., 1998) and annual mean conditions (Mann et al., 2000b) suggests markedly different behaviour from the Northern Hemisphere. The only obvious similarity is the unprecedented warmth of the late 20th century. Speleothem evidence (isotopic evidence from calcite deposition in stalagmites and stalactites) from South Africa indicates anomalously cold conditions only prior to the 19th century, while speleothem (records derived from analysing stalagmites and stalagtites) and glacier evidence from the Southern Alps of New Zealand suggests cold conditions during the mid-17th and mid-19th centuries (Salinger, 1995). Dendroclimatic evidence from nearby Tasmania (Cook et al., 2000) shows no evidence of unusual coldness at these times. Differences in the seasons most represented by this proxy information prevent a more direct comparison.

As with the "Little Ice Age", the posited "Medieval Warm Period" appears to have been less distinct, more moderate in amplitude, and somewhat different in timing at the hemispheric scale than is typically inferred for the conventionally-defined European epoch. The Northern Hemisphere mean temperature estimates of Jones et al. (1998), Mann et al. (1999), and Crowley and Lowery (2000) show temperatures from the 11th to 14th centuries to be about $0.2^{\circ} \mathrm{C}$ warmer than those from the 15 th to 19th centuries, but rather below mid-20th century temperatures. The long-term hemispheric trend is best described as a modest and irregular cooling from AD 1000 to around 1850 to 1900, followed by an abrupt 20th century warming. Regional evidence is, however, quite variable. Crowley and Lowery (2000) show that western Greenland exhibited anomalous warmth locally only around AD 1000 (and to a lesser extent, around AD 1400), with quite cold conditions during the latter part of the 11th century, while Scandinavian summer temperatures appeared relatively warm only during the 11th and early 12th centuries. Crowley and Lowery (2000) find no evidence for warmth in the tropics. Regional evidence for medieval warmth elsewhere in the Northern Hemisphere is so variable that eastern, yet not western, China appears to have been warm by 20th century standards from the 9th to 13th centuries. The 12th and 14th centuries appear to have been mainly cold in China (Wang et al., 1998a,b; Wang and Gong, 2000). The restricted evidence from the Southern Hemisphere, e.g., the Tasmanian tree-ring temperature reconstruction of Cook et al. (1999), shows no evidence for a distinct Medieval Warm Period.

Medieval warmth appears, in large part, to have been restricted to areas in and neighbouring the North Atlantic. This may implicate the role of ocean circulation-related climate variability. The Bermuda rise sediment record of Keigwin (1996) suggests warm medieval conditions and cold 17th to 19th century conditions in the Sargasso Sea of the tropical North Atlantic. A sediment record just south of Newfoundland (Keigwin and Pickart, 1999), in contrast, indicates cold medieval and warm 16th to 19th century upper ocean temperatures. Keigwin and Pickart (1999) suggest that these temperature contrasts were associated 
with changes in ocean currents in the North Atlantic. They argue that the "Little Ice Age" and "Medieval Warm Period" in the Atlantic region may in large measure reflect century-scale changes in the North Atlantic Oscillation (see Section 2.6). Such regional changes in oceanic and atmospheric processes, which are also relevant to the natural variability of the climate on millennial and longer time-scales (see Section 2.4.2), are greatly diminished or absent in their influence on hemispheric or global mean temperatures.

\subsubsection{Volcanic and Solar Effects in the Recent Record}

Recent studies comparing reconstructions of surface temperature and natural (solar and volcanic) radiative forcing (e.g., Lean et al., 1995; Crowley and Kim, 1996, 1999; Overpeck et al., 1997; Mann et al., 1998; Damon and Peristykh, 1999; Free and Robock, 1999; Waple et al., 2001) suggest that a combination of solar and volcanic influences have affected large-scale temperature in past centuries. The primary features of the Northern Hemisphere mean annual temperature histories of Mann et al. (1999a) and Crowley and Lowery (2000) from AD 1000 to 1900 have been largely reproduced based on experiments using an Energy Balance Model forced by estimates of these natural radiative forcings (Crowley, 2000; Mann, 2000) making the argument that the "Little Ice Age" and "Medieval Warm Period", at the hemispheric mean scale, are consistent with estimates of naturally-forced climate variability. Several studies indicate that the combined effect of these influences has contributed a small component to the warming of the 20th century. Most of these studies isolate greenhouse radiative forcing as being dominant during late 20th century warming (see Crowley, 2000). This argues against a close empirical relationship between certain sun-climate parameters and large-scale temperature that has been claimed for the 20th century (Hoyt and Schatten, 1997). The reader is referred to Chapter 6 for a detailed discussion of these radiative forcings, and to Chapter 12 for comparisons of observed and model simulations of recent climate change.

\subsubsection{Summary}

Since the SAR there have been considerable advances in our knowledge of temperature change over the last millennium. It is likely that temperatures were relatively warm in the Northern Hemisphere as a whole during the earlier centuries of the millennium, but it is much less likely that a globally-synchronous, well defined interval of "Medieval warmth" existed, comparable to the near global warmth of the late 20th century. Marked warmth seems to have been confined to Europe and regions neighbouring the North Atlantic. Relatively colder hemispheric or global-scale conditions did appear to set in after about AD 1400 and persist through the 19th century, but peak coldness is observed during substantially different epochs in different regions. By contrast, the warming of the 20th century has had a much more convincing global signature (see Figure 2.9). This is consistent with the palaeoclimate evidence that the rate and magnitude of global or hemispheric surface 20th century warming is likely to have been the largest of the millennium, with the 1990s and 1998 likely to have been the warmest decade and year, respectively, in the Northern Hemisphere. Independent estimates of hemispheric and global ground temperature trends over the past five centuries from sub-surface information contained in borehole data confirm the conclusion that late 20th century warmth is anomalous in a longterm context. Decreasing temporal resolution back in time of these estimates and potential complications in inferring surface air temperature trends from sub-surface ground temperature measurements precludes, however, a meaningful direct comparison of the borehole estimates with high-resolution temperature estimates based on other proxy climate data. Because less data are available, less is known about annual averages prior to 1,000 years before the present and for conditions prevailing in most of the Southern Hemisphere prior to 1861 .

\subsection{How Rapidly did Climate Change in the Distant Past?}

\subsubsection{Background}

Only during the 1980s was the possibility of rapid climatic changes occurring at the time-scale of human life more or less fully recognised, largely due to the Greenland ice core drilled at Dye 3 in Southern Greenland (Dansgaard et al., 1982, 1989). A possible link between such events and the mode of operation of the ocean was then subsequently suggested (Oeschger et al., 1984; Broecker et al., 1985; see Broecker, 1997, for a recent review). The SAR reviewed the evidence of such changes since the peak of the last inter-glacial period about $120 \mathrm{ky} \mathrm{BP}$ (thousands of years Before Present). It concluded that: (1) large and rapid climatic changes occurred during the last Ice Age and during the transition towards the present Holocene; (2) temperatures were far less variable during this latter period; and (3) suggestions that rapid changes may have also occurred during the last inter-glacial required confirmation.

These changes are now best documented from ice core, deep-sea sediment and continental records. Complementary and generally discontinuous information comes from coral and lake level data. The time-scale for the Pleistocene deep-sea core record is based on the orbitally tuned oxygen isotope record from marine sediments (Martinson et al., 1987), constrained by two radiometrically dated horizons, the peak of the last interglacial (about $124 \mathrm{ky} \mathrm{BP}$ ) and the Brunhes/Matuyama reversal of the Earth's magnetic field at about $780 \mathrm{ky} \mathrm{BP} .{ }^{14} \mathrm{C}$-dating is also used in the upper $50 \mathrm{ky} \mathrm{BP}$; the result is a deep-sea core chronology believed to be accurate to within a few per cent for the last million years. ${ }^{14} \mathrm{C}$-dating is also used for dating continental records as well as the counting of annual layers in tree rings and varved lake records, whereas ice-core chronologies are obtained by combining layer counting, glaciological models and comparison with other dated records. The use of globally representative records, such as changes in continental ice volume recorded in the isotopic composition of deep-sea sediments, or changes in atmospheric composition recorded in air bubbles trapped in ice cores, now allow such local records to be put into a global perspective. Studies still largely focus on the more recent glacial-interglacial cycle (the last 120 to $130 \mathrm{ky}$ ). Table 2.4 is a guide to terminology. 
Table 2.4: Guide to terminology used in palaeoclimate studies of the last 150,000 years.

\begin{tabular}{|c|c|}
\hline "Event", Stage & Estimated age (calendar years) \\
\hline Holocene & $\sim 10 \mathrm{ky} \mathrm{BP}$ to present \\
\hline Holocene maximum warming (also & Variable? \\
\hline referred to as "climatic optimum") & $\sim 4.5$ to $6 \mathrm{ky} \mathrm{BP}$ (Europe) 10 to $6 \mathrm{ky} \mathrm{BP}(\mathrm{SH})$ \\
\hline Last deglaciation & $\sim 18$ to $10 \mathrm{ky} \mathrm{BP}$ \\
\hline Termination 1 & $\sim 14 \mathrm{ky} \mathrm{BP}$ \\
\hline Younger Dryas & $\sim 12.7$ to $11.5 \mathrm{ky} \mathrm{BP}$ \\
\hline Antarctic cold reversal & 14 to $13 \mathrm{ky} \mathrm{BP}$ \\
\hline Bölling-Alleröd warm period & 14.5 to $13 \mathrm{ky} \mathrm{BP}$ (Europe) \\
\hline Last glacial & $\sim 74$ to $14 \mathrm{ky} \mathrm{BP}$ \\
\hline LGM (last glacial maximum) & $\sim 25$ to $18 \mathrm{ky} \mathrm{BP}$ \\
\hline Last interglacial peak & $\sim 124$ ky BP \\
\hline Termination 2 & $\sim 130 \mathrm{ky} \mathrm{BP}$ \\
\hline Eemian/MIS stage $5 \mathrm{e}$ & $\sim 128$ to $118 \mathrm{ky} \mathrm{BP}$ \\
\hline Heinrich events & Peaks of ice-rafted detritus in marine sediments, $\sim 7$ to $10 \mathrm{ky}$ time-scale. \\
\hline Dansgaard-Oeschger events & Warm-cold oscillations determined from ice cores with duration $\sim 2$ to $3 \mathrm{ky}$. \\
\hline Bond cycles & $\begin{array}{l}\text { A quasi-cycle during the last Ice Age whose period is equal to the time between } \\
\text { successive Heinrich events. }\end{array}$ \\
\hline Terminations & Periods of rapid deglaciation. \\
\hline
\end{tabular}

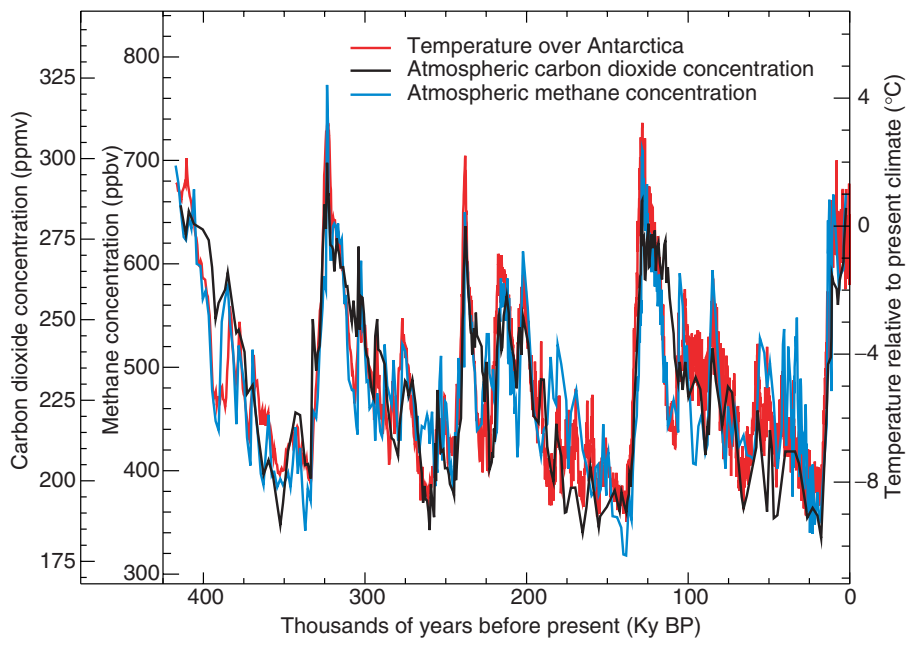

Figure 2.22: Variations of temperature, methane, and atmospheric carbon dioxide concentrations derived from air trapped within ice cores from Antarctica (adapted from Sowers and Bender, 1995; Blunier et al., 1997; Fischer et al., 1999; Petit et al., 1999).

Before reviewing important recent information about rapid changes, we briefly mention progress made on two aspects of the palaeoclimate record of relevance for future climate. The first deals with the relationship between modern and past terrestrial data and SSTs around the time of the Last Glacial Maximum (about $20 \mathrm{ky}$ $\mathrm{BP}$ ); this is important because of the use of glacial data to validate climate models. New results obtained since the SAR both from marine and terrestrial sources (reviewed in Chapter 8), agree on a tropical cooling of about $3^{\circ} \mathrm{C}$. The second concerns the greenhouse gas record $\left(\mathrm{CO}_{2}\right.$ and $\left.\mathrm{CH}_{4}\right)$ which has now been considerably extended due to the recent completion of drilling of the Vostok ice core in central East Antarctica. The strong relationship between $\mathrm{CO}_{2}$ and $\mathrm{CH}_{4}$ and Antarctic climate documented over the last climatic cycle has been remarkably confirmed over four climatic cycles, spanning about $420 \mathrm{ky}$ (Figure 2.22). Present day levels of these two important greenhouse gases appear unprecedented during this entire interval (Petit et al., 1999; and Figure 2.22). From a detailed study of the last three glacial terminations in the Vostok ice core, Fischer et al. (1999) conclude that $\mathrm{CO}_{2}$ increases started $600 \pm 400$ years after the Antarctic warming. However, considering the large uncertainty in the ages of the $\mathrm{CO}_{2}$ and ice $(1,000$ years or more if we consider the ice accumulation rate uncertainty), Petit $e t$ al. (1999) felt it premature to ascertain the sign of the phase relationship between $\mathrm{CO}_{2}$ and Antarctic temperature at the initiation of the terminations. In any event, $\mathrm{CO}_{2}$ changes parallel Antarctic temperature changes during deglaciations (Sowers and Bender, 1995; Blunier et al., 1997; Petit et al., 1999). This is consistent with a significant contribution of these greenhouse gases to the glacial-interglacial changes by amplifying the initial orbital forcing (Petit et al., 1999).

We also now have a better knowledge of climate variability over the last few climatic cycles as illustrated by selected palaeotemperature records back to about 400 ky (Figure 2.23). The amplitude of the glacial-interglacial temperature change was lower in tropical and equatorial regions (e.g., curve c) than in mid- and high latitudes (other curves). During glacial periods, the climate of the North Atlantic and adjacent regions (curves a and b) was more variable than in the Southern Hemisphere (curve d). Also (not shown), full glacial periods were characterised by very high fluxes of dust (seen in ice-core records and in continental and marine records). A combination of increased dust source area, stronger atmospheric transport and a weaker hydrological cycle (Yung et al., 1996; Mahowald et al., 1999; Petit et al., 1999) probably generated these changes. 


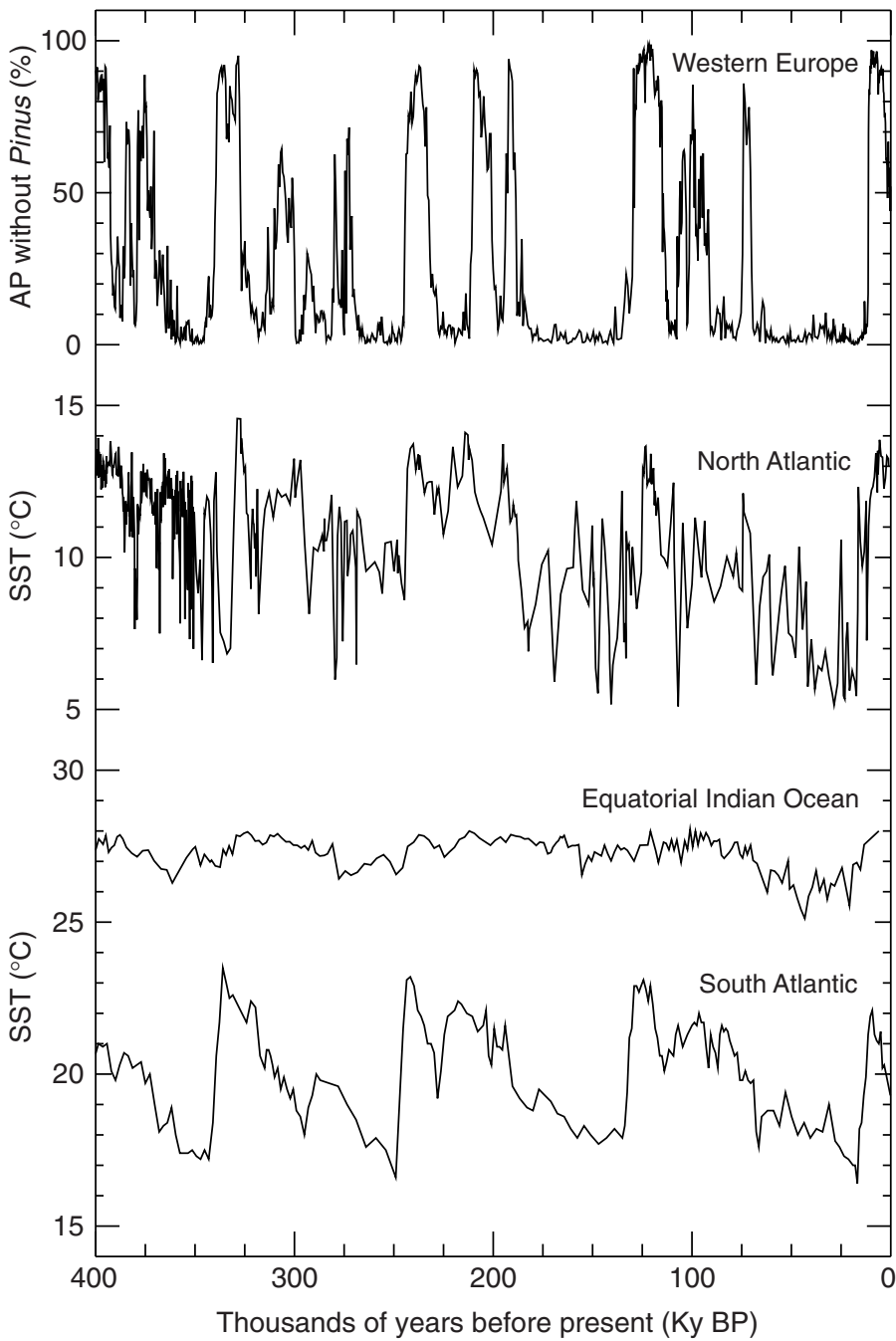

Figure 2.23: Time-series illustrating temperature variability over the last about 400 ky (updated from Rostek et al., 1993; Schneider et al., 1996; MacManus et al., 1999; Reille et al., 2000). The uppermost time-series describes the percentage of tree pollen that excludes pollen from pine tree species. The higher this percentage, the warmer was the climate.

\subsubsection{How Stable was the Holocene Climate?}

Ice core, marine and terrestrial records show that the Holocene was marked by a millennial-scale mode of variability (Meese $e t$ al., 1994; O'Brien et al., 1995; Bond et al., 1997; Yiou et al., 1997a,b). These variations affect both atmospheric (Mayewski et al., 1997) and oceanic (Bianchi and McCave, 1999) indicators. The occurrence of very large floods in the south-western United States also reflects substantial low-frequency variability (Ely et al., 1993). SSTs reconstructed from analyses of a sub-tropical, high sedimentation rate site off West Africa might indicate a remarkably high amplitude Holocene variability of 5 to $8^{\circ} \mathrm{C}$ on a time-scale about 1,500 years (deMenocal, 1998). During the later Holocene, New Zealand speleothems indicate a lowering of temperature after about $7 \mathrm{ky} \mathrm{BP}$, with small advances of the mountain glaciers in the Southern Alps near about 4 and $2.5 \mathrm{ky}$ BP (Salinger and McGlone, 1989). Speleothem records also indicate a temperature decrease of about $1.5^{\circ} \mathrm{C}$ some 2 to $3 \mathrm{ky}$ ago (Williams et al., 1999). These indications are consistent with cooler periods at these times shown by South African speleothems (Partridge, 1997). By contrast, temperature peaks appeared in China at about $7 \mathrm{ky} \mathrm{BP}$ and at 5.5 to $6 \mathrm{ky}$ BP (Wang and Gong, 2000).

Central Greenland ice cores and European lake isotopic records show correlated temperature variations within the Holocene, with a roughly 50\% higher amplitude at Summit Greenland, compared to Europe (Figure 2.24). The most prominent event in both records occurred about 8,200 years BP (Alley et al., 1997; von Grafenstein et al., 1998; Barber et al., 1999) when annual mean temperatures dropped by as much as $2^{\circ} \mathrm{C}$ in mid-Europe and the European alpine timberline fell by about $200 \mathrm{~m}$ (Wick and Tinner, 1999). The event may be related to a significant decrease of SST in the Norwegian Sea (KlitgaardKristensen et al., 1998). Lake records from the southern border of the Sahara indicate extremely dry conditions during this time, and probably also during other cool but less dramatic events of this kind (Street-Perrot and Perrot, 1990 ; Gasse and Van Campo, 1994). The about 8,200 year cooling may also have been worldwide (Stager and Mayewski, 1997), although abrupt early Holocene climate changes recorded in a North American lake are thought to reflect a different event (Hu et al., 1999). Thus cooling is indicated in the New Zealand Southern Alps, with small advances of the mountain glaciers at about 8,000 years BP (Salinger and McGlone, 1989).

Further abrupt climatic changes and reversals on millennial time-scales during the Holocene are documented from pollen and lake level records e.g., in Europe (Magny, 1995; Pazdur et al., 1995; Combourieu-Nebout et al., 1998), North Africa (Gasse et al., 1990; Lamb et al., 1995), North America (Jacobson et al., 1987; Overpeck et al., 1991) and Australia (Kershaw et al., 1991). Holocene lake level changes in Europe have been shown to correlate (Magny, 1995; Yu and Harrisson, 1996) with millennial-scale changes in North Atlantic SST and salinity records (Duplessy et al., 1992; Gasse and van Campo, 1994), suggesting a possible link between millennial thermohaline circulation variability and atmospheric circulation over Europe.

The early Holocene was generally warmer than the 20th century but the period of maximum warmth depends on the region considered. It is seen at the beginning of the Holocene (about 11 to $10 \mathrm{ky} \mathrm{BP}$ ) in most ice cores from high latitude regions e.g., northwest Canada (Ritchie et al., 1989), central Antarctica (Ciais et al., 1992; Masson et al., 2000) and in some tropical ice cores such as Huascaran in Peru (Thompson et al., 1995). It is also seen during the early Holocene in the Guliya ice core in China (Thompson $e t$ al., 1998) but not in two other Chinese cores (Dunde, Thompson et al., 1989; and Dasuopu, to be published). North Africa experienced a greatly expanded monsoon in the early and mid-Holocene, starting at 11 ky BP (Petit-Maire and Guo, 1996), and declining thereafter. In New Zealand the warmest conditions occurred between about 10 to $8 \mathrm{ky} \mathrm{BP}$, when there was a more complete forest cover than at any other time. Glacial activity was at a minimal level in the Southern Alps and speleothem analyses indicate temperatures were about $2^{\circ} \mathrm{C}$ warmer than present (Salinger and McGlone, 1989; Williams et al., 1999). 


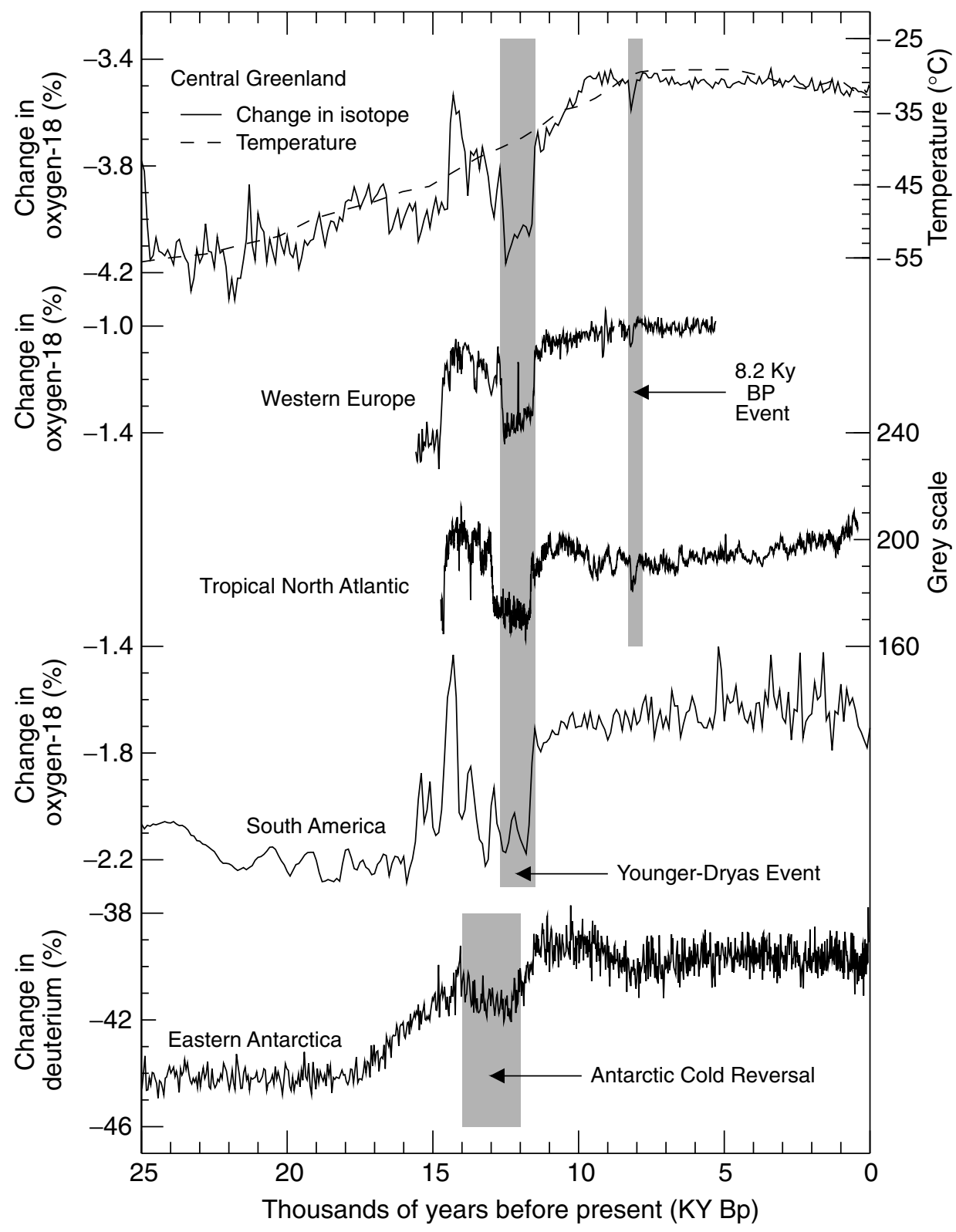

Figure 2.24: Records of climate variability during the Holocene and the last climatic transition, including the 8.2 ky BP event (adapted from Johnsen et al., 1992; Hughen et al., 1996; Thompson et al., 1998; von Grafenstein et al., 1999; Jouzel et al., 2001). The shaded areas show the 8.2 ky BP event, the Younger Dryas event and the Antarctic Cold Reversal. The grey scale used in the Tropical North Atlantic record is a measure of sea surface temperature, deduced from the colour of plankton rich layers within an ocean sediment core.

By contrast, central Greenland (Dahl-Jensen et al., 1998), and regions downstream of the Laurentide ice sheet, did not warm up until after $8 \mathrm{ky}$ BP (including Europe: COHMAP Members, 1988; eastern North America: Webb et al., 1993). The East Asian monsoon did not commence its expanded phase until after 8 ky BP (Sun and Chen, 1991; Harrison et al., 1996; Yu and Qin, 1997; Ren and Zhang, 1998). A more detailed description of the climate at $6 \mathrm{ky} \mathrm{BP}$ as well as of the mechanisms involved is given in Chapter 8. Long-term climate changes during the Holocene are consistent with the effects of orbital forcing, modified by the persistence of the Laurentide ice sheet (which finally disappeared around $6 \mathrm{ky} \mathrm{BP}$ ).

Seasonal to interannual climate variability may also have varied its character during the Holocene. This is a period for which a variety of palaeo-proxies and archaeological investigations (e.g., Sandweiss et al., 1996; Rodbell et al., 1999) provide evidence for past variations in the strength and frequency of ENSO extremes. A 16-year long time-series of temperature and hydrological balance from a coral dated at 5,370 years BP from the Great Barrier Reef (Gagan et al., 1998) implies that ENSO, or its teleconnections to Australia, were substantially different in the mid-Holocene than today. Mid-Holocene changes in the spectrum of ENSO variability have also been implicated by sedimentary palaeoclimatic records in Australasia (McGlone et al., 1992; Shulmeister and Lees, 1995) and South America (Sandweiss et al., 1996; Rodbell et al., 1999).

To sum up, the Holocene shows both long-term trends (including changes in the nature of ENSO) and millennial time- 
scale variability although the amplitude of the variability is small compared with that characteristic of Ice Ages. As more detailed information becomes available, the timing of the Holocene maximum warmth is seen to differ across the globe. There appears to be a south to north pattern, with southern latitudes displaying maximum warming a few millennia before the Northern Hemisphere regions. Interestingly, the Holocene appears by far the longest warm "stable" period (as far as seen from the Antarctic climate record) over the last $400 \mathrm{ky}$, with profound implications for the development of civilisation (Petit $e t$ al., 1999).

\subsubsection{How Fast did Climate Change during the Glacial Period?}

The most extreme manifestation of climate change in the geological record is the transition from full glacial to full inter-glacial conditions. During the most recent glacial cycle, peak glacial conditions prevailed from about 25 to $18 \mathrm{ky} \mathrm{BP}$. Temperatures close to those of today were restored by approximately $10 \mathrm{ky}$ BP. However, warming was not continuous. The deglaciation was accomplished in two main stages, with a return to colder conditions (Younger Dryas/Antarctic Cold Reversal) or, at the least, a pause in the deglaciation.

The central Greenland ice core record (GRIP and GISP2) has a near annual resolution across the entire glacial to Holocene transition, and reveals episodes of very rapid change. The return to the cold conditions of the Younger Dryas from the incipient inter-glacial warming 13,000 years ago took place within a few decades or less (Alley et al., 1993). The warming phase, that took place about 11,500 years ago, at the end of the Younger Dryas was also very abrupt and central Greenland temperatures increased by $7^{\circ} \mathrm{C}$ or more in a few decades (Johnsen et al., 1992; Grootes et al., 1993; Severinghaus et al., 1998). Most of the changes in windblown materials and some other climate indicators were accomplished in a few years (Alley et al., 1993; Taylor et al., 1993; Hammer et al., 1997). Broad regions of the Earth experienced almost synchronous changes over periods of 0 to 30 years (Severinghaus et al., 1998), and changes were very abrupt in at least some regions (Bard et al., 1987), e.g. requiring as little as 10 years off Venezuela (Hughen et al., 1996). Fluctuations in ice conductivity indicate that atmospheric circulation was reorganised extremely rapidly (Taylor et al., 1993). A similar, correlated sequence of abrupt deglacial events also occurred in the tropical and temperate North Atlantic (Bard et al., 1987; Hughen et al., 1996) and in Western Europe (von Grafenstein et al., 1999).

A Younger-Dryas type event is also recorded in a Bolivian ice core (Thompson et al., 1998; Sajama, South America in Figure 2.24) and in a major advance of a mountain glacier in the Southern Alps of New Zealand (Denton and Hendy, 1994). However there is recent evidence against a significant Younger Dryas cooling here (Singer et al., 1998) and at other sites of the Southern Hemisphere (reviewed by Alley and Clarke, 1999). Instead, the Antarctic (and Southern Ocean) climate was characterised by a less pronounced cooling (the Antarctic Cold Reversal: Jouzel et al., 1987) which preceded the Younger Dryas by more than 1 ky (Jouzel et al., 1995; Sowers and Bender, 1995; Blunier et al., 1997). Curiously, one coastal site in Antarctica,
Taylor Dome (Steig et al., 1998) exhibited cooling in phase with the North Atlantic. Recent series obtained at Law Dome, another coastal site of East Antarctica, show instead a cold reversal preceding the Younger Dryas as in other Antarctic records. This suggests that the Taylor Dome record is of limited geographical significance but it also suggests that there is more to be discovered about this cooling event in the Southern Hemisphere.

The inception of deglacial warming about $14.5 \mathrm{ky} \mathrm{BP}$ was also very rapid, leading to the Bölling-Alleröd warm period in less than twenty years (Severinghaus and Brook, 1999). Almost synchronously, major vegetation changes occurred in Europe and North America with a rise in African lake levels (Gasse and van Campo, 1994). There was also a pronounced warming of the North Atlantic and North Pacific (Koç and Janssen, 1994; Sarnthein et al., 1994; Kotilainen and Shackleton, 1995; Thunnell and Mortyn, 1995; Wansaard, 1996; Watts et al., 1996; Webb et al., 1998).

The rate of temperature change during the recovery phase from the last glacial maximum provides a benchmark against which to assess warming rates in the late 20th century. Available data indicate an average warming rate of about $2^{\circ} \mathrm{C} /$ millennium between about 20 and $10 \mathrm{ky} \mathrm{BP}$ in Greenland, with lower rates for other regions. Speleothem data from New Zealand, and positions of mountain glacier moraine termini suggest warming rates of $2^{\circ} \mathrm{C} /$ millennium from 15 to $13 \mathrm{ky} \mathrm{BP}$ (Salinger and McGlone, 1989). Speleothem data for South Africa suggest a warming rate of $1.5^{\circ} \mathrm{C} /$ millennium (Partridge, 1997) over the same time period. On the other hand, very rapid warming at the start of the Bölling-Alleröd period, or at the end of the Younger Dryas may have occurred at rates as large as $10^{\circ} \mathrm{C} / 50$ years for a significant part of the Northern Hemisphere.

Oxygen isotope measurements in Greenland ice cores demonstrate that a series of rapid warm and cold oscillations called Dansgaard-Oeschger events punctuated the last glaciation (Figure 2.23, see North Atlantic SST panel, and Dansgaard et al., 1993). Associated temperature changes may be as high as $16^{\circ} \mathrm{C}$ (Lang et al., 1999). These oscillations are correlated with SST variations in several North Atlantic deep-sea cores (Bond et al., 1993). There was clearly a close relation between these ice core temperature cycles and another prominent feature of North Atlantic deep-sea core records, the Heinrich events. Heinrich events occurred every 7,000 to 10,000 years during times of sea surface cooling in the form of brief, exceptionally large, discharges of icebergs from the Laurentide and European ice sheets which left conspicuous layers of detrital rocks in deep-sea sediments. Accompanying the Heinrich events were large decreases in the oxygen isotope ratio of planktonic foraminifera, providing evidence of lowered surface salinity probably caused by melting of drifting ice (Bond et al., 1993). Heinrich events appear at the end of a series of saw-toothed shaped, near millennial temperature cycles. Each set of millennial cycles is known as a Bond cycle. Each cycle was characterised by a succession of progressively cooler relatively warm periods (interstadials) during the Ice Age period. Each cooling trend ended with a very rapid, high amplitude, warming and a massive discharge of icebergs. The impact of these Heinrich events on the climate system extended far beyond the northern North Atlantic. At the 
time of major iceberg discharges, strong vegetation changes have been detected in Florida (Grimm et al., 1993; Watts et al., 1996), oceanic changes occurred in the Santa Barbara Basin off California (Behl and Kennet, 1996) and changes in loess grainsize, associated with atmospheric circulation changes, have been detected in China (Porter and An, 1995; Ding et al., 1998).

Deep-sea cores also show the presence of ice rafting cycles in the intervals between Heinrich events (Bond and Lotti, 1995). Their duration varies between 2,000 and 3,000 years and they closely coincide with the Dansgaard-Oeschger events of the last glaciation. A study of the ice-rafted material suggests that, coincident with the Dansgaard-Oeschger cooling, ice within the Icelandic ice cap and within or near the Gulf of Saint Lawrence underwent nearly synchronous increases in rates of calving. The Heinrich events reflect a slower rhythm of iceberg discharges, probably from the Hudson Strait.

Air temperature, SST and salinity variations in the North Atlantic are associated with major changes in the thermohaline circulation. A core from the margin of the Faeroe-Shetland channel covering the last glacial period reveals numerous oscillations in benthic and planktonic foraminifera, oxygen isotopes and ice-rafted detritus (Rasmussen et al., 1996a). These oscillations correlate with the Dansgaard-Oeschger cycles, showing a close relationship between the deep ocean circulation and the abrupt climatic changes of the last glaciation. Warm episodes were associated with higher SST and the presence of oceanic convection in the Norwegian Greenland Sea. Cold episodes were associated with low SST and salinity and no convection in the Norwegian Greenland Sea (Rasmussen et al., 1996b). Cores from the mid-latitudes of the North Atlantic show that the iceberg discharges in Heinrich events resulted in both low salinity and a reduced thermohaline circulation (Cortijo et al., 1997; Vidal et al., 1997).

These rapid climatic events of the last glacial period, best documented in Greenland and the North Atlantic, have smoothed counterparts in Antarctica (Bender et al., 1994; Jouzel et al., 1994). A peak in the concentration of the isotope beryllium-10 in ice cores (Yiou et al., 1997a), changes in the concentration of atmospheric methane (Blunier et al., 1998) and in the isotopic content of oxygen in ice cores (Bender et al., 1999) indicate links between the Northern and Southern Hemisphere climates over this period. Large Greenland warming events around 36 and 45 ky BP lag their Antarctic counterparts by more than 1,000 years. This argues against coupling between northern and southern polar regions via the atmosphere but favours a connection via the ocean (Blunier et al., 1998).

New evidence suggests that the North Atlantic has three modes of operation. These are: deep-water sinking in the GIN (Greenland-Iceland-Norwegian) Seas and the Labrador Sea, deep-water sinking in the North Atlantic or in the Labrador Sea but not the GIN Seas (Duplessy et al., 1991; Labeyrie et al., 1992) in the cold phase of Dansgaard-Oeschger events and at glacial maximum, and little deep-water sinking in the GIN or Labrador Seas (Heinrich events) (Sarnthein et al., 1994; Vidal et al., 1997, 1998; Alley and Clark, 1999; Stocker, 2000). The first type corresponds to modern, warm conditions. Shut-down of convection in the GIN Seas has a strong effect on the high latitude Atlantic atmosphere and on areas that respond to it such as the monsoon regions of north Africa (Street-Perrott and Perrott, 1990). However, cross-equatorial Atlantic ocean surface transport that supplies the water for the formation of the Labrador Sea deep-water continues to remove heat from the South Atlantic under these conditions. The additional "Heinrich shut-down" of the North Atlantic and Labrador Sea deep-water formation allows this heat to remain in the South Atlantic (Crowley, 1992), and may increase deep-water formation either south of the area affected by melt-water injection (Vidal et al., 1997, 1998) or in the Southern Ocean (Broecker, 1998). This reorganisation could cause warming of regions of the South Atlantic and downwind of it (Charles et al., 1996; Blunier et al., 1998) through a seesaw relationship with the North Atlantic. However, the behaviour of Taylor Dome in the Antarctic and several other southern sites (see above) which exhibit cooling in phase with the North Atlantic argue for an additional atmospheric link to some southern regions.

\subsubsection{How Stable was the Previous Inter-glacial?}

Assessment of present day climate variability benefits from comparison with conditions during inter-glacial periods that are broadly comparable with the Holocene. The most recent such inter-glacial began about $130 \mathrm{ky}$ BP, lasting until about $71 \mathrm{ky} \mathrm{BP}$ when final deterioration into the last glacial began. However, only the Eemian interval, from about 130 to $120 \mathrm{ky} \mathrm{BP}$ corresponds to a climate as warm as, or warmer than, today e.g., Figure 2.22.

The study of atmospheric composition changes has revealed that rapid changes of properties observed for the lowest part of the Greenland cores (GRIP Project Members, 1993; Grootes et al., 1993) do not correspond to climatic instabilities during the last inter-glacial (Chappellaz et al., 1997). The extent to which climate was more or less stable during this last inter-glacial than during the Holocene is unclear. Early evidence from marine cores (CLIMAP, 1984; McManus et al., 1994) and other ice cores (Jouzel et al., 1993) indicated that the Eemian climate was rather stable. A high resolution North Atlantic record shows a lack of substantial fluctuations during the last inter-glacial but also indicates that the Eemian began and ended with abrupt changes in deep-water flow, with transitions occurring in less than 400 years (Adkins et al., 1997). In New Zealand, there were at least three periods of milder climate than typical of the Holocene during the last inter-glacial (Salinger and McGlone, 1989). Study of an Indonesian fossil coral indicates that ENSO was robust during the last glacial period (Hughen et al., 1999).

A rapid and significant cooling event within the Eemian period has been detected from European continental pollen records (Cheddadi et al., 1998). High winter temperatures prevailed for 3.5 to $4 \mathrm{ky}$ after the deglaciation, but then dropped by as much as 6 to $10^{\circ} \mathrm{C}$ in mid-Eemian times, accompanied by a decrease in precipitation. In Antarctica, the last inter-glacial is also marked by a short (about $5 \mathrm{ky}$ ) period of warm temperatures followed by a slightly cooler interval (Petit et al., 1999). Further evidence for Eemian climate variability is found in marine records. An invasion of cold, low salinity water in the Norwegian 
Sea (Cortijo et al., 1994) was probably associated with a reduction in warm water transport by the North Atlantic Drift and the thermohaline circulation. Overall, the last inter-glacial appears, at least during its first part, warmer than present day climates by at least $2^{\circ} \mathrm{C}$ in many sites, i.e., comparable to anthropogenic warming expected by the year 2100. However, the geographical coverage of reliable and well-dated temperature time-series is too sparse to provide a global estimate.

\subsubsection{Summary}

Current evidence indicates that very rapid and large temperature changes, generally associated with changes in oceanic and atmospheric circulation, occurred during the last glacial period and during the last deglaciation, particularly in higher latitudes of the Northern Hemisphere. During the warming phases, and the Younger Dryas pause, there is evidence of almost worldwide, nearly synchronous events. However, as with the Holocene maximum warming and the Last Glacial Maximum, these changes appear to have occurred asynchronously between the Northern Hemisphere and at least part of the Southern Hemisphere. During the Holocene smaller but locally quite large climate changes occurred sporadically; similar changes may have occurred in the last inter-glacial. Evidence is increasing, therefore, that a rapid reorganisation of atmospheric and ocean circulation (time-scales of several decades or more) can occur during inter-glacial periods without human interference.

\subsection{How have Precipitation and Atmospheric Moisture Changed?}

\subsubsection{Background}

Increasing global surface temperatures are very likely to lead to changes in precipitation and atmospheric moisture, because of changes in atmospheric circulation, a more active hydrological cycle, and increases in the water holding capacity throughout the atmosphere. Atmospheric water vapour is also a climatically critical greenhouse gas, and an important chemical constituent in the troposphere and stratosphere.

Precipitation measurement and analysis are made more difficult by accompanying natural phenomena such as wind and the use of different instruments and techniques (Arkin and Ardanuy, 1989). Because of the substantial under-catch of precipitation gauges during solid precipitation, frequent light rainfall events, or windy conditions, the true precipitation in the Arctic is more than $50 \%$ higher than the measured values (Førland and Hanssen-Bauer, 2000). Gauge under-catch is substantially less in warmer, less windy climates with heavier rainfall. New, satellite-derived precipitation estimates offer the prospect of near-global climatologies covering at least one or two decades, but multi-decadal global changes cannot be estimated with high confidence.

For all these reasons it is useful to compare changes in many of the moisture-related variables, such as streamflow and soil moisture, with precipitation to help validate long-term precipitation trends.

\subsubsection{Changes in Precipitation and Related Variables}

\subsubsection{Land}

Overall, global land precipitation has increased by about $2 \%$ since the beginning of the 20th century (Jones and Hulme, 1996; Hulme et al., 1998). The increase is statistically significant but has been neither spatially nor temporally uniform (Karl and Knight, 1998; Doherty et al., 1999). Dai et al. (1997b) found a global secular increase in precipitation separate from ENSO and other modes of variability. Data from over 20,000 stations contributed to the changes since 1900 shown in Figure 2.25. The effects of changes in windshields on winter precipitation measurements were taken into account for most mid- and high latitude observations. Dai et al. (1997b) indicated that instrumental discontinuities are unlikely to significantly impact other observations.

\section{Mid- and high latitudes}

Over the 20th century, annual zonally averaged precipitation increased by between 7 to $12 \%$ for the zones $30^{\circ} \mathrm{N}$ to $85^{\circ} \mathrm{N}$ and by about $2 \%$ between $0^{\circ} \mathrm{S}$ to $55^{\circ} \mathrm{S}$ (Figure 2.25(ii)). The increase in the Northern Hemisphere is likely to be slightly biased because adjustments have not been made for the increasing fraction of precipitation falling in liquid as opposed to frozen form. The exact rate of precipitation increase depends on the method of calculating the changes, but the bias is expected to be small because the amount of annual precipitation affected by this trend is generally only about a few per cent. Nevertheless, this unsteady, but highly statistically significant trend toward more precipitation in many of these regions is continuing. For example, in 1998 the Northern Hemisphere high latitudes $\left(55^{\circ} \mathrm{N}\right.$ and higher) had their wettest year on record and the mid-latitudes have had precipitation totals exceeding the 1961 to 1990 mean every year since 1995.

Figure 2.25(i) shows mostly increasing precipitation in the Northern Hemisphere mid- and high latitudes, especially during the autumn and winter, but these increases vary both spatially and temporally. For example, precipitation over the United States has increased by between 5 to $10 \%$ since 1900 (Figure 2.25(ii)) but this increase has been interrupted by multi-year anomalies such as the drought years of the 1930s and early 1950s (Karl and Knight, 1998; Groisman et al., 1999). The increase is most pronounced during the warm seasons. Using data selected to be relatively free of anthropogenic influences such as ground water pumpage or land use changes, several recent analyses (Lettenmaier et al., 1999; Lins and Slack, 1999; Groisman et al., 2001) have detected increases in streamflow across much of the contiguous United States, confirming the general tendency to increasing precipitation. However, Lins and Michaels (1994) found in some regions that increased streamflow did not relate well to an increase in rainfall. This has been further evaluated by Groisman et al. (2001) who show that changes in snow-cover extent also influence the timing and volume of streamflow.

Regionally, Mekis and Hogg (1999) showed that precipitation in Canada has increased by an average of more than $10 \%$ over the 20th century. Zhang et al. (2000) report an increase in Canadian heavy snowfall amounts north of $55^{\circ} \mathrm{N}$ and Akinremi et al. (1999) found rainfall significantly increasing in the Canadian 
prairies from 1956 to 1995 . Multi-decadal streamflow data in Canada are not extensive, but there are no apparent inconsistencies between observed changes in streamflow or precipitation (Zhang et al., 2000).

Over the last 50 years there has been a slight decrease in annual precipitation over China (Zhai et al., 1999a), which is supported by a significant (5\% confidence level) decrease in the number of rainy days (3.9\%/decade; Figure 2.25 (ii)). In contrast, the area affected by the upper $10 \%$ of heaviest precipitation has significantly increased. Zhai et al. (1999b) show a significant increase in precipitation over the middle and lower reaches of the Yangtze River and west China during the latter part of the 20th century, while also detecting a declining trend in precipitation over northern China.

There have been marked increases in precipitation in the latter part of the 20th century over northern Europe, with a general decrease southward to the Mediterranean (Schönwiese and Rapp, 1997; Figure 2.25(i)). Dry wintertime conditions over southern Europe and the Mediterranean (Piervitali et al., 1998; Romero et al., 1998) and wetter than normal conditions over many parts of northern Europe and Scandinavia (Hanssen-Bauer and Førland, 2000) are linked to strong positive values of the North Atlantic Oscillation, with more anticyclonic conditions over southern Europe and stronger westerlies over northern Europe (Section 2.6.5).

Based on recent research (Bogdanova and Mescherskaya, 1998; Groisman and Rankova, 2001), the precipitation trend for the last century over the former USSR as reported by the SAR was slightly overestimated. The new results indicate that precipitation has increased since 1891 by about $5 \%$ west of $90^{\circ} \mathrm{E}$ for both warm and cold seasons. Georgievsky et al. (1996) also noted increases in precipitation over the last several decades over western Russia, accompanied by increases in streamflow and a rise in the level of the Caspian Sea. In eastern Russia a negative precipitation trend since 1945 is embedded in the century-long positive precipitation trend (Figure 2.25(ii); Gruza et al., 1999). Soil moisture data for large regions of Eurasia (Robock et al., 2000) show large upward trends. The rate of increase is more than $1 \mathrm{~cm} /$ decade in the available soil moisture in the top $1 \mathrm{~m}$ of soil. These large positive trends occur simultaneously with positive trends in temperature that would normally reduce soil moisture. Increases in precipitation (and cloud cover, Section 2.5.5) are believed to have more than compensated for the increased losses due to evapotranspiration.

An analysis of rainfall data since 1910 by Haylock and Nicholls (2000) reveals a large decrease in total precipitation and related rain days in south-western Australia. Annual total rainfall has increased over much of Australia with significant increases of 15 to $20 \%$ in large areas. The increase in total rainfall has been accompanied by a significant $10 \%$ rise in the average number of rain days over Australia (Hennessy et al., 1999). Elsewhere in the Southern Hemisphere, a long-term increase in precipitation in Argentina has been observed for the period 1900 to 1998 (Figure 2.25(i); Dai et al., 1997b).

\section{Tropics and sub-tropics}

The increase in precipitation in the mid- and high latitudes contrasts with decreases in the northern sub-tropics (with marginal statistical significance) which were largely responsible for the decade-long reduction in global land precipitation from the mid-1980s through the mid-1990s. Since the SAR, record low precipitation has been observed in equatorial regions, while the sub-tropics have recovered from their anomalously low values of the 1980s.

Regionally positive but non-significant trends have occurred in the rainy season rainfall in north-east Brazil and northern Amazonia (Marengo et al., 1998). River data from northern Amazonia indicate wetter periods in the mid-1970s, and in 1990, as well as drier periods between 1980 to 1990 , consistent with rainfall anomalies. Northern Amazonian rainfall appears to be modulated by multi-decadal climate variations.

There is little evidence for a long-term trend in Indian monsoonal rainfall but there are multi-decadal variations (Kumar et al., 1999a,b). From 1906 to about 1960, monsoonal rainfall increased then decreased through 1974 and has increased since (see Section 2.6). In central America for much of the period from the early 1940s to present, western Mexico has experienced an increasingly erratic monsoonal rainfall (Douglas and Englehart, 1999).

Since 1976, increases in precipitation in the South Pacific have occurred to the north-east of the South Pacific Convergence Zone (SPCZ) while decreases have occurred to its south-west (Salinger et al., 1996). Manton et al. (2001) found significant decreases in rain days since 1961 throughout Southeast Asia and western and central South Pacific, but increases in the north of French Polynesia and Fiji.

Streamflow data for major rivers in south-eastern South America for the period 1901 to 1995 show that streamflow has increased since the mid-1960s, and was accompanied by a significant decrease in the amplitude of the seasonal cycle of most of those rivers (Garcia and Vargas, 1998; Genta et al., 1998). Figure 2.25(i) shows increases in precipitation since 1900 along the South American eastern coastal areas, with less extensive increases since 1976.

There has been a pattern of continued aridity since the late 1960s throughout North Africa south of the Sahara. This pattern is most persistent in the western region. The driest period was in the 1980s with some recovery occurring during the 1990s, particularly in the easternmost sectors where rainfall in some years was near or just above the long-term mean (Nicholson et al., 2000). Southern Africa was relatively moist in the $1950 \mathrm{~s}$ and 1970s (Nicholson et al., 2000); but Hulme (1996) found significant decreases in precipitation being observed since the late 1970s. Early 2000, however, has seen flood-producing rains in the eastern part of southern Africa.

\subsubsection{Palaeo-drought}

Palaeoclimate proxy evidence (tree rings, lake sediments and pollen evidence) has been used to estimate variability in drought and precipitation patterns in past centuries. Much of the recent research has emphasised the North American region (e.g., Cook et al., 1999a), where a key conclusion is that the range of regional drought variability observed during the 20th century may not be representative of the larger range of 
(i)

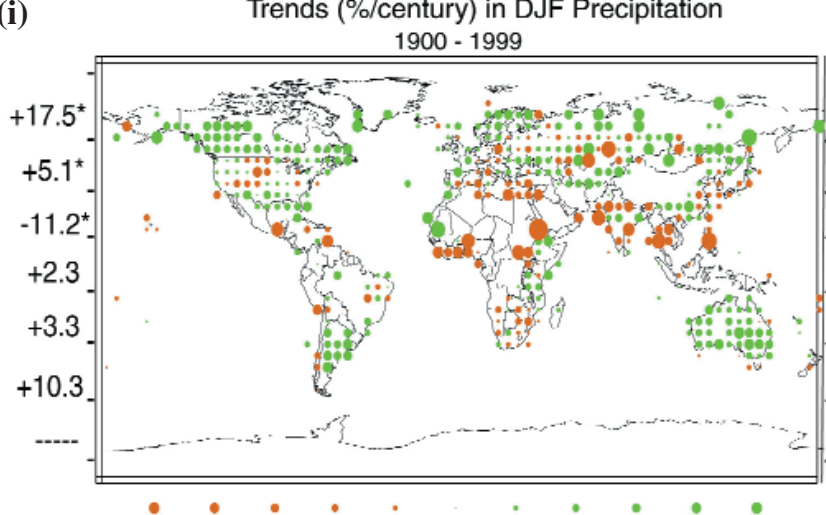

$-50 \%-40 \%-30 \%-20 \%-10 \% \quad 0 \% \quad 10 \% 20 \% \quad 30 \% \quad 40 \% \quad 50 \%$

Trends (\%/century) in JJA Precipitation

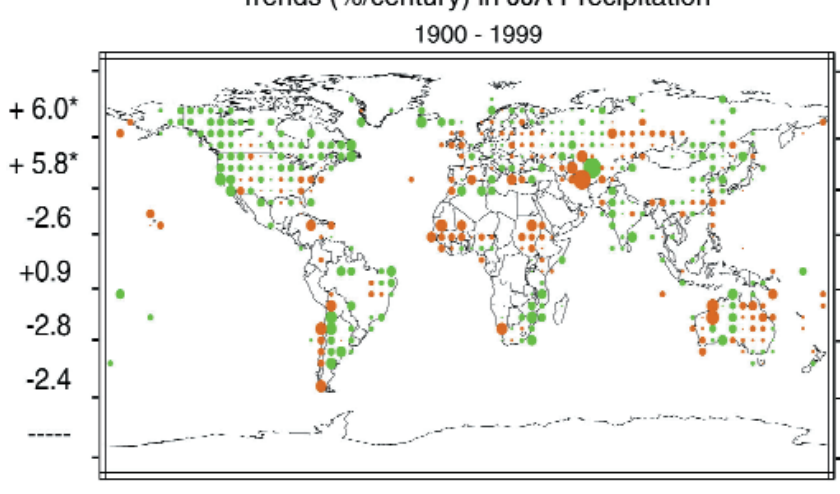

$-50 \%-40 \%-30 \%-20 \%-10 \% \quad 0 \% \quad 10 \% \quad 20 \% \quad 30 \% \quad 40 \% 50 \%$

(ii)

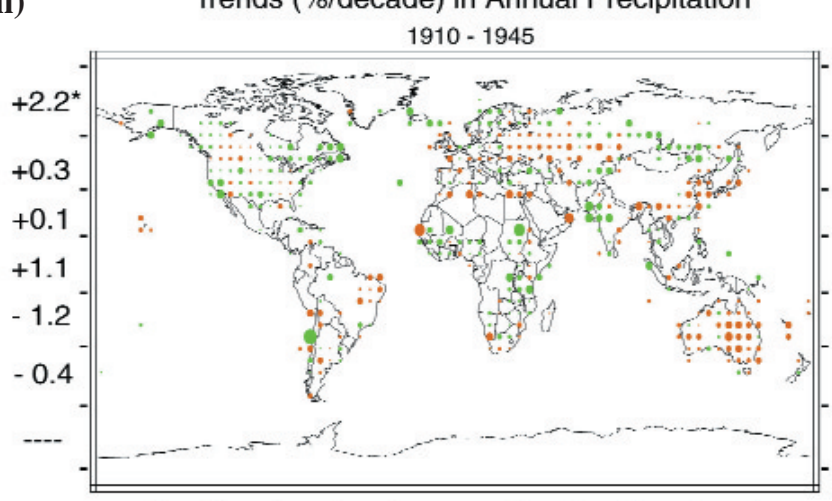

$-20 \%-16 \%-12 \%-8 \% \quad-4 \% \quad 0 \% \quad 4 \% \quad 8 \% \quad 12 \% \quad \frac{0}{6} \% \quad 20 \%$

Trends (\%/decade) in Annual Precipitation 1976 - 1999

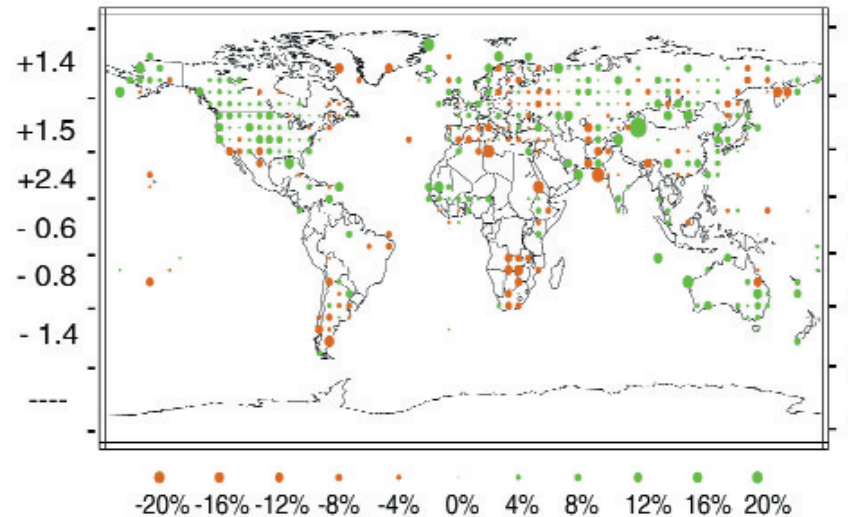

Trends (\%/century) in MAM Precipitation

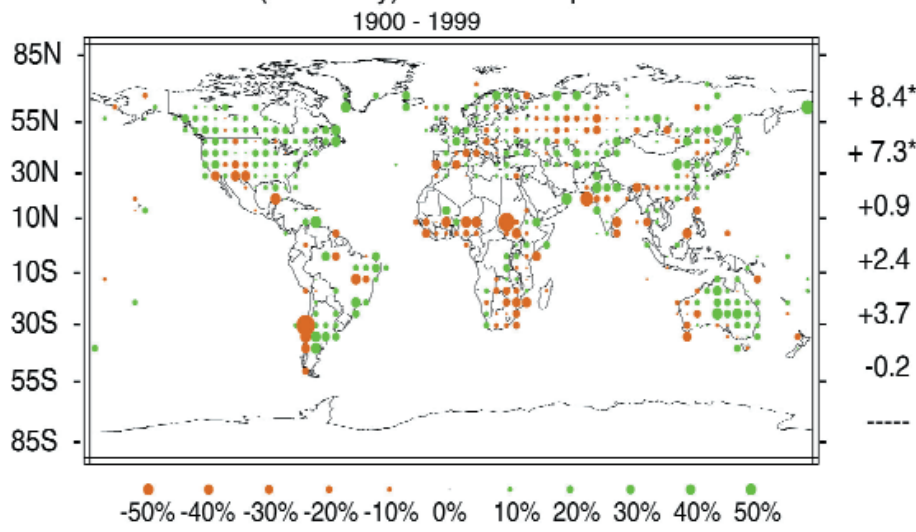

Trends (\%/century) in SON Precipitation

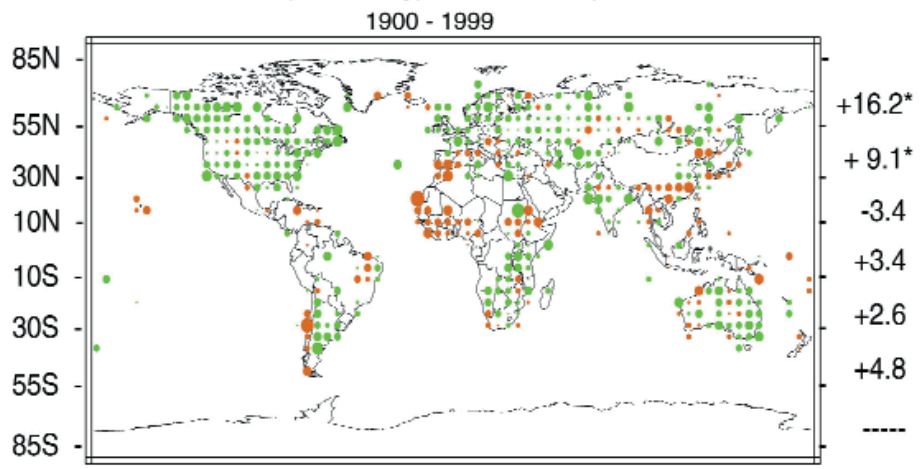

$-50 \%-40 \%-30 \%-20 \%-10 \% \quad 0 \% \quad 10 \% \quad 20 \% \quad 30 \% \quad \stackrel{\circ}{40} \% \quad 50 \%$

Trends (\%/decade) in Annual Precipitation

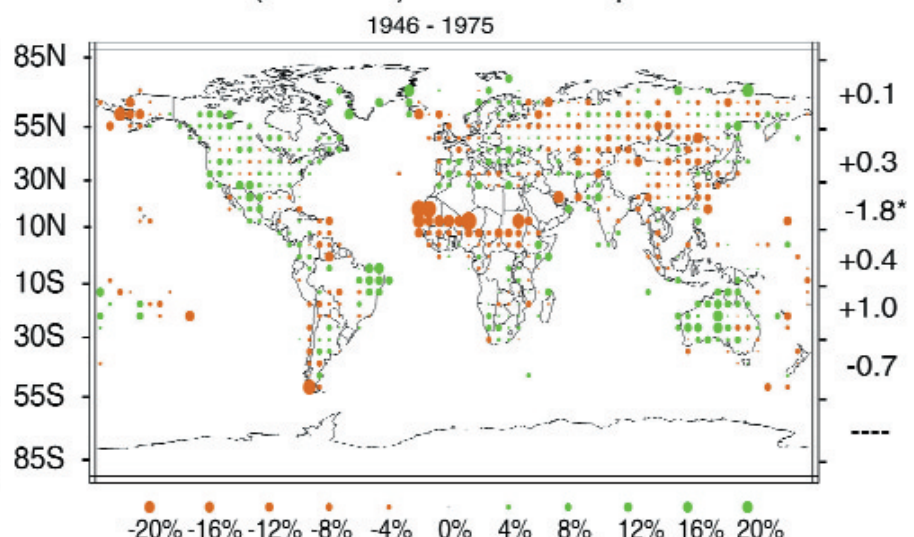

Trend (\%/century) in Annual Precipitation $1900-1999$

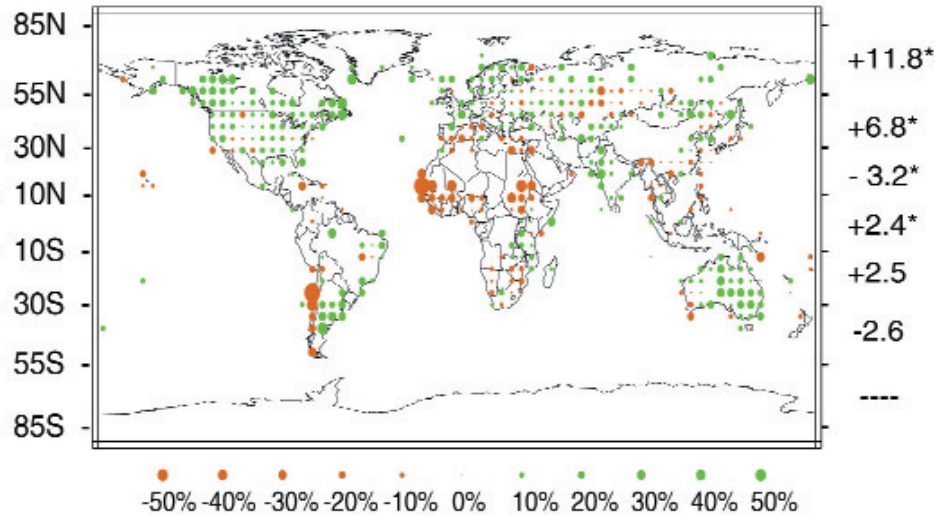


Figure 2.25(i): Trends for 1900 to 1999 for the four seasons. Precipitation trends are represented by the area of the circle with green representing increases and brown representing decreases. Annual and seasonal trends were calculated using the following method. Precipitation anomalies in physical units were calculated for each station based on 1961 to 1990 normals and averaged into $5^{\circ} \times 5^{\circ}$ grid cells on a monthly basis. The 1961 to 1990 monthly mean precipitation for each grid cell was added to the monthly anomalies and the resulting grid cell values summed into annual and seasonal totals. This series was converted into percentages of normal precipitation, and trends calculated from the percentages. Average trends within six latitude bands $\left(85^{\circ} \mathrm{N}\right.$ to $55^{\circ} \mathrm{N}, 55^{\circ} \mathrm{N}$ to $30^{\circ} \mathrm{N}, 30^{\circ} \mathrm{N}$ to $10^{\circ} \mathrm{N}, 10^{\circ} \mathrm{N}$ to $10^{\circ} \mathrm{S}, 10^{\circ} \mathrm{S}$ to $30^{\circ} \mathrm{S}, 30^{\circ} \mathrm{S}$ to $55^{\circ} \mathrm{S}$ ) are shown in the legend of each map. The 1961 to 1990 monthly mean precipitation for the latitude band was added to the anomaly time-series and the resulting values totalled across all months within the season or year. The significance of each trend (based on a 5\% level) was determined using a t-test and a non-parametric test statistic. Trends found to be significant under both tests are indicated with an asterisk.

Figure 2.25(ii): As in Figure 2.25(i) except annual trends for the three periods of changing rates of global temperature (shown in Figure 2.9) and the full period, 1900 to 1999 . During the 100 -year periods, calculation of grid cell trends required at least $66 \%$ of the years without missing data and at least three years of data within each decade except the first and last. During the shorter periods, calculation of grid cell trends required at least $75 \%$ of the years without missing data. Stations with more than one sixth of their data missing during the normal period and grid cells with more than one season or year without any measurable precipitation during the normal period were excluded from consideration. Due to the nature of trend estimation, it is not possible to cumulatively sum the trends for each of the three periods to obtain an overall trend. drought evident in past centuries (Laird et al., 1996; Woodhouse and Overpeck, 1998). Hughes and Graumlich (1996) and Hughes and Funkhouser (1999) provide evidence of multi-decadal mega-droughts in the western Great Basin of North America in the 10th to 14th centuries. Nonetheless, the 20th century dust bowl still stands out as the most extreme drought of the past several centuries, the period when North American continental scale reconstruction is possible. Swetnam and Betancourt (1998) argue that recent spring wetness in the American south-west is greater than that observed in at least the last thousand years. Evidence of significant changes in regional hydroclimatic patterns is not limited, however, to North America. Stine (1994) argues that enhanced drought conditions occurred synchronously in South America. Ice accumulation at Quelccaya in the Andes, and on the Dunde Ice Cap on the Tibetan Plateau (Thompson, 1996) was slower in the first half of the last millennium than the last 500 years, but 500-year averages are not easily related to the palaeo-temperature data (Figure 2.21). Pollen evidence indicates significant changes in summer rainfall patterns in China in the earlier centuries of the past millennium (Ren, 1998). The relationship between such past changes in regional drought and precipitation patterns, and large-scale atmospheric circulation patterns associated with ENSO, for example, is an area of active current research (e.g., Cole and Cook, 1998).

\subsubsection{Ocean}

The strong spatial variability inherent in precipitation requires the use of estimates based on satellite observations for many regions. Thus satellite data are essential to infer global changes in precipitation, as the oceans account for $70 \%$ of the global surface area. Since adequate observations were not made until the early 1970s, no satellite-based record is sufficiently long to permit estimates of century-long changes. The first satellite instrument specifically designed to make estimates of precipitation did not begin operation until 1987. At this time three data sets are available: (a) the Global Precipitation Climatology Project (GPCP) product, which spans the period from 1987 to the present (Huffman et al., 1997); (b) the CPC Merged Analysis of Precipitation (CMAP) product, covering the period from 1979 to 1998 (Xie and Arkin, 1997); and (c) MSU-derived precipitation estimates since 1979 (Spencer, 1993). While the period from 1987 appears to be well observed, it is too short to draw conclusions regarding decadal-scale variations. The longer CMAP data set assumes that the various satellite-derived estimates have no trend over the period, and hence no longer time-scale conclusions are possible. Nonetheless, analyses of the CMAP product and associated data from the NCEP reanalysis project indicate that there have been substantial average increases in precipitation over the tropical oceans during the last twenty years, related to increased frequency and intensity of ENSO (Trenberth et al., 2001). ENSO conditions are not related to positive precipitation anomalies everywhere over the tropical oceans (e.g., south-western Tropical Pacific). 


\subsubsection{Water Vapour}

Although measurement problems hinder the analysis of longterm water vapour changes (Elliott, 1995; Rind, 1998), several recent studies tend to confirm and extend the findings of lower tropospheric water vapour increases reported in the SAR. Furthermore, new analyses indicate upward trends in nearsurface humidity. Knowledge about changes in water vapour at upper tropospheric and lower stratospheric levels is of great importance because strong alterations in radiative forcing can result from small absolute changes in water vapour at these levels (Chapters 6 and 7). New data presented here from the SPARC WAVAS (Stratospheric Processes and their Role in Climate / Water Vapour Assessment) project (Kley et al., 2000) are starting to cast light on changes at these levels. Note that water vapour pressure, and specific humidity (for a constant relative humidity) increase non-linearly with increasing temperature.

\subsubsection{Surface water vapour}

Water vapour pressure, dew-point or relative humidity at the surface is conventionally measured using wet and dry bulb thermometers exposed in thermometer screens at climate stations. The quality of these data has been little studied. Wet bulb thermometers are not usually aspirated, so that the cooling of the wet bulb, and therefore the deduced specific or relative humidity, depends on the flow rate of air within the screen. This may often differ from the assumed airflow. Occasionally wet bulbs may dry out. Thus it is not possible to judge fully the accuracy of surface vapour pressure trends presented here.
Schönwiese et al. (1994) and Schönwiese and Rapp (1997) found small increases in surface vapour pressure over most of Europe from 1961 to 1990. The annual trends are weak. Statistically significant changes are confined to increases of about 0.5 to $1.5 \mathrm{hPa}$ (relative to mean values of 12 to $15 \mathrm{hPa}$ ) in the southern and eastern Mediterranean region (with the largest increase in summer) and decreases of about $0.5 \mathrm{hPa}$ over parts of Turkey (mainly in springtime).

Specific humidity trends over the United States were overwhelmingly positive for the period 1961 to 1995 , with magnitudes of several per cent per decade, and with the largest and most statistically significant trends in spring and summer (Gaffen and Ross, 1999). Night-time specific humidity trends were generally stronger than daytime trends. Relative humidity showed smaller increases, especially in winter and spring. The specific humidity and derived dew point trends are broadly consistent, both spatially and in their day-night differences, with temperature trends. Schwartzman et al. (1998) found that the diurnal dewpoint cycle is changing over North America, with a relative decline in late afternoon and a small rise at midday.

Increases in water vapour over the former Soviet Union, Eastern China, the United States and tropical Western Pacific islands have been found in some seasons by Sun et al. (2000) in the second half of the 20th century, but with decreases in Canada in autumn. The selective character of the findings prevents any assessment of statistical significance. Wang and Gaffen (2001) found that specific humidity trends over China were overwhelmingly positive over 1951 to 1994, with the largest and most statistically significant trends in north-west China north of $35^{\circ} \mathrm{N}$ and

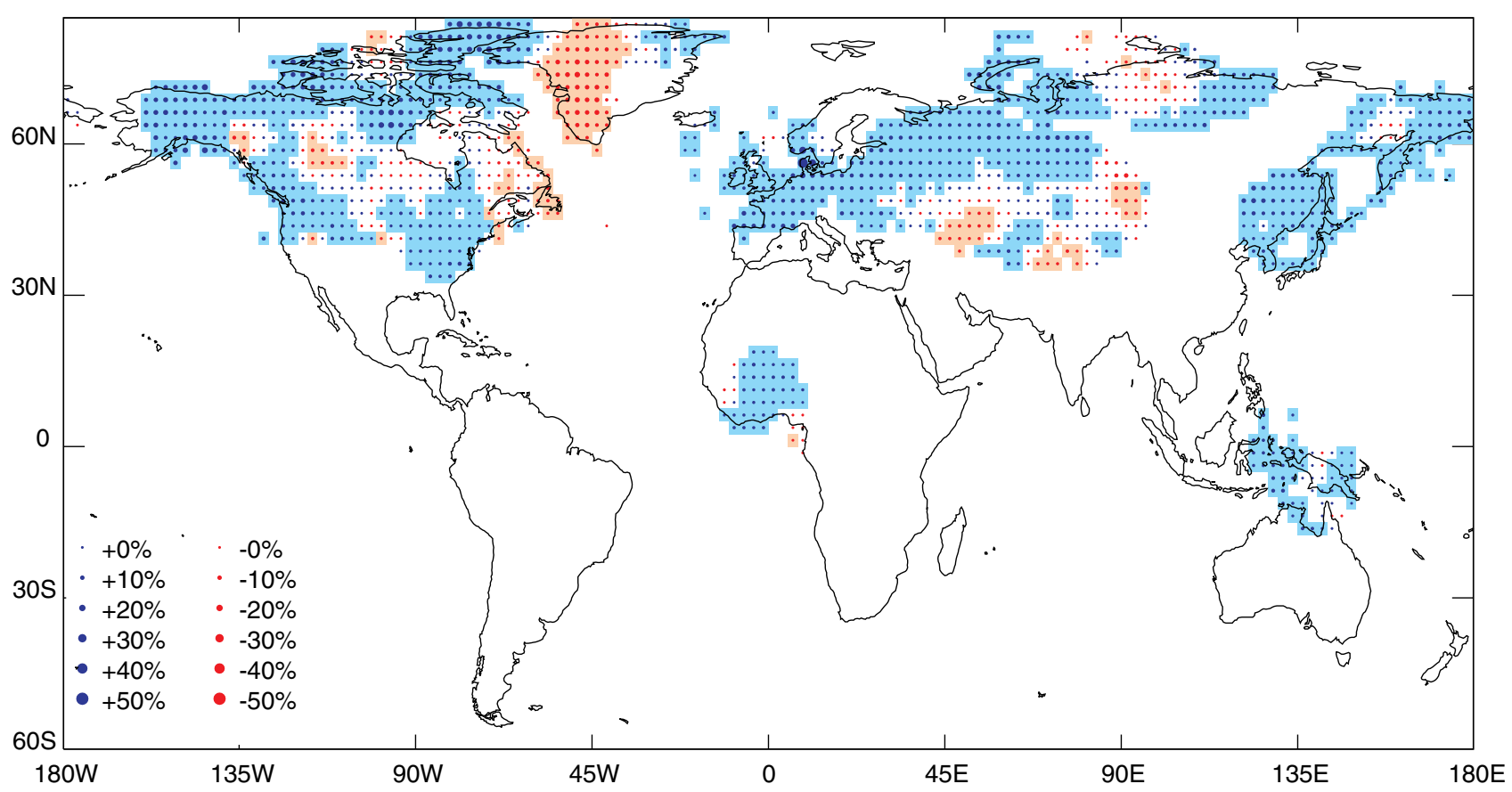

Figure 2.26: Trends in annual mean surface water vapour pressure, 1975 to 1995, expressed as a percentage of the 1975 to 1995 mean. Areas without dots have no data. Blue shaded areas have nominally significant increasing trends and brown shaded areas have significant decreasing trends, both at the 5\% significance level. Biases in these data have been little studied so the level of significance may be overstated. From New et al. (2000). 
west of $105^{\circ} \mathrm{E}$. Trends were larger in summer and night-time trends were generally larger than daytime ones.

Recently New et al. (2000) have estimated linear trends for annual and seasonal values of surface vapour pressure over land using calculated monthly vapour pressure data from climate stations. Figure 2.26 shows trends for the 21 years from 1975 to 1995 , corresponding to much of the recent period of global warming described in Section 2.2.2.3. Although the uncertain quality of the data prevents any definitive conclusions about statistical significance, nominal significance of trends at the $5 \%$ level was estimated after smoothing the annual data to reduce the influence of outliers at the beginning and end of this short series. Few Southern Hemisphere data have been analysed, but Figure 2.26 shows that there have been widespread nominally significant increases in annual mean water vapour in the Northern Hemisphere. These increases are reflected in the individual seasons, although nominally significant annual mean increases are more extensive. Regional decreases over eastern Canada are explained by colder conditions in the winter half year associated with the increasingly positive phase of the North Atlantic Oscillation (Section 2.6.5).

\subsubsection{Lower-tropospheric water vapour}

Radiosonde and satellite observations of water vapour above the surface have been analysed for evidence of long-term change. Both data sources have had serious data quality and temporal homogeneity problems (Elliott, 1995), although recent work to determine trends in water vapour from the surface to $500 \mathrm{hPa}$ since 1973 has been based on radiosonde data judged to be largely unaffected by these problems (Ross and Elliott, 2001). Published satellite data are insufficiently homogeneous or too short in length to deduce reliable trends or low-frequency variations.

\section{Radiosonde observations}

Ross and Elliott $(1996,1998)$ analysed surface-to-500 hPa precipitable water over the Northern Hemisphere for 1973 to 1995 using quality-controlled data. Increases in precipitable water were found over North America except for north-east Canada. Over Eurasia, only China and the Pacific islands show coherent regional increases. The remainder of Eurasia shows a mixture of positive and negative trends, with a tendency for negative trends over Eastern Europe and western Russia. Mid-tropospheric water vapour trends tend to be of the same sign as temperature trends over North America, China, and the Pacific, but elsewhere the temperature trends are more consistently positive than the water vapour trends. Figure 2.27 summarises the results. Lower-tropospheric dew-point data for the period 1961 to 1995 also show increases, though smaller than those for the 1973 to 1995 period, and few are statistically significant (Ross and Elliott, 2001).

Zhai and Eskridge (1997) found increases of about 1 to $3 \% / d e c a d e$ in surface-to-200 hPa precipitable water over China for 1970 to 1990. Increases were most significant in spring. Percentage trends were larger over the 700 to $400 \mathrm{hPa}$ layer than the surface-700 hPa layer. Gutzler (1996) found that specific humidity data at $1,000,700$, and $300 \mathrm{hPa}$ at four western tropical Pacific radiosonde stations from 1973 to 1993 gave increases of 3 to $9 \% /$ decade, with larger percentage increases at increasing height above the surface. In contrast, Peixoto and Oort (1996) found decreases in zonal mean relative humidity between 1974 and 1988. The decreases are more marked at $300 \mathrm{hPa}$, where they are more likely to be associated with instrument changes than at lower levels, and are more pronounced at higher latitudes than in the tropics.

\subsubsection{Upper-tropospheric and lower-stratospheric water vapour}

Recently assessed increases in lower stratospheric water vapour mixing ratio over the last few decades are likely to have caused a decrease in stratospheric temperatures by an amount comparable to that produced by ozone decreases (Forster and Shine, 1999; Smith et al., 2001) (see lower-stratospheric temperature trends in Section 2.2.3). These changes also impact on ozone chemistry (Chapter 4) and on radiative forcing of the atmosphere (Chapters 6 and 7). Data from over twenty-five instruments that measure water vapour concentration and relative humidity in the upper troposphere and stratosphere were recently compared and

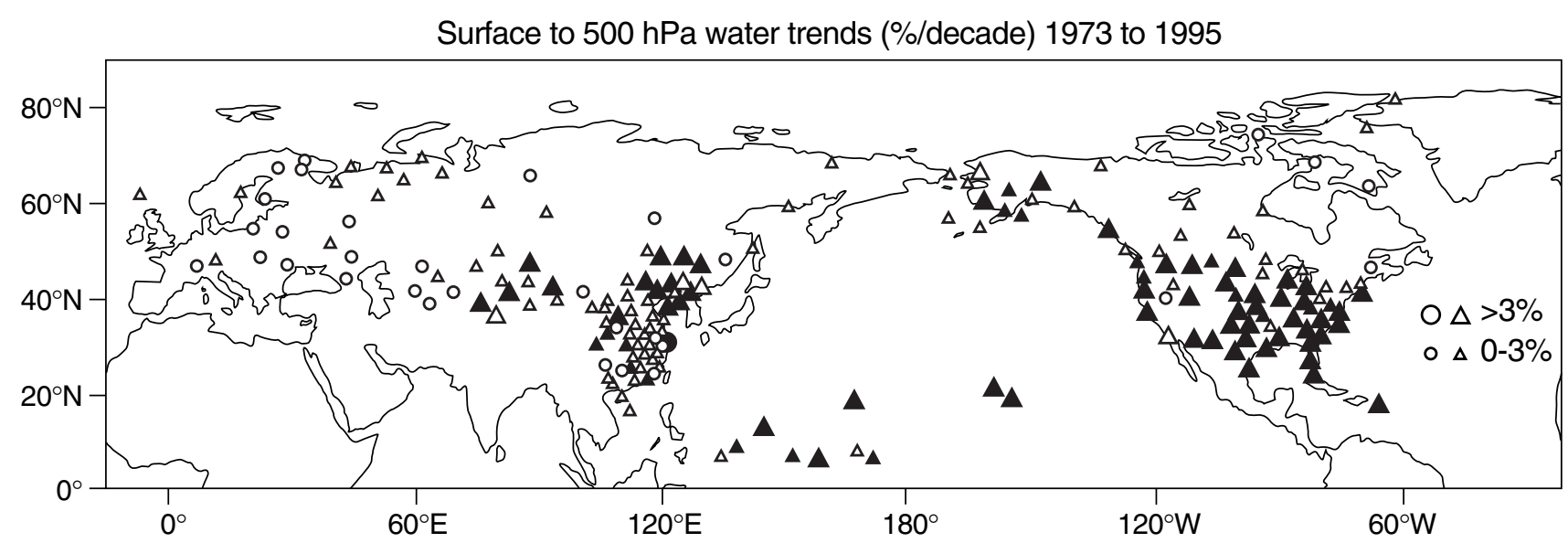

Figure 2.27: Annually averaged trends in surface to $500 \mathrm{hPa}$ precipitable water at 0000UTC for the period 1973 to 1995 . Positive trends are indicated by triangles and negative trends by circles. Filled symbols indicate the trends were statistically significant at the 5\% level according to the Spearman test. The two sizes of symbols give an indication of the magnitude of the trend. From Ross and Elliott (2001). 
assessed in the international SPARC study (Kley et al., 2000). The purpose of the study, which included measurements made by both in situ and remote sensing techniques utilising balloons, aircraft and satellites, was to determine the data quality and to estimate the magnitude of any trends. The study showed that some stratospheric instruments have sampled over a long enough period that several overlapping time-series of intermediate length (8 to 15 years) can be used to help evaluate stratospheric changes. A reasonable degree of consistency was found among stratospheric measurements made from near the tropopause up to as high as $50 \mathrm{~km}$ (about $1 \mathrm{hPa}$ ). Most observations were within $\pm 10 \%$ of the grand mean of all measurements to which they were compared.

Accurate balloon observations of lower-stratospheric water vapour are available from 1964 to 1976 over Washington, D.C. and from 1980 to present over Boulder, Colorado, USA (e.g., Mastenbrook, 1968; Harries, 1976; Mastenbrook and Oltmans, 1983; Oltmans and Hofmann, 1995). The SPARC study shows that these point measurements are nevertheless representative of global stratospheric conditions above about 18 to $20 \mathrm{~km}$, but not of the lowest stratosphere where there can be significant regional and seasonal changes. A positive lower stratosphere trend of about 1 to $1.5 \%$ year in specific humidity (about $0.04 \mathrm{ppm} /$ year) since the mid-1960s is indicated by the balloon data (Oltmans et al., 2000). The increase was not monotonic but showed several rapid rises with plateaux in between. Even though the recent satellite record is relatively short, these measurements have revealed changes of the same character. The satellite results show a spatial pattern of trends in the lower stratosphere, and suggest a slowing in the positive trend after 1996 (Smith et al., 2000). Although not definitive, these observations are consistent in suggesting that lower-stratospheric water vapour has increased globally on average at about $1 \% / y e a r$ over at least the past forty years, but at a variable rate.

Although radiosondes have made observations of water vapour in the upper troposphere (i.e., above $500 \mathrm{hPa}$ ) since the 1950s, these observations have suffered from instrumental errors (Elliott and Gaffen, 1991). Peixoto and Oort (1996) have reexamined these observations for the period 1974 to 1988 and found large trends in upper-tropospheric humidity at the $300 \mathrm{hPa}$ level. They concluded that these trends were unrealistically large and were likely to be due to instrument changes. Satellite observations of upper-tropospheric humidity (UTH) measurements made by TOVS (Television infrared observation satellite Operational Vertical Sounder) since 1979, and representative of a deep layer between 500 to $200 \mathrm{hPa}$, show very large interannual variability (Bates et al., 1996). The SPARC assessment of these observations (Kley et al., 2000) indicated that they were of sufficient quality for trend analyses. The SPARC study and an analysis by Bates and Jackson (2001) show large regional trends that are attributed to circulation changes associated with ENSO, decadal variability over equatorial Africa, and decadal variability of the Arctic Oscillation (see Section 2.6). Statistically significant positive trends of $0.1 \%$ year are found for $10^{\circ} \mathrm{N}$ to $10^{\circ} \mathrm{S}$, and a non-significant trend of $0.04 \% / y e a r$ for $60^{\circ} \mathrm{N}$ to $60^{\circ} \mathrm{S}$, but this includes a component negative trend of $-0.1 \% / y e a r$ for $30^{\circ} \mathrm{S}$ to $60^{\circ} \mathrm{S}$. The trends in large zonal bands tend to be residuals from cancellations in sign and magnitude of much larger regional trends. These UTH trends should be treated with caution especially in the deep tropics because of significant interannual variability and persistence, both of which hamper trend detection.

In summary, in situ and radiosonde measurements tend to show increasing water vapour in the lower troposphere and near the surface, though this is not seen everywhere, and data quality is still an issue. The longer, more reliable data sets suggest multidecadal increases in atmospheric water vapour of several per cent per decade over regions of the Northern Hemisphere. New analyses of balloon and satellite records indicate that stratospheric water vapour above $18 \mathrm{~km}$ shows an increase of about 1\%/year for the period 1981 to 2000 but with a slowing of the positive trend after 1996. Satellite observations of upper-tropospheric humidity from 1980 to 1997 show statistically significant positive trends of $0.1 \% / y e a r$ for the zone $10^{\circ} \mathrm{N}$ to $10^{\circ} \mathrm{S}$.

\subsubsection{Evaporation}

Only evaporation from the land surface is discussed, as nothing new since the SAR has emerged on oceanic evaporation changes.

\subsubsection{Land}

The SAR reported widespread decreases of pan evaporation over the USA and Russia during the 20th century. Pan evaporation measurements are an index of evaporation from a surface with an unlimited supply of water (potential evaporation). Interpretation of this result involving potential evaporation as a decrease in actual land surface evaporation is contradictory to the temperature and precipitation increase reported in these areas, and the general intensification of the hydrological cycle over northern extra-tropical land areas (Brutsaert and Parlange, 1998). Further analysis by Lawrimore and Peterson (2000) supports Brutsaert and Parlange's (1998) interpretation, as does Golubev et al. (2001). Using parallel observations of actual evaporation and pan evaporation at five Russian experimental sites, Golubev et al. (2001) developed a method to estimate actual land surface evaporation from the pan evaporation measurements. They showed that using this method, actual evaporation is shown to have increased during the second half of the 20th century over most dry regions of the United States and Russia. Similarly, over humid maritime regions of the eastern United States (and northeastern Washington state) actual evaporation during the warm season was also found to increase. Only over the heavily forested regions of Russia and the northern United States did actual evaporation decrease. The increase in actual evaporation is related to the greater availability of moisture at the surface, due to increases in precipitation and the higher temperatures.

\subsubsection{Clouds}

Clouds are important in the Earth's climate system because of their effects on solar radiation, terrestrial radiation and precipitation. Different cloud types contribute to total cloud amount and are associated with a wide variety of thermal and dynamic processes in the climate system (see Chapter 7, Section 7.2.2). 
Therefore knowing the variations in total cloud amount and different cloud types would significantly contribute to improving our understanding of the role of clouds in contemporary climate change. Several analyses of cloud amounts for regions of the world have been performed since the SAR. Problems with data homogeneity, particularly concerning biases with changing times of observation (Sun and Groisman, 2000; Sun et al., 2001) have been addressed in several studies, but other issues continue to be a source of uncertainty.

\subsubsection{Land}

Dai et al. (1997a, 1999) and Kaiser (1998) examined cloud cover changes over the former USSR and China during the last four to five decades, to add to earlier analyses for Europe, the United States, Canada, and Australia by Henderson-Sellers (1992) and Karl and Steurer (1990). These studies show 20th century increases in cloud cover over much of the United States (mostly confined to the first 80 years) and the former USSR, which are significantly negatively correlated with changes in the diurnal range of surface air temperature (DTR) (as shown earlier in Figure 2.3). Sun and Groisman (2000) showed that in the former USSR low-level cloud cover significantly decreased during the period 1936 to 1990. However, this was more than offset by a significant increase in cumulus and cirrus clouds during the past several decades. Over much of China, however, daytime and night-time total cloud cover exhibited significant decreasing trends of 1 to $2 \%$ sky cover/decade for both day and night observations between 1951 and 1994 (Kaiser, 1998, 2000), which the DTR failed to follow (Figure 2.3). This discrepancy may result from the increasing effect of industrial aerosols on the DTR since the late 1970s (Dai et al., 1999). Tuomenvirta et al. (2000) show increasing trends in cloud cover during the period 1910 to 1995 for northern Europe, which are consistent with decreases in the DTR. A new analysis (Neff, 1999) reveals a dramatic increase (15 to 20\%) of spring and summer cloud amount at the South Pole during the past four decades in this region. This appears to be related to the observed delay in the breakdown of the spring polar vortex and is believed to be related to decreases in stratospheric temperatures.

There are few analyses of the amounts of various cloud types or changes over the tropics and sub-tropics. Correlations with observed precipitation and clouds observed by satellites suggest that much of the increase in the total cloud amount is likely to have resulted from increases in thick, precipitating clouds (Dai $e t$ al., 1997a). Hahn et al. (1996) show decreasing decadal scale trends in cloud cover over much of China, as well as over most of South America and Africa for the period 1971 to 1991. The latter two areas have little surface-based information.

\subsubsection{Ocean}

The SAR presented analyses of inter-decadal changes in marine cloud coverage. The data have now been re-examined and doubt has been cast on some of the previous findings (Bajuk and Leovy, 1998a; Norris, 1999). Additional data have also reversed some of the previous trends. In the SAR a 3\% increase in cumulonimbus clouds was reported for the period 1952 to 1981. An update of this analysis showed a gradual rise in cumulonimbus cloud amount from the mid-1950s to the mid-1970s, with a gradual decline thereafter (Bajuk and Leovy, 1998a). Bajuk and Leovy (1998b) cast doubt on the homogeneity of the cloud amounts derived from ship data. They find that inter-decadal variations of the frequency of occurrence of cloud amount for a given cloud type are generally unrelated to similar time-scale variations in SST and large-scale divergence of the surface winds. Nonetheless, some regional changes and variations based on ship reports of low and middle clouds are likely to be rather robust. Variations in these categories of cloud are consistent with variations of other climate system variables. Examples include: (1) a long-term upward trend in altostratus and nimbostratus across the mid-latitude North Pacific and North Atlantic Oceans (Parungo et al., 1994; Norris and Leovy, 1995); (2) ENSO related variations in the frequency of low cloud types across the Pacific and Indian Oceans (Bajuk and Leovy, 1998b); and (3) interannual variations in summer season stratiform clouds across the North Pacific (Norris et al., 1998). Norris (1999) found an increase in total sky cover of approximately $2 \%$, and an increase of approximately $4 \%$ in low cloud cover in his analyses of ship reports between 1952 and 1995 . He finds no evidence for changes in observation practices that may have affected these trends. The trends are dominated by a globally consistent mode and are as large or larger in the tropics and Southern Hemisphere as in the Northern Hemisphere. This argues against attribution to increased anthropogenic aerosol amounts.

\subsubsection{Global}

Although satellite estimates of changes and variations in cloud amount and type contain systematic biases, Rossow and Schiffer (1999) showed improved calibration and cloud detection sensitivities for the International Satellite Cloud Climatology Program (ISCCP) data set. Using data from 1983 to 1994, a globally increasing trend in monthly mean cloudiness reversed during the late 1980s and early 1990s. There now appears to be an overall trend toward reduced total cloud amounts over both land and ocean during this period. An estimate for aircraft-induced cirrus cover for the late 1990s ranges from 0 to $0.2 \%$ of the surface of the Earth (IPCC, 1999).

\subsubsection{Summary}

Since the SAR, land surface precipitation has continued to increase in the Northern Hemisphere mid- and high latitudes; over the sub-tropics, the drying trend has been ameliorated somewhat. Where data are available, changes in annual streamflow relate well to changes in total precipitation. Over the Southern Hemisphere land areas no pronounced changes in total precipitation are evident since the SAR. The changes in precipitation in mid- and high latitudes over land have a strong correlation with long-term changes in total cloud amount. Little can be said about changes in ocean precipitation as satellite data sets have not yet been adequately tested for time-dependent biases. Changes in water vapour have been analysed most for selected Northern Hemisphere regions, and show an emerging pattern of surface and tropospheric water vapour increases over the past few 
decades, although there are still untested or uncorrected biases in these data. Limited data from the stratosphere also suggest increases in water vapour but this result must be viewed with great caution. Over land, an increase in cloud cover of a few per cent since the turn of the century is observed, which is shown to closely relate to changes in the diurnal temperature range. Changes in ocean cloud amount and type show systematic increases of a few per cent since the 1950s, but these relate poorly to SST or surface wind divergence changes, casting some doubt on the integrity of the trends. No changes in observing practices can be identified, however, that might have led to time-dependent biases in the ocean cloud amount and frequency statistics.

\subsection{Are the Atmospheric/Oceanic Circulations Changing?}

\subsubsection{Background}

Changes or fluctuations in atmospheric and oceanic circulation are important elements of climate. Such circulation changes are the main cause of variations in climate elements on a regional scale, sometimes mediated by parallel changes in the land surface (IPCC, 1990, 1996). ENSO and NAO are such examples. On decadal time-scales, the Pacific Decadal Oscillation (PDO) and the related Inter-decadal Pacific Oscillation (IPO) may account for approximately half the global mean variation in surface temperatures. They are also prominently linked to regional variations in temperature and precipitation (Higgins et al., 2000). This section documents regional changes and slow fluctuations in atmospheric circulation over past decades, and demonstrates that these are consistent with large-scale changes in other variables, especially temperature and precipitation. Note that there is much evidence that many of the atmospheric circulation changes we observe, particularly in the extra-tropics, are the net result of irregular fluctuations between preferred states of the atmosphere (Palmer, 1993, 1999) that last for much shorter times. Thus changes in circulation on decadal time-scales involve changes in the frequency of such states. Chapter 7 discusses this in more detail. The focus of this section is on long-term variation and change, rather than on shorter-term variability.

\subsubsection{El Niño-Southern Oscillation and Tropical/Extra-tropical Interaction}

ENSO is the primary global mode of climate variability in the 2 to 7 year time band. El Niño is defined by SST anomalies in the eastern tropical Pacific while the Southern Oscillation Index (SOI) is a measure of the atmospheric circulation response in the Pacific-Indian Ocean region. This sub-section assesses the variability of ENSO over the past few centuries.

Multiproxy-based reconstructions of the behaviour of ENSO have recently been attempted for the past few centuries, including a boreal winter season SOI reconstruction based on highly ENSO-sensitive tree-ring indicators (Stahle et al., 1998). A multiproxy-based reconstruction of the boreal cold-season (Oct-Mar) NINO 3 (SST anomalies in the tropical Pacific from $5^{\circ} \mathrm{N}$ to $5^{\circ} \mathrm{S}, 150^{\circ} \mathrm{W}$ to $90^{\circ} \mathrm{W}$ ) index (Mann et al., 2000b) has also been made. Figure 2.28 compares the behaviour of these

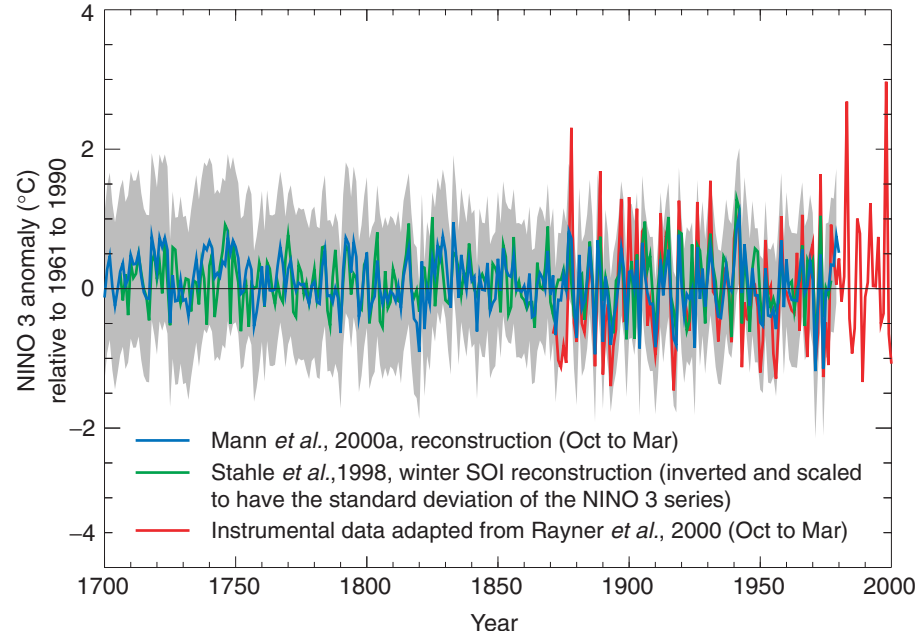

Figure 2.28: Reconstructions since 1700 of proxy-based ENSO indices. Shown are the Northern Hemisphere cold-season (Oct-Mar) mean NINO 3 index of Mann et al. (2000a) and the Northern Hemisphere winter SOI index of Stahle et al. (1998). The SOI series is scaled to have the same standard deviation as the NINO 3 index, and is reversed in sign to be positively correlated with the NINO 3 series. An instrumental NINO 3 index from 1871 to 2000 is shown for comparison (Rayner et al., 2000; see also Figure 2.29), with two standard error limits (grey shaded) of the proxy NINO 3 reconstruction.

two series with recent ENSO behaviour. The SOI reconstruction has been rescaled to have the sign and variance of the NINO 3 reconstruction; the two reconstructions, based on independent methods and partially independent data, have a linear correlation $(r=0.64)$ during the pre-calibration interval. While the estimated uncertainties in these reconstructed series are substantial, they suggest that the very large 1982/83 and $1997 / 98$ warm events might be outside the range of variability of the past few centuries. However, the reconstructions tend to underestimate the amplitude of ENSO events, as is clearly evident for the large 1877/78 event. Only a richer network of ENSO-sensitive proxy indicators can improve this situation, such as the new long tropical coral series becoming available (see Dunbar and Cole, 1999).

Instrumental records have been examined to search for possible changes in ENSO over the past 120 years. Three new reconstructions of SST in the eastern Equatorial Pacific (Figure 2.29) that use optimum interpolation methods exhibit strong similarities. The dominant 2 to 6 year time-scale in ENSO is apparent. Both the activity and periodicity of ENSO have varied considerably since 1871 with considerable irregularity in time. There was an apparent "shift" in the temperature of the tropical Pacific around 1976 to warmer conditions, discussed in the SAR, which appeared to continue until at least 1998. During this period ENSO events were more frequent, intense or persistent. It is unclear whether this warm state continues, with the persistance of the long La Niña from late 1998 until early 2001. ENSO has been related to variations of precipitation and temperature over much of the tropics and sub-tropics, and some mid-latitude areas. 


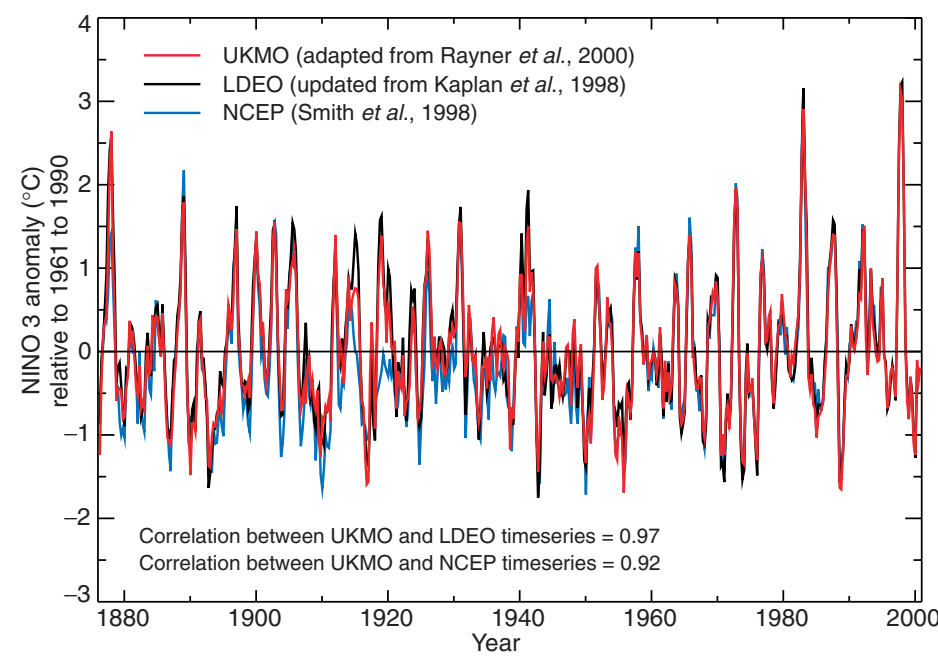

Figure 2.29: El Niño-La Niña variations from 1876 to 2000 measured by sea surface temperature in the region $5^{\circ} \mathrm{N}$ to $5^{\circ} \mathrm{S}, 150$ to $90^{\circ} \mathrm{W}$. Reconstructions using pattern analysis methods from (a) red: UK Met Office (UKMO) Hadley Centre sea ice and sea surface temperature data set version 1 (Rayner et al., 2000); (b) black: from the LamontDoherty Earth Observatory (LDEO) (Kaplan et al., 1998); (c) blue: the National Centers for Environmental Prediction (NCEP) analysis (Smith et al., 1998). 1876 is close to the earliest date for which reasonably reliable reconstructions can be made.

A number of recent studies have found changes in the interannual variability of ENSO over the last century, related in part to an observed reduction in ENSO variability between about 1920 and 1960. Various studies (Wang and Wang, 1996; Torrence and Compo, 1998; Torrence and Webster, 1998; Kestin et al., 1999) show more robust signals in the quasi-biennial and 'classical' 3 to 4 year ENSO bands ( 3.4 and 7 years) during the first and last 40 to 50 years of the instrumental record. A period of very weak signal strength (with a near 5-year periodicity) occurs in much of the intervening epoch.

The 1990s have received considerable attention, as the recent behaviour of ENSO seems unusual relative to that of previous decades. A protracted period of low SOI from 1990 to 1995, during which several weak to moderate El Niño events occurred with no intervening La Niña events (Goddard and Graham, 1997) was found by some studies (e.g., Trenberth and Hoar, 1996) to be statistically very rare. Whether global warming is influencing El Niño, especially given the remarkable El Niño of 1997/98, is a key question (Trenberth, 1998b), especially as El Niño affects global temperature itself (Section 2.2 and Chapter 7).

\subsubsection{Decadal to Inter-decadal Pacific Oscillation, and the North Pacific Oscillation}

Recently, 'ENSO-like' spatial patterns in the climate system, which operate on decadal to multi-decadal time-scales, have been identified. This lower-frequency SST variability is less equatorially confined in the central and eastern Pacific, and relatively more prominent over the extra-tropics, especially the north-west
Pacific, and has a similar counterpart in night marine air temperatures (Tanimoto et al., 1993; Folland et al., 1999a; Allan, 2000). The corresponding sea level pressure (SLP) signature is also strongest over the North Pacific, and its December-February counterpart in the mid-troposphere more closely resembles the Pacific-North America (PNA) pattern (Zhang et al., 1997b; Livezey and Smith, 1999). There is ambiguity about whether inter-decadal Pacific-wide features are independent of global warming. In the longer Folland et al. (1999) analyses since 1911 they appear to be largely independent, but in the Livezey and Smith analysis of more recent SST data they are an integral part of a global warming signal. Using a different method of analysis of data since 1901, Moron et al. (1998) find a global warming signal whose pattern in the Pacific is intermediate between these two analyses.

The PDO of Mantua et al. (1997), with lower-frequency variations in the leading North Pacific SST pattern, may be related to the same Pacific-wide features, and parallels the dominant pattern of North Pacific SLP variability. The relationship is such that cooler than average SSTs occur during periods of lower than average SLP over the central North Pacific and vice versa. Recently, the IPO, a Pacific basin-wide feature, has been described, which includes low-frequency variations in climate over the North Pacific (Power et al., 1998, 1999; Folland et al., 1999a). The time-series of this feature is broadly similar to the inter-decadal part of the North Pacific PDO index of Mantua et al. (1997). The IPO may be a Pacific-wide manifestation of the PDO and seems to be part of a continuous spectrum of low-frequency modulation of ENSO, and so may be partly stochastic. When the IPO is in a positive phase, SST over a large area of the south-west Pacific is cold, as is SST over the extra-tropical north-west Pacific. SST over the central tropical Pacific is warm but less obviously warm over the equatorial far eastern Pacific unlike ENSO. Warmth also extends into the tropical west Pacific, unlike the situation on the ENSO time-scale.

The IPO shows three major phases this century: positive from 1922 to 1946 and from 1978 to at least 1998, with a negative phase between 1947 and 1976. Arguably, the structure of this pattern, nearly symmetrical about the equator and only subtly different from ENSO, is a strong indication of the importance of the tropical Pacific for many remote climates on all time-scales (Garreaud and Battisti, 1999). Power et al. (1999) showed that the two phases of the IPO appear to modulate year-to-year ENSO precipitation variability over Australia. Salinger and Mullan (1999) showed that prominent sub-bidecadal climate variations in New Zealand, identified in the temperature signal by Folland and Salinger (1995), are related to a SST pattern like the IPO. The IPO is a significant source of decadal climate variation throughout the South Pacific, and modulates ENSO climate variability in this region (Salinger et al., 2001). Similarly, the PDO (and likely the IPO) may play a key role in modulating ENSO teleconnections across North America on inter-decadal time-scales (Gershunov and Barnett, 1998; Livezey and Smith, 1999).

A simple and robust index of climate variability over the North Pacific is the area-weighted mean SLP, averaged over most of the extra-tropical North Pacific Ocean, of Trenberth and Hurrell 
(1994). A general reduction in SLP after about 1976 has been particularly evident during the winter half (November to March) of many of these years. This is characterised by a deeper-thannormal Aleutian low pressure system, accompanied by strongerthan-normal westerly winds across the central North Pacific and enhanced southerly to south-westerly flow along the west coast of North America, as reviewed in the SAR (Figure 3.17). Consequently, there have been increases in surface air temperature and SST over much of western North America and the eastern North Pacific, respectively, over the past two decades, especially in winter, but decreases in SST, or only modest warming, over parts of the central extra-tropical North Pacific (Figure 2.10). Numerous studies have suggested that the mid-1970s changes in the atmospheric and oceanic circulation may reflect one or more low-frequency variations over the North Pacific, one being the PDO (Kawamura, 1994; Latif and Barnett, 1994; Mann and Park, 1994, 1996; Deser and Blackmon 1995; Zhang et al., 1997b; White and Cayan, 1998; Enfield and Mestas-Nuñez, 1999).

\subsubsection{Monsoons}

Variations in the behaviour of the North African summer monsoon were highlighted in IPCC (1990). Moron (1997) demonstrated that long-term variations of Sahel annual rainfall, particularly the wet 1950s and the dry 1970 to 1980 s, are seen over the Guinea coast area, although trends are strongest in the Sahel. The significant decrease in Guinea coast rainfall (Ward, 1998 ) is present in both the first and second rainy seasons, but is strongest in the second. Janicot et al. (1996) and Moron (1997) demonstrated that the moderate influence of ENSO (towards drier conditions) has increased since 1960, with warm events associated more strongly with large-scale anomalous dry conditions over the Guinea and Sahel belts. Ward et al. (1999) show that the Sahel has become moderately wetter since 1987, despite the increased drying influence of ENSO events, a trend that continued to 1999 (Parker and Horton, 2000). This recent behaviour may be related to a quasi-hemispheric variation of SST (e.g., Enfield and Mestas-Nuñez, 1999) shown to be related to Sahel rainfall by Folland et al. (1986), and which may be related to the recent strong increase in North Atlantic SST mentioned in Section 2.2.2.2. Many other parts of tropical Africa are influenced by ENSO towards either drier or wetter conditions than normal, sometimes modulated by regional SST anomalies near Africa (e.g., Nicholson and Kim, 1997; Nicholson, 1997; Indeje et al., 2000), but few trends can be discerned.

Multi-decadal and decadal variations of the Indian monsoon have been widely noted (e.g., Pant and Kumar, 1997) but links with El Niño do not now seem straightforward (Slingo et al., 1999). However, despite the recent strong El Niño episodes, the inverse relationship between the ENSO and the Indian summer monsoon (weak monsoon arising from an ENSO event) has broken down in the recent two decades (Kumar et al., 1999a). This link operated on multi-decadal time-scales with NINO 3 SST until at least 1970. Kumar et al. suggest that persistently increased surface temperatures over Eurasia in winter and spring (Figure 2.10) have favoured an enhanced land-ocean thermal gradient conducive to stronger monsoons; they also observe a shift away from India in the sinking node of the Walker circulation in El Niño. Changes have also occurred in relationships with Indian monsoon precursors (Kumar et al., 1999b). One possibility is that warming over the Indian Ocean (Figures 2.9, 2.10) may have increased moisture and rainfall for a given state of the atmospheric circulation (Kitoh et al., 1997). There may be a link to multi-decadal variations in Pacific SST, but this remains to be investigated, together with other monsoon indices (e.g., Goswami et al., 1997).

It has been known for some time that the position of the western North Pacific sub-tropical high affects the East Asian monsoon. Gong and Wang (1999a) showed that summer (June to August) precipitation over central and eastern China near $30^{\circ} \mathrm{N}$ is positively correlated with the intensity of the high, with negative correlations to the north and south. A location of the sub-tropical high further south than normal is conducive to heavy summer rainfall in this region. Time-series of the subtropical high show an increase in areal extent in the 1920s, then another increase from the mid-1970s to 1998, giving frequent wet summers in this region in recent years. The north-east winter monsoon has also shown low-frequency variations. Thus the strength of the Siberian high increased to a peak around 1968, and then weakened to a minimum around 1990 (Gong and Wang, 1999b), in phase with the increased frequency of the positive phase of the NAO (Wallace, 2000 and next section). This is likely to have contributed to strong recent winter warming in China shown in Figure 2.10.

\subsubsection{The Northern Hemisphere excluding the North Pacific Ocean}

The atmospheric circulation over the Northern Hemisphere has exhibited anomalous behaviour over the past several decades. In particular, the dominant patterns of atmospheric variability in the winter half-year have tended to be strongly biased to one phase. Thus SLP has been lower than average over the mid- and high latitudes of the North Atlantic Ocean, as well as over much of the Arctic, while it has been higher than average over the subtropical oceans, especially the Atlantic. Moreover, in the past thirty years, changes in these leading patterns of natural atmospheric variability appear to be unusual in the context of the observational record.

The dominant pattern of atmospheric circulation variability over the North Atlantic is known as the NAO, and its wintertime index is shown in Figure 2.30 (updated from Hurrell, 1995). As discussed in the SAR, positive values of the NAO give stronger than average westerlies over the mid-latitudes of the Atlantic with low SLP anomalies in the Icelandic region and over much of the Arctic and high SLP anomalies across the sub-tropical Atlantic and into southern Europe. The positive, enhanced westerly, phase of the NAO is associated with cold winters over the north-west Atlantic and warm winters over Europe, Siberia and eastern Asia (Thompson and Wallace, 2001) as well as wet conditions from Iceland to Scandinavia and dry winters over southern Europe. A sharp reversal is evident in the NAO index starting around 1970 from a negative towards a positive phase. 


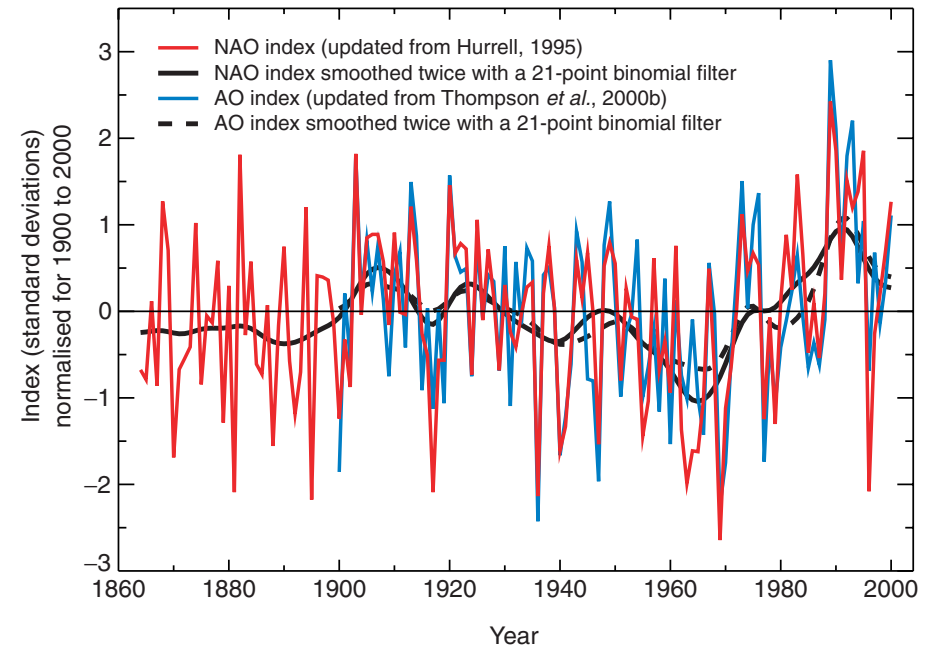

Figure 2.30: December to March North Atlantic Oscillation (NAO) indices, 1864 to 2000, and Arctic Oscillation (AO) indices, 1900 to 2000, updated from Hurrell (1995) and updated from Thompson and Wallace (2000) and Thompson et al. (2000b), respectively. The indices were normalised using the means and standard deviations from their common period, 1900 to 2000, smoothed twice using a 21-point binomial filter where indicated and then plotted according to the years of their Januarys.

Since about 1985, the NAO has tended to remain in a strong positive phase, though with substantial interannual variability. Hurrell (1996) and Thompson et al. (2000a) showed that the recent upward trend in the NAO accounts for much of the regional surface winter half-year warming over northern Europe and Asia north of about $40^{\circ} \mathrm{N}$ over the past thirty years, as well as the cooling over the north-west Atlantic (see Section 2.2.2.3). Moreover, when circulation changes over the North Pacific are also considered, much of the pattern of the Northern Hemisphere winter half-year surface temperature changes since the mid1970s can be explained. This can be associated with changes in the NAO, and in the PNA atmospheric pattern related to ENSO or the PDO (Graf et al., 1995; Wallace et al., 1995; Shabbar et al., 1997; Thompson and Wallace, 1998, 2000).

The changes in atmospheric circulation over the Atlantic are also connected with much of the observed pressure fall over the Arctic in recent years (Walsh et al., 1996). Other features related to the circulation changes include the strengthening of sub-polar westerlies from the surface of the North Atlantic up, in winter as high as the lower stratosphere (Thompson et al., 2000a) and pronounced regional changes in precipitation patterns (Hurrell, 1995; Dai et al., 1997b; Hurrell and van Loon 1997; Section 2.5.2.1). Associated precipitation increases have resulted in the notable advance of some Scandinavian glaciers (Hagen et al., 1995), while decreases to the south of about $50^{\circ} \mathrm{N}$ have contributed to the further retreat of Alpine glaciers (Frank, 1997; see also Section 2.2.5.3)

The NAO is regarded (largely) by some as the regional expression of a zonally symmetrical hemispheric mode of variability characterised by a seesaw of atmospheric mass between the polar cap and the mid-latitudes in both the Atlantic and Pacific Ocean basins (Thompson and Wallace, 1998, 2001). This mode has been named the AO (Figure 2.30). The time-series of the NAO and $\mathrm{AO}$ are quite similar: the correlation of monthly anomalies of station data SLP series of NAO and $\mathrm{AO}$ is about 0.7 (depending on their exact definitions and epochs) while seasonal variations shown in Figure 2.30 have even higher correlations. The NAO and AO can be viewed as manifestations of the same basic phenomenon (Wallace, 2000).

Changes and decadal fluctuations in sea-ice cover in the Labrador and Greenland Seas, as well as over the Arctic, appear well correlated with the NAO (Chapman and Walsh, 1993; Maslanik et al., 1996; McPhee et al., 1998; Mysak and Venegas, 1998; Parkinson et al., 1999; Deser et al., 2000). The relationship between the SLP and ice anomaly fields is consistent with the idea that atmospheric circulation anomalies force the sea-ice variations (Prisenberg et al., 1997). Feedbacks or other influences of winter ice anomalies on the atmosphere have been more difficult to detect, although Deser et al. (2000) suggest that a local response of the atmospheric circulation to the reduced sea-ice cover east of Greenland in recent years is also apparent (see also Section 2.2.5.2).

A number of studies have placed the recent positive values of the NAO into a longer-term perspective (Jones et al., 1997a; Appenzeller et al., 1998; Cook et al., 1998; Luterbacher et al., 1999; Osborn et al., 1999) back to the 1700s. The recent strength of the positive phase of the NAO seems unusual from these reconstructions but, as in Figure 2.28, these proxy data reconstructions may underestimate variability. An extended positive phase occurred in the early 20th century (Figure 2.30), particularly pronounced in January (Parker and Folland, 1988), comparable in length to the recent positive phase. Higherfrequency variability of the NAO also appears to have varied. Hurrell and van Loon (1997) showed that quasi-decadal (6 to 10 year) variability has become more pronounced over the latter half of the 20th century, while quasi-biennial variability dominated in the early instrumental record.

\subsubsection{The Southern Hemisphere}

Since the SAR there has been more emphasis on analysis of decadal variability over the Southern Hemisphere. The Southern Hemisphere gridded SLP data for the period 1950 to 1994 show two dominant modes in annual average values, similar to those identified by Karoly et al. (1996) using station data. The first mode unambiguously represents the Southern Oscillation and reflects the tendency towards more frequent and intense negative phases over the past several decades. The second mode represents anomalies throughout the mid-latitude regions across the Indian Ocean and western Pacific, which contrast with anomalies elsewhere.

The Trans-Polar Index (TPI) is the only large-scale station pressure-based extra-tropical Southern Hemisphere circulation index in regular use. It is based on the normalised pressure difference between New Zealand and South America and has been recalculated and extended by Jones et al. (1999b). On decadal and longer time-scales the TPI reflects movement in the phase of wave number one around the Southern Hemisphere. 
Troughing (low pressure) was more frequent in the New Zealand region in the 1920s, and at a maximum in the 1940s. Anticyclonicity was favoured from the late 1950s to 1976, with troughing in the South American sector. Troughing was again apparent in the New Zealand sector in the 1990s (Salinger et al., 1996).

A leading mode of variability in the extra-tropical Southern Hemisphere circulation on interannual to multi-decadal timescales is a zonally elongated north-south dipole structure over the Pacific, stretching from the sub-tropics to the Antarctic coast (Mo and Higgins, 1998; Kidson, 1999; Kiladis and Mo, 1999). It is strongly related to ENSO variability. The lower-frequency dipole structure contributes to variability in blocking frequency across the far south Pacific (Renwick, 1998; Renwick and Revell, 1999).

ENSO variability is also implicated in the modulation of a "High Latitude Mode" (HLM) (Kidson, 1988; Karoly, 1990), especially over the austral summer. The HLM is now also called the "Antarctic Oscillation" (AAO); they appear to be the same phenomenon with the same structure (Thompson and Wallace, 2000). The AAO is a zonal pressure fluctuation between midand high latitudes of the Southern Hemisphere, centred on 55 to $60^{\circ} \mathrm{S}$. It has recently been further studied (Gong and Wang, 1999c; Kidson, 1999; Thompson and Wallace, 2001; Figure 2.31) and shown to extend into the lower stratosphere between the Antarctic and the sub-tropical latitudes of the Southern Hemisphere. The AAO appears to persist all year but may be most active from mid-October to mid-December when it extends into the stratosphere (Thompson and Wallace, 2001). In its high index phase, it consists of low pressure or heights above the Antarctic and the near Southern Ocean with high heights north of about $50^{\circ} \mathrm{S}$. Although the data are sparse, there is evidence that, like the $\mathrm{NAO}$, the $\mathrm{AAO}$ has tended to move more towards a positive index phase, despite lower pressures being observed over the New Zealand region during the 1990s. This change is also associated with with increasing westerly winds in mid-latitudes. Thompson and Wallace (2001) show that most of Antarctica is rather cold in this phase, except for the Antarctic Peninsula which is warm due to additional advection of relatively warm air from seas to the west. This may explain some of the behaviour of Antarctic temperatures in the last two decades (Figure 2.10; Comiso, 2000).

Other work has identified the likely existence of an Antarctic Circumpolar Wave (ACW) (Jacobs and Mitchell, 1996; White and Peterson, 1996), a multi-annual climate signal in the Southern Ocean, with co-varying and perhaps coupled SST and SLP anomalies that move around the Southern Ocean. Its long-term variability is not yet known.

\subsubsection{Summary}

The interannual variability of ENSO has fluctuated substantially over the last century, with notably reduced variability during the period 1920 to 1960 , compared with adjacent periods. It remains unclear whether global warming has influenced the shift towards less frequent La Niña episodes from 1976 to 1998, including the abnormally protracted ENSO

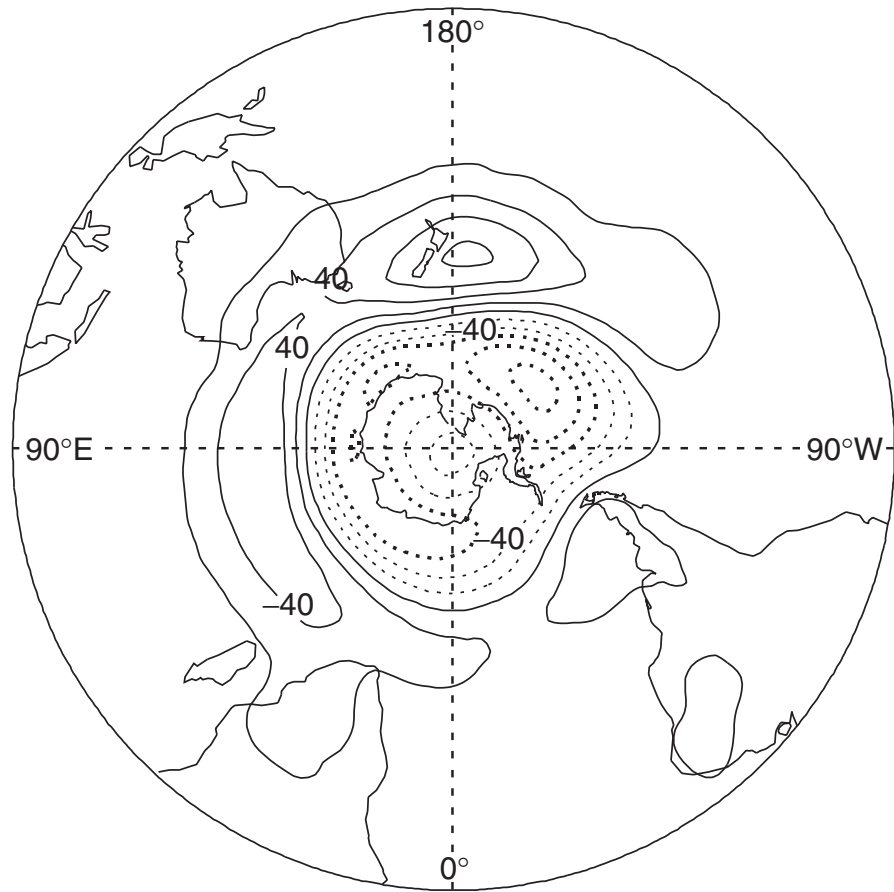

Figure 2.31: The High Latitude Mode (Kidson, 1988) or Antarctic Oscillation (AAO), defined as the first orthogonal pattern (covariance eigenvector of the Southern Hemisphere monthly surface pressure, January 1958 to December 1997) (Gong and Wang, 1999c; Kiladis and Mo, 1999). Data from NCAR/NCEP Reanalysis (Kalnay et al., 1996). Note that Thompson and Wallace (2000) use $850 \mathrm{hPa}$ height to define their AAO.

1990 to 1995 event and the exceptionally strong 1982/83 and $1997 / 98$ events. Analysis of SST patterns indicates that a global warming pattern may have increased the background temperature in the region most affected by ENSO, but there is some ambiguity in the details of this pattern.

Since the SAR, 'ENSO-like' features operating on decadal to multi-decadal time-scales have been identified, such as the PDO and IPO. They appear to be part of a continuous spectrum of ENSO variability that has subtly changing SST patterns as time-scales increase and which may have distinctive effects on regional climate around the Pacific basin. For the period since 1900, El Niño (La Niña) events are more prevalent during positive (negative) phases of the IPO.

In the Northern Hemisphere, pronounced changes in winter atmospheric and oceanic circulations over the North Pacific in the 1970s (the North Pacific Oscillation) have been paralleled by wintertime circulation changes over the North Atlantic, recorded by the NAO. In the North Pacific, spatially coherent changes have occurred in surface temperature across the North Pacific and western North America, while the enhanced westerly phase of the NAO has caused considerable winter halfyear temperature and precipitation changes over a vast area of extra-tropical Eurasia. In the Southern Hemisphere, a feature quite like the NAO, the HLM or the AAO, also appears to have moved into an enhanced westerly phase in middle latitudes. 


\subsection{Has Climate Variability, or have Climate Extremes, Changed?}

\subsubsection{Background}

Changes in climate variability and extremes of weather and climate events have received increased attention in the last few years. Understanding changes in climate variability and climate extremes is made difficult by interactions between the changes in the mean and variability (Meehl et al., 2000). Such interactions vary from variable to variable depending on their statistical distribution. For example, the distribution of temperatures often resembles a normal distribution where non-stationarity of the distribution implies changes in the mean or variance. In such a distribution, an increase in the
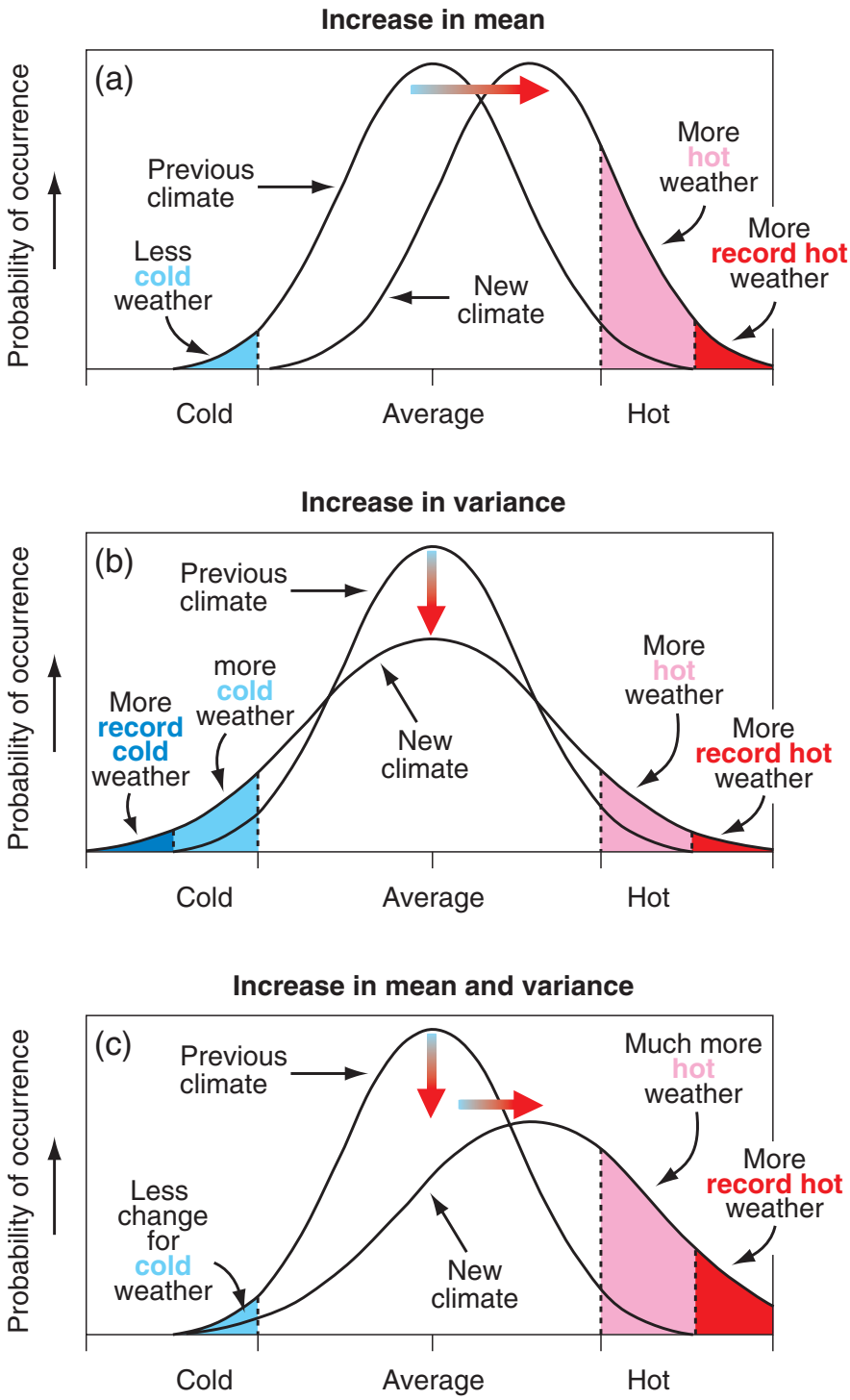

Figure 2.32: Schematic showing the effect on extreme temperatures when (a) the mean temperature increases, (b) the variance increases, and (c) when both the mean and variance increase for a normal distribution of temperature. mean leads to new record high temperatures (Figure 2.32a), but a change in the mean does not imply any change in variability. For example, in Figure 2.32a, the range between the hottest and coldest temperatures does not change. An increase in variability without a change in the mean implies an increase in the probability of both hot and cold extremes as well as the absolute value of the extremes (Figure 2.32b). Increases in both the mean and the variability are also possible (Figure 2.32c), which affects (in this example) the probability of hot and cold extremes, with more frequent hot events with more extreme high temperatures and fewer cold events. Other combinations of changes in both mean and variability would lead to different results.

Consequently, even when changes in extremes can be documented, unless a specific analysis has been completed, it is often uncertain whether the changes are caused by a change in the mean, variance, or both. In addition, uncertainties in the rate of change of the mean confound interpretation of changes in variance since all variance statistics are dependent on a reference level, i.e., the mean.

For variables that are not well approximated by normal distributions, like precipitation, the situation is even more complex, especially for dry climates. For precipitation, for example, changes in the mean total precipitation can be accompanied by other changes like the frequency of precipitation or the shape of the distribution including its variability. All these changes can affect the various aspects of precipitation extremes including the intensity of precipitation (amount per unit time).

This section considers the changes in variability and extremes simultaneously for two variables, temperature and precipitation. We include new analyses and additional data compiled since the SAR which provide new insights. We also assess new information related to changes in extreme weather and climate phenomena, e.g., tropical cyclones, tornadoes, etc. In these analyses, the primary focus is on assessing the stationarity (e.g., the null hypothesis of no change) of these events, given numerous inhomogeneities in monitoring.

\subsubsection{Is There Evidence for Changes in Variability or Extremes?}

The issues involved in measuring and assessing changes in extremes have recently been comprehensively reviewed by Trenberth and Owen (1999), Nicholls and Murray (1999), and Folland et al. (1999b). Despite some progress described below, there remains a lack of accessible daily climate data sets which can be intercompared over large regions (Folland $e t$ al., 2000). Extremes are a key aspect of climate change. Changes in the frequency of many extremes (increases or decreases) can be surprisingly large for seemingly modest mean changes in climate (Katz, 1999) and are often the most sensitive aspects of climate change for ecosystem and societal responses. Moreover, changes in extremes are often most sensitive to inhomogeneous climate monitoring practices, making assessment of change more difficult than assessing the change in the mean. 


\subsubsection{Temperature}

Given the number of ways in which extreme climate events and variability about the mean can be defined, (e.g., extreme daily temperatures, large areas experiencing unusual temperatures, severity of heat waves, number of frosts or freezes, changes in interannual variability of large area temperatures, etc.) extreme care must be exercised in generalising results. Here we assess the evidence for changes in temperature extremes or variability, first based on global analyses and then on more detailed regional analyses.

Parker et al. (1994) compared the interannual variability of seasonal temperature anomalies from the 1954 to 1973 period to the 1974 to 1993 period for most of the globe. They found a small increase in variability overall with an especially large increase in central North America. By restricting the analyses to the latter half of the 20th century, Parker et al. (1994) minimised the potential biases due to an increasing number of observations in this period. Several other studies found a reduction in other aspects of variability over longer time periods. Jones (1999) also analysed global data and found no change in variability, but since 1951 the rise in global mean temperatures can be attributed to an increase (decrease) in areas with much above (below) normal temperatures. They also analysed the change in the aggregated total of much below and much above normal temperatures (upper and lower ten percentiles). They found little overall change, except for a reduced number of much above or below normal temperatures during the 1960s and 1970s. Michaels et al. (1998) examined $5^{\circ}$ latitude $\times 5^{\circ}$ longitude monthly temperature anomalies for many grid cells around the world and found an overall decrease in intraannual variance over the past 50 to 100 years. They also examined the daily maximum and minimum temperatures from the United States, China, and the former Soviet Union and found a general decline in the intra-monthly temperature variability. As reported in the SAR, a related analysis by Karl et al. (1995b) found reduced day-to-day variability during the 20th century in the Northern Hemisphere, particularly in the United States and China. Recently, Collins et al. (2000) has identified similar trends in Australia. By analysing a long homogenised daily temperature index for four stations in Northern Europe, Moberg et al. (2000) also found a progressive reduction in all-seasons inter-daily variability of about $7 \%$ between 1880 and 1998. Balling (1998) found an overall decrease in the spatial variance of both satellite-based lowertropospheric measurements from 1979 to 1996 and in near-surface air temperatures from 1897 to 1996.

Consequently, there is now little evidence to suggest that the interannual variability of global temperatures has increased over the past few decades, but there is some evidence to suggest that the variability of intra-annual temperatures has actually quite widely decreased. Several analyses find a decrease in spatial and temporal variability of temperatures on these shorter time-scales.

There have been a number of new regional studies related to changes in extreme temperature events during the 20th century. Gruza et al. (1999) found statistically significant increases in the number of days with extreme high temperatures across Russia using data back to 1961 and on a monthly basis back to 1900 . Frich et al. (2001) analysed data spanning the last half of the 20th century across most of the Northern Hemisphere mid- and high latitudes and found a statistically significant increase ( 5 to $>15 \%)$ in the growing season length in many regions. Heino et al. (1999) also found that there has been a reduction in the number of days with frost (the number of days with minimum temperature $\leq 0^{\circ} \mathrm{C}$ ) in northern and central Europe. Thus, some stations now have as many as 50 fewer days of frost per year compared with earlier in the 20th century. Easterling et al. (2000) found there has been a significant decrease in the number of days below freezing over the central United States (about seven per year). For Canada, Bonsal et al. (2001) also found fewer days with extreme low temperatures during winter, spring and summer, and more days with extreme high temperatures during winter and spring. This has led to a significant increase in the frost-free period. Decreasing numbers of days with freezing temperatures have been found in Australia and New Zealand over recent decades (Plummer et al., 1999; Collins et al., 2000). In addition, while increases in the frequency of warm days have been observed, decreases in the number of cool nights have been stronger. Frich et al. (2001) show a reduced number of days with frost across much of the globe (Figure 2.33) while Michaels et al. (2000) find that much of the warming during the 20th century has been during the cold season in the mid- to high latitudes, consistent with the reduction of extremely low temperatures. Frich et al. (2001) have also found a statistically significant reduction in the difference between the annual extremes of daily maximum and minimum temperatures during the latter half of the 20th century. In China, strong increases in the absolute minimum temperature have been observed, with decreases in the 1-day seasonal extreme maximum temperature (Zhai et al., 1999a) since the 1950s. Wang and Gaffen (2001), however, for a similar period, found an increase in "hot" days in China. Hot days were defined as those days above the 85th percentile during July and August based on an "apparent temperature" index related to human discomfort in China (Steadman, 1984). The number of extremely cold days has also been shown to be decreasing in China (Zhai et al., 1999a). Manton et al. (2001) found significant increases in hot days and warm nights, and decreases in cool days and cold nights since 1961 across the Southeast Asia and South Pacific Region. Jones et al. (1999c) have analysed the 230-year-long daily central England data set that has been adjusted for observing inhomogeneities. They found that the increase in temperature observed in central England corresponds mainly to a reduction in the frequency of much below normal daily temperatures. An increase of the frequency of much above normal temperatures was less apparent.

Analyses of 20th century trends in the United States of shortduration episodes (a few days) of extreme hot or cold weather did not show any significant changes in frequency or intensity (Kunkel et al., 1996, 1999; Karl and Knight, 1997). For Australia, Collins et al. (2000) found higher frequencies of multi-day warm nights and days, and decreases in the frequency of cool days and nights. In an extensive assessment of the change in frequency of heat waves during the latter half of the 20th century, Frich et al. (2001) find some evidence for an increase in heat-wave frequency, but several regions have opposite trends (Figure 2.33c). The extreme heat in the United States during several years in the 1930s dominates the time-series of heat waves in that region. On the other hand, trends in the frequency of extreme apparent tempera- 
Number of frost days with $\operatorname{Tmin}<0^{\circ} \mathrm{C}$

Change (\%) between two multi-decadal averages during second half of the 20th century

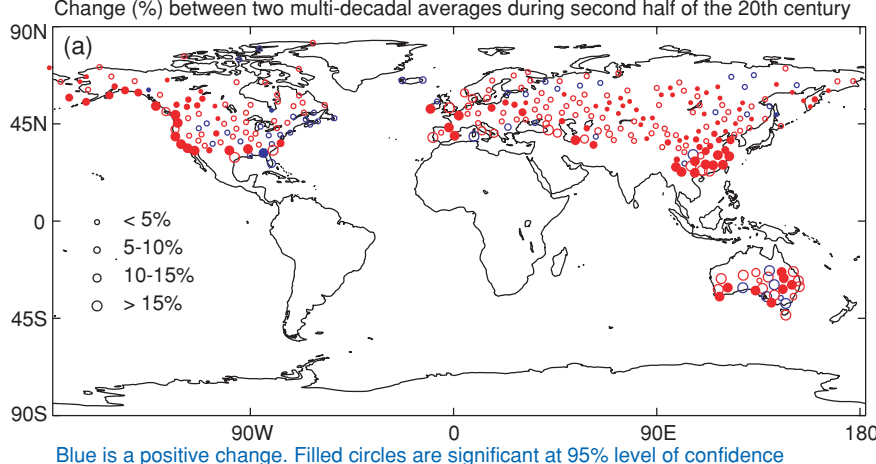

Annual anomalies

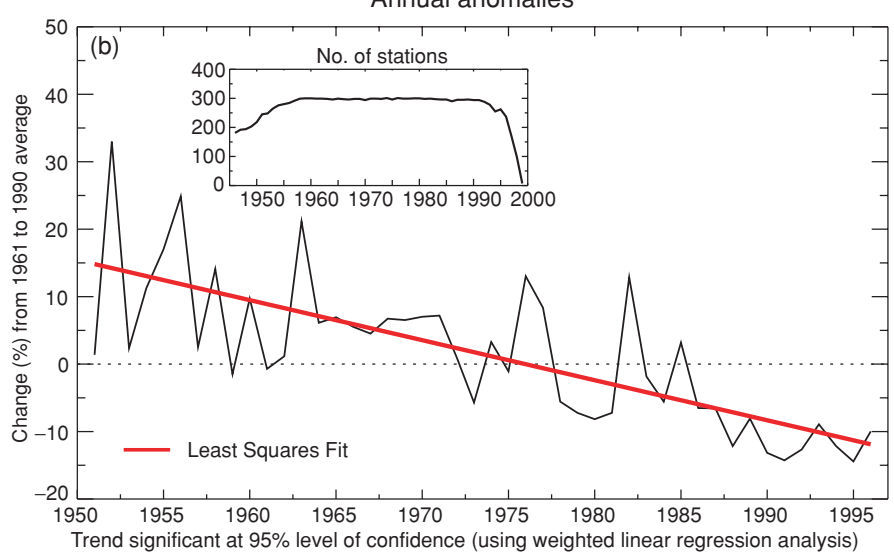

Heat Wave Duration Index

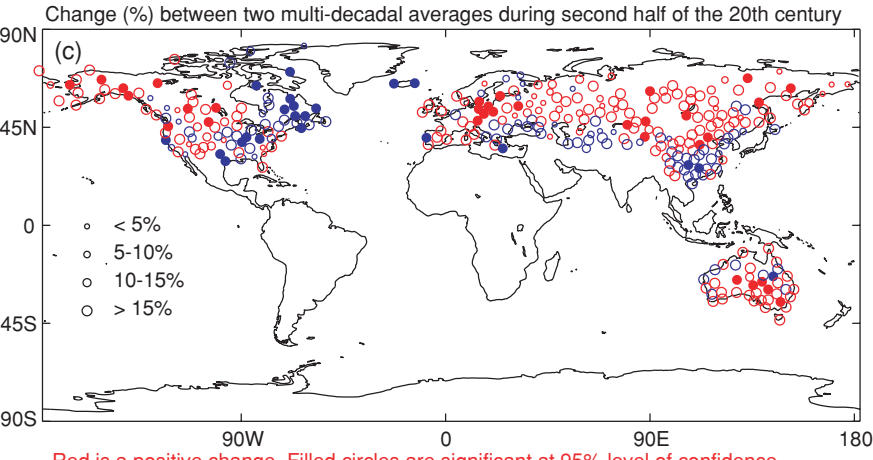

Red is a positive change. Filled circles are significant at $95 \%$ level of confidence

Annual anomalies

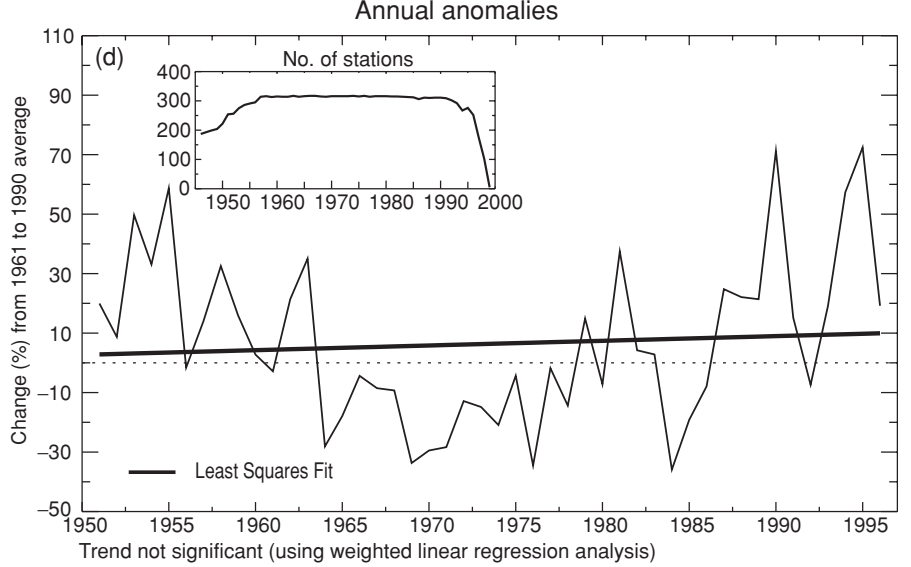

Figure 2.33: Changes in the number of frost days (a, b) and in heat-wave duration (c, d) from Frich et al. (2001). Panel (a) shows the percent changes in the total number of days with a minimum temperature of less than $0^{\circ} \mathrm{C}$ between the first and last half of the period, approximately 1946 to 1999. The red circles indicate negative changes and the blue circles indicate positive changes. Panel (c) shows percentage changes in the maximum number of consecutive days (for periods with $>5$ such days) with maximum temperatures $>5^{\circ} \mathrm{C}$ above the 1961 to 1990 daily normal. The changes are for the first and second half of the period, approximately 1946 to 1999 . The red circles indicate positive changes and the blue circles indicate negative changes. In both panels, the size of each circle reflects the size of the change and solid circles represent statistically significant changes. Panels (b) and (d) show the average annual values of these quantities expressed as percentage differences from their 1961 to 1990 average values. The trend shown in panel (b) is statistically significant at the $5 \%$ level.

tures are significantly larger for 1949 to 1995 during summer over most of the USA (Gaffen and Ross, 1998). Warm humid nights more than doubled in number over 1949 to 1995 at some locations. Trends in nocturnal apparent temperature in the USA, however, are likely to be associated, in part, with increased urbanisation. Nevertheless, using methods and data sets to minimise urban heat island effects and instrument changes, Easterling et al. (2000) arrived at conclusions similar to those of Gaffen and Ross (1998).

During the 1997/98 El Niño event, global temperature records were broken for sixteen consecutive months from May 1997 through to August 1998. Karl et al. (2000) describe this as an unusual event and such a monthly sequence is unprecedented in the observational record. More recently, Wigley (2000) argues that if it were not for the eruption of Mt. Pinatubo, an approximately equal number of record-breaking temperatures would have been set during the El Niño of 1990/91. As temperatures continue to warm, more events like these are likely, especially when enhanced by other factors, such as El Niño.

\subsubsection{Precipitation}

A better understanding of the relationship between changes in total precipitation and intense precipitation events has been achieved since the SAR. Although many areas of the globe have not been analysed, and considerable data remain inaccessible, enough data have been analysed to confirm some basic properties of the changes in extreme precipitation. Groisman et al. (1999) developed a simple statistical model of the frequency of daily precipitation based on the gamma distribution. They applied this model to a variety of regions around the world (40\% of the global land area) during the season of greatest precipitation. Although Wilks (1999) shows that the gamma distribution under some circumstances can underestimate the probability of the highest rainfall amounts, Groisman et al. (1999) applied the distribution to the upper 5 and 10 percentiles of the distribution which are less subject to underestimation. Their analysis period varied from region to region, but within each region it generally spanned at least the last several decades, and for some regions much of the 20th century (Australia, United States, Norway, and South 


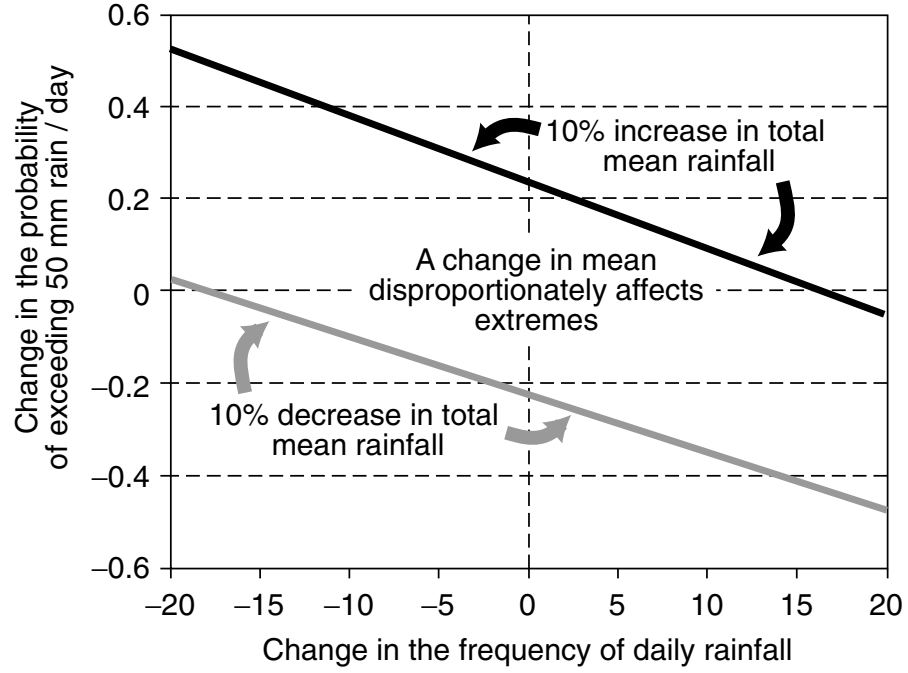

Figure 2.34: An example (from Groisman et al., 1999) of the sensitivity of the frequency of heavy daily rainfall to a shift in the mean total rainfall, based on station data from Guangzhou, China. This example uses a threshold of $50 \mathrm{~mm}$ of precipitation per day. It shows the effects of a $10 \%$ increase and a $10 \%$ decrease in mean total summer rainfall, based on a gamma distribution of the rainfall with a constant shape parameter.

Africa). In the model used by Groisman et al. (1999), the mean total precipitation is also proportional to the shape and scale parameters of the gamma distribution as well as to the probability of precipitation on any given day. The shape parameter of the gamma distribution tends to be relatively stable across a wide range of precipitation regimes, in contrast to the scale parameter. Given the conservative nature of the shape parameter, it is possible to illustrate the relationships between changes in the mean total precipitation, the probability of precipitation (which is proportional to the number of days with precipitation), and changes in heavy precipitation (Figure 2.34). Given no change in the frequency (number of days) of precipitation, a 10\% change in the mean total precipitation is amplified to a larger percentage change in heavy precipitation rates compared to the change in the mean. Using the statistical theory of extremes, Katz (1999) obtained results consistent with those of Groisman et al. (1999). For many regions of the world it appears that the changes in the frequency or probability of precipitation events are either small enough, or well enough expressed in the high rainfall rates (Karl and Knight, 1998; Gruza et al., 1999; Haylock and Nicholls, 2000) that an increase in the mean total precipitation is disproportionately reflected in increased heavy precipitation rates (Figure 2.35).

Given the patterns of mean total precipitation changes (Section 2.5.2) during the 20th century, it could be anticipated that, in general, for those areas with increased mean total precipitation, the percentage increase in heavy precipitation rates should be significantly larger, and vice versa for total precipitation decreases. Regional analyses of annual precipitation in the United States (Karl and Knight, 1998; Trenberth, 1998a; Kunkel et al., 1999); Canada (Stone et al., 1999); Switzerland (Frei and Schär, 2001); Japan ( Iwashima and Yamamoto, 1993; Yamamoto and Sakurai, 1999); wintertime precipitation in the UK (Osborn et al., 2000); and rainy season precipitation in Norway, South

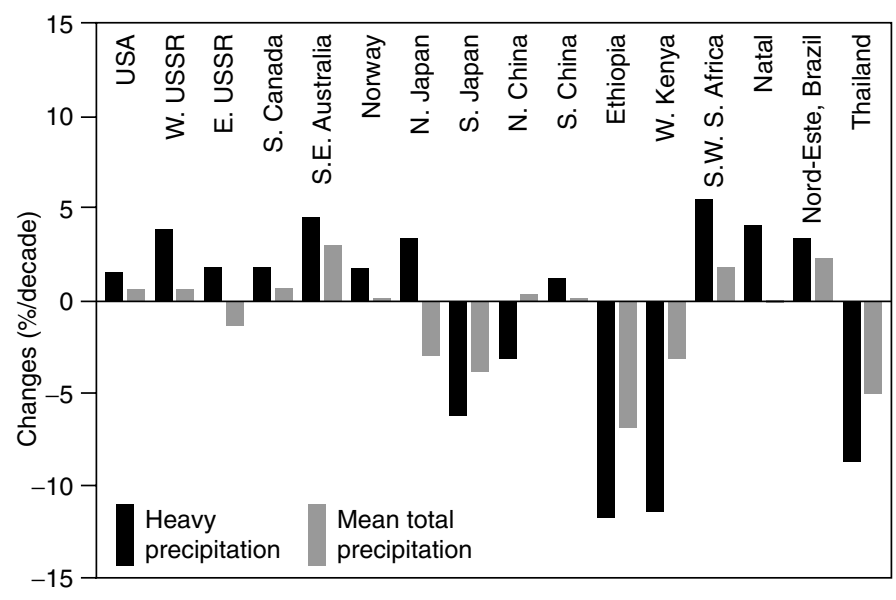

Figure 2.35: Linear trends (\%/decade) of heavy precipitation (above the 90th percentile) and total precipitation during the rainy season over various regions of the globe. Seasons for each region usually span at least 50 years. Note that the magnitudes of the changes in heavy precipitation frequencies are always higher than changes in mean precipitation totals (Easterling et al., 2000).

Africa, the Nord Este of Brazil, and the former USSR (Groisman et al., 1999; Gruza et al., 1999; Easterling et al., 2000) confirm this characteristic of an amplified response for the heavy and extreme events.

Increases in heavy precipitation have also been documented even when mean total precipitation decreases (for example, see Northern Japan in Figure 2.35, or Manton et al., 2001). This can occur when the probability of precipitation (the number of events) decreases, or if the shape of the precipitation distribution changes, but this latter situation is less likely (Buffoni et al., 1999; Groisman et al., 1999; Brunetti et al., 2000a,b). For example, in Siberia for the summer season during the years 1936 to 1994 there was a statistically significant decrease in total precipitation of $1.3 \% /$ decade, but the number of days with precipitation also decreased. This resulted in an increase (1.9\%/decade) in the frequency of heavy rainfall above $25 \mathrm{~mm}$. The opposite can also occur when the number of rainfall events increases; thus Førland et al. (1998) found no trends in 1-day annual maximum precipitation in the Nordic countries, even when mean total precipitation increased.

There has also been a 10 to $45 \%$ increase in heavy rainfall, as defined by the 99th percentile of daily totals, over many regions of Australia from 1910 to 1995, but few individual trends were statistically significant (Hennessy et al., 1999). In southwest Australia, however, a 15\% decrease has been observed in winter rainfall on very wet days (Hennessy et al., 1999; Haylock and Nicholls, 2000).

In Niger, a recent analysis of hourly rainfall data (Shinoda $e t$ al., 1999) reveals that the droughts in the 1970s and 1980s were characterised primarily by a reduced frequency of heavy rainfall events (those exceeding $30 \mathrm{~mm} /$ day) rather than by a reduction in rainfall amount within heavy events. Such a result is still consistent with the model of Groisman et al. (1999), as a decrease in the 
Max. 5 day precipitation total

Change (\%) between two multi-decadal averages during second half of 20th century

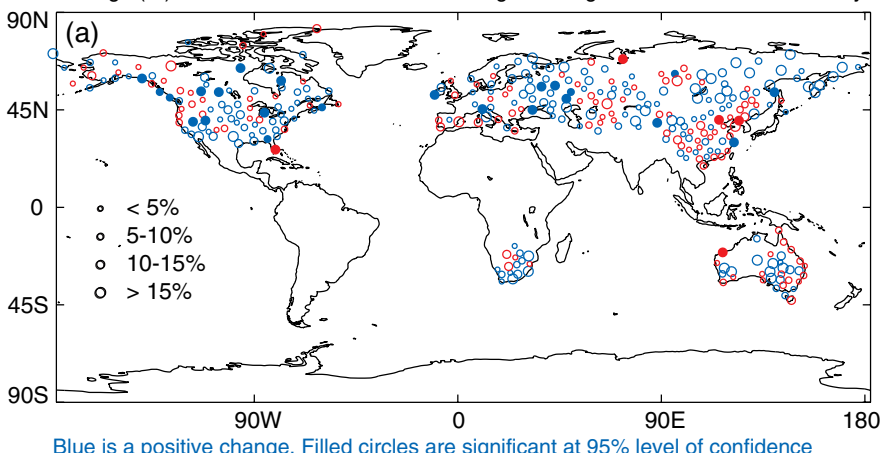

Blue is a positive change. Filled circles are significant at $95 \%$ level of confidence

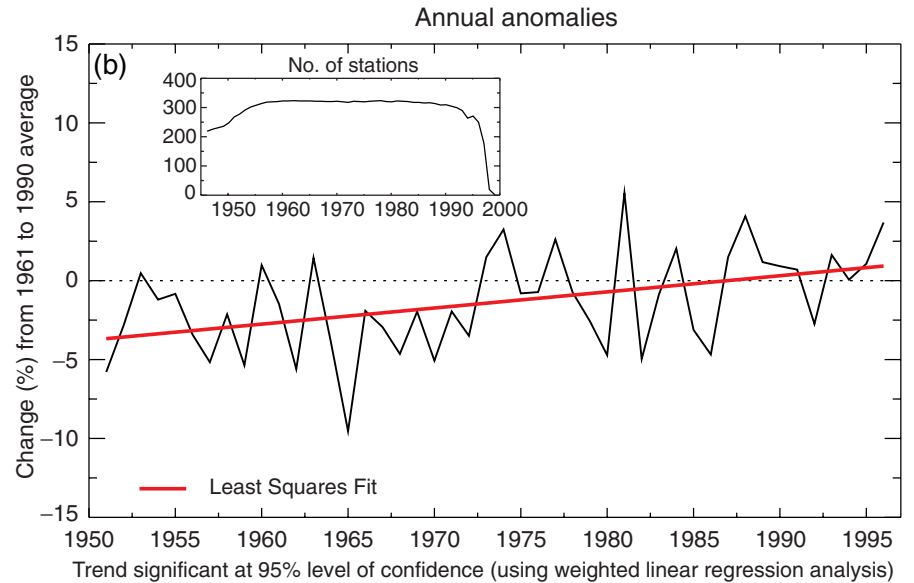

Fraction of total precipitation in the uppermost 5 percentile

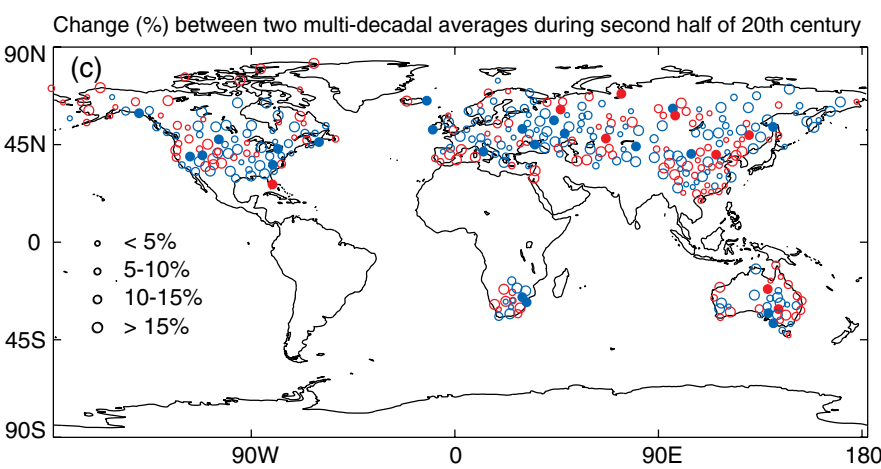

Blue is a positive change. Filled circles are significant at $95 \%$ level of confidence

Annual anomalies

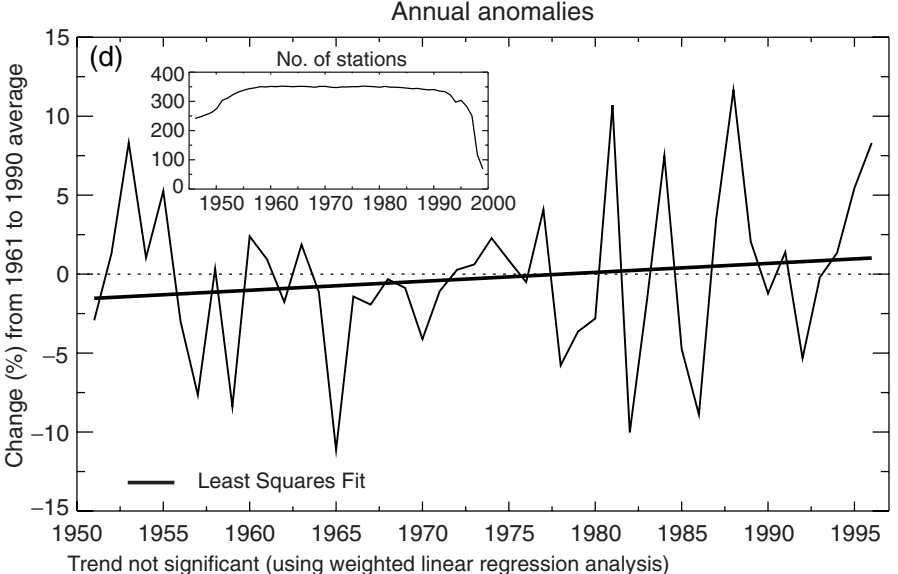

Figure 2.36: Changes in the maximum annual 5-day precipitation total $(\mathrm{a}, \mathrm{b})$ and in the proportion of annual precipitation occurring on days on which the 95th percentile of daily precipitation, defined over the period 1961 to 1990, was exceeded (c, d). The analysis shown is from Frich $e t$ al. (2001). Panels (a) and (c) show percentage changes in these quantities between the first and last half of the period, approximately 1946 to 1999 . In both panels, the red circles indicate negative changes and the blue circles indicate positive changes. The size of each circle reflects the size of the change and solid circles represent statistically significant changes. Panels (b) and (d) show the average annual values of the quantities expressed as percentage differences from their 1961 to 1990 average values. The trend shown in panel (b) is statistically significant at the 5\% level.

frequency of rainfall events has been responsible for the decrease in total rainfall. In the Sahel region of Nigeria, however, there has been a decrease in the heaviest daily precipitation amounts, coincident with an overall decrease in annual rainfall. This pattern is apparent throughout the Sudano-Sahel Zone, including the Ethiopian plateau (Nicholson, 1993; Tarhule and Woo, 1998; Easterling et al., 2000). Again, it is apparent that there has been an amplified response of the heaviest precipitation rates relative to the percentage change in total precipitation.

Since large portions of the mid- and high latitude land areas have had increasing precipitation during the last half the 20th century, the question arises as to how much of this area is affected by increases in heavy and extreme precipitation rates. The Frich $e t$ al. (2001) analysis suggests an overall increase in the area affected by more intense daily rainfall. Figure 2.36 shows that widely distributed parts of the mid- and high latitudes have locally statistically significant increases in both the proportion of mean annual total precipitation falling into the upper five percentiles and in the annual maximum consecutive 5-day precipitation total. However, for the regions of the globe sampled taken as a whole, only the latter statistic shows a significant increase. Regional analyses in
Russia (Gruza et al., 1999), the United States (Karl and Knight, 1998) and elsewhere (Groisman et al., 1999; Easterling et al., 2000) confirm this trend. Although the trends are by no means uniform, as would be anticipated with the relatively high spatial and interannual variability of precipitation, about $10 \%$ of the stations analysed show statistically significant increases at the 5\% level. This equates to about a $4 \%$ increase in the annual maximum 5-day precipitation total (Figure 2.36b). The number of stations reflecting a locally significant increase in the proportion of total annual precipitation occurring in the upper five percentiles of daily precipitation totals outweighs the number of stations with significantly decreasing trends by more than 3 to 1 (Figure 2.36c). Although not statistically significant when averaging over all stations, there is about a $1 \%$ increase in the proportion of daily precipitation events occurring in the upper five percentiles (Figure 2.36d). Overall, it is likely that there has been a 2 to $4 \%$ increase in the number of heavy precipitation events when averaged across the mid- and high latitudes.

It has been noted that an increase (or decrease) in heavy precipitation events may not necessarily translate into annual peak (or low) river levels. For example, in the United States, Lins 
and Slack (1999) could not detect an increase in the upper quantiles of streamflow, despite the documented increase in heavy and extreme precipitation events. It is possible that this null result is partly due to the method of analysis, but it is also attributable to the timing of the annual peak streamflow discharge, which in the United States is usually in late winter or early spring. A reduced snow cover extent in the mountainous West changes the peak river flow, as does timing of increases in heavy and extreme precipitation reported in the United States, which is best reflected during the warm season. Groisman et al. (2001) and Zhang et al. (2000) also show reduced peak streamflow in areas with reduced spring snow cover extent. Nonetheless, in much of the United States where spring snow melt does not dominate peak or normal flow, Groisman et al. (2001) show increasing high streamflow related to increasing heavy precipitation.

It is noteworthy that the influence of warmer temperatures and increased water vapour in the atmosphere (Section 2.5.3) are not independent events, and are likely to be jointly related to increases in heavy and extreme precipitation events.

\subsubsection{Is There Evidence for Changes in Extreme Weather or Climate Events?}

In this section we assess changes in the intensity and frequency of various weather phenomena. One aspect of change that is important, but which is beyond the analysis of present records, relates to changes in the tracks of storms. Severe storms are often rare, so the analysis of large areas and long lengths of homogeneous storm records are required to assess changes. So far this combination of data is not available.

\subsubsection{Tropical cyclones}

This section updates the information provided in the SAR regarding changes in tropical cyclones across various ocean basins and those affecting the nearby continents. As reported in the SAR, a part of the multi-decadal trend of tropical cyclones occurring in the Australian region $\left(105^{\circ}\right.$ to $\left.160^{\circ} \mathrm{E}\right)$ is likely to be artificial, as the forecasters in the region no longer classify some weak ( $>990 \mathrm{hPa}$ central pressure) systems as "cyclones" (Nicholls et al., 1998). By considering only the moderate and intense tropical cyclones (central pressure $\leq 990 \mathrm{hPa}$ ), this artificial trend is eliminated. The remaining moderate and strong tropical cyclones reveal a numerical decline since the late 1980s, but the trend is not statistically significant. Similarly, the trend in intense tropical cyclones (minimum central pressure below $970 \mathrm{hPa}$ ) is not significantly different from zero. Nicholls et al. (1998) attributed the decrease in moderate cyclones to more frequent occurrences of El Niño during the 1980s and 1990s. However, a weak trend in the intense tropical cyclones implies that while ENSO modulates the total frequency of cyclones in the region, other factors must be more important in regulating their intensity. For example, new work by Higgins and Shi (2000) and Maloney and Hartmann (2001) show that 30 to 80 day Madden-Julian oscillations modulate tropical cyclone activity.

As reported in the SAR, the north-east sub-tropical Pacific has experienced a significant upward trend in tropical cyclone frequency in the short period examined, but additional data since
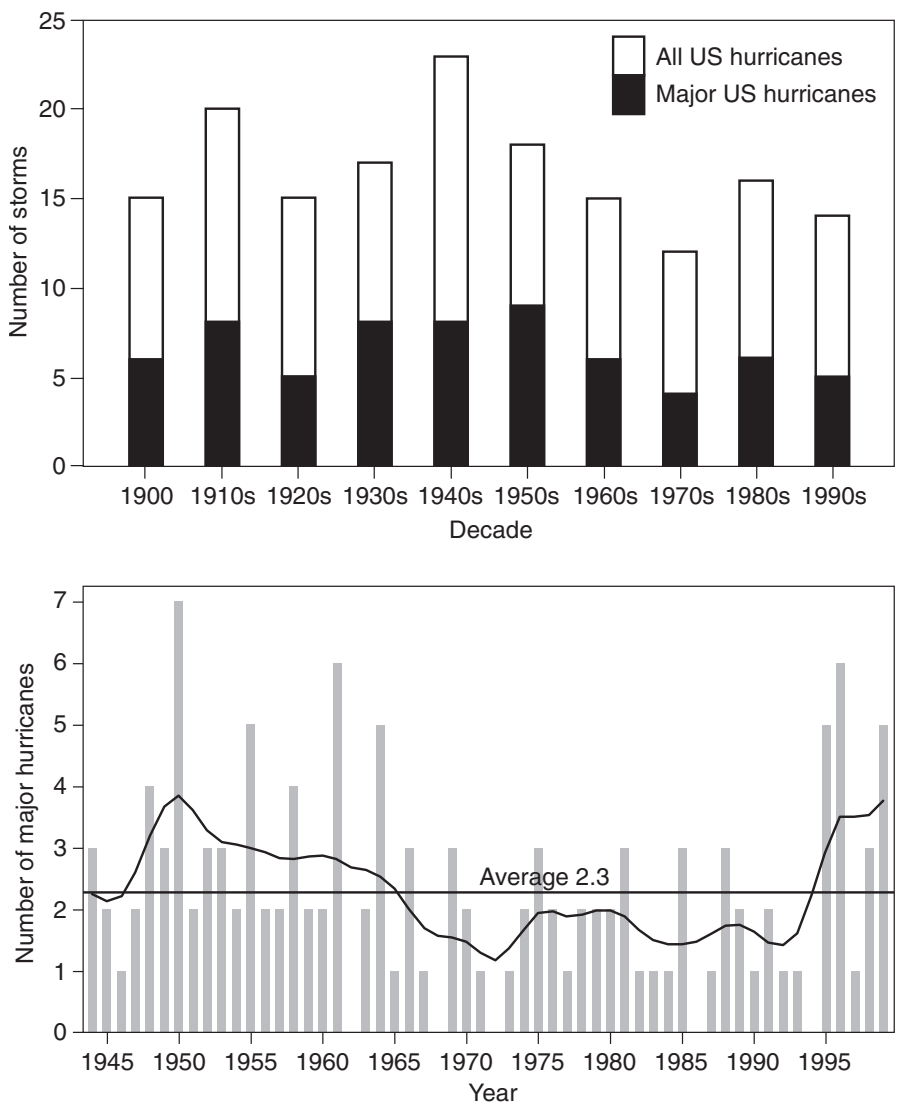

Figure 2.37: Top figure, decadal variations in hurricanes making landfall in the USA (updated from Karl et al., 1995). Bottom figure, interannual variability in the number of major hurricanes (SaffirSimpson categories 3, 4, and 5) and the long-term average across the North Atlantic (from Landsea et al., 1999).

that time show no appreciable trend. There is no appreciable longterm variation of the total number of tropical storm strength cyclones observed in the north Indian, south-west Indian and south-west Pacific Oceans east of $160^{\circ}$ E. (Neumann, 1993; Lander and Guard, 1998). For the north-west sub-tropical Pacific basin, Chan and Shi (1996) found that the frequency of typhoons and the total number of tropical storms and typhoons have been more variable since about 1980. There was an increase from 1981 to 1994 , which was preceded by a nearly identical magnitude of decrease from about 1960 to 1980 . No analysis has been done on the frequency of intense typhoons (having winds of at least 50 $\mathrm{m} / \mathrm{s}$ ) due to an overestimation of the intensity of such storms in the 1950s and 1960s (Black, 1993).

There has been an extensive analysis of the North Atlantic basin for the entire basin back to 1944, and also for the United States landfall tropical storms and hurricanes back to 1899 . The all-basin data, however, have been affected by a bias in the measurement of strong hurricanes. This bias has been removed in an approximate way to provide estimates of the true occurrence of intense (or major) hurricanes since 1944 in the North Atlantic (Landsea, 1993). Earlier events lack reliable data on the strong inner core of the hurricanes. The United States record of landfall frequency and intensity of hurricanes is very reliable because of 
the availability of central pressure measurements at landfall (Jarrell et al., 1992). Both of these data sets continue to show considerable inter-decadal variability, but no significant long-term trends (Figure 2.37, from Landsea et al., 1999). Active years occurred from the late 1940s to the mid-1960s, quiet years occurred from the 1970s to the early 1990s, and then there was a shift again to active conditions from 1995 to 1999. Concurrent with these frequency changes, there have been periods with a strong mean intensity of the North Atlantic tropical cyclones (mid1940 s to the 1960s and 1995 to 1999) and a weak intensity (1970s to early 1990s). There has been no significant change in the peak intensity reached by the strongest hurricane each year (Landsea $e t$ al., 1996). As might be anticipated, there is a close correspondence between the intensity of hurricanes in the North Atlantic and those making landfall in the United States (Figure 2.37).

Using historical records, Fernandez-Partagas and Diaz (1996) estimated that overall Atlantic tropical storm and hurricane activity for the years 1851 to 1890 was $12 \%$ lower than the corresponding forty year period of 1951 to 1990 , although little can be said regarding the intense hurricanes. They based this assessment upon a constant ratio of USA landfalling tropical cyclones to all-basin activity, which is likely to be valid for multidecadal time-scales. However, this also assumes that FernandezPartagas and Diaz were able to uncover all USA landfalling tropical cyclones back to 1851 , which may be more questionable.

\subsubsection{Extra-tropical cyclones}

Extra-tropical cyclones are baroclinic low pressure systems that occur throughout the mid-latitudes of both hemispheres. Their potential for causing property damage, particularly as winter storms, is well documented, where the main interest is in wind and wind-generated waves. In place of direct wind measurements, which suffer from lack of consistency of instrumentation, methodology and exposure, values based on SLP gradients have been derived which are more reliable for discerning long-term changes. Over the oceans, the additional measurements of wave heights and tide gauge measurements provide additional ways of indirectly evaluating changes in extra-tropical storm strength and frequency (see Chapter 11, Section 11.3.3). Global analyses of changes in extra-tropical storm frequency and intensity have not been attempted, but there have been several large-scale studies. Jones et al. (1999c) developed a gale index of geostrophic flow and vorticity over the UK for the period 1881 to 1997. This revealed an increase in the number of severe gale days over the UK since the 1960s, but no long-term increase when considering the century period. Serreze et al. (1997) found increases in cold season cyclones in the Arctic region for the period 1966 to 1993. Angel and Isard (1998) found significant increases in strong cyclones $(<993 \mathrm{mb})$ in the Great Lakes region from 1900 to 1990 during the cold season. Graham and Diaz (2001) find evidence for increases in strong cyclones over the Pacific Ocean between 25 and $40^{\circ} \mathrm{N}$ since 1948 and link the increase to increasing sea surface temperatures in the western Tropical Pacific. Alexandersson et al. $(1998,2000)$ similarly studied extreme geostrophic wind events in the north-western European area based on homogenised observations during the period 1881 to 1998. These studies revealed an increase in the number of extreme wind events around and to the north of the North Sea. The WASA group (1998) similarly investigated the storm related sea level variations at gauge stations in the south-eastern part of the North Sea. They found no long-term trend during the last 100 years, but a clear rise since a minimum of storminess in the 1960s, which is consistent with the rise in extreme geostrophic wind found by Jones et al. (1999c). This increase is also consistent with changes in the NAO (Figure 2.30). Some analyses have focused on hemispheric changes in cyclone activity. Lambert (1996) analysed gridded SLP over both the North Atlantic and North Pacific Oceans for the period 1891 to 1991 . He found a significant increase in intense extra-tropical storms, especially over the last two decades of his analysis, but the data were not completely homogenised. Simmonds and Keay (2000) used data from 1958 to 1997 in the Southern Hemisphere and found an increase in cyclone activity through 1972 before decreasing through 1997 with strong decreases during the 1990s.

Hourly values of water levels provide a unique record of tropical and extra-tropical storms where stations exist. Zhang et al. (1997a) have analysed century-long records along the East Coast of the United States. They calculated several different measures of storm severity, but did not find any long-term trends. On the other hand, they did find that the effect of sea level rise over the last century has exacerbated the beach erosion and flooding from modern storms that would have been less damaging a century ago.

Another proxy for cyclone intensity is wave height (see Chapter 11, Section 11.3.3). Several studies report increased wave height over the past three decades in the North Atlantic (approximately $2.5 \mathrm{~cm} / \mathrm{yr}$ ) and in coastal areas, though no longerterm trends were evident (Carter and Draper, 1988; Bacon and Carter, 1991; Bouws et al., 1996; Kushnir et al., 1997; WASA Group, 1998).

It appears that recent work points towards increases over time in extra-tropical cyclone activity during the latter half of the 20th century in the Northern Hemisphere, and decreased activity in the Southern Hemisphere. However, the mechanisms involved are not clear, and it is not certain whether the trends are multi-decadal fluctuations, or rather part of a longer-term trend. Furthermore decreased cyclone activity in higher latitudes of the Southern Hemisphere is not obviously consistent with an increase in the positive phase of the Antarctic Oscillation in the last fifteen years or so (Section 2.6.6). A more fundamental question is whether we would expect more or fewer extra-tropical cyclones with increased warming. As pointed out by Simmonds and Keay (2000), the specific humidity increases as temperatures increase, and this increased moisture should enhance extra-tropical cyclones, but Zhang and Wang (1997) suggest that cyclones transport energy more efficiently in a more moist atmosphere, therefore requiring fewer extra-tropical cyclones (see Chapters 7 and 10 for more discussion).

\subsubsection{Droughts and wet spells}

In the SAR, an intensification of the hydrological cycle was projected to occur as the globe warms. One measure of such intensification is to examine whether the frequency of droughts and wet spells are increasing. Karl et al. (1995c) examined the 
proportion of land areas having a severe drought and a severe moisture surplus over the United States. Dai et al. (1998) extended this analysis to global land areas using the water balance approach of the Palmer Drought Severity Index. Longterm global trends for 1900 to 1995 are relatively small for both severe drought and wet area statistics. However, during the last two to three decades, there have been some increases in the globally combined severe dry and wet areas, resulting from increases in either the dry area, e.g., over the Sahel, eastern Asia and southern Africa or the wet areas, e.g., over the United States and Europe. Most of the increases occurred after 1970. Except for the Sahel, however, the magnitude of dry and wet areas of the recent decades is not unprecedented during this century, but it should be noted that rainfall in the Sahel since the height of the drought has substantially increased. In related work, Frich et al. (2001) found that in much of the mid- and high latitudes, there has been a statistically significant increase in both the number of days with precipitation exceeding $10 \mathrm{~mm}$ per day and in the number of consecutive days with precipitation during the second half of the 20th century.

Recent changes in the areas experiencing severe drought or wet spells are closely related to the shift in ENSO towards more warm events since the late 1970s, and coincide with record high global mean temperatures. Dai et al. (1998) found that for a given value of ENSO intensity, the response in areas affected by drought or excessive wetness since the 1970s is more extreme than prior to the 1970s, also suggesting an intensification of the hydrological cycle.

\subsubsection{Tornadoes, hail and other severe local weather}

Small-scale severe weather phenomena (SCSWP) are primarily characterised by quasi-random temporal and spatial events. These events, in turn, have local and regional impacts, often with significant damage and sometimes loss of life. Tornadoes and thunderstorms and related phenomena such as lightning, hail, wind, dust, water spouts, downpours and cloudbursts belong to this group. In the light of the very strong spatial variability of SCSWP, the density of surface meteorological observing stations is too coarse to measure all such events. Moreover, areally consistent values of SCSWP are inherently elusive. Statistics of relatively rare events are not stable at single stations, observational practices can be subjective and change over time, and the metadata outlining these practices are often not readily available to researchers. For these reasons, monitoring the occurrence of local maxima and minima in smoothed SCSWP series, as well as checking for trends of the same sign for different but related SCSWP (e.g., thunderstorms, hail, cloud bursts), are important for checking inconsistencies. Because of the inherent difficulty in working with these data, there have been relatively few largescale analyses of changes and variations in these events. Nonetheless, a few new regional analyses have been completed since the SAR.

A regional analysis by Dessens (1995) and more recent global analysis by Reeve and Toumi (1999) show that there is a significant interannual correlation between hail and lightning and mean minimum temperature and wet bulb temperatures. Using a three-year data set, Reeve and Toumi (1999) found a statistically

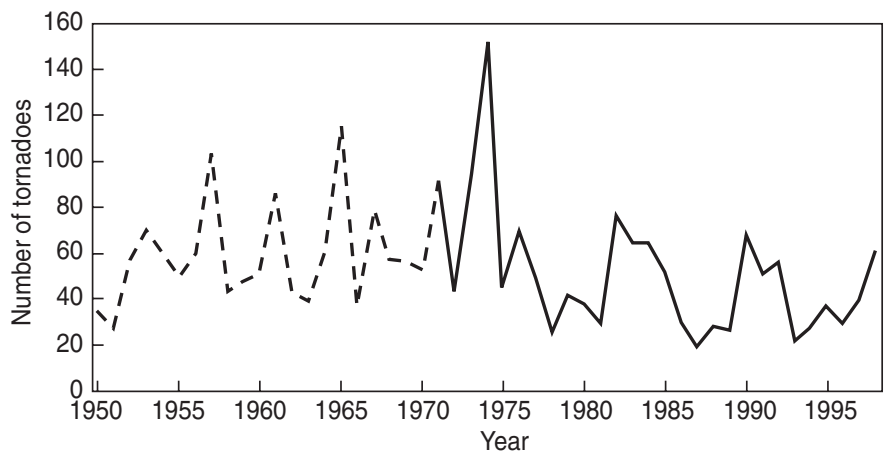

Figure 2.38: Annual total number of very strong through violent (F3-F5) tornadoes reported in the USA, which are defined as having estimated wind speeds from approximately 70 to $164 \mathrm{~ms}^{-1}$. The Fujita tornado classification scale was implemented in 1971. Prior to 1971, these data are based on storm damage reports (National Climatic Data Center, NOAA).

significant relationship between lightning frequency and wet bulb temperature. They show that with a $1^{\circ} \mathrm{C}$ increase in global wetbulb temperature there is a $40 \%$ increase in lightning activity, with larger increases over the Northern Hemisphere land areas (56\%). Unfortunately, there are few long-term data sets that have been analysed for lightning and related phenomena such as hail or thunderstorms, to calculate multi-decadal hemispheric or global trends.

A regional analysis assessed the temporal fluctuations and trends in hail-day and thunder-day occurrences during a 100year period, from 1896 to 1995 , derived from carefully screened records of 67 stations distributed across the United States. Upward hail day trends were found in the High PlainsRockies and the south-east, contrasting with areas with no trend in the northern Midwest and along the East Coast, and with downward trends elsewhere (Changnon and Changnon, 2000). The major regions of decrease and increase in hail activity match regions of increased and decreased thunder activity for 1901 to 1980 well (Changnon, 1985; Gabriel and Changnon, 1990) and also crop-hail insurance losses (Changnon et al., 1996; Changnon and Changnon, 1997). In general, hail frequency shows a general decrease for most of the United States over the last century, with increases over the High Plains, the region where most of the crop-hail damage occurs in the United States. So, despite an increase in minimum temperature of more than $1{ }^{\circ} \mathrm{C}$ since 1900 and an increase in tropospheric water vapour over the United States since 1973 (when records are deemed reliable), no systematic increase in hail or thunder days was found.

In south Moravia, Czech Republic, a decreasing linear trend in the frequency of thunderstorms, hailstorms and heavy rain from 1946 to 1995 was related to a significant decrease in the occurrence of these phenomena during cyclonic situations, when 90\% of these phenomena occur in that region (Brázdil and Vais, 1997). Temperatures have increased in this area since 1946.

Since 1920, the number of tornadoes reported annually in the United States has increased by an order of magnitude, but this increase reflects greater effectiveness in collecting tornado 
reports (Doswell and Burgess, 1988; Grazulis, 1993; Grazulis et al., 1998). On the other hand, severe tornadoes are not easily overlooked. Restricting the analysis to very strong and violent tornadoes results in a much different assessment (Figure 2.38) showing little long-term change, though some years like 1974 show a very large number of tornadoes. Furthermore, consideration of the number of days with tornadoes, rather than number of tornadoes, reduces the artificial changes that result from modern, more detailed damage surveys (e.g., Doswell and Burgess, 1988). The data set of "significant" tornado days developed by Grazulis (1993) shows a slow increase in number of days with significant tornadoes from the early 1920s through the 1960s, followed by a decrease since that time.

\subsubsection{Summary}

Based on new analyses since the SAR, it is likely that there has been a widespread increase in heavy and extreme precipitation events in regions where total precipitation has increased, e.g., the mid- and high latitudes of the Northern Hemisphere. Increases in the mean have often been found to be amplified in the highest precipitation rates total. In some regions, increases in heavy rainfall have been identified where the total precipitation has decreased or remained constant, such as eastern Asia. This is attributed to a decrease in the frequency of precipitation. Fewer areas have been identified where decreases in total annual precipitation have been associated with decreases in the highest precipitation rates, but some have been found. Temperature variability has decreased on intra-seasonal and daily time-scales in limited regional studies. New record high night-time minimum temperatures are lengthening the freeze and frost season in many mid- and high latitude regions. The increase in global temperatures has resulted mainly from a significant reduction in the frequency of much below normal seasonal mean temperatures across much of the globe, with a corresponding smaller increase in the frequency of much above normal temperatures. There is little sign of long-term changes in tropical storm intensity and frequency, but inter-decadal variations are pronounced. Owing to incomplete data and relatively few analyses, we are uncertain as to whether there has been any large-scale, long-term increase in the Northern Hemisphere extra-tropical cyclone intensity and frequency though some, sometimes strong, multi-decadal variations and recent increases were identified in several regions. Limited evidence exists for a decrease in cyclone frequency in the Southern Hemisphere since the early 1970s, but there has been a paucity of analyses and data. Recent analyses of changes in severe local weather (tornadoes, thunder days, lightning and hail) in a few selected regions provide no compelling evidence for widespread systematic long-term changes.

\subsection{Are the Observed Trends Internally Consistent?}

It is very important to compare trends in the various indicators to see if a physically consistent picture emerges, as this will critically affect the final assessment of our confidence in any such changes. A number of qualitative consistencies among the various indicators of climate change have increased our confidence in our analyses of the historical climate record: Figure 2.39a and $\mathrm{b}$ summarises the changes in various temperature and hydrological indicators, respectively, and provides a measure of confidence about each change. Of particular relevance are the changes identified below:

- Temperature over the global land and oceans, with two estimates for the latter, are measured and adjusted independently, yet all three show quite consistent increasing trends ( 0.52 to $0.61^{\circ} \mathrm{C} /$ century) over the 20th century.

- The nearly worldwide decrease in mountain glacier extent and mass is consistent with 20th century global temperature increases. A few recent exceptions in maritime areas have been affected by atmospheric circulation variations and related precipitation increases.

- Though less certain, substantial proxy evidence points to the exceptional warmth of the late 20th century relative to the last 1,000 years. The 1990s are likely to have been the warmest decade of the past 1,000 years over the Northern Hemisphere as a whole.

- Satellite and balloon measurements agree that lower-tropospheric temperatures have increased only slightly since 1979, though there has been a faster rate of global surface temperature increase. Balloon measurements indicate a larger lowertropospheric temperature increase since 1958, similar to that shown by global surface temperature measurements over the same period. Balloon and satellite measurements agree that lower-stratospheric temperatures have declined significantly since 1979.

- Since 1979 , trends in worldwide land-surface air temperature derived from weather stations in the Northern Hemisphere, in regions where urbanisation is likely to have been strong, agree closely with satellite derived temperature trends in the lower troposphere above the same regions. This suggests that urban heat island biases have not significantly affected surface temperature over the period.

- The decrease in the continental diurnal temperature range since around 1950 coincides with increases in cloud amount and, at least since the mid-1970s in the Northern Hemisphere, increases in water vapour.

- Decreases in spring snow cover extent since the 1960s, and in the duration of lake and river ice over at least the last century, relate well to increases in Northern Hemispheric surface air temperatures.

- The systematic decrease in spring and summer Arctic sea-ice extent in recent decades is broadly consistent with increases of temperature over most of the adjacent land and ocean. The large reduction in the thickness of summer and early autumn Arctic sea ice over the last thirty to forty years is consistent 
with this decrease in spatial extent, but we are unsure to what extent poor temporal sampling and multi-decadal variability are affecting the conclusions.

- The increases in lower-tropospheric water vapour and temperature since the mid-1970s are qualitatively consistent with an enhanced hydrological cycle. This is in turn consistent with a greater fraction of precipitation being delivered from extreme and heavy precipitation events, primarily in areas with increasing precipitation, e.g., mid- and high latitudes of the Northern Hemisphere.

- Where data are available, changes in precipitation generally correspond with consistent changes in streamflow and soil moisture.

We conclude that the variations and trends of the examined indicators consistently and very strongly support an increasing global surface temperature over at least the last century, although substantial shorter-term global and regional deviations from this warming trend are very likely to have occurred.
Temperature Indicators

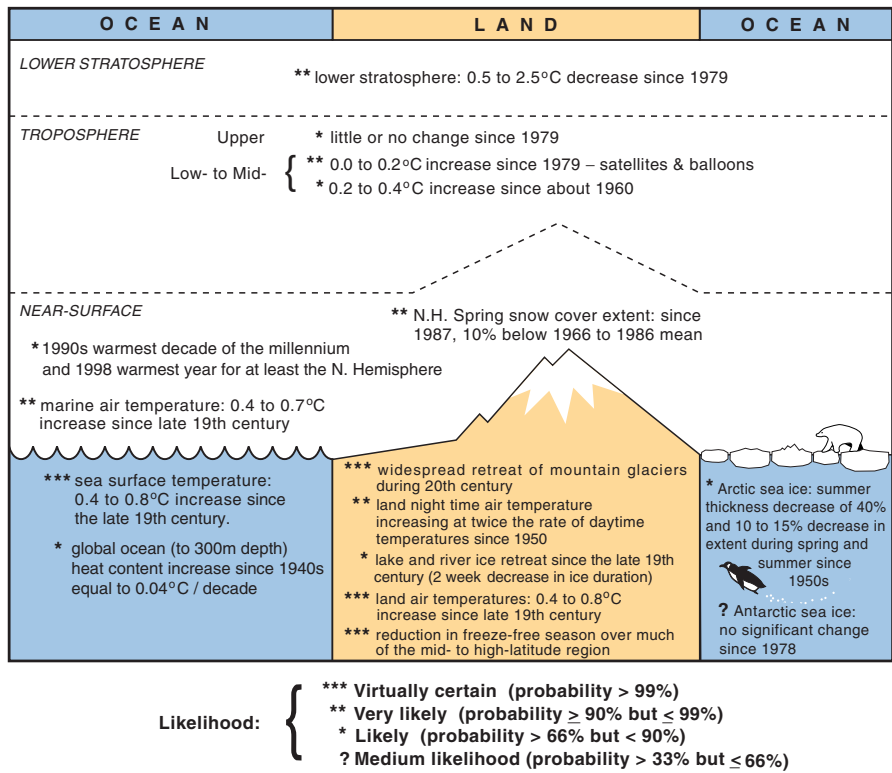

Figure 2.39a: Schematic of observed variations of various temperature indicators.

Hydrological and Storm-Related Indicators

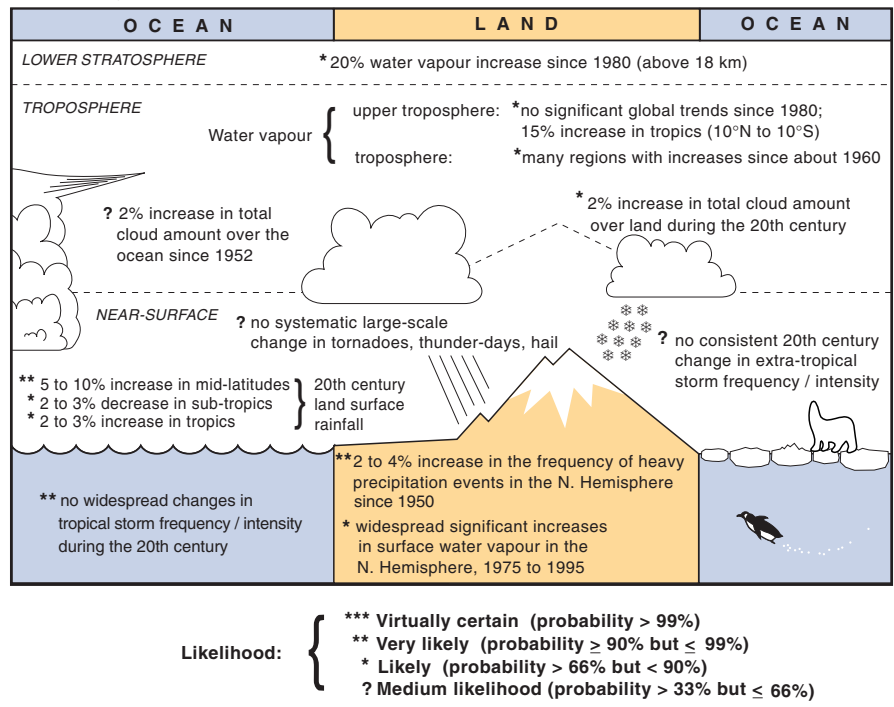

Figure 2.39b: Schematic of observed variations of various hydrological and storm-related indicators. 


\section{References}

Adkins, J.F., E.W. Boyle, L. Keigwin and E. Cortijo, 1997: Variability of the North Atlantic thermohaline circulation during the Last interglacial period. Nature, 390, 154-156.

Akinremi, O.O., S.M. McGinn and H.W. Cutforth, 1999: Precipitation trends on the Canadian Prairies. J. Climate, 12, 2996-3003.

Alexandersson, H., T. Schmith, K. Iden and H. Tuomenvirta, 1998: Long-term variations of the storm climate over NW Europe. Global Atmosphere and Ocean Systems, 6, 97-120.

Alexandersson, H., T. Schmith, K. Iden and H. Tuomenvirta, 2000: Trends in storms in NW Europe derived from an updated pressure data set. Clim. Res., 14, 71-73.

Allan, R.J., 2000: ENSO and climatic variability in the last 150 years. In: El Niño and the Southern Oscillation: Multiscale Variability, Global and Regional Impacts, edited by Diaz, H.F. and V. Markgraf, Cambridge University Press, Cambridge, UK, pp. 3-56.

Allard, M., B. Wang and J.A. Pilon, 1995: Recent cooling along the southern shore of Hudson Strait Quebec, Canada, documented from permafrost temperature measurements. Arctic and Alpine Research, 27, 157-166.

Alley, R.B. and P.U. Clark, 1999: The deglaciation of the Northern Hemisphere: a global perspective. Ann. Rev. Earth Planet. Sci., 149182.

Alley, R.B., D.A. Meese, C.A. Shuman, A.J. Gow, K.C. Taylor, P.M Grootes, J.W.C. White, M. Ram, E.D. Waddington, P.A. Mayewski and G.A. Zielinski, 1993: Abrupt increase in Greenland snow accumulation at the end of the Younger Dryas event. Nature, 362, 527-529.

Alley, R.B., P.A. Mayewski, T. Sowers, M. Stuiver, K.C. Taylor and P.U. Clark, 1997: Holocene climatic instability: A prominent, widespread event 8200 years ago. Geology, 25, 483-486.

Ames, A., 1998: A documentation of glacier tongue variations and lake development in the Cordillera Blanca, Peru. Z. Gletscherkd. Glazialgeol., 34(1), 1-36.

Anderson, W.L., D.M. Robertson and J.J. Magnuson, 1996: Evidence of recent warming and El Nino-related variations in ice breakup of Wisconsin Lakes. Limnol. Oceanogr., 41(5), 815-821.

Angel, J.R. and S.A. Isard, 1998: The frequency and intensity of Great Lake cyclones. J. Climate, 11, 61-71.

Angell, J.K., 1988: Variations and trends in tropospheric and stratospheric global temperatures, 1958-87. J. Climate, 1, 1296-1313.

Angell, J.K., 1999: Comparison of surface and tropospheric temperature trends estimated from a 63-station radiosonde network, 1958-1998. Geophys. Res. Lett., 26, 2761-2764.

Angell, J.K, 2000: Difference in radiosonde temperature trend for the period 1979-1998 of MSU data and the period 1959-1998 twice as long. Geophys. Res. Lett., 27, 2177-2180.

Appenzeller, C., T.F. Stocker and M. Anklin, 1998: North Atlantic oscillation dynamics recorded in Greenland ice cores. Science, 282, 446-449.

Arhan, M., H. Mescier, B. Bourles and Y. Gouriou, 1998: Hydrographic sections across the Atlantic at $7^{\circ} 30^{\prime} \mathrm{N}$ and $4^{\circ} 30^{\prime}$ S. Deep Sea Res., Part I, 45, 829-872.

Arkin, P.A. and P.E. Ardanuy, 1989: Estimating climatic-scale precipitation from space: a review. J. Climate, 2, 1229-1238.

Assel, R.A., 1983: Description and analysis of a 20-year (1960-79) digital ice-concentration database for the Great Lakes of North America. Ann. Glaciol., 4, 14-18.

Assel, R.A. and D.M. Robertson, 1995: Changes in winter air temperatures near Lake Michigan during 1851-1993 as determined from regional lake-ice records. Limnol. Oceanogr., 40, 165-176.

Bacon, S. and D.J.T. Carter, 1991: Wave Climate Changes in the North Atlantic and the North Sea. Int. J. Climatol., 11, 545-558.

Bajuk, L.J. and C.B. Leovy, 1998a: Are there real interdecadal variations in marine low clouds? J. Climate, 11, 2910-2921.

Bajuk, L.J. and C.B. Leovy, 1998b: Seasonal and interannual variations in stratiform and convective clouds over the tropical Pacific and Indian Oceans from ship observations. J. Climate, 11, 2922-2941.

Balling, R.C., Jr., 1998: Analysis of daily and monthly spatial variance components in historical temperature records. Physical Geography, 18, 544-552.

Barber, D.C., A. Dyke, C. Hillaire-Marcel, A.E. Jennings, J.T. Andrews, M.W. Kerwin, G. Bilodeau, R. McNeely, J. Southon, M.D. Morehead and J.M. Gagnon, 1999: Forcing of the cold event of 8,200 years ago by catastrophic drainage of Laurentide lakes. Nature, 400, 344-347.

Bard, E., M. Arnold, P. Maurice, J. Duprat, J. Moyes and J.C. Duplessy, 1987: Retreat velocity of the North Atlantic polar front during the last deglaciation determined by $14 \mathrm{C}$ accelerator mass spectrometry. Science, 328, 791-794

Barnett, T.P., B. Santer, P.D. Jones and R.S. Bradley, 1996: Estimates of low frequency natural variability in near-surface air temperature. The Holocene, 6, 255-263.

Basist, A.N. and M. Chelliah, 1997: Comparison of tropospheric temperatures derived from the NCEP/NCAR reanalysis, NCEP operational analysis and the Microwave Sounding Unit. Bull. Am. Met. Soc., 78, 1431-1447.

Bates, J.J. and D.L. Jackson, 2001: Trends in upper tropospheric humidity, Geophys. Res Lett., in press.

Bates, J., X. Wu and D. Jackson, 1996: Interannual variability of uppertropospheric water vapor band brightness temperature. J. Climate, $\mathbf{9}$, 427-438.

Behl, R.J. and J.P. Kennet, 1996: Brief interstadial events in the Santa Barbara basin, NE Pacific, during the past 60 kyr. Nature, 379, 243246.

Belkin, I.M., S. Levitus, J. Anotonov and S.-A. Malmberg, 1998: "Great Salinity Anomalies" in the North Atlantic. Progress in Oceanography, 41, 1-68.

Beltrami, H. and A.E. Taylor, 1994: Records of climatic change in the Canadian Arctic:Combination of geothermal and oxygen isotope data yields high resolution ground temperature histories. EOS, Transactions, American Geophysical Union, 75(44), 75.

Bender, M., T. Sowers, M.L. Dickson, J. Orchado, P. Grootes, P.A. Mayewski and D.A. Meese, 1994: Climate connection between Greenland and Antarctica during the last 100,000 years. Nature, 372, 663-666.

Bender, M., B. Malaize, J. Orchado, T. Sowers and J. Jouzel, 1999: High precision correlations of Greenland and Antarctic ice core records over the last 100 kyr. Geophysical Monograph, 112, Mechanisms of global climate change at millenial timescales, edited by P.U. Clark, R.S. Webb and L.D. Keigwin, 149-164.

Bianchi, G.G. and N.I. McCave, 1999: Holocene periodicity in North Atlantic climate and deep-ocean flow South of Iceland. Nature, 397, 515-517.

Bigg, G.R. and M. Inonue, 1992: Rossby waves and El Nino 1935-1946. Quart. J. R. Met. Soc., 118, 125-152.

Bindoff, N.L. and T.J. McDougall, 2000: Decadal changes along an Indian Ocean section at $32 \mathrm{~S}$. and their interpretation. $J$. Phys.Oceanogr., 30, 1207-1222.

Bjørgo, E., O.M. Johannessen and M.W. Miles, 1997: Analysis of merged SMMR/SSMI time series of Arctic and Antarctic sea ice parameters, Geophys. Res. Lett., 24, 413-416.

Black, D.E., L.C. Peterson, J.T. Overpeck, A. Kaptan, M.N. Evans and M. Kashgarian, 1999: Eight centuries of North Atlantic Ocean Atmosphere Variability. Science, 286, 1709-1713.

Black, P.G., 1993: Evolution of maximum wind estimates in typhoons. In: Tropical Cyclone Disasters, edited by J. Lighthill, Z. Zhemin, G. Holland and K. Emanuel, Peking University Press, Beijing, 104-115.

Blunier, T., J. Schwander, B. Stauffer, T. Stocker, A. Dällenbach, A. Indermühle, J. Tschumi, J. Chappellaz, D. Raynaud, J.M. Barnola, 
1997: Timing of the Antarctic Cold Reversal and the atmospheric $\mathrm{CO}_{2}$ increase with respect to the Younger Dryas event. Geophys. Res. Lett., 24(21), 2683-2686.

Blunier, T., J. Chappellaz, J. Schwander, A. Dällenbach, B. Stauffer, T. Stocker, D. Raynaud, J. Jouzel, H.B. Clausen, C.U. Hammer and S.J. Johnsen, 1998: Asynchrony of Antarctic and Greenland climate change during the last glacial period. Nature, 394, 739-743.

Bogdanova, E.G. and A.V. Mestcherskaya, 1998: Influence of moistening losses on the homogeneity of annual precipitation time series. Russian Meteorol. Hydrol., 11, 88-99.

Bond, G. and R. Lotti, 1995: Iceberg discharges into the North Atlantic on millennial time scales during the last glaciation. Science, 267, 1005-1010.

Bond, G., W.S. Broecker, S.J. Johnsen, J. McManus, L.D. Labeyrie, J. Jouzel and G. Bonani, 1993: Correlations between climate records from North Atlantic sediments and Greenland ice. Nature, 365, 143 147.

Bond, G., Showers, W. Cheseby, M. Lotti, R. Almasi, P. deMenocal, P. Priore, P. Cullen, H.I. Hajdas and G. Bonani, 1997: A pervasive Millennial-scale cycle in North Atlantic Holocene and glacial climates. Science, 278, 1257-1266.

Bönisch, G., J. Blindheim, J.L. Bullister, P. Schlosser and D.W.R. Wallace, 1997: Long-term trends of temperature, salinity, density, and transient tracers in the central Greenland Sea. J. Geophys. Res., 102(C8), 18553-18571.

Bonsal, B.R., X. Zhang, L.A.Vincent and W.D. Hogg, 2001: Characteristics of daily and extreme temperatures over Canada. $J$. Climate, in press.

Bottomley, M., C.K. Folland, J. Hsiung, R.E. Newell and D.E. Parker, 1990: Global Ocean Surface Temperature Atlas "GOSTA". HMSO, London, 20pp+iv, 313 plates.

Bouws, E., D.Jannink and G.J. Komen, 1996: The Increasing Wave Height in the North Atlantic Ocean. Bull. Am. Met. Soc., 77, 22752277.

Bradley, R.S., 1999: Paleoclimatology: reconstructing climates of the Quaternary Harcourt. Academic Press, San Diego, 610 pp.

Bradley, R.S. and P.D. Jones, 1993: 'Little Ice Age' summer temperature variations: their nature and relevance to recent global warming trends. The Holocene, 3, 367-376.

Bradley, R.S. and P.D. Jones (eds.), 1995: Climate Since A.D. 1500 (Revised edition) Routledge, London, 706 pp.

Brázdil, R., 1996: Reconstructions of past climate from historical sources in the Czechs Lands. In: Climatic Variations and Forcing Mechanisms of the Last 2000 Years, P.D. Jones, R.S. Bradley and J. Jouzel (eds.), NATO ASI Series, Springer Verlag, Berlin, Heidelberg, 41, 409-431.

Brázdil, R. and T. Vais, 1997: Thunderstorms and related weather extremes in south Moravia, Czech Republic in 1946-1995: Data results, impacts. Preprints of the Workshop on Indices and Indicators for Climate Extremes, NOAA/NCDC, Asheville NC USA, 3-6 June 1997, 4 pp.

Brázdil, R., M. Budykov, I. Auer, R. Böhm, T. Cegnar, P. Fasko, M Lapin, M. Gajic-Capka, K. Zaninovic, E. Koleva, T. Niedzwiedz, S. Szalai, Z. Ustrnul and R.O. Weber, 1996: Trends of maximum and minimum daily temperatures in central and southeastern Europe. Int. J. Climatol., 16, 765-782.

Brecher, H.H. and L.G. Thompson, 1993: Measurement of the retreat of Qori Kalis glacier in the tropical Andes of Peru by terrestrial photogrammetry. Photogrammetric Engineering and Remote Sensing, 59(6), 1017-1022.

Briffa, K.R., 2000: Annual climate variability in the Holocene: interpreting the message of ancient trees. Quat. Sci. Rev., 19, 87-105.

Briffa, K.R., P.D. Jones, F.H. Schweingruber, S.G. Shiyatov, and E.R. Cook, 1995: Unusual twentieth-century summer warmth in a 1,000year temperature record from Siberia. Nature, 376, 156-159.
Briffa, K.R., P.D. Jones, F.H. Schweingruber, S.G. Shiyatov and E.A. Vaganov, 1996: Development of a North Eurasian chronology network: Rationale and preliminary results of comparative ring-width and densitometric analyses in northern Russia. In: Tree Rings, Environment, and Humanity. Radiocarbon 1996, J.S. Dean, D.M. Meko and T.W. Swetnam (eds.), Department of Geosciences, The University of Arizona, Tucson, pp. 25-41.

Briffa, K.R., F.H. Schweingruber, P.D. Jones, T.J. Osborn, S.G. Shiyatov and E.A. Vaganov, 1998a: Reduced sensitivity of recent tree-growth to temperature at high northern latitudes. Nature, 391, 678-682.

Briffa, K.R., P.D. Jones, F.H. Schweingruber and T.J. Osborn, 1998b: Influence of volcanic eruptions on Northern Hemisphere summer temperature over the past 600 years. Nature, 393, 450-455.

Broecker, W.S., 1997: Thermohaline circulation, the Achilles heel of our climate system: Will man-made $\mathrm{CO}_{2}$ upset the current balance? Science, 278, 1582-1588.

Broecker, W.S., 1998: Paleocean circulation during the last deglaciation A bipolar seasaw? Paleoceanography, 13, 119-121.

Broecker, W.S., D.M. Peteet and D. Rind, 1985: Does the oceanatmosphere system have more than one mode of operation? Nature, 315, 21-26.

Brown, J., O.J. Ferrians, Jr., J.A. Heginbottom and E.S. Melnikov, 1997: Circum-Arctic map of permafrost and ground-ice conditions. U.S. Geological Survey Circum-Pacific Map CP- 45, 1:10,000,000, Reston, Virginia.

Brown, N. and A. Issar (eds.), 1998: Water, Environment and Society in Times of Climatic Change. Kluwer, pp. 241-271.

Brown, R.D., 2000: Northern Hemisphere snow cover variability and change, 1915-1997. J. Climate, 13, 2339-2355.

Brown, R.D. and B.E. Goodison, 1996: Interannual variability in reconstructed Canadian snow cover, 1915-1992. J. Climate, 9, 12991318.

Brown, R.D. and R.O. Braaten, 1998: Spatial and temporal variability of Canadian monthly snow depths, 1946-1995. Atmosphere-Ocean, 36, $37-45$.

Brown, S.J., D.E. Parker, C.K. Folland and I. Macadam, 2000: Decadal variability in the lower-tropospheric lapse rate. Geophys. Res. Lett., 27, 997-1000.

Brunet-India, M., E. Aguilar, O. Saladie, J. Sigro and D. Lopez, 1999a: Evolución térmica reciente de la región catalana a partir de la construccion de series climáticas regionales. In: Raso Nadal, J. M. and Martin-Vide, J.: La Climatología española en los albores del siglo XXI, Barcelona: Publicaciones de la A.E.C., Serie A, 1, 91-101.

Brunet-India, M., E. Aguilar, O. Saladie, J. Sigro and D. Lopez, 1999b: Variaciones y tendencias contemporaneas de la temperatura máxima, mínima y amplitud térmica diaria en el NE de España, In: Raso Nadal, J. M. Martin-Vide, J.: La Climatología española en los albores del siglo XXI, Barcelona: Publicaciones de la A.E.C., Serie A, 1, 103-112.

Brunetti, M., L. Buffoni, M. Maugeri and T. Nanni, 2000a: Trends of minimum and maximum daily temperatures in Italy from 1865 to 1996. Theoretical and Applied Climatology, 66, 49-60.

Brunetti, M., S. Cecchini, M. Maugeri and T. Nanni, 2000b: Solar and terrestrial signals in precipitation and temperature in Italy from 1865 to 1996. Advances in Geosciences, W. Schroeder (Editor), IAGA, pp. 124-133.

Brutsaert, W. and M.B. Parlange, 1998: Hydrological cycle explains the evaporation paradox. Nature, 396, 30.

Bryden, H.L., M.J. Griffiths, A.M. Lavin, R.C. Millard, G. Parrilla and W.M. Smethie, 1996: Decadal changes in water masses characteristics at $24^{\circ} \mathrm{N}$ in the subtropical Atlantic Ocean. J. Climate, 9, 31623186.

Buffoni, L., M. Maugeri and T. Nanni, 1999: Precipitation in Italy from 1833 to 1996. Theoretical and Applied Climatology, 63, 33-40.

Burgess, M.M., S.L. Smith, J. Brown, V. Romanovsky and K. Hinkel, 
2000: The Global Terrestrial Network for Permafrost (GTNet-P): permafrost monitoring contributing to global climate observations. Geological Survey of Canada, Current Research 2000E-14, 8 pp. (online, http://www.nrcan.gc.ca/gsc/bookstore)

Burn, C.R., 1998: Field investigations of permafrost and climatic change in northwest North America; Proceedings of Seventh International Conference on Permafrost, Yellowknife, Canada, June 1998, Université Laval, Quebec, Collection Nordicana No. 57, pp. 107-120

Carmack, E.C., R.W. MacDonald, R.W. Perkin, F.A. McLaughlin and R.J. Pearson, 1995: Evidence for warming of Atlantic water in the southern Canadian Basin of the Arctic Ocean: Results from the Larsen-93 expedition. Geophys. Res. Lett., 22, 1061-1064.

Carter, D.J.T. and L. Draper, 1988: Has the Northeast Atlantic Become Rougher? Nature, 332, 494.

Cavalieri, D.J., P. Gloersen, C.L. Parkinson, J.C. Comiso and H.J. Zwally, 1997: Observed hemispheric asymmetry in global sea ice changes. Science, 278, 1104-1106.

Chan, J.C.L. and J. Shi, 1996: Long-term trends and interannual variability in tropical cyclone activity over the western North Pacific. Geophys. Res. Lett., 23, 2765-2767.

Changnon, D. and S.A. Changnon, 1997: Surrogate data to estimate crop-hail loss. J. Appl. Met., 36, 1202-1210.

Changnon, S.A., 1985: Secular variations in thunder-day frequencies in the twentieth century. J. Geophys. Res., 90, 6181-6194.

Changnon, S.A. and D. Changnon, 2000: Long-term fluctuations in hail incidences in the United States. J. Climate, 13, 658-664.

Changnon, S.A., D. Changnon, E.R. Fosse, D.C. Hoganson, R.J. Roth and J. Totsch, 1996: Impacts and Responses of the Weather Insurance Industry to Recent Weather Extremes. Final Report to UCAR from Changnon Climatologist, CRR-41, Mahomet, IL, 166 pp.

Chanin, M.L. and V. Ramaswamy, 1999: "Trends in Stratospheric Temperatures" in WMO (World Meteorological Organization), Scientific Assessment of Ozone Depletion: 1998, Global Ozone Research and Monitoring Project - Report No. 44, Geneva, pp. 5.15.59.

Chao, Y., M. Ghil and J.C. McWilliams, 2000: Pacific Interdecadal variability in this century's sea surface temperatures. Geophys. Res. Lett., 27, 2261-2264.

Chapman, W.L. and J.E. Walsh, 1993: Recent variations of sea ice and air temperature in high latitudes. Bull. Am. Met. Soc., 74, 33-47.

Chappellaz, J., E. Brook, T. Blunier and B. Malaizé, 1997: $\mathrm{CH}_{4}$ and $\delta^{18} \mathrm{O}$ of $\mathrm{O}_{2}$ records from Greenland ice: A clue for stratigraphic disturbance in the bottom part of the Greeland. Ice Core Project and the Greeland Ice Sheet Project 2 ice-cores. J. Geophys. Res., 102, $26547-$ 26557.

Charles, C.D., J. Lynch-Stieglitz, U.S. Niennemann and R.G. Fairbanks, 1996: Climate connections between the two hemispheres revealed by deep sea sediment core/ice core correlations. Earth Planet Sci. Lett., 142, 19-27.

Chase, T.N., R.A. Pielke Sr., J.A. Knaff, T.G.F. Kittel and J.L. Eastman, 2000: A comparison of regional trends in 1979-1997 depth-averaged tropospheric temperatures. Int. J. Climatol., 20, 503-518.

Cheddadi, R., K. Mamakowa, J. Guiot, J.L. de Beaulieu, M. Reille, V. Andrieu, W. Grasnoszewki and O. Peyron, 1998: Was the climate of the Eemian stable ? A quntitative climate reconstruction from seven European climate records. Paleogeography, Paleoclimatology, Paleoecology, 143, 73-85.

Christy, J.R., 1995: Temperature above the surface. Clim. Change, 31, 455-474.

Christy, J.R. and R. T. McNider, 1994: Satellite greenhouse warming. Nature, 367, 325.

Christy, J.R., R.W. Spencer and E. Lobl, 1998: Analysis of the merging procedure for the MSU daily temperature time series. J. Climate, $\mathbf{5}$, 2016-2041.

Christy, J.R., R.W. Spencer and W.D. Braswell, 2000: MSU tropospheric
temperatures:Dataset construction and radiosonde comparisons. $J$. Atmos. Oceanic Tech., 17, 1153-1170.

Christy, J.R., D.E. Parker, S.J. Brown, I. Macadam, M. Stendel and W.B. Norris, 2001: Differential trends in tropical sea surface and atmospheric temperatures. Geophys. Res. Lett., 28, 183-186.

Ciais, P., J.R. Petit, J. Jouzel, C. Lorius, N.I. Barkov, V. Lipenkov and V. Nicolaïev, 1992: Evidence for an Early Holocene climatic optimum in the Antarctic deep ice core record. Clim. Dyn., 6, 169-177.

Clausen, H.B., C.U. Hammer, J. Christensen, C.S. Schott Hvidberg, D. Dahl-Jensen, M. Legrand and J.P. Steffensen, 1995: 1250 years of global volcanism as revealed by central Greenland ice cores. In: Ice Core Studies of Global Biogeochemical Cycles, Nato ASI, Series I, vol 30., edited by R.J. Delmas, Springer-Verlag, New York, pp. 517532.

CLIMAP Project Members, 1984: The last interglacial ocean. Quat. Res., 21, 123-224.

Clow, G.D., A.H. Lachenbruch and C.P. McKay, 1991: Investigation of borehole temperature data for recent climate changes: Examples from Alaskan Arctic and Antarctica. In: Proceedings of the International Conference on the Role of Polar Regions in Global Change, June 11-15, 1990, Geophysical Institute, University of Alaska, Fairbanks, vol. 2, 533.

COHMAP Members, 1988: Climatic changes of the last 18,000 years: observations and model simulations. Science, 241, 1043-1052.

Cole, J.E. and E.R. Cook, 1998: The changing relationship between ENSO variability and moisture balance in the continental United States. Geophys. Res. Lett., 25, 4529-4532.

Coles, V.J., M.S. McCartney, D.B. Olson and W.M. Smethie Jr., 1996: Changes in the Antarctic bottom water properties in the western South Atlantic in the late 1980's. J. Geophys. Res., 101(C4), 89578970.

Collins, D.A., P.M. Della-Marta, N. Plummer and B.C. Trewin, 2000: Trends in annual frequencies of extreme temperature events in Australia. Australian Meteorological Magazine, 49, 277-292.

Combourieu-Nebout, N., M. Paterne and J.L. Turon, 1998: A highresolution record of the last deglaciation in the Central Mediterranean Sea: Palaeovegetation and palaeohydrological evolution. Quat. Sci. Rev., 17, 303-317.

Comiso, F., 2000: Variability and trends in Antarctic temperatures from in situ and satellite infrared measurements. J. Climate, 13, 16741696.

Cook, E.R., 1995: Temperature histories in tree rings and corals. Clim. Dyn., 11, 211-222.

Cook, E.R., R.D. D'Arrigo and K.R. Briffa, 1998: A reconstruction of the North Atlantic Oscillation using tree-ring chronologies from North America and Europe. The Holocene, 8, 9-17.

Cook, E.R., D.M. Meko, D.W. Stahle and M.K. Cleaveland, 1999: Drought reconstructions for the continental United States. J. Climate, 12, 1145-1162.

Cook, E.R., B.M. Buckley and R.D. D'Arrigo, 2000: Warm-Season Temperatures since 1600 B.C. Reconstructed from Tasmanian Tree Rings and Their Relationship to Large-Scale Sea Surface Temperature Anomalies. Clim. Dyn., 16, 79-91.

Cortijo, E., J. Duplessy, L. Labeyrie, H. Leclaire, J. Duprat and T. van Weering, 1994: Eemian cooling in the Norwegian Sea and North Atlantic ocean preceding ice-sheet growth. Nature, 372, 446-449.

Cortijo, E., L.D. Labeyrie, L. Vidal, M. Vautravers, M. Chapman, J.C. Duplessy, M. Elliot, M. Arnold and G. Auffret, 1997: Changes in the sea surface hydrology associated with Heinrich event 4 in the North Atlantic Ocean $\left(40-60^{\circ} \mathrm{N}\right)$. Earth Planet. Sci. Lett., 146, 29-45.

Crowley, T.J., 1992: North Alantic Deep Water Cools The Southern Hemisphere. Paleoceanography, 7, 489-497.

Crowley, T.J., 2000: Causes of Climate Change Over the Past 1000 Years. Science, 289, 270-277.

Crowley, T.J. and K.Y. Kim, 1996: Comparison of proxy records of 
climate change and solar forcing. Geophys. Res. Lett., 23, 359-362.

Crowley, T.J. and K.Y. Kim, 1999: Modeling the temperature response to forced climate change over the last six centuries. Geophys. Res. Lett., 26, 1901-1904.

Crowley, T.J. and T. Lowery, 2000: How warm was the Medieval warm period? Ambio, 29, 51-54.

Cullen, H., R. D'Arrigo, E. Cook and M.E. Mann, 2001: Multiproxybased reconstructions of the North Atlantic Oscillation over the past three centuries. Paleoceanography, 16, 27-39.

Dahl-Jensen, D., K. Mosegaard, N. Gundestrup, G.D. Clow, S.J. Johnsen, A.W. Hansen and N. Balling, 1998: Past temperatures directly from the Greenland ice sheet. Science, 282, 268-271.

Dai, A., A.D. DelGenio and I.Y. Fung, 1997a: Clouds, precipitation, and temperature range. Nature, 386, 665-666.

Dai, A., I.Y. Fung and A.D. Del Genio, 1997b: Surface observed global land precipitation variations during 1900-88. J. Climate, 10, 2943 2962.

Dai, A., K.E. Trenberth and T.R. Karl, 1998: Global variations in droughts and wet spells: 1900-1995. Geophys. Res. Lett., 25, 33673370.

Dai, A., K.E. Trenberth and T.R. Karl, 1999: Effects of clouds, soil moisture, precipitation and water vapor on diurnal temperature range. J. Climate, 12, 2452-2473.

Damon, P.E. and A.N. Peristykh, 1999: Solar cycle length and 20th century Northern Hemisphere Warming. Geophys. Res. Lett., 26, 2469-2472.

Dansgaard, W., H.B. Clausen, N. Gundestrup, C.U. Hammer, S.J. Johnsen, P. Krinstindottir and N. Reeh, 1982: A new Greenland deep ice core. Science, 218, 1273-1277.

Dansgaard, W., J.W. White and S.J. Johnsen, 1989: The abrupt termination of the Younger Dryas climate event. Nature, 339, 532-534.

Dansgaard, W., S.J. Johnsen, H.B. Clausen, D. Dahl-Jensen, N.S Gundestrup, C.U. Hammer, C.S. Hvidberg, J.P. Steffensen, A.E. Sveinbjörnsdottir, J. Jouzel and G. Bond, 1993: Evidence for general instability of past climate from a $250 \mathrm{kyr}$ ice core. Nature, $\mathbf{3 6 4}, 218$ 219.

D'Arrigo, R.D., E.R. Cook and G.C. Jacoby, 1996: Annual to decadalscale variations in northwest Atlantic sector temperatures inferred from Labrador tree rings. Canadian Journal of Forest Research, 26, 143-148.

D’Arrigo, R.D., E.R. Cook, M.J. Salinger, J. Palmer, P.J. Krusic, B.M. Buckley and R. Villalba, 1998: Tree-ring records from New Zealand: long-term context for recent warming trend. Clim. Dyn., 14, 191-199.

De la Mare, W.K., 1997: Abrupt mid-twentieth century decline in Antarctic sea-ice extent from whaling records. Nature, 389, 57-60.

Delworth, T.L. and M.H. Mann, 2000: Observed and simulated multidecadal variability in the Northern Hemisphere. Clim. Dyn., 16, 661-676.

de Menocal, P., 1998: Subtropical signatures of millenial-scale Holocene climate variability. International Conference of Paleoceanography.

Denton, G. and C.H. Hendy, 1994: Younger Dryas age advance of the Franz Josef glacier in the Southern Alps of New Zealand. Science, 264, 1434-1437.

Deser, C. and M.L. Blackmon, 1995: On the relationship between tropical and North Pacific sea surface temperature variations. $J$. Climate, 8, 1677-1680.

Deser, C., J.E. Walsh and M.S. Timlin, 2000: Arctic sea ice variability in the context of recent wintertime atmospheric circulation trends. $J$. Climate, 13, 617-633.

Dessens, J., 1995: Severe convective weather in the context of a nighttime global warming. Geophys. Res. Lett., 22, 1241-1244.

Diaz, H.F. and H.F. Graham, 1996: Recent changes in tropical freezing heights and the role of sea surface temperature. Nature, 383, 152-155.

Dickson, R.R., J. Lazier, J. Meincke, P. Rhines and J. Swift, 1996: Longterm co-ordinated changes in the convective activity of the North
Atlantic. Prog. Oceanogr., 38, 241-295.

Diggle, P.J., K.Y. Liang and S.L. Zeger, 1999: Analysis of longitudinal data. Clarendon Press, Oxford, 253 pp.

Ding, Y., 1998: Recent degradation of permafrost in China and the response to climatic warming. In: Proceedings of the Seventh International Conference on Permafrost, Yellowknife, Canada, June 1998, Université Laval, Quebec, Collection Nordicana No. 57, pp. 221-224.

Ding, Z.L., N.W. Rutter, T.S. Liu, J.M. Sun, J.Z. Ren, D. Rokosh and S.F. Xiong, 1998: Correlation of Dansgaard-Oeschger cycles between Greenland ice and Chinese loess. Paleoclimates, 2, 281-291.

Doherty, R.M., M. Hulme and C.G. Jones, 1999: A gridded reconstruction of land and ocean precipitation for the extended Tropics from 1974-1994. Int. J. Climatol., 19, 119-142.

Doswell, C.A. III and D.W. Burgess, 1988: On some issues of United States tornado climatology. Mon. Wea. Rev., 116, 495-501.

Douglas, A.V. and P.J. Englehart, 1999: Inter-monthly variability of the Mexican summer monsoon. Proceedings of the Twenty-Second Annual Climate Diagnostics and Prediction Workshop, Berkeley, CA, October 6-10, 1997, Washington, D.C.: U.S. Department of Commerce, NOM, NTIS \#PB97-159164, pp. 246-249.

Dunbar, R.B. and J.E.Cole, 1999: Annual Records of Tropical Systems, (ARTS): A PAGES Report 99-1/CLIVAR Initiative: Recommendations for Research. Summary of scientific priorities and implementation strategies: ARTS Planning Workshop, Kauai, Hawaii, PAGES Report 99-1.

Dunkerton, T., D. Delisi and M. Baldwin, 1998: Middle atmosphere cooling trend in historical rocketsonde data. Geophys. Res. Lett., 25, 3371-3374.

Duplessy, J.C., L. Labeyrie, A. Juillet-Leclerc, F. Maitre, J. Duprat and M. Sarnthein, 1991: Surface salinity reconstruction of the North Atlantic Ocean during the last glacial maximum. Oceanologica Acta, 14, 311-324.

Duplessy, J.C., L. Labeyrie, M. Arnold, M. Paterne, J. Duprat and T.C.E. van Weering, 1992: Changes in surface salinity of the North Atlantic Ocean during the last deglaciation. Nature, 358, 485-487.

Easterling, D.R., B. Horton, P.D. Jones, T.C. Peterson, T.R. Karl, D.E. Parker, M.J. Salinger, V. Razuvayev, N. Plummer, P. Jamason and C.K. Folland, 1997: Maximum and minimum temperature trends for the globe. Science, 277, 364-367.

Easterling, D.R., J.L. Evans, P.Ya. Groisman, T.R. Karl, K.E. Kunkel and P. Ambenje, 2000: Observed variability and trends in extreme climate events. Bull. Am. Met. Soc., 81, 417-425.

Elliott, W.P., 1995: On detecting long-term changes in atmospheric moisture. Clim. Change, 31, 349-367.

Elliott, W. and D. Gaffen, 1991: On the utility of radiosonde humidity archives for climate studies. Bull. Am. Met. Soc., 72, 1507-1520.

Ely, L.L., E. Yehouda, V.R. Baker and D.R. Cayan, 1993: A 5000-year record of extreme floods and climate change in the Southwestern United States. Science, 262, 410-412.

Enfield, D.B. and A.M. Mestas-Nuñez, 1999: Multiscale variabilities in global sea surface temperatures and their relationships with tropospheric climate patterns. J. Climate, 12, 2719-2733.

Environmental Working Group (EWG), 1997: Joint U.S.-Russian Atlas of the Arctic Ocean [CD-ROM], Natl. Snow and Ice Data Centre, Boulder, Colorado, USA.

Eskridge, R.E., O.A. Alduchov, I.V. Chernykh, Z. Panmao, A.C. Polansky and S.R. Doty, 1995: A Comprehensive aerological reference data set (CARDS): Rough and systematic errors. Bull. Am. Met. Soc., 76, 1759-1775.

Evans, J.S., R. Toumi, J.E. Harries, M.P. Chipperfield and J.R. Russell III, 1998: Trends in stratospheric humidity and the sensitivity of ozone to those trends. J. Geophys. Res., 103, 8715-8725.

Fallot, J.-M., R.G. Barry and D. Hoogstrate, 1997: Variations of mean cold season temperature, precipitation and snow depths during the 
last 100 years in the Former Soviet Union (FSU). Hydrol. Sci. J., 42, 301-327.

Fernandez-Partagas, J. and H.F. Diaz, 1996: Atlantic hurricanes in the second half of the 19th Century. Bull. Am. Met. Soc., 77, 2899-2906.

Fischer, H., M. Wahlen, J. Smith, D. Mastroiani and B. Deck, 1999: Ice core records of atmospheric $\mathrm{CO}_{2}$ around the last three glacial terminations. Science, 283, 1712-1714.

Fisher, D.A. 1997: High resolution reconstructed Northern Hemisphere temperatures for the last few centuries: using regional average tree ring, ice core and historical annual time series. Paper U32C-7 in Supplement to EOS, Transactions, American Geophysical Union Vol. 78 No. 46, abstract.

Fisher, D.A., R.M. Koerner, K. Kuivinen, H.B. Clausen, S.J. Johnsen, J.P. Steffensen, N. Gundestrup and C.U. Hammer, 1996: Intercomparison of ice core $(\mathrm{O}-18)$ and precipitation records from sites in Canada and Greenland over the last 3500 years and over the last few centuries in detail using EOF techniques. In: Climate Variations and Forcing Mechanisms of the Last 2000 Years, edited by P.D. Jones, R.S. Bradley and J. Jouzel, NATO ASI Series I, Vol. 41, pp. 297-328.

Fisher, D.A., R.M. Koerner, J.C. Bourgeois, G. Zielinski, C. Wake, C.U. Hammer, H.B. Clausen, N. Gundestrup, S.J. Johnsen, K. GotoAzuma, T. Hondoh, E. Blake and M. Gerasimoff, 1998: Penny Ice Cap, Baffin Island, Canada, and the Wisconsinan Foxe Dome Connection: two states of Hudson Bay ice cover. Science, 279, 692695.

Fleming, K.M., J.A. Dowdeswell and J. Oerlemans, 1997: Modelling the mass balance of northwest Spitsbergen glaciers and response to climate change. Ann. Glaciol., 24, 203-210.

Folland, C.K. and D.E. Parker, 1995: Correction of instrumental biases in historical sea surface temperature data. Quart. J. R. Met. Soc., 121, 319-367.

Folland, C.K. and M.J. Salinger, 1995: Surface temperature trends in New Zealand and the surrounding ocean, 1871-1993. Int. J. Climatol., 15, 1195-1218.

Folland, C.K., D.E. Parker and T.N. Palmer, 1986: Sahel rainfall and worldwide sea temperatures 1901-85. Nature, 320, 602-607.

Folland, C.K., R.W. Reynolds, M. Gordon and D.E. Parker, 1993: A study of six operational sea surface temperature analyses. J. Climate, 6, 96-113.

Folland, C.K., M.J. Salinger and N. Rayner, 1997: A comparison of annual South Pacific island and ocean surface temperatures. Weather and Climate, 17, 23-42.

Folland, C.K., D.M.H. Sexton, D.J. Karoly, C.E. Johnson, D.P. Rowell and D.E. Parker, 1998: Influences of anthropogenic and oceanic forcing on recent climate change. Geophys. Res. Lett., 25, 353-356.

Folland, C.K., D.E. Parker, A.W. Colman and R.Washington, 1999a: Large scale modes of ocean surface temperature since the late nineteenth century. In: Beyond El Niño: Decadal and Interdecadal Climate Variability, A. Navarra (ed.), Springer-Verlag, Berlin, pp. 73102

Folland, C.K., C. Miller, D. Bader, M. Crowe, P. Jones, N. Plummer, D.E. Parker, J. Rogers and P. Scholefield, 1999b: Workshop on Indices and Indicators for climate extremes, Asheville, NC, USA, 36 June 1999: Breakout Group C: Temperature indices for Climate Extremes. Clim. Change, 42, 31-43.

Folland, C.K., N. Rayner, P. Frich, T. Basnett, D. Parker and B. Horton, 2000: Uncertainties in climate data sets - a challenge for WMO. WMO Bull., 49, 59-68.

Folland, C.K., N.A. Rayner, S.J. Brown, T.M. Smith, S.S. Shen, D.E. Parker, I. Macadam, P.D. Jones, R.N. Jones, N. Nicholls and D.M.H. Sexton, 2001: Global temperature change and it uncertainties since 1861. Geophys. Res. Lett., in press.

Førland, E.J. and I. Hassen-Bauer, 2000: Increased precipitation in the Norwegian Arctic: True or false? Clim. Change, 46, 485-509.

Førland, E.J., H. Alexandersson, A. Drebs, I. Hassen-Bauer, H. Vedin and O.E. Tveito, 1998: Trends in maximum 1-day precipitation in the Nordic region, DNMI-KLIMA 14/98, pp. 55, Norwegian Meteorological Institute, N-0313 Oslo, Norway.

Forster, P.M. and K.P. Shine, 1999: Stratospheric water vapour changes as a possible contributor to observed stratospheric cooling. Geophys. Res. Lett., 26, 3309-3312.

Frank, P., 1997: Changes in the glacier area in the Austrian Alps between 1973 and 1992 derived from LANDSAT data. MPI report 242, $21 \mathrm{pp}$.

Free, M. and A. Robock, 1999: Global Warming in the Context of the Little Ice Age. J. Geophys. Res., 104 (D16), 19057-19070.

Freeland, H., K. Denman, C.S. Wong, F. Whitney and R. Jacques, 1997: Evidence of change in the winter mixed layer in the Northeast Pacific Ocean. Deep Sea Res., Part I, 44(12), 2117-2129.

Frei, A., D.A. Robinson and M.G. Hughes, 1999: North American snow extent: 1900-1994. Int. J. Climatol., 19, 1517-1534.

Frei, C. and C. Schär, 2001: Detection probability of trends in rare events: Theory and application to heavy precipitation in the Alpine Region. J. Climate, 14, 1568-1584.

French, H.M. and I.E. Egorov, 1998: 20th century variations in the southern limit of permafrost near Thompson, northern Manitoba, Canada. In: Proceedings of Seventh International Conference on Permafrost, Yellowknife, Canada, June 1998, Université Laval, Quebec, Collection Nordicana No. 57, pp. 297-304.

Frich, P., L.V. Alexander, P. Della-Marta, B. Gleason, M. Haylock, A. Klein-Tank and T. Peterson, 2001: Observed coherent changes in climatic extremes during the second half of the 20th Century. Clim. Res., in press.

Fritts, H.C., 1976: Tree Rings and Climate. Academic Press, London.

Fritts, H.C., 1991: Reconstructing large-scale climatic patterns from Tree Ring Data. The University of Arizona Press, Tucson.

Gabriel, K.R. and S.A. Changnon, 1990: Temporal features in thunder days in the United States. Clim. Change, 15, 455-477.

Gaffen, D.J., 1994: Temporal inhomogeneities in radiosonde temperature records. J. Geophys. Res., 99, 3667-3676.

Gaffen, D.J. and R.J. Ross, 1998: Increased summertime heat stress in the U.S. Nature, 396, 529-530.

Gaffen, D.J. and R.J. Ross, 1999: Climatology and trends of U.S. surface humidity and temperature. J. Climate, 13, 811-828.

Gaffen, D.J., B.D. Santer, J.S. Boyle, J.R. Christy, N.E. Graham and R. J. Ross, 2000a: Multidecadal changes in the vertical structure of the tropical troposphere. Science, 287, 1242-1245.

Gaffen, D.J., M.A. Sargent, R.E. Habermann and J.R. Lazante, 2000b: Sensitivity of tropospheric and stratospheric temperature trends to radiosonde data quality. J. Climate, 13, 1776-1796.

Gagan, M.K., L.K. Ayliffe, D. Hopley, J.A. Cali, G.E. Mortimer, J. Chappell, M.T. McCulloch and M.J. 1998: Heat, temperature and surface-ocean water balance of the mid-Holocene tropical western Pacific. Science, 279, 1014-1018.

Gallo, K.P., D.R. Easterling and T.C. Peterson, 1996: The influence of land use/land cover on climatological values of the diurnal temperature range. J. Climate, 9, 2941-2944.

Garcia, N.O. and W.M. Vargas, 1998: The temporal climatic variabilitiy in the 'Rio de la Plata' Basin displayed by the river discharges. Clim. Change, 38, 359-379.

Garreaud, R.D. and D.S. Battisti, 1999: Interannual (ENSO) and interdecadal variability in the Southern Hemisphere tropospheric circulation. J. Climate, 12, 2113-2123.

Gasse, F. and E. Van Campo, 1994: Abrupt post-glacials eveents in West asia and north Africa. Earth Planet Sci. Lett., 126, 453-456.

Gasse, F., R. Tehet and A. Durand, 1990: The arid-humid transition in the Sahara and the Sahel during the last deglaciation. Nature, 346, 141146.

Genta, J.L., G. Perez-Iribarren and C.R. Mechoso, 1998: A recent increasing trend in the streamflow of rivers in southeastern South America. J. Climate, 11, 2858-2862. 
Georgievsky, V.Yu., A.V. Ezhov, A.L. Shalygin, I.A. Shiklomanov and A.I. Shiklomanov, 1996: Assessment of the effect of possible climate changes on hydrological regime and water resources of rivers in the former USSR. Russian Meteorol. And Hydrol., 11, 66-74.

Gershunov, A. and T.P. Barnett, 1998: Interdecadal modulation of ENSO teleconnections. Bull. Am. Met. Soc., 79, 2715-2725.

Goddard, L. and N.E. Graham, 1997: El Nino in the 1990s. J. Geophys. Res., 102, 10423-10436.

Golitsyn, G.S., A.I. Semenov, N.N. Shefov, L.M. Fishkova, E.V. Lysenko and S.P. Perov, 1996: Long-term temperature trends in the middle and upper atmosphere. Geophys. Res. Lett., 23, 1741-1744.

Golubev, V.S., J.H. Lawrimore, P.Ya. Groisman, N.A. Speranskaya, S.A. Zhuravin, M.J. Menne, T.C. Peterson and R.W. Malone, 2001: Evaporation changes over the contiguous United States and the Former USSR: The re-assessment. Geophys. Res. Lett., in press.

Gong, D.Y. and S.W. Wang, 1999a: Experiments on the reconstruction of historical monthly mean northern hemispheric $500 \mathrm{hPa}$ heights from surface data. Report on the Department of Geophysics, Peking University

Gong, D.Y. and S.W. Wang, 1999b: Variability of the Siberian High and the possible connection to global warming. Acta Geographica Sinica, 54 (2), 142-150 (in Chinese).

Gong, D.Y. and S.W. Wang, 1999c: Definition of Antarctic Oscillation index. Geophys. Res. Lett., 26, 459-462.

Goswami, B.N., V. Krishnamurthy and H. Annamalai, 1997: A broad scale circulation index for the interannual variability of the Indian summer monsoon. Report No. 46, COLA, 4041 Powder Mill Road, Suite 302, Calverton, MD, 20705, USA.

Graf, H.F., J. Perlwitz, I. Kirchner and I. Schult, 1995: Recent northern winter climate trends, ozone changes and increased greenhouse gas forcing. Contrib. Phys. Atmos., 68, 233-248.

Graham, N.E. and H.F. Diaz, 2001: Evidence for intensification of North Pacific Winter Cyclones since 1948. J. Climate, in press.

Gravis, G.F., N.G. Moskalenko and A.V. Pavlov, 1988: Perennial changes in natural complexes of the cryolithozone. In: Proceedings of the Fifth International Conference on Permafrost, Trondheim, Norway, vol. 1, 165-169.

Grazulis, T.P., 1993: Significant Tornadoes, 1680-1991. Environmental Films, St. Johnsbury, VT, 1326 pp.

Grazulis, T.P., C.A. Doswell III, H.E. Brooks and M. Biddle, 1998: A new perspective of the societal impacts of North American tornadoes covering two centuries. Preprints, 19th Conference on Severe Local Storms. American Meteorological Society, Minneapolis, MN, 196199.

Greuell, J.W. and J. Oerlemans, 1987: Sensitivity studies with a mass balance model including temperature profile calculations inside the glacier. Zeits. Gletscherk. Glaziageol., 22, 101-124.

Grimm, E.C., G.L. Jacobson, W.A. Watts, B.C.S. Hansen and K.A. Maasch, 1993: A 50000-year record of climate oscillations from Florida and its temporal correlation with the Heinrich events. Science, 261, 198-200.

GRIP project members, 1993: Climatic instability during the last interglacial period revealed in the Greenland summit ice-core. Nature, 364, 203-207.

Groisman, P.Ya. and D. Easterling, 1994: Variability and trends of total precipitation and snowfall over the United States and Canada. $J$. Climate, 7, 184-205.

Groisman, P.Ya. and E.Ya. Rankova, 2001: Precipitation trends over the Russian permafrost-free zone: Removing the artifacts of preprocessing. Int. J. Climatol., in press.

Groisman, P.Ya., T.R. Karl, D.R. Easterling, R.W. Knight, P.B. Jamason, K.J. Hennessy, R. Suppiah, C.M. Page, J. Wibig, K. Fortuniak, V.N. Razuvaev, A. Douglas, E. Førland and P.M. Zhai, 1999: Changes in the probability of heavy precipitation: Important indicators of climatic change. Clim. Change, 42, 243-283.
Groisman, P.Ya., R.W. Knight and T.R. Karl, 2001: Heavy precipitation and high streamflow in the United States: Trends in the 20th century. Bull. Am. Met. Soc., 82, 219-246.

Grootes, P.M., M. Stuiver, J.W.C. White, S.J. Johnsen and J. Jouzel, 1993: Comparison of the oxygen isotope records from the GISP2 and GRIP Greenland ice cores. Nature, 366, 552-554.

Grove, J.M. and R. Switsur, 1994: Glacial geological evidence for the'Medieval Warm Period. Clim. Change, 26, 143-169.

Grumbine, R.W., 1996: Automated Passive Microwave Sea Ice Concentration Analysis at NCEP. US Department of Commerce, National Ocean And Atmospheric Administration, National Weather Service, National Centers for Environmental Prediction, Technical Note, OMB contribution 120, March, 1996, 13 pp. Also: (http://polar.wwb.noaa.gov/seaice/docs/ssmi.auto/ssmi120.html)

Gruza, G., E. Rankova, V. Razuvaev and O. Bulygina, 1999: Indicators of climate change for the Russian Federation. Clim. Change, 42, 219242.

Gutzler, D., 1996: Low-frequency ocean-atmosphere variability across the tropical western Pacific. J. Atmos. Sci., 53, 2773-2785.

Haeberli, W., G. Cheng, A.P. Gorbunov and S.A. Harris, 1993: Mountain permafrost and climatic change. Permafrost and Periglacial Processes, 4, 165-174.

Haeberli, W., M. Hoelzle and S. Suter (eds.), 1998: Into the second century of worldwide glacier monitoring: prospects and strategies, A contribution to the International Hydrological Programme (IHP) and the Global Environment Monitoring System (GEMS). UNESCO Studies and Reports in Hydrology, 56, Paris.

Hagen, J.O., K. Melvold, T. Eiken, E. Isaksson and B. Lefauconnier, 1995: Recent trends in the mass balance of glaciers in Scandinavia and Svalbard. Proceedings of the international symposium on environmental research in the Arctic. Watanabe, Okitsugu (Eds.), Tokyo, Japan, 19-21 July, 1995, National Institute of Polar Research, 343-354.

Hahn, C.J., S.G. Warren and J. London, 1996: Edited synoptic cloud reports from ships and land stations over the globe, 1982-1991. Rep\#NDP026B, 45 pp. [Available from Carbon Dioxide Information Analysis Center, Oak Ridge National Laboratory, P.O. Box 2008, Oak Ridge, TN 37831-6050.]

Halsey, L.A., D.H. Vitt and S.C. Zoltai, 1995: Disequilibrium response of permafrost in boreal continental western Canada to climate change. Clim. Change, 30, 57-73.

Hammer, C.U., H.B. Clausen and C.C. Langway, 1997: 50,000 years of recorded global volcanism. Clim. Change, 35, 1-15.

Hanawa, K., S.Yasunaka, T. Manabe and N. Iwasaka, 2000: Examination of correction to historical SST data using long-term coastal SST data taken around Japan. J. Met. Soc. Japan, 78, 187-195.

Hansen, J. and S. Lebedeff, 1988: Global surface temperatures: update through 1987. Geophys. Res. Lett., 15, 323-326.

Hansen, J.E., M. Sato, A. Lacis, R. Ruedy, I. Tegen and E. Matthews, 1998: Climate forcings in the Industrial era. Proc. Natl. Acad. Sci., USA, 95, 12753-12758.

Hansen, J., R. Ruedy, J. Glascoe and M. Sato, 1999: GISS analysis of surface temperature change. J. Geophys. Res., 104(D24), 3099731022.

Hanssen-Bauer, I. and E.J. Førland, 2000: Temperature and precipitation variations in Norway 1900-1994 and their links to atmospheric circulation. Int. J. Climatol., 20, 1693-1708.

Harries, J.E., 1976: The distribution of water vapor in the stratosphere. Rev. Geophys. Space Phys., 14, 565-575.

Harrison, S.P., G. Yu and P.E. Tarasov, 1996: Late quaternary lake-level record from Northern Eurasia. Quat. Res., 45, 138-159.

Hastenrath, S. and P.D. Kruss, 1992: The dramatic retreat of Mount Kenya's glaciers between 1963 and 1987: greenhouse forcing. Ann. Glaciol., 16, 127-133.

Hastenrath, S. and A. Ames, 1995: Recession of Yanamarey glacier in 
Cordillera Blanca, Peru during the 20th century. J. Glaciol., 41(137), 191-196.

Hastenrath, S. and L. Greischar, 1997: Glacier recession on Kilimanjaro, East Africa, 1912-89. J. Glaciol., 43, 455-459.

Haylock, M. and N. Nicholls, 2000: Trends in extreme rainfall indices for an updated high quality data set for Australia, 1910-1998. Int. J. Climatol., 20, 1533-1541.

Heino, R., R. Brázdil, E. Forland, H. Tuomenvirta, H. Alexandersson, M. Beniston, C. Pfister, M. Rebetez, G. Rosenhagen, S. Rösner and J. Wibig, 1999: Progress in the study of climatic extremes in Northern and Central Europe. Clim. Change, 42, 151-181.

Helland-Hansen, B. and F. Nansen, 1920: Temperature variations in the North Atlantic Ocean and in the atmosphere. Introductory studies on the cause of climatological variations. Smithsonian Miscellaneous Collections, 70(4), publication 2537, Washington, DC.

Henderson-Sellers, A., 1992: Continental cloudiness changes this century. Geo Journal, 27, 255-262.

Hennessy, K.J., R. Suppiah and C.M. Page, 1999: Australian rainfall changes, 1910-1995. Australian Meteorological Magazine, 48, 1-13.

Higgins, R.W. and W. Shi, 2000: Dominant factors responsible for interannual variability of the summer, monsoon in the southwestern United States. J. Climate, 13, 759-776.

Higgins, R.W., A. Leetmaa, Y. Xue and A. Barnston, 2000: Dominant factors influencing the seasonal predictability of US precipitation and surface air temperature. J. Climate, 13, 3994-4017.

Holzhauser, H. and H.J. Zumbühl, 1996: To the history of the Lower Grindelwald Glacier during the last 2800 years - paleosols, fossil wood and historical pictorial records - new results. Z. Geomorph. N. F., 104, 95-127.

Hoyt, D.V. and K.H. Schatten, 1997: The role of the sun in climatic change. Oxford University Press, Oxford, 279 pp.

Hu, F.S., D. Slawinski, H.E.J. Wright, E. Ito, R.G. Johnson, K.R. Kelts, R.F. McEwan and A. Boedigheimer, 1999: Abrupt changes in North American climate during early Holocene times. Nature, 400, 437440.

Huang, S., H.N. Pollack and P.Y. Shen, 1997: Late quaternary temperature changes seen in world-wide continental heat flow measurements. Geophys. Res. Lett., 24, 1947-1950.

Huang, S., H.N. Pollack and P.Y. Shen, 2000: Temperature trends over the past five centuries reconstructed from borehole temperatures. Nature, 403, 756-758.

Huffman, G., R.F. Adler, P.A. Arkin, J. Janowiak, P. Xie, R. Joyce, R. Ferraro, A. Chang, A. McNab, A. Gruber and B. Rudolf, 1997: The Global Precipitation Climatology Project (GPCP) merged precipitation data sets. Bull. Am. Met. Soc., 78, 5-20.

Hughen, K.A., J.T. Overpeck, L.C. Peterson and S. Trumbore, 1996: Rapid climate changes in the tropical Atlantic region during the last deglaciation. Nature, 380, 51-54.

Hughen, K.H., D. P. Schrag, S.B. Jacobsen and W. Hantor, 1999: El Niño during the last interglacial period recorded by a fossil coral from Indonesia. Geophys. Res. Lett., 26, 3129-3132.

Hughen, K.A., J.T. Overpeck and R. Anderson, 2000: Recent warming in a 500-year paleoclimate record from Upper Soper Lake, Baffin Island, Canada. The Holocene, 10, 9-19.

Hughes, M.G. and D.A. Robinson, 1996: Historical snow cover variability in the Great Plains region of the USA: 1910 through to 1993. Int. J. Climatol., 16, 1005-1018.

Hughes, M.G., A. Frei and D.A. Robinson, 1996: Historical analysis of North American snow cover extent: merging satellite and station derived snow cover observations. Proc.1996 Eastern Snow Conf., Williamsburg, VA, 21-32.

Hughes, M.K. and H.F. Diaz, 1994: Was there a "Medieval Warm Period" and if so, where and when? Clim. Change, 26, 109-142.

Hughes, M.K. and L.J. Graumlich, 1996: Multimillennial dendroclimatic records from Western North America. In: Climatic Variations and
Forcing Mechanisms of the Last 2000 Years, R.S. Bradley, P.D. Jones and J. Jouzel (eds.), Springer Verlag, Berlin, pp. 109-124.

Hughes, M.K. and G. Funkhouser, 1999: Extremes of moisture availability reconstructed from tree rings for recent millennia in the Great Basin of Western North America. In: The Impacts of Climatic Variability on Forests, Beinston, M. and J. Innes (eds.), SpringerVerlag, Berlin, pp. 99-107.

Hughes, M.K., E.A. Vaganov, S. Shiyatov, R.Touchan and G. Funkhouser, 1999: Twentieth century summer warmth in northern Yakutia in a 600 year context. The Holocene, 9, 603-308.

Hulme, M., 1996: Recent climatic change in the world's drylands. Geophys. Res. Lett., 23, 61-64.

Hulme, M., T.J. Osborn and T.C. Johns, 1998: Precipitation sensitivity to global warming: Comparison of observations with HadCM2 simulations. Geophys. Res. Lett., 25, 3379-3382.

Hurrell, J.W., 1995: Decadal trends in the North Atlantic Oscillation regional temperatures and precipitation. Science, 269, 676-679.

Hurrell, J.W., 1996: Influence of variations in extratropical wintertime teleconnections on Northern Hemisphere temperatures. Geophys. Res. Lett., 23, 665-668.

Hurrell, J.W. and K.E. Trenberth, 1996: Satellite versus surface estimates of air temperature since 1979. J. Climate, 9, 2222-2232.

Hurrell, J.W. and H. van Loon, 1997: Decadal variations in climate associated with the North Atlantic Oscillation. Clim. Change, 36, 301-326.

Hurrell, J.W. and K.E. Trenberth, 1998: Difficulties in obtaining reliable temperature trends: reconciling the surface and satellite Microwave Sounding Unit records. J. Climate, 11, 945-967.

Hurrell, J.W. and K.E. Trenberth, 1999: Global sea surface temperature analyses: multiple problems and their implications for climate analysis, modeling and reanalysis, Bull. Am. Met. Soc., 80, 26612678.

Hurrell, J.W., S.J. Brown, K.E. Trenberth and J.R. Christy, 2000: Comparison of tropospheric temperatures from radiosondes and satellites: 1979-1998. Bull. Am. Met. Soc., 81, 2165-2177.

IAHS(ICSI)/UNEP/UNESCO, 1998: Fluctuations of the Glaciers, 1990-95. W. Haeberli, M. Hoelzle, S. Suter and R. Frauenfelder (eds.), World Glacier Monitoring Service, University and ETH, Zurich.

IAHS(ICSI)/UNEP/UNESCO, 1999: Glacier mass balance bulletin no. 5, W. Haeberli, M. Hoelzle and R. Frauenfelder (eds.), World Glacier Monitoring Service, University and ETH, Zurich.

Indeje, M., H.M. Semazzi and L.J. Ogallo, 2000: ENSO signals in East African rainfall seasons. Int. J. Climatol., 20, 19-46.

IPCC, 1990: Climate Change, The IPPC Scientific Assessment. J.T. Houghton, G.J. Jenkins and J.J. Ephraums (eds.), Cambridge University Press, Cambridge, UK, 365 pp.

IPCC, 1992: Climate Change 1992: The Suppliementary Report to the IPCC Scientific Assessment. J.T. Houghton, B.A. Callander and S.K. Varney (eds.), Cambridge University Press, Cambridge, UK, 198 pp.

IPCC, 1996: Climate Change 1995: The Science of Climate Change. Contribution of Working Group I to the Second Assessment Report of the Intergovernmental Panel on Climate Change [Houghton, J.T., L.G. Meira Filho, B.A. Callander, N. Harris, A. Kattenberg, and K. Maskell (eds.)]. Cambridge University Press, Cambridge, United Kingdom and New York, NY, USA, 572 pp.

IPCC, 1999: IPCC Special Report Aviation and the Global Atmosphere. Cambridge University Press, Cambridge, UK, 373 pp.

Iwashima, T. and R. Yamamoto, 1993: A statistical analysis of the extreme events: Long-term trend of heavy daily precipitation. J. Met. Soc. Japan, 71, 637-640.

Jacka, T.H. and W.F. Budd, 1998: Detection of temperature and sea-iceextent change in the Antarctic and Southern Ocean, 1949-96. Ann. Glaciol., 27, 553-559.

Jacobs, G.A. and J.L. Mitchell, 1996: Ocean circulation variations 
associated with the Antarctic Circumpolar Wave. Geophys. Res. Lett. 23, 2947-2950.

Jacobson, G.L., T. Webb III and E.C. Grimm, 1987: Patterns and rates of vegetation change during deglaciation of eastern North America. In: North American and Adjacent Oceans during the Last Deglaciation (eds. W.F. Ruddiman and H.E. Wright), Decade of North American Geology, G.S.A., Boulder, CO, pp. 277-288.

Jacoby, G.C., R.D. D’Arrigo and T. Davaajamts, 1996: Mongolian tree rings and 20th century warming. Science, 273, 771-773.

Janicot, S., V. Moron and B. Fontaine, 1996: Sahel droughts and ENSO dynamics. Geophys. Res. Lett., 23, 551-554.

Jarrell, J.D., P.J. Hebert and M. Mayfield, 1992: Hurricane experience levels of coastal county populations from Texas to Maine. NOAA Tech. Memo, NWS NHC 46, Coral Gables, Florida, USA, 152 pp.

Johannessen, O.M., M.W. Miles and E. Bjørgo, 1995: The Arctic's shrinking sea ice. Nature, 376, 126-127.

Johannessen, O.M., E.V. Shalina and M.W. Miles, 1999: Satellite evidence for an Arctic Sea Ice Cover in Transformation. Science, 286, 1937-1939.

Jóhannesson, T., 1997: The response of two Icelandic glaciers to climate warming computed with a degree-day glacier mass balance model coupled to a dynamic glacier model. J. Glaciol., 43, 321-327.

Johnsen, S.J., H.B. Clausen, W. Dansgaard, K. Fuhrer, N. Gundestrup, C.U. Hammer, P. Iversen, J. Jouzel, B. Stauffer and J.P. Steffensen, 1992: Irregular glacial interstadials recorded in a new Greenland ice core. Nature, 359, 311-313.

Johnson, G.C. and A.H. Orsi, 1997: Southwest Pacific Ocean water-mass changes between 1968/69 and 1990/91. J. Climate, 10, 306-316.

Jones, E.P., K. Aagaard, E.C. Carmack, R.W. MacDonals, F.A. McLaughlin, R.G. Perkin and J.H. Swift, 1996: Recent Changes in Arctic Ocean Thermohaline Structure: Results from the Canada/US 1994 Arctic Ocean Section. Mem. Natl. Inst. Polar Res. Special Issue, 51, 307-315.

Jones, P.D., 1994: Hemispheric surface air temperature variations: a reanalysis and an update to 1993. J. Climate, 7, 1794-1802.

Jones, P.D., 1999: Classics in physical geography revisited - Manley's CET series. Progress in Physical Geography, 23, 425-428.

Jones, P.D. and K.R. Briffa, 1992: Global surface air temperature variations during the twentieth century: Part 1 , spatial temporal and seasonal details. The Holocene, 2, 165-179.

Jones, P.D. and M. Hulme, 1996: Calculating regional climatic time series for temperature and precipitation: methods and illustrations. Int. J. Climatol., 16, 361-377.

Jones, P.D., P.Ya. Groisman, M. Coughlan, N. Plummer, W.C Wang, and T.R. Karl, 1990:Assessment of urbanization effects in time series of surface air temperature over land. Nature, 347, 169-172.

Jones, P.D., T. Jónsson and D. Wheeler, 1997a: Extension of the North Atlantic Oscillation using early instrumental pressure observations from Gibraltar and south-west Iceland. Int. J. Climatol., 17, 14331450.

Jones, P.D., T.J. Osborn and K.R. Briffa, 1997b: Estimating sampling errors in large-scale temperature averages. J. Climate, 10, 2548-2568.

Jones, P.D., K.R. Briffa, T.P., Barnett and S.F.B. Tett, 1998: High-resolution palaeoclimatic records for the last millennium: interpretation, integration and comparison with General Circulation Model control run temperatures. The Holocene, 8, 455-471.

Jones, P.D., M. New, D.E. Parker, S. Martin and I.G. Rigor, 1999a: Surface air temperature and its changes over the past 150 years. Rev. Geophys., 37, 173-199.

Jones, P.D., M.J. Salinger and A.B. Mullan, 1999b: Extratropical circulation indices in the Southern Hemisphere. Int. J. Climatol., 19, 13011317.

Jones, P.D., E.B. Horton, C.K. Folland, M. Hulme, D.E. Parker and T.A. Basnett, 1999c: The use of indices to identify changes in climatic extremes. Clim. Change, 42, 131-149.
Jones, P.D., T.J. Osborn, K.R. Briffa, C.K. Folland, E.B. Horton, L.V. Alexander, D.E. Parker and N.A. Rayner, 2001: Adjusting for sampling density in grid box land and ocean surface temperature time series. J. Geophys. Res., 106, 3371-3380.

Jouzel, J., C. Lorius, J.R. Petit, C. Genthon, N.I. Barkov, V.M. Kotlyakov and V.M. Petrov, 1987: Vostok ice core: a continuous isotope temperature record over the last climatic cycle (160,000 years). Nature, 329, 402-408.

Jouzel, J., N.I. Barkov, J.M. Barnola, M. Bender, J. Bender, J. Chappelaz, C. Genthron, V.M. Kotlyakov, V. Lipenkiv, C. Lorius, J.R. Petit, D. Raynaud, G. Raisbeck, C. Ritz, T. Sowers, M. Stievenard, F. Yiou and P. Yiou, 1993: Extending the Vostok ice core record of paleoclimate to the penultimate glacial period. Nature, 364, 407-412.

Jouzel, J., C. Lorius, S.J. Johnsen and P. Grootes, 1994: Climate instabilities: Greenland and Antarctic records. C.R. Acad. Sci. Paris, t 319, série II, pp. 65-77.

Jouzel, J., R. Vaikmae, J.R. Petit, M. Martin, Y. Duclos, M. Stievenard, C. Lorius, M. Toots, M.A. Mélières, L.H. Burckle, N.I. Barkov and V.M. Kotlyakov, 1995: The two-step shape and timing of the last deglaciation in Antarctica. Clim. Dyn., 11, 151-161.

Jouzel, J., V. Masson, O. Cattani, S. Falourd, M. Stievenard, B. Stenni, A. Longinelli, S.J. Johnson, J.P. Steffenssen, J.R. Petit, J. Schwander and R. Souchez, 2001: A new $27 \mathrm{kyr}$ high resolution East Antarctic climate record. Geophys. Res. Lett., in press.

Joyce, T.M. and P. Robbins, 1996: The long-term hydrographic record at Bermuda. J. Climate, 9, 3121-3131.

Joyce, T.M., R.S. Pickart and R.C. Millard, 1999: Long-term hydrographic changes at $52^{\circ}$ and $66^{\circ} \mathrm{W}$ in the North Atlantic Subtropical Gyre and Caribbean. Deep-Sea Res., Part II, 46, 245278.

Kagan, R.L., 1997: Averaging of Meteorological Fields. Translation by UK Ministry of Defence Linguistic Services of original Russian 1979 text. Eds: L.S. Gandon and T.M. Smith, Kluwer, London, 279 pp.

Kaiser, D.P., 1998: Analysis of total cloud amount over China, 19511994. Geophys. Res. Lett., 25, 3599-3602.

Kaiser, D.P., 2000: Decreasing cloudiness over China! An updated analysis examining additional variables. Geophys. Res. Lett., 27, 2193-2196.

Kalnay, E., M. Kanamitsu, R. Kistler, W Collins, D. Deaven, I. Gandin, M. Iredell, S. Saha, G. White, J. Woollen, Y. Zhu, M. Chelliah, W. Ebisuzaki, W. Higgins, J. Janowiak, K.C. Mo, C. Ropelewski, J. Wang, A. Leetmaa, R. Reynolds, R. Jenne and D. Joseph, 1996: The NCEP/NCAR 40-year Reanalysis Project. Bull. Am. Met. Soc., 77, 437-471.

Kaplan, A., Y. Kushnir, M.A. Cane and M. Benno Blumenthal, 1997: Reduced space optimal analysis for historical data sets: 136 years of Atlantic sea surface temperatures. J. Geophys. Res., 102(C13), 27835-27860.

Kaplan, A., M.A. Cane, Y.A. Kushnir and A.C. Clement, 1998: Analyses of global sea surface temperature, 1856-1991. J. Geophys. Res., 103(C9), 18567-18589.

Karl, T.R. and P.M. Steurer, 1990: Increased cloudiness in the United States during the first half of the twentieth century: fact or fiction? Geophys. Res. Lett., 17, 1925-1928.

Karl, T.R. and R.W. Knight, 1997: The 1995 Chicago heat wave: How likely is a recurrence? Bull. Am. Met. Soc., 78, 1107-1119.

Karl, T.R. and R.W. Knight, 1998: Secular trends of precipitation amount, frequency, and intensity in the USA. Bull. Am. Met. Soc., 79, 231-241.

Karl, T.R., V.E. Derr, D.R. Easterling, C.K. Folland, D.J. Hofmann, S. Levitus, N. Nicholls, D.E. Parker and G.W. Withee, 1995a: Critical issues for long-term climate monitoring. Clim. Change, 31, 185-221, 1995a and In: Long-term climate Monitoring by the Global Climate Observing System, T. Karl (ed.), Kluwer, Dordrecht, pp. 55-91.

Karl, T.R., R.W. Knight and N. Plummer, 1995b: Trends in high- 
frequency climate variability in the twentieth century. Nature, $\mathbf{3 7 7}$, 217-220.

Karl, T.R., R.W. Knight, D.R. Easterling and R.G. Quayle, 1995c: Trends in U.S. climate during the Twentieth Century. Consequences, 1, 3-12.

Karl, T.R., R.W. Knight, and B. Baker, 2000: The record breaking global temperatures of 1997 and 1998: evidence for an increase in the rate of global warming? Geophys. Res. Lett., 27, 719-722.

Karoly, D.J., 1990: The role of transient eddies in low-frequency zonal variations of the Southern Hemisphere circulation. Tellus, 42A, 4150.

Karoly, D.J., P. Hope and P.D. Jones, 1996: Decadal variations of the Southern Hemisphere circulation. Int. J. Climatol., 16, 723-738.

Katz, R.W., 1999: Extreme value theory for precipitation: Sensitivity analysis for climate change. Advances in Water Resources, 23, 133 139.

Kawamura, R., 1994: A rotated EOF analysis of global sea surface temperature variability with interannual and interdecadal scales. $J$. Phys. Oceanogr., 24, 707-715.

Keckhut, P., F.J. Schmidlin, A. Hauchecorne and M.-L. Chanin, 1999: Stratospheric and mesospheric cooling trend estimates from US rocketsondes at low latitude stations $\left(8^{\circ} \mathrm{S}-34^{\circ} \mathrm{N}\right)$, taking into account instrumental changes and natural variability. J. Atmos. And SolarTerr. Phys., 61, 447-459.

Keigwin, L., 1996: The Little Ice Age and Medieval Warm Period in the Sargasso Sea. Science, 274, 1504-1508.

Keigwin, L.D. and R.S. Pickart, 1999: Slope water current over the Laurentian Fan on Interannual to Millennial Time Scales. Science, 286, 520-523.

Kershaw, A.P., D.M. D'Costa, J.R.C.M. Mason and B.E. Wagstaff, 1991: Palynological evidence for Quaternary vegetation and environments of Mainland Southeastern Australia. Quat. Sci. Rev., 10, 391-404.

Kestin, T.S., D.J. Karoly, J.I. Jano and N.A. Rayner, 1999: Timefrequency variability of ENSO and stochastic simulations. J. Climate, 11, 2258-2272.

Kidson, J.W., 1988: Interannual variations in the Southern Hemisphere circulation. J. Climate, 1, 1177-1198.

Kidson, J.W., 1999: Principal modes of Southern Hemisphere low frequency variability obtained from NCEP/NCAR reanalyses. $J$. Climate, 12, 2808-2830.

Kiladis, G.N. and K.C. Mo, 1999: Interannual and intraseasonal variability in the Southern Hemisphere, Chapter 8. In: Meteorology of the Southern Hemisphere, American Meteorological Society, Boston.

King, J.C., 1994: Recent climate variability in the vicinity of the Antarctic Peninsula. J. Climate, 14, 357-361.

Kley, D., J.M. Russell and C. Phillips (eds.), 2000: SPARC Assessment of upper tropospheric and tratospheric water vapour. WCRP-No. 113, WMO/TD-No. 1043, SPARC Report No.2, 325 pp.

Klitgaard-Kristensen, D., H.P. Sejrup, H. Haflidason, S. Johnsen and M. Spurk, 1998: The short cold period 8,200 years ago documented in oxygen isotope records of precipitation in Europe and Greenland. J. Quaternary Sciences, 13, 165-169.

Knight, R.W., 1984: Introduction to a new sea-ice database. Ann. Glaciol., 5, 81-84.

Koç, N. and E. Jansen, 1994: Response of the high-latitude NorthernHemisphere to orbital climate forcing-evidence from the Nordic seas. Geology, 22, 523-526.

Kotilainin, A.T. and N.J. Shackleton, 1995: Rapid climate variability in the North Pacific Ocean during the past 95,000 years. Nature, 377, 323-326.

Kumar, K., K. Rupa, K.K. Kumar and G.B. Pant, 1994: Diurnal asymmetry of surface temperature trends over India. Geophys. Res. Lett., 21, 677-680.

Kumar, K.K., R. Kleeman, M.A. Crane and B. Rajaopalan, 1999a: Epochal changes in Indian monsoon-ENSO precursors. Geophys. Res. Lett., 26, 75-78.
Kumar, K.K., B. Rajaopalan and M.A. Crane, 1999b: On the weakening relationship between the Indian monsoon and ENSO. Science, 284, 2156-2159.

Kunkel, K.E., S.A. Changnon, B.C. Reinke and R.W. Arritt, 1996: The July 1995 heat wave in the Midwest: A climatic perspective and critical weather factors. Bull. Am. Met. Soc., 77, 1507-1518.

Kunkel, K.E., K. Andsager and D.R. Easterling, 1999: Long-term trends in extreme precipitation events over the conterminous United States and Canada. J. Climate, 12, 2515-2527.

Kushnir, Y., V.J. Cardon, J.G. Greenwood and M.A. Cane, 1997: The recent increase in North Atlantic wave heights. J. Climate, 10, $2107-$ 2113.

Laberge, M.J. and S. Payette, 1995: Long-term monitoring of permafrost change in a palsa peatland in northern Quebec, Canada: 1983-1993. Arctic and Alpine Research, 27, 167-171.

Labeyrie, L., J.C. Duplessy, J. Duprat, A. Juillet-Leclerc, J. Moyes, E. Michel, N. Kallel and N.J. Shackleton, 1992: Changes in vertical structure of the North Atlantic Ocean between glacial and modern times. Quat. Sci. Rev., 11, 401-413.

Lachenbruch, A.H. and B.V. Marshall, 1986: Changing climate: geothermal evidence from permafrost in the Alaskan Arctic. Science, 234, 689-696.

Lachenbruch, A.H., T.T Cladouhos and R.W. Saltus, 1988: Permafrost temperature and the changing climate. In: Proceedings of the Fifth International Conference on Permafrost, Trondheim, Norway, 3, 9-17.

Laird, K.R., S.C. Fritz, K.A. Maasch and B.F. Cumming, 1996: Greater Drought Intensity and frequency before AD 1200 in the Northern Great Plains. Nature, 384, 552-554.

Lamb, H.F., F. Gasse, A. Bekaddour, N. El Hamouti, S. van der Kaars, W.T. Perkins, N.J. Pearce and C.N. Roberts, 1995: Relation between century-scale Holocene arid intervals in temperate and tropical zones. Nature, 373, 134-137.

Lambert, S.J., 1996: Intense extratopical Northern Hemisphere winter cyclone events: 1189-1991. J. Geophys. Res., 101, 21319-21325.

Lamoureux, S.F. and R.S. Bradley, 1996: A 3300 year varved sediment record of environmental change from northern Ellesmere Island, Canada. J. Paleolimnology, 16, 239-255.

Lander, M.A. and C.P. Guard, 1998: A look at global tropical cyclone activity during 1995: Contrasting high Atlantic activity with low activity in other basins. Mon. Wea. Rev., 126, 1163-1173.

Landsea, C.W., 1993: A climatology of intense (or major) Atlantic hurricanes. Mon. Wea. Rev., 121, 1703-1713.

Landsea, C.W., N. Nicholls, W.M. Gray and L.A. Avila, 1996: Downward trends in the frequency of intense Atlantic hurricanes during the past five decades. Geophys. Res. Lett., 23, 1697-1700.

Landsea, C.W., R.A. Pielke, Jr., A.M. Mestas-Nunez and J.A. Knaff, 1999: Atlantic basin hurricanes: Indices of climatic changes. Clim. Change, 42, 89-129.

Lang, C., M. Leuenberger, J. Schwander and J. Johnsen, 1999: $16^{\circ} \mathrm{C}$ rapid temperature variation in central Greenland 70000 years ago. Science, 286, 934-937.

Latif, M. and T.P. Barnett, 1994: Causes of decadal climate variability over the North Pacific and North America. Science, 266, 634-637.

Lawrimore, J.H. and T.C. Peterson, 2000: Pan evaporation trends in dry and humid regions of the United States. J. Hydrometeor., 1, 543-546.

Lazier, J.R.N., 1995: The salinity decrease in the Labrador Sea over the past thirty years. In: Natural Climate Variability on Decade-toCentury Time Scales, D.G. Martinson, K. Bryan, M. Ghil, M.M. Hall, T. Karl, E.S. Sarachik, S. Sorooshian, and L.D. Talley (eds.), National Academy Press, Washington, D.C., pp. 295-305.

Lean, J., J. Beer and R.S. Bradley, 1995: Reconstruction of solar irradiance since 1610: Implications for climatic change. Geophys. Res. Lett., 22, 3195-3198.

Leathers, D.J. and A.W. Ellis, 1996: Synoptic mechanisms associated 
with snowfall increases to the lee of Lakes Erie and Ontario. Int. J. Climatol., 16, 1117-1135.

Lettenmaier, D.P., A.W. Wood, R.N. Palmer, E.F. Wood and E.Z. Stakhiv, 1999: Water resources implications of global warming: A U.S. regional perspective. Clim. Change, 43, 537-579.

Levitus, S. and J. Antonov, 1997: Variability of heat storage of and the rate of heat storage of the world ocean. NOAA NESDIS Atlas 16, US Government Printing Office, Washington, D.C., 6 pp., 186 figures.

Levitus, S., R. Gelfeld, T. Boyer and D. Johnson, 1994: Results of the NODC and IOC Data Archaeology and Rescue projects In: Key to Oceanographic Records Documentation No. 19, National Oceanographic Data Center, Washington, D.C., 67 pp.

Levitus, S., R. Gelfeld, M. E. Conkright, T. Boyer, D. Johnson, T. O'Brien, C. Stephens, C. Forgy, O. Baranova, I. Smolyar, G. Trammell and R. Moffatt, 2000a: Results of the NODC and IOC Data Archaeology and Rescue projects. In: Key to Oceanographic Records Documentation No. 19, National Oceanographic Data Center, Washington, D.C., $19 \mathrm{pp}$.

Levitus, S., J.Antonov, T.P. Boyer and C. Stephens, 2000b: Warming of the World Ocean. Science, 287, 2225-2229.

Lewis, T., 1998: The effect of deforestation on ground surface temperatures. Global and Planetary Change, 18, 1-13.

Lins, H.F. and P.J. Michaels, 1994: Increasing U.S. streamflow linked to greenhouse forcing. Eos Trans. AGU, 75, 281, 284-285.

Lins, H F. and J.R. Slack, 1999: Streamflow trends in the United States. Geophys. Res. Lett., 26, 227-230.

Livezey, R.E. and T.M. Smith, 1999: Covariability of aspects of North American climate with global sea surface temperatures on interannual to interdecadal timescales. J. Climate, 12, 289-302.

Luterbacher, J., C. Schmutz, D. Gyalistras, E. Xoplaki and H. Wanner, 1999: Reconstruction of monthly NAO and EU indices back to A.D. 1675. Geophys. Res. Lett., 26, 759-762.

Lysenko, E.V., G. Nelidova and A. Prostova, 1997: Changes in the stratospheric and mesospheric thermal conditions during the last 3 decades: 1. The evolution of a temperature trend. Isvestia, Atmos. and Oceanic Physics, 33(2), 218-225.

MacManus, J., D.W. Oppo and J.L.Cullen, 1999: A 0.5 Million-Year Record of Millenial scale climate variability in the North Atlantic. Science, 283, 971-975.

Magnuson, J.J., D.M. Robertson, B.J. Benson, R.H. Wynne, D.M. Livingston, T. Arai, R.A. Assel, R.G. Barry, V. Card, E. Kuusisto, N.G. Granin, T.D. Prowse, K.M. Stewart and V.S. Vuglinski, 2000: Historical trends in lake and river ice cover in the Northern Hemisphere. Science, 289, 1743-1746.

Magny, M., 1995: Successive oceanic and solar forcing indicated by Younger Dryas and early Holocene climatic oscillations in the Jura. Quat. Res., 43, 279-285.

Mahowald, N., K.E. Kohfeld, M. Hansson, Y. Balkanski, S.P. Harrison, I.C. Prentice, M. Schulz and H. Rodhe, 1999: Dust sources and deposition during the last glacial maximum and current climate: a comparison of model results with paleodata from ice cores and marine sediments. J. Geophys. Res., 104, 15895-15916.

Majorowicz, J.A. and A. Judge, 1994: Climate induced ground warming at the southern margins of permafrost. EOS, Transactions, American Geophysical Union, 75(44), 84.

Maloney, E.D. and D.L. Hartmann, 2001: The Madden-julian Oscillation, Barotropic Dynamics, and North Pacific Tropical Cyclone Formation, Part I: Observations. J. Atmos. Sci., in press.

Mann, M.E., 2000: Lessons for a New Millennium. Science, 289(14), 253-254.

Mann, M.E. and J. Park, 1994: Global-scale modes of surface temperature variability on interannual to century timescales. J. Geophys. Res., 99, 25819-25833

Mann, M.E. and J. Park, 1996: Joint spatiotemporal modes of surface temperature and sea level pressure variability in the Northern
Hemisphere during the last century. J. Climate, 9, 2137-2162.

Mann, M.E., J. Park and R.S. Bradley, 1995: Global interdecadal and century-scale oscillations during the past five centuries. Nature, 378, 266-270.

Mann, M.E., R.S. Bradley and M.K. Hughes, 1998: Global-scale temperature patterns and climate forcing over the past six centuries. Nature, 392, 779-787.

Mann, M.E., R.S. Bradley, and M.K. Hughes, 1999: Northern Hemisphere Temperatures During the Past Millennium: Inferences, Uncertainties, and Limitations. Geophys. Res. Lett., 26, 759-762.

Mann, M.E., R.S. Bradley and M.K. Hughes, 2000a: Long-term variability in the El Nino Southern Oscillation and associated teleconnections. In: El Nino and the Southern Oscillation: Multiscale Variability and its Impacts on Natural Ecosystems and Society, H.F. Diaz and V. Markgraf (eds.), Cambridge University Press, Cambridge, UK, 357-412.

Mann, M.E., E. Gille, R.S. Bradley, M.K. Hughes, J.T. Overpeck, F.T. Keimig and W. Gross, 2000b: Global temperature patterns in past centuries: An interactive presentation. Earth Interactions, 4/4, 1-29.

Manton, M.J., P.M. Della-Marta, M.R. Haylock, K.J. Hennessy, N. Nicholls, L.E. Chambers, D.A. Collins, G. Daw, A. Finet, D. Gunawan, K. Inape, H. Isobe, T.S. Kestin, P. Lafale, C.H. Leyu, T. Lwin, L. Maitrepierre, N. Ouprasitwong, C.M. Page, J. Pahalad, N. Plummer, M.J. Salinger, R. Suppiah, V.L. Tran, B. Trewin, I. Tibig and D. Yee, 2001: Trends in extreme daily rainfall and temperature in Southeast Asia and the South Pacific: 1961-1998. Int. J. Climatol., 21, 269-284.

Mantua, N.J., S.R. Hare, Y. Zhang, J.M. Wallace and R.C. Francis, 1997: A Pacific interdecadal climate oscillation with impacts on salmon production. Bull. Am. Met. Soc., 78, 1069-1079.

Marengo, J.A., J. Tomasella and C.R. Uvo, 1998: Trends in streamflow and rainfall in tropical South America: Amazonia, Eastern Brazil and Northwestern Peru. J. Geophys. Res.,103, 1775-1783.

Martinson, D.G., N.G. Pisias, J.D. Hays, J. Imbrie, T.C. Moore and N.J. Shackleton, 1987: Age Dating and the Orbital Theory of the Ice Ages: Development of a High-Resolution 0-300,000 Years Chronostratigraphy. Quat. Res., 27, 1-30.

Martin-Vide, J. and M. Barriendos, 1995: The use of rogation ceremony records in climatic reconstruction: A case study from Catalonia (Spain). Clim. Change, 30, 201-221.

Maslanik, J.A., M.C. Serreze and R.G. Barry, 1996: Recent decreases in Arctic summer ice cover and linkages to atmospheric circulation anomalies. Geophys. Res. Lett., 23, 1677-1680.

Masson, V., F. Vimeux, J. Jouzel, V. Morgan, M. Delmotte, C. Hammer, S.J. Johnsen, V. Lipenkov, J.R. Petit, E. Steig, M. Stievenard and R. Sousmis Vaikmae, 2000: Holocene climate variability in Antarctica based on 11 ice-core isotopic records. Quat. Res., 54, 348-358.

Mastenbrook, H.J., 1968: Water vapor distribution in the stratosphere and high troposphere. J. Atmos. Sci., 25, 299-311.

Mastenbrook, H.J. and S. Oltmans, 1983: Stratospheric water vapor variability for Washington D.C./Boulder, CO.: 1964-1982. J. Atmos. Sci., 40, 2157-2165.

Mayewski, P.A. and I.D. Goodwin, 1997: International Trans-Antarctic Scientific Expedition (ITASE). PAGES/SCAR Workshop Report Series, 97-1.Bern Switzerland, 48 pp.

Mayewski, P.A., L.D. Meeker, M.S. Twickler, S. Whitlow, Y. Qinzhao, W.B. Lyons and M. Prentice, 1997: Major features and forcing of high-latitude northern hemisphere atmospheric circulation using a 110,000-year-long glaciochemical series. J. Goephys. Res., 102, 26345-26366.

McGlone, M.S., A.P. Kershaw and V. Markgraf, 1992: El Niño/Southern Oscillation and climatic variability in Australasian and South American paleoenvironmental records. In: El Niño: Historical and paleoclimatic aspects of the Southern Oscillation, H.F. Diaz and V. Markgraf (eds.), Cambridge, Cambridge University Press, pp. 435- 
462.

McManus, J.F., G.C. Bond, W.S. Broecker, S. Johnsen, L. Labeyrie and S. Higgins, 1994: High-resolution climate records from the North Atlantic during the last interglacial. Nature, 317, 326-329.

McPhee, M.G., T.P. Stanton, J.H. Morison and D.G. Martinson, 1998: Freshening of the upper ocean in the Arctic: Is perennial sea ice disappearing? Geophys. Res. Lett., 25, 1729-1732.

Meehl, G.A., J. Arblaster and W. Strand, 1998: Global decadal scale climate variability. Geophys. Res. Lett., 25, 3983-3986.

Meehl, G.A., T. Karl, D.R. Easterling, S. Changnon, R. Pielke, Jr., D. Changnon, J. Evans, P.Ya. Groisman, T.R. Knutson, K.E. Knukel, L.O. Mearns, C. Parmesan, R. Pulwarty, T. Root, R.T. Sylves, P. Whetton and F. Zwiers, 2000: An introduction to trends in extreme weather and climate events: Observations, socioeconomic impacts, terrestrial ecological impacts, and model projections. Bull. Am. Met. Soc., 81, 413-416.

Meese, D.A. and 13 others, 1994: The accumulation record from the GISP2 core as an indicator of climate change throughout the Holocene. Science, 266, 1680-1682.

Mekis, E. and W.D. Hogg, 1999: Rehabilitation and analysis of Canadian daily precipitation time series. Atmosphere-Ocean, 37(1), 53-85.

Melling, H., 1998: Hydrographic changes in the Canada Basin of the Arctic Ocean, 1979-1996. J. Geophys. Res., 103(C4), 7637-7645.

Meshcherskaya, A.V., I.G. Belyankina and M.P. Golod, 1995: Monitoring tolshching cnozhnogo pokprova $\mathrm{v}$ osnovioi zerno proizvodyashchei zone Byvshego SSSR za period instrumental'nykh nablyugenii. Izvestiya Akad. Nauk SSR., Sser. Geograf., pp. 101-110.

Michaels, P.J. and P.C. Knappenberger, 2000: Natural signals in the MSU lower tropospheric temperature record. Geophys. Res. Lett., 27, 2905-2908.

Michaels, P.J., R.C. Balling, Jr. , R.S. Vose and P.C. Knappenberger, 1998: Analysis of trends in the variability of daily and monthly historical temperature measurements. Clim. Res., 10, 27-33.

Michaels, P.J., P.C. Knappenberger, R.C. Balling Jr. and R.E. Davis, 2000: Observed warming in cold anticyclones. Clim. Res., 14, 1-6.

Minobe, S., 1997: A 50-70 year climatic oscillation over the North Pacific and North America. Geophys. Res. Lett., 24, 683-686.

Mo, K.C. and R.W. Higgins, 1998: The Pacific South American modes and tropical convection during the Southern Hemisphere winter. Mon. Wea. Rev., 126, 1581-1596.

Mo, T., 1995: A study of the Microwave Sounding Unit on the NOAA12 satellite. IEEE Trans. Geoscience and Remote Sensing, 33, 11411152.

Moberg, A., P.D. Jones, M. Barriendos, H. BergstrØm. D. Camuffo, C. Cocheo, T.D. Davies, G. Demar?e, J. Martin-Vide, M. Maugeri, R. Rodriquez and T. Verhoeve, 2000: Day-to-day temperature variability trends in 160-275-year long European instrumental records. $J$. Geophys. Res., 105(D18), 22849-22868.

Morgan, V.I. and T.D. van Ommen, 1997: Seasonality in late-Holocene climate from ice core records. The Holocene, 7, 351-354.

Moron, V., 1997: Trend, decadal and interannual variability in annual rainfall in subequatorial and tropical North Africa (1900-1994). Int. J. Climatol., 17, 785-806.

Moron, V., R. Vautard and M. Ghil, 1998: Trends, Interdecadal and interannual oscillations in global sea-surface temepratures. Clim. Dyn., 14, 545-569.

Mysak, L.A. and S.A. Venegas, 1998: Decadal climate oscillations in the Arctic: a new feedback loop for atmospheric-ice-ocean interactions. Geophys. Res. Lett., 25, 3607-3610.

Nagurnyi, A.P., V.G. Korostelev and P.A. Abaza, 1994: Wave method for evaluating the effective thickness of sea ice in climate monitoring. Bulletin of the Russian Academy of Sciences, Physics Supplement, Physics of Vibrations, pp. 168-241.

Nagurnyi, A.P., V.G. Korostelev and V.V. Ivanov, 1999: Multiyear variability of sea ice thickness in the Arctic Basin measured by elastic-gravity oscillation of the ice cover. Meteorologiya I gidrologiya, 3, 72-78.

Nash, J. and G.F. Forrester, 1986: Long-term monitoring of stratospheric temperature trends using radiance measurements obtained by the TIROS-N series of NOAA spacecraft. Adv. Space Res., 6, 37-44.

National Climatic Data Center (NCDC), 1997: Products and Services Guide, Asheville, NC: US Department of Commerce, NOAA, 60 pp.

Neff, W.D., 1999: Decadal time scale trends and variability in the tropospheric circulation over the South Pole. J. Geophys. Res., 104(D22), 27217-27251.

Nelson, F.E. and J. Brown, 1997: Global change and permafrost. Frozen Ground, 21, 21-24.

Nelson, F.E., K.M. Hinkel, N.I. Shiklomanov, G.R. Mueller, L.L. Miller and D.A. Walker, 1998: Active-layer thickness in north-central Alaska: systematic sampling, scale, and spatial autocorrelation. $J$. Geophys. Res., 103, 28963-28973.

Neumann, C.J., 1993: Global Overview, Global Guide to Tropical Cyclone Forecasting. WMO/TC-No. 560, Report No. TCP-31, World Meteorological Organization, Geneva, pp. 1.1-1.43.

New, M., M. Hulme and P.D. Jones, 2000: Representing twentieth century space-time climate variability, II: Development of 1901-1996 monthly grids of terrestrial surface climate. J. Climate, 13, 22172238.

Nicholls, N. and W. Murray, 1999: Workshop on Indices and Indicators for climate extremes, Asheville, NC, USA, 3-6 June 1999. Breakout Group B: Precipitation. Clim. Change, 42, 23-29.

Nicholls, N., C.W. Landsea and J. Gill, 1998: Recent trends in Australian region tropical cyclone activity. Met. Atmos. Phys., 65, 197-205.

Nicholson, S.E., 1993: An overview of African rainfall fluctuations of the last decade. J. Climate, 6, 1463-1466.

Nicholson, S.E., 1997: An analysis of the ENSO signal in the tropical Atlantic and western Indian oceans. Int. J. Climatol., 17, 345-375.

Nicholson, S.E. and J. Kim, 1997: The relationship of the El NinoSouthern Oscillation to African rainfall. Int. J. Climatol., 17, 117135.

Nicholson, S.E., B. Some and B. Kane, 2000: An analysis of recent rainfall conditions in west Arica, including the rainy seasons of the 1997 El Niño and the 1998 La Niña years. J. Climate, 13, 2628-2640.

Nixon, F.M. and A.E. Taylor, 1998: Regional active layer monitoring across the sporadic, discontinuous and continuous permafrost zones, Mackenzie Valley, northwestern Canada. In: Proceedings of the Seventh International Conference on Permafrost (Lewcowicz, A.G. and M. Allard (eds.)) Centre d'Etudes Nordiques, Université Laval, Québec, pp. 815-820.

Norris, J.R., 1999: On trends and possible artifacts in global ocean cloud cover between 1952 and 1995. J. Climate, 12, 1864-1870.

Norris, J.R. and C.B. Leovy, 1995: Comments on "Trends in global marine cloudiness and anthropogenic sulphur". J. Climate, 8, 21092110.

Norris, J.R., Y. Zhang and J.M. Wallace, 1998: Role of low clouds in summertime atmosphere-ocean interactions over the North Pacific. $J$. Climate, 11, 2482-2490.

NRC (National Research Council), 2000: Reconciling Observations of Global Temperature Change. National Academy Press, Washington D.C., 85 pp.

O'Brien, S., P.A. Mayewski, L.D. Meeker, D.A. Meese, M.S. Twickler and S.I. Whitlow, 1995: Complexity of Holocene climate as reconstructed from a Greenland ice core. Science, 270, 1962-1964.

Oerlemans, J., 1989: On the response of valley glaciers to climatic change. In: Glacier fluctuations and climatic change, J. Oerlemans, (ed.), Dordrecht, Kluwer Academic, pp. 353-372.

Oerlemans, J., 1992: Climate sensitivity of glaciers in southern Norway: application of an energy-balance model to Nigardsbreen, Hellstugubreen and Alfotbreen. J. Glaciol., 38, 223-232.

Oerlemans, J., 1994: Quantifying global warming from the retreat of 
glaciers. Science, 264, 243-245.

Oerlemans, J., B. Anderson, A. Hubbard, P. Huybrechts, T. Jóhannesson, W.H. Knap, M. Schmeits, A.P. Stroeven, R.S.W. van de Wal, J. Wallinga and Z. Zuo, 1998: Modelling the response of glaciers to climate warming. Clim. Dyn., 14, 267-274.

Oeschger, H., J. Beer, U. Siegenthaler, B. Stauffer, W. Dansgaard and C.C. Langway, 1984: Late glacial climate history from ice cores. In: Climate processes and climate sensitivity, J.E. Hansen and T. Takahashi (eds.), American Geophysical Union, Washington.

Oltmans, S.J. and D.J. Hofmann, 1995: Increase in lower-stratospheric water vapour at a mid-latitude Northern Hemisphere site from 19811994. Nature, 374, 146-149.

Oltmans, S.J., S.H. Voemel, D. Hofmann, K. Rosenlof and D. Kley, 2000: The increase in stratospheric water vapor from balloon-borne, frostpoint hygrometer measurements at Washington, DC and Boulder, Colorado. Geophys. Res. Lett., 27, 3453-3456.

Osborn, T.J., K.R. Briffa, S.F.B. Tett and P.D. Jones, 1999: Evaluation of the North Atlantic Oscillation as simulated by a coupled climate model. Clim. Dyn., 15, 685-702.

Osborn, T.J., M. Hulme, P.D. Jones and T.A, Basnett, 2000: Observed trends in the daily intensity of United Kingdom precipitation. Int. J. Climatol., 20, 347-364.

Osterkamp, T.E., 1994: Evidence for warming and thawing of discontinuous permafrost in Alaska. EOS, Transactions, American Geophysical Union, 75, 85.

Osterkamp, T.E. and V.E. Romanovsky, 1999: Evidence for warming and thawing of discontinuous permafrost in Alaska. Permafrost and Periglacial Processes, 10(1), 17-37.

Østrem, G., O. Liestøl and B. Wold, 1977: Glaciological investigations at Nigardsbreen, Norway. Norsk Geogr. Tidsskr., 30, 187-209.

Overpeck, J.T., P.J. Bartlein and T. Webb III, 1991: Potential magnitude of future vegetation change in eastern North America: Comparisons with the past. Science, 252, 692-695.

Overpeck, J., K. Hughen, D. Hardy, R. Bradley, R. Case, M. Douglas, B. Finney, K. Gajewski, G. Jacoby, A. Jennings, S. Lamoureux, A. Lasca, G. MacDonald, J. Moore, M. Retelle, S. Smith, A. Wolfe and G. Zielinski, 1997: Arctic environmental change of the last four centuries. Science, 278, 1251-1256.

Palecki, M.A. and R.G. Barry, 1986: Freeze-up and break-up of lakes as an index of temperature changes during the transition seasons: A case study for Finland. J. Clim. Appl. Met., 25, 893-902.

Palmer, T.N., 1993: A nonlinear dynamical perspective on climate change. Weather, 48, 313-326.

Palmer, T.N., 1999: A nonlinear dynamical perspective on climate prediction. J. Climate, 12, 575-591.

Pant, G.B. and K.R. Kumar, 1997: Climates of South Asia, John Wiley, Chichester, 320pp.

Parker, D.E., 1994: Effects of changing exposures of thermometers at land stations. Int. J. Climatol., 14, 102-113.

Parker, D.E. and C.K. Folland, 1988: The nature of climatic variability. Met. Mag., 117, 201-210.

Parker, D.E. and D.I. Cox, 1995: Towards a consistent global climatological rawinsonde data-base. Int. J. Climatol., 15, 473-496.

Parker, D.E. and E.B. Horton, 1999: Global and regional climate in 1998. Weather, 54, 173-184.

Parker, D.E. and E.B. Horton, 2000: Global and regional climate in 1999. Weather, 55, 188-199.

Parker, D.E., P.D. Jones, C.K. Folland and A. Bevan, 1994: Interdecadal changes of surface temperature since the late nineteenth century. $J$. Geophys. Res., 99, 14373-14399.

Parker, D.E., C.K. Folland and M. Jackson, 1995: Marine surface temperature: observed variations and data requirements. Clim. Change, 31, 559-600.

Parker, D.E., H. Wilson, P.D. Jones, J. Christy and C.K. Folland, 1996: The impact of Mount Pinatubo on climate. Int. J. Climatol., 16, $487-$
497.

Parker, D.E., M. Gordon, D.P.N. Cullum, D.M.H. Sexton, C.K. Folland and N. Rayner, 1997: A new global gridded radiosonde temperature data base and recent temperature trends. Geophys. Res. Lett., 24, 1499-1502.

Parkinson, C.L., 2000: Variability of Arctic sea ice. The view from space, an 18-year record. Arctic, 53, 341-358.

Parkinson, C.L., D.J. Cavalieri, P. Gloersen, H.J. Zwally and J.C. Comiso, 1999: Arctic sea ice extents, areas, and trends, 1978-1996. J. Geophys. Res., 104(C9), 20837-20856.

Parrilla, G., A. Lavín, H.L. Bryden, M.J. García and R. Millard, 1994: Rising temperatures in the subtropical North Atlantic Ocean over the past 35 years. Nature, $\mathbf{3 6 9}, 48-51$.

Partridge, T.C., 1997: Cainozoic environmental change in southern Africa, with special emhpasis on the last 200,000 years. Progress in Physical Geography, 21, 3-22.

Parungo, F., J.F. Boatman, H. Sievering, S.W. Wilkison and B.B. Hicks, 1994: Trends in global marine cloudiness and anthropogenic sulphur. J. Climate, 7, 434-440.

Pavlov, A.V., 1994: Current changes of climate and permafrost in the Arctic and Sub-Arctic of Russia. Permafrost and Periglacial Processes, 5, 101-110.

Pavlov, A.V., 1998: Active layer monitoring in Northern West Siberia. Proceedings of the Seventh International Conference on Permafrost, Yellowknife, Canada, June 1998, Université Laval, Quebec, Collection Nordicana No. 57, pp. 875-881.

Pazdur, A., M.R. Fontugne and T. Goslar, 1995: Late glacial and Holocene water-level changes of the Gosciaz Lake, central Poland, derived from carbon-isotope studies of laminated sediment. Quat. Sci. Rev., 14, 125-135.

Peel, D.A., R. Mulvaney, E.C. Pasteur and C. Chenery, 1996: Climate changes in the Atlantic Sector of Antarctica over the past 500 years from ice-core and other evidence. In: Climate Variations and Forcing Mechanisms of the Last 2000 Years. NATO ASI Series I vol 41, P.D. Jones, R.S. Bradley and J. Jouzel (eds.), pp. 243-262.

Peixoto, J.P. and A.H. Oort, 1996: The climatology of relative humidity in the atmosphere. J. Climate, 9, 3443-3463.

Peterson, J.A. and L.F. Peterson, 1994: Ice retreat from the neoglacial maxima in the Puncak Jayakesuma area, Republic of Indonesia. $Z$. Gletscherkd. Glazialgeol., 30, 1-9.

Peterson, T.C. and R.S.Vose, 1997: An overview of the global historical climatology network temperature data base. Bull. Am. Met. Soc., 78, 2837-2849.

Peterson, T.C., H. Daan, and P.D. Jones, 1997: Initial selection of a GCOS surface network. Bull. Am. Met. Soc., 78, 2145-2152.

Peterson, T.C., T.R. Karl, P.F. Jamason, R. Knight and D.R. Easterling, 1998a: The first difference method: maximizing station density for the calculation of long-term temperature change. J. Geophys. Res. Atmos., 103, 25967-25974.

Peterson, T.C., D.R. Easterling, T.R. Karl, P. Groisman, N. Nicholls, N. Plummer, S. Torok, I. Auer, R. Boehm, D. Gullett, L. Vincent, R. Heino, H. Tuomenvirta, O. Mestre, T. Szentimrey, J. Salinger, E.J. Førland, I. Hanssen-Bauer, H. Alexandersson, P. Jones and D. Parker, 1998b: Homogeneity adjustments of in situ atmospheric climate data: a review. Int. J. Climatol., 18, 1495-1517.

Peterson, T.C., K.P. Gallo, J. Livermore, T.W. Owen, A. Huang and D.A. McKittrick, 1999: Global rural temperature trends. Geophys. Res. Lett., 26, 329-332.

Petit, J.R., J. Jouzel, D. Raynaud, N.I. Barkov, J.M. Barnola, I. Basile, M. Bender, J. Chappellaz, J. Davis, G. Delaygue, M. Delmotte, V.M. Kotyakov, M. Legrand, V.Y. Lipenkov, C. Lorius, L. Pepin, C. Ritz, E. Saltzman and M. Stievenard, 1999: Climate and Atmospheric History of the Past 420,000 years from the Vostok Ice Core, Antarctica. Nature, 399, 429-436.

Petit-Maire and Z.T. Guo, 1996: Mise en evidence de variations 
cimatiques, holocenes rapides, en phase dans les deserts actuels de Chine du nor et due Nord de l'Afrique, C.R. Acad. Sci., Paris, 322, Serie Iia, pp. 847-851.

Pfister, C., 1995: Monthly temperature and precipitation in central Europe from 1525-1979: quantifying documentary evidence on weather and its effects. In: Climate since A.D. 1500, R.S. Bradley and P.D.Jones (eds.), Routledge, London, pp. 118-142.

Pfister, C., 1999: Wetternachhersage: 500 Jahre Klimavariationen und Naturkatastrophen 1496-1995. Paul Haupt, Bern, 304 pp.

Pfister, C. and R. Brázdil, 1999: Climatic Variability in SixteenthCentury Europe and its Social Dimension: A Synthesis. In: Climatic Variability in Sixteenth-Century Europe and its Social Dimension, C. Pfister, R. Brázdil and R. Glaser (eds.), Special Issue of Clim. Change, 43, 5-54.

Pfister, C., G. Kleinlogel, G. Schwarz-Zanetti and M. Wegmann, 1996: Winters in Europe: The fourteenth century. Clim. Change, 34, 91108 .

Pfister, C., J. Luterbacher, G. Schwarz-Zanetti and M. Wegmann, 1998: Winter air temperature variations in Central Europe during the Early and High Middle Ages (A.D. 750-1300). Holocene, 8, 547-564.

Pfister, C., R. Brázdil, R. Glaser, M. Barriendos Vallvé, D. Camuffo, M. Deutsch, P. Dobrovoln?, S. Enzi, E. Guidoboni, O. Kotyza, S. Militzer, L. Rácz, and F.S. Rodrigo, 1999: Documentary Evidence on Climate in Sixteenth-Century Europe. In: Climatic Variability in Sixteenth-Century Europe and its Social Dimension, C. Pfister, R. Brázdil and R. Glaser (eds.), Kluwer, Dordrech,Special Issue of Clim. Change, 43, 55-110.

Pielke, Sr. , R.A., J. Eastman, T.N. Chase, J. Knaff and T.G.F. Kittel, 1998a: Errata to 1973-1996 Trends in depth-averaged tropospheric temperature. J. Geophys. Res., 103(D14), 16927-16933.

Pielke, Sr. , R.A., J. Eastman, T.N. Chase, J. Knaff and T.G.F. Kittel, 1998b: 1973-1996 Trends in depth-averaged tropospheric temperature. J. Geophys. Res., 103(D22), 28909-28912.

Piervitali, E., M. Colacino and M. Conte, 1998: Rainfall over the Central-Western Mediterranean basin in the period 1951-1995. Part I: Precipitation trends. Geophysics and Space Physics, 21C(3), 331344.

Plummer, N., M.J. Salinger, N. Nicholls, R. Suppiah, K.J. Hennessy, R.M. Leighton, B.C. Trewin, C.M. Page and J.M. Lough, 1999: Changes in climate extremes over the Australian region and New Zealand during the twentieth century. Clim. Change, 42, 183-202.

Pollack, H., S. Huang and P.Y. Shen, 1998: Climate change revealed by subsurface temperatures: A global perspective. Science, 282, 279281.

Polovina, J.J., G.T. Mitchum and G.T. Evans, 1995: Decadal and basinscale variation in mixed layer depth and the impact on biological production in the Central and North Pacific, 1960-88. Deep Sea Res., Part I, 42(10), 1701-1716.

Porter, S.C. and Z. An, 1995: Correlation between climate events in the North Atlantic and China during the last glaciation. Nature, 375, 305308 .

Power, S., F. Tseitkin, S. Torok, B. Lavery, R. Dahni and B. McAvaney, 1998: Australian temperature, Australian rainfall and the Southern Oscillation, 1910-1992: coherent variability and recent changes. Australian Met. Mag., 47, 85-101.

Power, S., T. Casey, C.K. Folland, A. Colman and V. Mehta, 1999: Interdecadal modulation of the impact of ENSO on Australia. Clim. Dyn., 15, 319-323.

Prabhakara, C., R. Iacovassi Jr. and J.-M. Yoo, 1998: Global warming deduced from MSU. Geophys. Res. Lett., 25, 1927-1930.

Prisenberg, S.J., I.K. Peterson, S. Narayanan and J.U. Umoh, 1997: Interaction between atmosphere, ice cover, and ocean off Labrador and Newfoundland from 1962-1992. Can. J. Aquat. Sci., 54, 30-39.

Quadfasel, D., A. Sy and B. Rudels, 1993: A ship of opportunity section to the North Pole: Upper ocean temperature observations. Deep Sea
Res., 40, 777-789.

Quayle, R.G., T.C. Peterson, A.N. Basist and C.S. Godfrey, 1999: An operational near-real-time global temperature index. Geophys. Res. Lett., 26, 333-335.

Quintana-Gomez, R.A., 1999: Trends of maximum and minimum temperatures in northern South America. J. Climate, 12, 2104-2112.

Raper, S.C.B., K.R. Briffa and T.M.L. Wigley, 1996: Glacier change in northern Sweden from AD 500: a simple geometric model of Storglaciären. J. Glaciol., 42, 341-351.

Rasmussen, T.L., E. Thomsen, L.D. Labeyrie and T.C.E. van Weering, 1996a: Circulation changes in the Faeroe-Shetland Channel correlating with cold events during the last glacial period (58-10 ka). Geology, 24, 937-940.

Rasmussen, T.L., T.C.E. van Weering and L.D. Labeyrie, 1996b: Climatic instability, ice sheets and ocean dynamics at high northern latitudes during the last glacial period (58-10 ka). Quaternary Science Reviews, 15, 1-10.

Rayner, N.A., E.B. Horton, D.E. Parker, C.K. Folland and R.B. Hackett, 1996: Version 2.2 of the global sea-ice and sea surface temperature data set, 1903-1994. Climate Research Technical Note 74, 43pp. (Available from National Meteorological Library, London Road, Bracknell, UK, RG12 2SZ).

Rayner, N.A., D.E. Parker, P. Frich, E.B. Horton, C.K. Folland and L.V. Alexander, 2000: SST and sea-ice fields for ERA40. In Proc. Second Int. WCRP Conf. On Reanalyses, Wokefield Park, Reading, UK, 2327 August 1999. WCRP-109, WMO/TD-NO. 985.

Reeve, N. and R. Toumi, 1999: Lightning activity as an indicator of climate change. Quart. J. R. Met. Soc., 125, 893-903.

Reille, M., J.L. de Beaulieu, H. Svobodova, V. Andrieu-Ponel and C. Goeury, 2000: Pollen biostratigraphy of the last five climatic cycles from a long continental sequence from the Velay region (Massif Central, France). J. Quat. Sci., 15, 665-685.

Ren, G., 1998: Pollen evidence for increased summer rainfall in the Medieval warm period at Maili, Northeast China. Geophys. Res. Lett., 25, 1931-1934.

Ren, G., 1999a: Some paloeclimatological problems associated with the present global warming. J. Appl. Met., 7(3), 361-370 (in Chinese with English abstract).

Ren, G., 1999b: Some progresses and problems in Paloeclimatology. Scientia Geographic Sinica, 19, 368-378.

Ren, G. and L. Zhang, 1998: A preliminary mapped summary of Holocene pollen data for Northeast China. Quat. Sci. Rev., 17, 669688.

Renwick, J.A., 1998: ENSO-related variability in the frequency of South Pacific blocking. Mon. Wea. Rev., 126, 3117-3123.

Renwick, J.A. and M.J. Revell, 1999: Blocking over the South Pacific and Rossby Wave Propagation. Mon. Wea. Rev., 127, 2233-2247.

Reverdin, G., D.R. Cayan and Y. Kushnir, 1997: Decadal variability of hydrography in the upper northern North Atlantic in 1948-1990. J. Geophys. Res., 102(C4), 8505-8531.

Reynolds, R.W., 1993: Impact of Mount Pinatubo aerosols on satellitederived sea surface temperatures. J. Climate, 6, 768-774.

Reynolds, R.W. and T.M. Smith, 1994: Improved global sea surface temperature analyses using optimum interpolation. J. Climate, 7, 929-948.

Rind, D., 1998: Just add water vapor. Science, 281, 1152-1153.

Ritchie, J.C., L.C. Cwynar and R.W. Spear, 1983: Evidence from NorthWest Canada for an early Holocene Milankovitch thermal maximum. Nature, 305, 126-128.

Robertson, D.M., R.R. Ragotzkie and J.J. Magnuson, 1992: Lake ice records used to detect historical and future climatic changes. Clim. Change, 21, 407-427.

Robinson, D.A., 1997: Hemispheric snow cover and surface albedo for model validation. Ann. Glaciol., 25, 241-245.

Robinson, D.A., 1999: Northern Hemisphere snow cover during the 
satellite era. Proc. 5th Conf. Polar Met. and Ocean., Dallas, TX American Meteorological Society, Boston, MA, pp. 255-260.

Robinson, D.A., K.F. Dewey and R.R. Heim, 1993: Global snow cover monitoring: An update. Bull. Am. Met. Soc., 74, 1689-1696.

Robock, A., Y.V. Konstantin, G. Srinivasan, J.K. Entin, S.E. Hollinger, N.A. Speranskaya, S. Liu and A. Namkhai, 2000: The global soil moisture data bank. Bull. Am. Met. Soc., 81, 1281-1299.

Rodbell, D., G.O. Seltzer, D.M. Anderson, D.B. Enfield, M.B. Abbott and J.H. Newman, 1999: A high-resolution 15000 year record of El Nino driven alluviation in southwestern Ecuador. Science, 283, 516520.

Rodrigo, F.S., M.J. Esteban-Parra, D. Pozo-Vazquez and Y. Castro-Diez, 1999: A 500-year precipitation record in Southern Spain. Int. J. Climatol., 19, 1233-1253.

Romanovsky, V.E. and T.E. Osterkamp, 1999: Permafrost Temperature Dynamics in Alaska and East Siberia During the Last 50 years. 11th Arctic Forum, ARCUS, Washington, DC, March 22-23.

Romero, R., J.A. Guijarro, C. Ramis and S. Alonso, 1998: A 30-year (1964-1993) daily rainfall data base for the Spanish Mediterranean regions: First exploratory study. Int. J. Climatol., 18, 541-560.

Ross, R.J. and W.P. Elliott, 1996: Tropospheric water vapor climatology and trends over North America: 1973-93. J. Climate, 9, 3561-3574.

Ross, R.J. and W.P. Elliott, 1998: Northern hemisphere water vapor trends. Ninth Symposium on Global Change Studies, Amer. Meteor. Soc., Preprints, pp. 39-41.

Ross, R.J. and W.P. Elliott, 2001: Radiosonde-based Northern Hemisphere tropospheric water vapour trends. J. Climate, 14, $1602-$ 1612.

Rossow, W.B. and R.A. Schiffer, 1999: Advances in understanding clouds from ISCCP. Bull. Am. Met. Soc., 80, 2261-2287.

Rostek, F., G. Ruhland, F. Bassinot, P.J. Müller, L. Labeyrie, Y. Lancelot and E. Bard, 1993: Reconstructing sea surface temperature and salinity using $\delta^{18} \mathrm{O}$ and alkenone records. Nature, 364, 319-321.

Rothrock, D.A., Y. Yu and G.A. Maykut, 1999: Thinning of the Arctic Sea-Ice Cover. Geophys. Res. Lett., 26, 3469-3472.

Salinger, M.J., 1995: Southwest Pacific temperature: trends in maximum and minimum temperatures. Atmos. Res., 37, 87-100.

Salinger, M.J. and M.S. McGlone, 1989: New Zealand Climate - The past two million years. The New Zealand Climate report 1990, Royal Society of New Zealand, Wellington, 13-17.

Salinger, M.J. and A.B. Mullan, 1999: New Zealand climate: temperature and precipitation variations and their links with atmospheric circulation. Int. J. Climatol., 19, 1049-1071.

Salinger, M.J., R.J. Allan, N. Bindoff, J. Hannah, B. Lavery, Z. Lin, J. Lindesay, N. Nicholls, N. Plummer and S. Torok, 1996: Observed variability and change in climate and sea level in Australia, New Zealand and the South Pacific. In: Greenhouse: Coping with Climate Change, W.J. Bouma, G.I. Pearman and M.R. Manning (eds.), CSIRO, Melbourne, Australia, pp. 100-126.

Salinger, M.J., J.A. Renwick and A.B. Mullan, 2001: Interdecadal Pacific Oscillation and South Pacific climate. Int. J. Climatol., accepted.

Sandweiss, D.H., J.B. Richardson III, E.J. Reitz, H.B.R. Rollins and K.A. Maasch, 1996: Geoarcheological evidence from Paru for a 5000 years B.P. onset of El Nino. Science, 273, 1531-1533.

Santer, B.D., J.J. Hnilo, T.M.L. Wrigley, J.S. Boyle, C. Doutriaux, M. Fiorino, D.E. Parker and K.E. Taylor, 1999: Uncertainties in observational based estimates of temperature change in the free atmosphere. J. Geophys. Res., 104, 6305-6333.

Santer, B.D., T.M.L. Wigley, J.S. Boyle, D.J. Gaffen, J.J. Hnilo, D. Nychka, D.E. Parker and K.E. Taylor, 2000: Statistical significance of trend differences in layer-average temperature time series. $J$. Geophys. Res., 105, 7337-7356.

SAR, see IPCC, 1996.

Sarnthein, M., K. Winn, S.J.A. Jung, J.C. Duplessy, L. Labeyrie, H.
Erlenkeuser and G. Ganssen, 1994: Changes in east Atlantic deep water circulation over the last 30,000 years. Paleoceanography, 9, 209-267.

Schindler, D.W., K.G. Beaty, E.J. Fee, D.R. Cruikshank, E.R. Devruyn, D.L. Findlay, G.A. Linsey, J.A. Shearer, M.P. Stainton and M.A. Turner, 1990: Effects of climatic warming on lakes of the central boreal forest. Science, 250, 967-970.

Schneider, R.R., P.J. Müller, G. Ruhland, G. Meinecke, H. Schmidt and G. Wefer, 1996: Late Quaternary surface temperatures and productivity in east-equatoricl South Atlantic: Response to changes in trade/monsoon wind forcing and surface water advection, 1996. In: The South Atlantic: Present and Past Circulation, G. Wefer, W.H. Berger, G. Siedler and D. Webb (eds.), Springer-Verlag, Berlin , pp. 527-551.

Schönwiese, C.D. and J. Rapp, 1997: Climate Trend Atlas of Europe Based on Observations 1891-1990. Kluwer Academic Publishers, Dordrecht, 228 pp.

Schönwiese, C.D., J. Rapp, T. Fuchs, and M. Denhard, 1994: Observed climate trends in Europe 1891-1990. Meteorol. Zeitschrift, 3, 22-28.

Schwartzman, P.D., P.J. Michaels and P.C. Knappenberger, 1998: Observed changes in the diurnal dewpoint cycles across North America. Geophys. Res. Lett., 25, 2265-2268.

Serreze, M.C., F. Carse and R.G. Barry, 1997: Icelandic low cyclone activity climatological features, linkages with the NAO, and relationships with recent changes in the Northern Hemisphere circulation. $J$. Climate, 10, 453-464.

Serreze, M.C., J.E. Walsh, F.S. Chapin III, T. Osterkamp, M. Dyurgerov, V. Romanovsky, W.C. Oechel, J. Morison, T. Zhang and R.G. Barry, 2000: Observational evidence of recent change in the northern highlatitude environment. Clim. Change, 46, 159-207.

Severinghaus, J.P. and E. Brook, 1999: Abrupt climate change at the End of the last glacial period inferred from trapped air in polar ice. Science, 286, 930-934.

Severinghaus, J.P., T. Sowers, E. Brook, R.B. Alley and M.L. Bender, 1998: Timing of abrupt climate change at the end of the Younger Dryas interval from thermally fractionated gases in polar ice. Nature, 391, 141-146.

Shabbar, A., K. Higuchi, W. Skinner and J.L. Knox, 1997: The association between the BWA index and winter surface temperature variability over eastern Canada and west Greenland. Int. J. Climatol., 17, 1195-1210.

Sharkhuu, N., 1998: Trends of permafrost development in the Selenge River Basin, Mongolia. Proceedings of the Seventh International Conference on Permafrost, Yellowknife, Canada, June 1998, Université Laval, Quebec, Collection Nordicana No. 57, pp. 979-986.

Shen, S.S., M. Thomas, C.F. Ropelewski and R.E. Livezey, 1998: An optimal regional averaging method with error estimates and a test using tropical Pacific SST data. J. Climate, 11, 2340-2350.

Shinoda, M., T. Okatani and M. Saloum, 1999: Diurnal variations of rainfall over Niger in the West African Sahel: A comparison between wet and drought years. Int. J. Climatol., 19, 81-94.

Shulmeister, J. and B.G. Lees, 1995: Pollen evidence form tropical Australia for the onset of an ENSO-dominated climate at c. 4000 BP. The Holocene, 5, 10-18.

Simmonds, I. and K. Keay, 2000: Variability of Southern Hemisphere extratropical cyclone behavior, 1958-97. J. Climate, 13(3), 550-561.

Singer, C., J. Shulmeister and B. McLea, 1998: Evidence against a significant Younger Dryas cooling event in New Zealand. Science, 281, 812-814.

Skinner, W.R. and J.A. Majorowicz, 1999: Regional climatic warming and associated twentieth century land-cover changes in north-western North America. Clim. Res., 12, 39-52.

Slingo, J.M., D.P. Rowell, K.R. Sperber, and F. Nortley, 1999: On the predictability of the interannual behaviour of the Madden-Julian Oscillation and its relationship with El Nino. Quart. J. R. Met. Soc., 
125, 583-609.

Smith, C.A., R. Toumi and J.D. Haigh, 2000: Seasonal trends in stratospheric water vapor. Geophys. Res. Lett., 27, 1687-1690.

Smith, C.A., J.D. Haigh and R. Toumi, 2001: Radiative forcing due to trends in stratospheric water vapor. Geophys. Res. Lett., 28, 179-182.

Smith, D.M., 1998: Recent increase in the length of the melt season of perennial Arctic sea ice. Geophys. Res. Lett., 25, 655-658.

Smith, T.M., R.W. Reynolds, R.E. Livezey and D.C. Stokes, 1996: Reconstruction of historical sea surface temperatures using empirical orthogonal functions. J. Climate, 9, 1403-1420.

Smith, T.M., R.E. Livezey and S.S. Shen, 1998: An improved method for analyzing sparce and irregularly distributed SST data on a regular grid: The tropical Pacific Ocean. J. Climate, 11, 1717-1729.

Sowers, T. and M. Bender, 1995: Climate records covering the last deglaciation. Science, 269, 210-214.

Spencer, R.W., 1993: Global oceanic precipitation from the MSU during 1979-92 and comparisons to other climatologies. J. Climate, 6, 13011326.

Spencer, R.W. and J.R. Christy, 1992a: Precision and radiosonde validation of satellite gridpoint temperature anomalies, Part I: MSU channel 2. J. Climate, 5, 847-857.

Spencer, R.W. and J.R. Christy, 1992b: Precision and radiosonde validation of satellite gridpoint temperature anomalies, Part II: A tropospheric retrieval and trends 1979-90. J. Climate, 5, 858-866.

Stager, J.C. and P.A. Mayewski, 1997: Abrupt Early to Mid-Holocene Climatic transition registered at the Equator and the Poles. Science, 276, 1834-1836.

Stahle, D.W., M.K. Cleaveland, M.D. Therrell, D.A. Gay, R.D. D'Arrigo, P.J. Krusic, E.R. Cook, R.J. Allan, J.E. Cole, R.B. Dunbar, M.D. Moore, M.A. Stokes, B.T. Burns, J. Villanueva-Diaz and L.G. Thompson, 1998: Experimental Dendroclimatic Reconstruction of the Southern Oscillation. Bull. Am. Met. Soc., 79, 2137-2152.

Steadman, R.G., 1984: A universal scale of apparent temperature. J. Clim. Appl. Met., 23, 1674-1687.

Steele, M. and T. Boyd, 1998: Retreat of the cold halocline layer in the Arctic Ocean. J. Geophys. Res., 103(C5), 10419-10435.

Steig, E., E.J. Brook, J.W.C. White, C.M. Sucher, M.L. Bender, S.J. Lehman, D.L. Morse, E.D. Waddigton and G.D. Clow, 1998: Synchronous climate changes in Antarctica and the North Atlantic. Science, 282, 92-95.

Stendel, M., J.R. Christy and L. Bengtsson, 2000: Assessing levels of uncertainty in recent temperature time series. Clim. Dyn., 16(8), 587601.

Sterin, A.M., 1999: An analysis of linear trends in the free atmosphere temperature series for 1958-1997. Meteorologiai Gidrologia, 5, 52 68.

Stine, S., 1994: Extreme and persistent drought in California and Patagonia during medieval time. Nature, 369, 546-549.

Stocker, T.F., 2000: Past and further reorganization in the climate system. Quat. Sci. Rev., 19, 301-319.

Stone, D.A., A.J. Weaver and F.W. Zwiers, 1999: Trends in Canadian precipitation intensity. Atmos. Ocean, 2, 321-347.

Street-Perrott, F.A. and R.A. Perrott, 1990: Abrupt climate fluctuations in the tropics: the influence of Atlantic ocean circulation. Nature, 343, 607-612.

Sun, B. and P.Ya. Groisman, 2000: Cloudiness variations over the former Soviet Union. Int. J. Climatol., 20, 1097-1111.

Sun, B., P.Ya. Groisman, R.S. Bradley, and F.T. Keimig, 2000: Temporal changes in the observed relationship between cloud cover and surface air temperature. J. Climate, 13, 4341-4357.

Sun, B., P.Ya. Groisman and I.I. Mokhov, 2001: Recent changes in cloud type frequency and inferred increases in convection over the United States and the Former USSR. J. Climate, 14, 1864-1880.

Sun, X.J. and Y.S. Chen, 1991: Palynological records of the last 11,000 years in China. Quat. Sci. Rev., 10, 537-544.
Swetnam, T.W. and J. L. Betancourt, 1998: Mesoscale disturbance amd ecological response to decadal climate variability in the American Southwest. J. Climate, 11, 3128-3147.

Tanimoto, Y., N. Iwasaka, K. Hanawa and Y. Toba, 1993: Characteristic variations of sea surface temperature with multiple time scales in the North Pacific. J. Climate, 6, 1153-1160.

Tarhule, A. and M. Woo, 1998: Changes in rainfall characteristics in northern Nigeria. Int. J. Climatol., 18, 1261-1271.

Taylor, K.C., G.W. Lamorey, G.A. Doyle, R.B. Alley, P.M. Grootes, P.A. Mayewski, J.W.C. White and L.K. Barlow, 1993: The "flickering switch" of late Pleistocene climate change. Nature, 361, 432-436.

Thie, J., 1974: Distribution and thawing of permafrost in the southern part of the discontinuous permafrost zone in Manitoba. Arctic, 27, 189-200.

Thompson, D.W.J. and J.M. Wallace, 1998: The Arctic oscillation signature in the wintertime geopotential height and temperature fields. Geophys. Res. Lett., 25, 1297-1300.

Thompson, D.W.J. and J.M. Wallace, 2000: Annual modes in the extratropical circulation Part I: month-to-month variability. J. Climate, 13, 1000-1016.

Thompson, D.W.J. and J.M. Wallace, 2001: Regional climate impacts of the Northern Hemisphere annular mode and associated climate trends. Nature, in press.

Thompson, D.W.J., J.M. Wallace and G.C. Hegerl, 2000b: Annual modes in the extratropical circulation Part II: trends. J. Climate, 13, 1018-1036.

Thompson, L.G., 1996: Climate changes for the last 2000 years inferred from ice core evidence in tropical ice cores. In: Climate Variations and Forcing Mechanisms of the Last 2000 Years, NATO ASI Series I, P.D. Jones, R.S. Bradley and J. Jouzel (eds.), 41, 281-297.

Thompson, L.G. and 13 others, 1989: Pleistocene climate record from Qinghai-Tibetan Plateau ice cores. Science, 246, 474-477.

Thompson, L.G., E. Mosley-Thompson, M.E. Davis, P.N. Lin, K.A. Henderson, J. Cole-Dai, J.F. Bolzan and K.B. Liu, 1995: Late Glacial Stage and Holocene Tropical Ice Core Records from Huascaran, Peru. Science, 269, 46-50.

Thompson, L.G., M.E. Davis, E. Mosley-Thompson, T.A. Sowers, K.A. Henderson, V.S. Zagorodnov, P.N. Lin, V.N. Mikhalenko, R.K. Campen, J.F. Bolzan, J. Cole-Dai and B. Francou, 1998: A 25,000year tropical climate history from Bolivian ice cores. Science, 282, 1858-1864.

Thompson, L.G., T. Yao, E. Mosley-Thompson, M.E. Davis, K.A. Henderson and P.N. Lin, 2000a: A high resolution millennial record of the South Asian Monsoon from Himalayan ice cores. Science, 289, 1916-1919.

Thunnell, R.C. and P.G. Mortyn, 1995: Glacial climate instability in the northeast Pacific Ocean. Nature, 376, 504-506.

Torrence, C. and G.P. Compo, 1998: A practical guide to wavelet analysis. Bull. Am. Met. Soc., 79, 61-78.

Torrence, C. and P.J. Webster, 1998: The annual cycle of persistence in the El Niño/Southern Oscillation. Quart. J. R. Met. Soc., 124, 19852004.

Torrence, C. and P.J. Webster, 1999: Interdecadal changes in the ENSOmonsoon system. J. Climate, 12, 2679-2690.

Trenberth, K.E., 1998a: Atmospheric moisture residence times and cycling: Implications for rainfall rates with climate change. Clim. Change, 39, 667-694.

Trenberth, K.E., 1998b: El Nino and global warming. J. Marine Education, 15, 12-18.

Trenberth, K.E. and J.W. Hurrell, 1994: Decadal atmosphere-ocean variations in the Pacific. Clim. Dyn., 9, 303-319.

Trenberth, K.E. and T.J. Hoar, 1996: The 1990-1995 El Niño-Southern Oscillation event: longest on record. Geophys. Res. Lett., 23, 57-60.

Trenberth, K.E. and T.W. Owen, 1999: Workshop on Indices and Indicators for climate extremes, Asheville, NC, USA, 3-6 June 1999: 
Breakout Group A: Storms. Clim. Change, 42, 9-21.

Trenberth, K.E., J.R. Christy and J.W. Hurrell, 1992: Monitoring global monthly mean surface temperatures. J. Climate, 5, 1405-1423.

Trenberth, K.E., J.M. Caron and D.P. Stepaniak, 2001: The Atmospheric Energy Budget and Implications for Surface Fluxes and Ocean Heat Transports. Clim. Dyn., 17, 259-276.

Tudhope, A.W., G.B. Shimmield, C.P. Chilcott, M. Jebb, A.E. Fallick and A.N. Dalgleish, 1995: Recent changes in climate in the far western equatorial Pacific and their relationship to the Southern Oscillation: oxygen isotope records from massive corals, Papua, New Guinea. Earth and Planetary Science Letters, 136, 575-590.

Tuomenvirta, H., H. Alexandersson, A. Drebs, P. Frich and P.O. Nordli, 2000: Trends in Nordic and Arctic temperature extremes and ranges. J. Climate, 13, 977-990.

Turrell, W.R., G. Slesser, R.D. Adams, R. Payne and P.A. Gillibrand, 1999: Decadal variability in the composition of Faroe Shetland Channel bottom water. Deep Sea Res. Part I, 46, 1-25.

Vaganov, E.A., M.K. Hughes, A.V. Kirdyanov, F.H. Schweingruber and P.P. Silkin, 1999: Influence of snowfall and melt timing on tree growth in subarctic Eurasia. Nature, 400, 149-151.

Van Ommen, T.D. and V. Morgan, 1996: Peroxide concentrations in the DSS ice core, Law Dome, Antarctica. J. Geophys. Res., 101(D10), 15147-15152.

Van Ommen, T.D. and V. Morgan, 1997: Calibrating the ice core paleothermometer using seasonality. J. Geophys. Res., 102(D8), 9351-9357.

Vaughan, D.G. and T. Lachlan-Cope, 1995: Recent retreat of ice shelves on the Antarctic Peninsula. Weather, 50 , 374-376.

Vaughan, D.G. and C.S.M. Doake, 1996: Recent atmospheric warming and retreat of ice shelves on the Antarctic Peninsula. Nature, 379, 328-331

Vidal, L., L.D. Labeyrie, E. Cortijo, M. Arnold, J.C. Duplessy, E. Michel, S. Becque and T.C.E. van Weering, 1997: Evidence for changes in the North Atlantic Deep Water linked to meltwater surges during the Heinrich events. Earth Planet. Sci. Lett., 146, 13-27.

Vidal, L., L.D. Labeyrie and T.C.E. van Weering, 1998: Benthic $\delta^{18} \mathrm{O}$ records in the North Atlantic over the last glacial period (60-10 kyr): Evidence for brine formation. Paleoceanography, 13, 245-251.

Villalba, R., E.R. Cook, R. D’Arrigo, G.C. Jacoby, P.D. Jones, J.M. Salinger and J. Palmer, 1997: Sea-level pressure variability around Antarctica since A.D. 1750 inferred from subantarctic tree-ring records. Clim. Dyn., 13, 375-390.

Vincent, L.A., 1998: A technique for the identification of inhomogeneities in Canadian temperature series. J. Climate, 11, 1094-1104.

Vincent, L.A. and D.W. Gullett, 1999: Canadian historical and homogeneous temperature datasets for climate change analysis. Int. J. Climatol., 19, 1375-1388.

Vinje, T., N. Nordlund and Å. Kvambekk, 1998: Monitoring ice thickness in Fram Strait. J. Geophys. Res., 103(C5), 10437-10449.

Vinnikov, K.Ya., P.Ya. Groisman and K.M. Lugina, 1990: Empirical data on contemporary global climate changes (temperature and precipitation). J. Climate, 3, 662-677.

Vinnikov, K.Y., A. Robock, S. Qiu and J.K. Entin, 1999a: Optimal design of surface networks for observation of soil moisture. $J$. Geophys. Res., 104, 19743-19749.

Vinnikov, K.Y., A. Robock, R.J. Stouffer, J.E. Walsh, C.L. Parkinson, D.J. Cavalieri, J.F.B. Mitchell, D. Garrett and V.F. Zakharov, 1999b: Global warming and Northern Hemisphere sea ice extent. Science, 286, 1934-1937.

Vitt, D.H., L.A. Halsey and S.C. Zoltai, 1994: The bog landforms of continental western Canada in relation to climate and permafrost patterns. Artic and Alpine Res., 26, 1-13.

Vonder Mühll, D., T. Stucki and W. Haeberly, 1998: Borehole temperatures in Alpine permafrost: a ten years series. Proceedings of the Seventh International Conference on Permafrost, Yellowknife,
Canada, June 1998, Université Laval, Quebec, Collection Nordicana No. 57, pp. 1089-1096.

von Grafenstein, U., H. Erlenkeuser, J. Muller, J. Jouzel and S.J. Johnsen, 1998: The cold event 8,200 years ago documented in oxygen isotope records of precipitation in Europe and Greenland. Clim. Dyn., 14, 73-81.

von Grafenstein, U., H. Erlenkeuser, A. Brauer, J. Jouzel and S.J. Johnsen, 1999: A mid-European decadal isotope-climate record from 15,500 to 5,000 years B.P. Science, 284, 1654-1657.

Wadhams, P. and N.R. Davis, 2000: Further evidence of sea ice thinning in the Arctic Ocean. Geophys. Res. Lett., 27, 3973-3976.

Wallace, J.M., 2000: North Atlantic Oscillation / Northern Hemisphere annular mode: Two paradigms - One phenomenon. Quart. J. R. Met. Soc., 126, 791-805.

Wallace, J.M., Y. Zhang and J.A. Renwick, 1995: Dynamic contribution to hemispheric mean temperature trends. Science, 270, 780-783.

Wallis, T.W.R., 1998: A subset of core stations from the Comprehensive Aerological Data Set (CARDS). J. Climate, 12, 272-282.

Walsh, J.E., 1978: Data set on Northern Hemisphere sea-ice extent. Glaciological Data, Report GD-2, World Data Center-A for Glaciology (Snow and Ice), part 1, pp. 49-51.

Walsh, J.M., W.L. Chapman and T.L. Shy, 1996: Recent decrease of sea level pressure in the central Arctic. J. Climate, 9, 480-486.

Wang, B. and H.M. French, 1994: Climate controls and high-altitude permafrost, Qinghai-Xizang (Tibet) Plateau, China. Permafrost and Periglacial Processes, 5, 87-100.

Wang, B. and Y. Wang, 1996: Temporal structure of the Southern Oscillation as revealed by waveform and wavelet analysis. J. Climate, 9, 1586-1598.

Wang, S.L., H.J. Jin, S. Li and L. Zhao, 2000: Permafrost Degradation on the Qinghai-Tibet Plateau and its Environmental Impacts. Permafrost and Periglacial Processes, 11, 43-53.

Wang, S.W. and D.Y. Gong, 2000: Climate in China during the four special periods in Holocene. Progress in Nature Science, 10(5), 379386.

Wang, S.W., J. Ye, D. Gong and J. Zhu, 1998a: Construction of mean annual temperature series for the last one hundred years in China, Quart. J. Appl. Met., 9(4), 392-401 (in Chinese).

Wang, S.W., J. Ye and D. Gong, 1998b: Climate in China during the Little Ice Age. Quaternary Sciences, 1, 54-64 (in Chinese).

Wang, X.L. and D.J. Gaffen, 2001: Late twentieth century climatology and trends of surface humidity and temperature in China. J. Climate, in press.

Wanner, H., C. Pfister, R. Bràzdil, P. Frich, K. Fruydendahl, T. Jonsson, J. Kington, H.H. Lamb, S. Rosenorn and E. Wishman, 1995: Wintertime European circulation patterns during the Late Maunder Minimum Cooling Period (1675-1704). Theor. Appl. Climatol., 51, 167-175.

Wansard, G., 1996: Quantification of paleotemperature changes during isotopic stage 2 in the La Draga continental sequence (NE Spain) based on the $\mathrm{Mg} / \mathrm{Ca}$ ratio of freshwater ostracods. Quarternary Science Review, 15, 237-245.

Waple, A., M.E. Mann and R.S. Bradley, 2001: Long-term Patterns of Solar Irradiance Forcing in Model Experiments and Proxy-based Surface Temperature Reconstructions. Clim. Dyn., in press.

Ward, M.N., 1998: Diagnosis and short-lead time prediction of summer rainfall in tropical North Africa and interannual and multi-decadal timescales. J. Climate, 11, 3167-3191.

Ward, M.N., P.J. Lamb, D.H. Portis, M. El Hamly, and R. Sebbari, 1999: Climate Variability in Northern Africa: Understanding Droughts in the Sahel and the Mahgreb. In: Beyond El Nino: Decadal and Interdecadal Climate Variability, A. Navarra (ed.), Springer, Berlin, pp. 119-140.

WASA Group (von Storch et al.), 1998: Changing waves and storms in the Northeast Atlantic? Bull. Am. Met. Soc., 79, 741-760. 
Watts, W.A., J.R.M. Allen and B. Huntley, 1996: Vegetation history and palaeoclimate of the last glacial period at Lago Grande Di Monticchio, Southern Italy. Quat. Sci. Rev., 15, 133-151.

Webb, I., Thompson and J.E. Kutzbach, 1998: An introduction to Late Quaternary Climates: Data Syntheses and Model Experiments. Quat. Sci. Rev., 17, 465-471.

Weber, R.O., P. Talkner and G. Stefanicki, 1994: Asymmetric diurnal temperature change in the Alpine region. Geophys. Res. Lett., 21, 673-676.

Weller, G. and P.A. Anderson (eds.), 1998: Implications of Global Change in Alaska and the Bering Sea Region. Proceedings of a Workshop, June 1997, Centre for Global Change and Arctic System Research, University of Alaska Fairbanks, Fairbanks, Alaska, 157 pp.

Wentz, F.J. and M. Schabel, 1998: Effects of orbital decay on satellitederived lower-tropospheric temperature trends. Nature, 394, 661-664.

White, J.W.C., L.K. Barlow, D.A. Fisher, P. Grootes, J. Jouzel, S. Johnsen, and P.A. Mayewski, 1998a: The climate signal in the stable isotopes of snow from Summit Greenland: results of comparisons with modern climate observations. Special Issue J. Geophys. Res., American Geophysical Union, 26425-26440.

White, W.B. and R. Peterson, 1996: An Antarctic circumpolar wave in surface pressure, wind, temperature, and sea ice extent. Nature, $\mathbf{3 8 0}$, 699-702.

White, W.B. and D.R. Cayan, 1998: Quasi-periodicity and global symmetries in interdecadal upper ocean temperature variability. $J$. Geophys. Res., 103(C10), 21335-21354.

White, W.B., J. Lean, D.R. Cayan and M.D. Dettinger, 1997: A response of global upper ocean temperature to changing solar irradiance. $J$. Geophys. Res., 102, 3255-3266.

White, W.B., D.R. Cayan and J. Lean, 1998b: Global upper ocean heat storage response to radiative forcing from changing solar irradiance and increasing greenhouse gas/aerosol concentrations. J. Geophys. Res., 103, 21355-21366.

Wick, L. and W. Tinner, 1999: Vegetation changes and timberline fluctuations in the Central Alps as indicators of Holocene climate oscillations. Arctic and Alpine Research, 29, 445-458.

Wigley, T.M.L., 2000: ENSO, volcanoes and record-breaking temperatures. Geophys. Res. Lett., 27, 4101-4104.

Wiles, G.C., R.D. D'Arrigo and G.C. Jacoby, 1998: Gulf of Alaska atmosphere-ocean variability over recent centuries inferred from coastal tree-ring records. Clim. Change, 38, 289-306.

Wilks, D.S., 1999: Interannual variability and extreme-value characteristics of several stochastic daily precipitation models. Agric. For. Meteorol., 93, 153-169.

Williams, P.W., A. Marshall, D.C. Ford and A.V. Jenkinson, 1999: Palaeoclimatic interpretation of stable isotope data from Holocene speleotherms of the Waitomo district, North Island, New Zealand. Holocene, 9, 649-657.

Wohlfarth, B., H. Linderson, B. Holmquist and I. Cato, 1998: The climatic significance of clastic varves in the Angermanalven Estuary, northern Sweden, AD 1860-1950. The Holocene, 8, 525-534.

Wolfe, S.A., E. Kotler and F.M. Nixon, 2000: Recent warming impacts in the Mackenzie Delta, Northwest Territories, and northern Yukon Territory coastal areas. Geological Survey of Canada, Current Research 2000-B1, 9 pp.

Wong, A.P.S., N.L. Bindoff and J.A. Church, 1999: Large-scale freshening of intermediate waters in the Pacific and Indian Oceans. Nature, 400, 440-443.

Woodhouse, C.A. and J.T. Overpeck, 1998: 2000 years of drought variability in the central United States. Bull. Am. Met. Soc., 79, $2693-$ 2714.

Wynne, R.H., T.M. Lilles, M.K. Clayton and J.J. Magnuson, 1998: The predominant spatial trends of mean ice breakup dates can be attributed to latitude and snowfall. Photogrammetric Engineering and Remote Sensing, ISSN: 0099-1112 (Falls Church, VA), 64, 607-618.

Xie, P. and P.A. Arkin, 1997: Global precipitation: A 17-year monthly analysis based on gauge observations, satellite estimates and numerical model outputs. Bull. Am. Met. Soc., 78, 2539-2558.

Yamamoto, R. and Y. Sakurai, 1999: Long-term intensification of extremely heavy rainfall intensity in recent 100 years. World Resource Rev., 11, 271-281.

Ye, H., H.R. Cho and P.E. Gustafson, 1998: The changes in Russian winter snow accumulation during 1936-83 and its spatial patterns. $J$. Climate, 11, 856-863.

Yiou, F., G.M. Raisbeck., S. Baumgartner, J. Beer, C. Hammer, S. Johnsen, J. Jouzel, P.W. Kubik, J. Lestringuez, M. Stievenard, M. Suter and P. Yiou, 1997a: Beryllium 10 in the Greenland Ice Core Project ice core at Summit Greenland. J. Geophys. Res., 102, 2678326794.

Yiou, P., K. Fuhrer, L.D. Meeker, J. Jouzel, S.J. Johnsen and P.A. Mayewski, 1997b: Paleoclimatic variability inferred from the spectral analysis of Greenland and Antarctic ice core data. J. Geophys. Res., 102, 26441-26454.

Yu, G. and S.P. Harrison, 1996: An evaluation of the simulated water balance of Eurasia and northern Africa at 6000 y BP using lake status data. Clim. Dyn., 12, 723-735.

Yu, G. and B. Qin, 1997: Holocene temperature and precipitation reconstructions and monsoonal climates in eastern China using pollen data. Paleoclimates, 2, 1-32.

Yung, Y.L., T. Lee, C.H. Wang and Y.T. Shieh, 1996: Dust: A diagnostic of the hydrologic cycle during the Last Glacial Maximum. Science, 271, 962-963.

Zenk, W. and N. Hogg, 1996: Warming trend in Antarctic Bottom Water flowing into the Brazil Basin. Deep Sea Res., Part I, 43, 1461-1473.

Zhai, P.M. and R.E. Eskridge, 1997: Atmospheric water vapor over China. J. Climate, 10, 2643-2652.

Zhai, P.M. and F.M. Ren, 1999: Changes of China's maximum and minimum temperatures in 1951-1990. Acta Meteor. Sinica, 13, 278290.

Zhai, P.M., A. Sun, F. Ren, X. Liu, B. Gao and Q. Zhang, 1999a: Changes of climate extremes in China. Clim. Change, 42, 203-218.

Zhai, P.M., F.M. Ren and Q. Zhang, 1999b: Detection of trends in China's precipitation extremes. Acta Meteorologica Sinica, 57, 208-216.

Zhang, K., B.C. Douglas and S.P. Leatherman, 1997a: East Coast storm surges provide unique climate record. EOS Trans. American Geophysical Union, 78(37).

Zhang, T., R.G. Barry, K. Knowles, J.A. Heginbottom and J. Brown, 1999: Statistics and characteristics of permafrost and ground-ice distribution in the Northern Hemisphere. Polar Geography, 2, 132154.

Zhang, X., L.A. Vincent, W.D. Hogg and A. Niitsoo, 2000: Temperature and precipitation trends in Canada during the 20th Century. Atmosphere-Ocean, 38, 395-429.

Zhang, Y. and W.C. Wang, 1997: Model-simulated northern winter cyclone and anticyclone activity under a greenhouse warming scenario. J. Climate, 10, 1616-1634.

Zhang, Y., J.M. Wallace and D.S. Battisti, 1997b: ENSO-like interdecadal variability: 1900-93. J. Climate, 10, 1004-1020. 
